
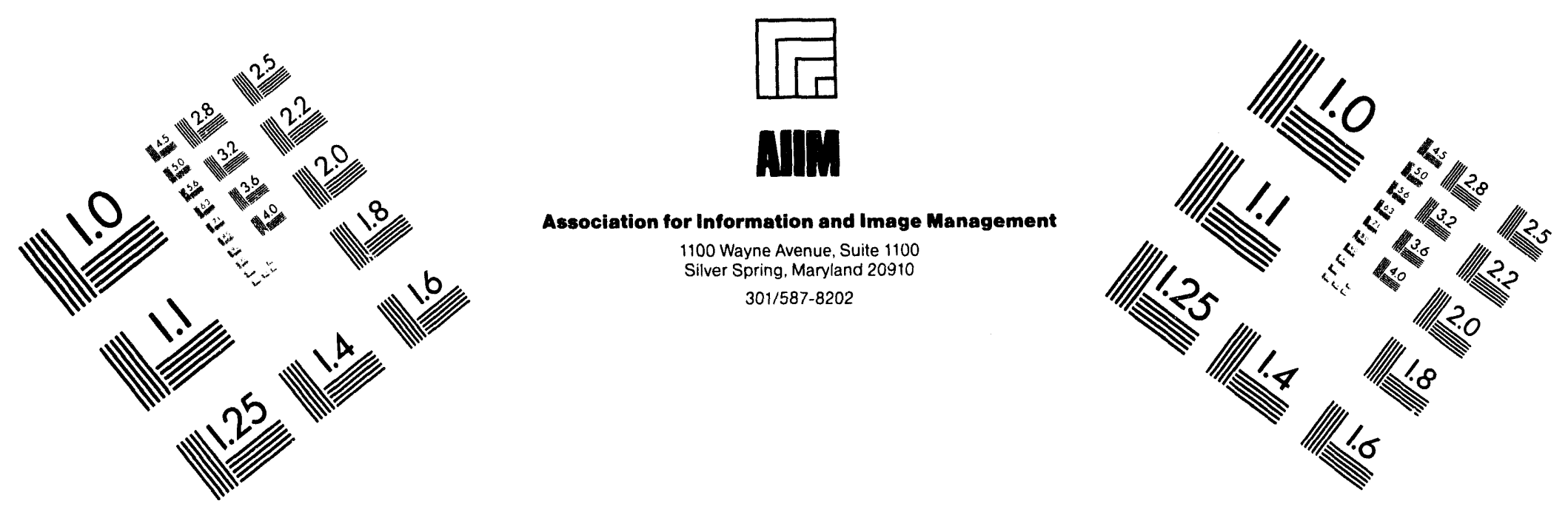

\title{
Centimeter
}

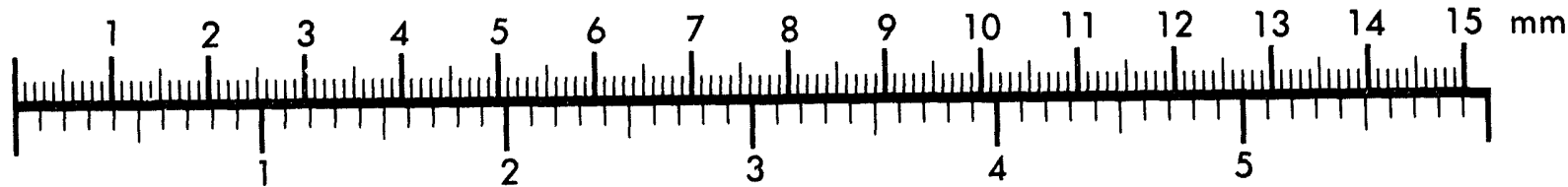

Inches
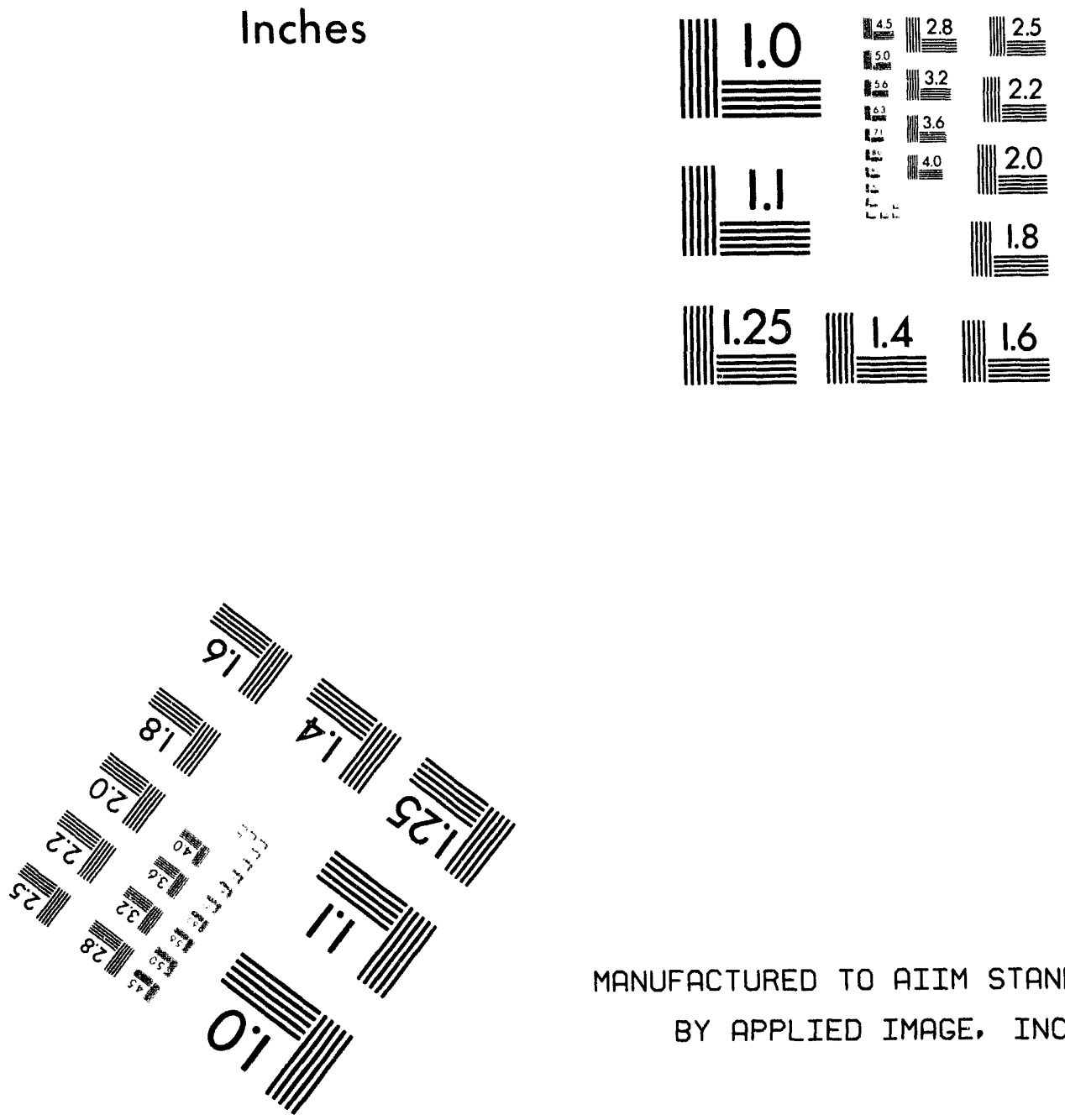

MANUFACTURED TO AIIM STANDARDS

BY APPLIED IMAGE, INC.

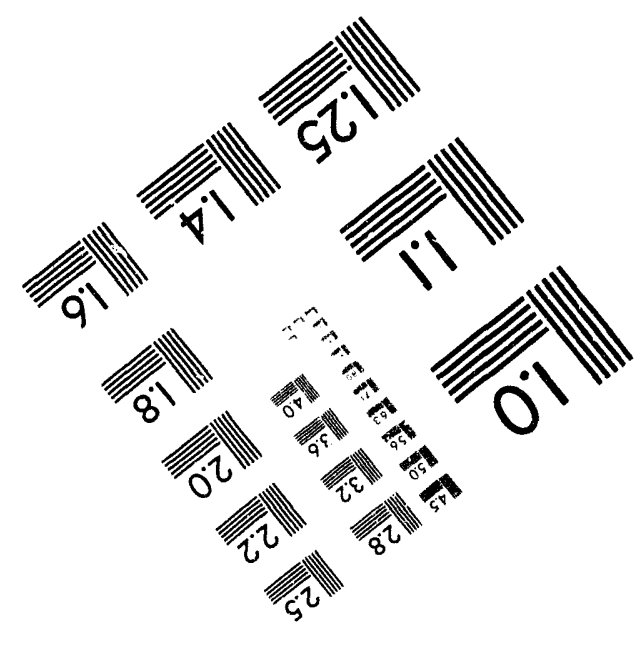



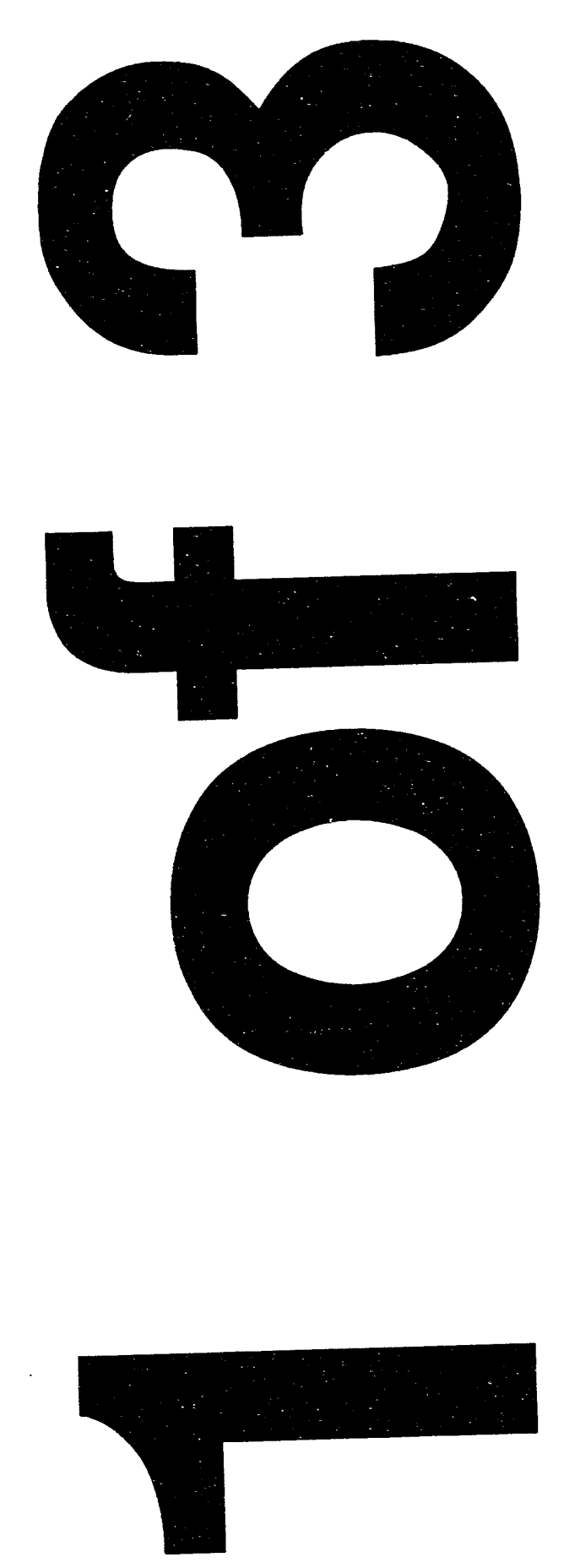


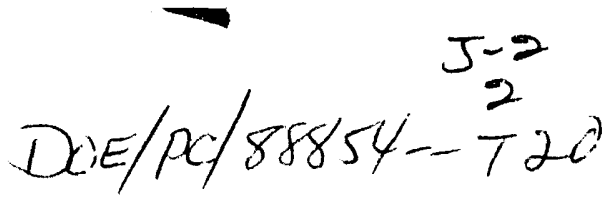

\section{Biodesulfurization Techniques: Application of Selected Microorganisms for Organic Sulfur Removal from Coals}

FINAL REPORT

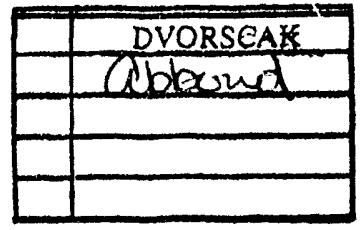

Published: August 1993

\section{DISCLAIMER}

This report was prepared as an account of work sponsored by an agency of the United States Government. Neither the United States Government nor any agency thereof, nor any of their employees, makes any warranty, express or implied, or assumes any legal liability or responsibility for the accuracy, completeness, or usefulness of any information, apparatus, product, or process disclosed, or represents that its use would not infringe privately owned rights. Reference herein to any sperific commercial product, process, or service by trade name, trademark, manufacturer, or otherwise does not necessarily constitute or imply its endorsement, recommendation, or favoring by the United States Government or any agency thereof. The views and opinions of authors expressed herein do not necessarily state or reflect those of the United States Government or any agency thereof.

RECIVED

AUO 221994

OSTI

Prepared by

Dr. Bill B. Elmore, Louisiana Tech University

Department of Chemical Engineering

Ruston, LA 71272

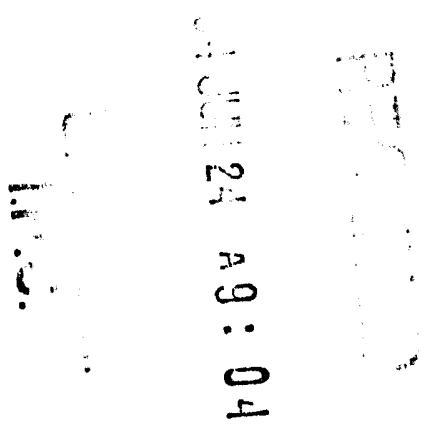

Prepared for

The United States Department of Energy

Pittsburgh Energy Technology Center

Contract No. DE-AC22-88PC88854

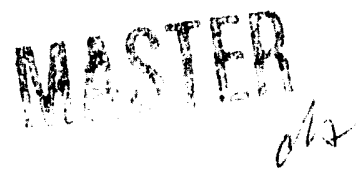




\begin{abstract}
As an alternative to post-combustion desulfurization of coal and pre-combustion desulfurization using physicochemical techniques, the microbial desulfurization of coal may be accomplished through the use of microbial cultures that, in an application of various microbial species, may remove both the pyritic and organic fractions of sulfur found in coal. Organisms have been isolated that readily depyritize coal but often at prohibitively low rates of desulfurization. Microbes have also been isolated that may potentially remove the organic-sulfur fraction present in coal (showing promise when acting on organic sulfur model compounds such as dibenzothiophene).
\end{abstract}

The isolation and study of microorganisms demonstrating a potential for removing organic sulfur from coal has been undertaken in this project. Additionally, the organisms and mechanisms by which coal is microbially depyritized has been investigated.

Three cultures were isolated that grew on dibenzothiophene (DBT), a model organic-sulfur compound, as the sole sulfur source. These cultures (UMX3, UMX9, and IGTS8) also grew on coal samples as the sole sulfur source (from which greater than $95 \%$ (w/w) of the pyritic sulfur had been previously removed).

Numerous techniques for pretreating and "cotreating" coal for depyritization were also evaluated for the ability to improve the rate or extent of microbial depyritization. These include prewashing the coal with various solvents and adding surfactants to the culture broth. Studies showed that in low slurry concentrations (e.g. $2 \% \mathrm{w} / \mathrm{v}$ ), organic inhibition of the depyritization rate existed as a result of organic by-products. In contrast, in more concentrated slurries (20\%c $w / v)$ the accumulation of leachable organics from the coal may have been the strongest limiting phenomenon to depyritization.

Using a bituminous coal containing $0.61 \%(\mathrm{w} / \mathrm{w}$ ) pyrite washed with organic solvents at low slurry concentrations $(2 \% \mathrm{w} / \mathrm{v})$, the extent of depyritization was increased approximately $25 \%_{\mathrm{c}}$ in two weeks as compared to controls. At slurry concentrations of $20 \% \mathrm{w} / \mathrm{v}$, a tetrachloroethylene treatment of the coal followed by depyritization with Thiobacillus ferrooxidans increased both the rate and extent of depyritization by approximately $10 \%$. 


\section{DISCLAIMER}

This report was prepared as an account of work spcnsored by an agency of the United States Government. Neither the United States Government nor any agency thereof, or any of their employees, makes any warranty, express or implied, or assumes any legal liability or responsibility for the accuracy, completeness, or use?ulness of any information, apparatus, product or process disclosed, or represents that its use would not iniringe privately owned rights. Reference herein to any specific commercial product, process, or service by trade name, trademark, manuiacturer, or otherwise, does not constitute or imply its endorsement. recommendation, or favoring by the United States Government or any agency thereot. The views and opinions of the authors expressed herein do not necessarily state or reilect those of the United Sta: $=s$ Government or any agency thereof. 


\section{TABLE OF CONTENTS}

Page

I.

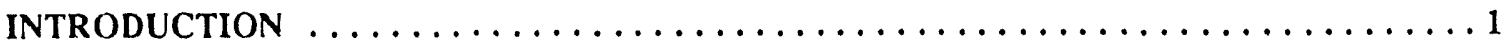

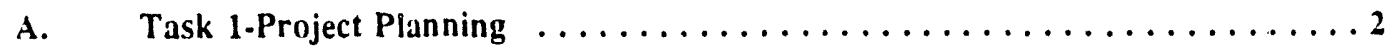

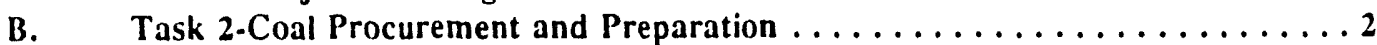

C. Task 3-Analytical Procedures for Total Organic Sulfur .............. 3

D. Task 4-Organic Sulfur Removal .......................

E. Task 5-Project Management and Reporting $\ldots \ldots \ldots \ldots \ldots \ldots \ldots \ldots \ldots \ldots$

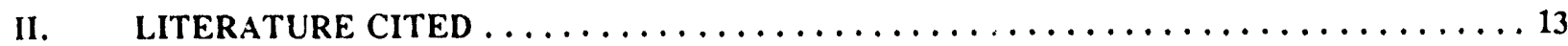

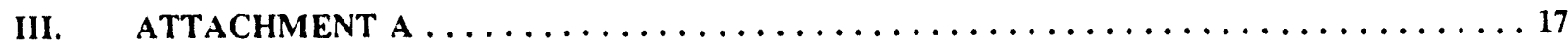

A. Appendix I--August 1,1988 to March $15,1989 \ldots \ldots \ldots \ldots \ldots \ldots 18$

B. Appendix II-.March 15, 1989 to March $15,1990 \ldots \ldots \ldots \ldots \ldots \ldots \ldots$

C. Appendix III--March 15,1990 to April $20,1992 \ldots \ldots \ldots \ldots \ldots 6 \ldots$

IV. ATTACHMENT B ............................... 129

Subcontract Report Summary for Task 4 as conducted

by Dr. Bailey Ward at the University of Mississippi

A. Appendix I-Biological Samples, DBT Flourescence Spray-Plate Assay, Culture Media, GC Methods, ASTM Sulfate Assay, Lehigh University Cultures, Solvent Extraction Methods, Chromatogram of Organic Sulfur Standards

B. Appendix II-Summary of DBT Spray-Plate Assays, Lehigh Cultures and Kodama Products, GC/MS, Sulfur-stress Assay

C. Appendix III-Solvent Extraction Efficiency, Thin-layer Chromatography, GC/MS Analysis

D. Appendix IV-Bioactivity on DBT-Sulfone, Spray-Plate Assay, Shake-flask Assays, Cell-Slurry Assays, ASTM Sulfate Assays

E. Appendix V-The UMX Consortium, The Sulfur-Stress Assay, Ion Chromatographic Sulfate Assay, Tests on Depyritized Coal, Focus on UMX3 and UMX9, Cell-free Extracts

F. Appendix VI-Assays on UMX3 and UMX9, Assays on IGTS-8, Taxonomic Studies, Tests of UMX3 and UMX9 on Coal

G. Appendix VII-Materials and Methods

H. Appendix VIII-Proceedings Manuscript, "Microbial Extraction of Sulfur from Model Coal Organosulfur Compounds", Purdy, Ward and Lepo, Third Sumposium on Biotechnology of Coal and Coal-Derived Substances, 23-24 September, 1991, Saalbau, Essen. 


\section{INTRODUCTION}

Research on microbial desulfurization has been active at Louisiana Tech since the late seventies. Several papers and theses have resulted (see references 3 and 14) as well as the sponsoring of a national symposium on "Biological and Chemical Removal of Sulfur and Trace Elements in Coal and Lignite" (44) in November of 1982. In 1982, three microorganisms with thiophenic sulfur oxidizing characteristics were isolated (Arrowood [3]). One organism, designated as OC7A, was separated from an oil sludge pond in Oil City, Louisiana. OC7-A was found to reduce the organic sulfur content of some coals by $25 \%$ in preliminary shaker flask tests in a 24 to 48 hour period at neutral $\mathrm{pH}$ and $25^{\circ} \mathrm{C}$. Organisms have also been isolated and tested that oxidize pyritic sulfur (Franklin [14]). A Thiobacillus ferrooxidans strain separated from an acid mine drainage in W. Virginia reduced pyritic sulfur by $95 \%$ in 10 to 14 day treatments.

Expertise was therefore considered present at Louisiana. Tech to launch a major effort in the biodesulfurization area. Concentration in this current project was focused on organic sulfur removal and initially involved further application of the OC7-A microorganism. The problems of reliably quantifying organic sulfur were also addressed at Louisiana Tech. Research was conducted with Scanning Electron Microscopy combined with Energy Dispersive X-Ray Spectroscopy (EDS-SEM). Analyses of National Bureau of Standards samples were used to develop an analytical method for determining organic sulfur directly. With this method, resident atoms are excited from the application of an electron beam. As these atoms subsequently decay, the wavelengths for the various atoms are monitored.

The research also involved a search for and isolation of new bacterial species exhibiting organic sulfur oxidizing abilities. Selected organisms were examined for the presence of DNA plasmids (extrachromosomal rings of DNA that replicate autonomously in bacteria) responsible for producing organic sulfur oxidation. Upon identification, it was planned that selected plasmids would be introduced into organisms capable of thriving at economically conducive conditions.

Final evaluation of $\mathrm{OC7}-\mathrm{A}$ and other microorganisms were to be evaluated for their application in batch or continuous bench-scale coal treatment systems.

The proposed research was divided into five tasks: (1) project planning, (2) coal procurement and preparation, (3) development of analytical techniques for determining organic sulfur content of coal directly, (4) isolation and deployment of microbes for removing organic sulfur (including plasmid studies) and (5) project management. Each task is addressed independently in the following discussion. Individual introductions and literature citations are provided for major tasks. Explanations of the proposed objectives and procedures for the major tasks are outlined through a series of subtasks. 


\section{Task 1. Project planning.}

This task was completed by Dr. Joseph Fernandes. The final, corrected copy of the Project Work Plan was submitted on December 13, 1988.

\section{Task 2. Coal Procurement and Preparation.}

Subtask 2-1: Grinding, Sieving, and Storage

The objective of this task was to grind and sieve all the coal to be utilized in this investigation.

The coal was ground to various mesh sizes in a ball-mill grinder. The ground coal was separated into mesh sizes ranging from 50 to 270. After grinding a single batch of coal (coal was received in 20 pound batches), the coal to be used in the various tests was riffled to ensure homogeneity of all samples. The coal was then stored (prior to and following microbial treatment) in plastic bags in an inert environment of argon or nitrogen until further use. Analysis and characterization of the coal followed grinding and biotreatment according to the ASTM methods prescribed.

\section{Subtask 2-2: Microbial Pvrite and Sulfate Removal}

This project was concerned primarily with addressing the problems of microbial organic sulfur removal. The coal was therefore further processed after grinding and sieving to remove a majority of the pyritic and sulfate forms of sulfur. This simplified the sulfur analyses and allowed a focus on eliminating the organic sulfur remaining.

The pyritic sulfur was initially removed utilizing Thiobacillus species in a process developed by Franklin (14) at Louisiana Tech. As the project progressed, stock cultures of Thiobacillus species were supplemented by cultures of Thiobacillus ferrooxidans and Thiobacillus thiooxidans obtained from the Americal Type Culture Collection (ATCC). A large batch process was used to depyritize the coal to be used throughout the duration of organic sulfur removal studies of the project. The coal was well mixed and stored dry, under inert gas (argon) to prevent further biological oxidation. A pyritic sulfur removal of greater than $90 \%$ was achieved in most instances. 


\section{Task 3. Analytical Procedures for Total Organic Sulfur}

\section{Background}

The removal of organically bound sulfur from coal prior to combustion offers many technical challenges. One of the most difficult is the development of an analytical procedure for organically bound sulfur that is: specific, accurate, precise, and fast. The method of reference is the American Society of Testing Materials (ASTM) procedure D-2492, Standard Test Methods for the Forms of Sulfur in Coal (2). This is an established procedure that is well accepted. It was originally published in 1966. It involves wet chemical procedures and determines the organic sulfur indirectly. The difference between the sum of the pyritic and sulfate sulfur and the total sulfur is attributed to organically bound sulfur.

This method provides a common reference point for other analytical methods. However, it is not a perfect procedure. It has been shown to yield a lower value for pyritic sulfur than other more direct analyses (24). Mossbauer spectroscopy provides a non-destructive assay of the pyritic sulfur in coal. This method uses a radioactive isotope of iron (Fe-57) and provides a specific value. The concentrations measured by this method are generally higher than those from ASTM D-2492.

Scanning Electron Microscopy combined with Energy Dispersive X-Ray Spectroscopy (EDSSEM) has been used to provide a direct determination of organic sulfur in raw and chemically treated coals (39). In this method, coal regions free of mineral inclusions were identified. A few cubic micrometers of this material were excited with the electron beam as the wavelengths for sulfur, iron, calcium, silicon, and aluminum were monitored. This enabled the exclusion of any data point that included any finely divided mineral matter. The reported results agree with the ASTM values for most samples if the counting statistics are considered.

The sulfur content of two Canadian coals were analyzed by several recently developed analytical techniques including EDS-SEM (1). However, the authors did not attempt to provide quantitative values for the organic sulfur by this method. They also conducted Fourier Transform Infra-Red spectroscopy with photoacoustics and electrophoresis in their study. This analysis found considerable differences between the coals even though their proximate analyses were similar. They attributed the differences to the incorporated clay and pyrite variations.

Instrumental neutron activation analysis (INAA) has been used in our laboratories to determine the trace element concentration in lignite (40) and in many other laboratories for the analysis of coals (24). INAA is an extremely sensitive method that provides data for many elements. The sulfur values are obviously total values. This method requires a large neutron flux and specialized handling equipment. Data reduction is accomplished in most cases by using the comparison method in this procedure. National Bureau of Standards (NBS) Standard Reference Materials (SRM) are included with each set of samples during the exposure times. Their known values are used to calculate the concentrations of the unknown samples. 


\section{$\underline{\text { Objectives }}$}

There have been many volumes of analytical procedures written for coal. It is an important fuel that has been used for centuries. We know many things about it. The one thing that all coal investigators seem to agree on is that coal composition is a variable. This fact requires that any study that attempts to measure the reduction of organic sulfur concentration by various procedures must begin with a sufficient quantity of coal that has been homogenized and analyzed as thoroughly as possible.

\section{Subtask 3-1: Characterization of Starting Material}

Sufficient quantities of coal that had been ground into desired particle sizes (but prior to any microbial treatment) were obtained from Task 2 . This material was stored in large plastic bags under an inert gas environment. Parameter variation resulting from storage was evaluated by an ultimate and proximate analysis characterizing each portion. ASTM D-2492 was followed to determine the forms of sulfur in the starting material. A sufficient number of analyses were conducted to insure that the deviations between samples and lots were within the ASTM limits for precision and repeatability.

\section{Subtask 3-2: Qualitv Assurance and Testing}

An overall QC/QA plan covering all phases of the project was submitted and approved after award of the contract.

Quality control for sulfur determination was maintained by running the same procedures on NBS SRM $1632 a$ and 1635. At least 1 out of each 25 samples was randomly selected as a standard. The data generated was used to construct and maintain quality control charts that were stored on the laboratory computer. If any standard samples fell out of the control limits, the analyses of that period were repeated and the cause of the error was corrected.

\section{Subtask 3-3: Analvtical Procedures}

Pyritic and sulfatic sulfur were determined via ASTM D-2492, organic sulfur by ASTM D-3177. and total sulfur by the Eschka method using a LECO Total Sulfur analyzer. 
Subtask 3-4: Mijroscopic Analysis

Initially, EDS-SEM analyses of NBS-SRM 1632a were conducted to determine the number of spots that must be excited and averaged in order to provide direct data that has no more variation than the ASTM procedure. The SEM was also used to photograph the macerals of the coal before and after the treatment procedures.

The distribution of pyritic and organic sulfur of a sample was mapped before and after biological treatment. An infrared analysis of the starting material was performed using a new sampling procedure that was developed at Louisiana Tech to minimize the strong absorption bands that interfere in the carion sulfur bond stretching region.

\section{Task 4. Organic Sulfur Removal}

\section{Background}

Organic sulfur makes up $1 / 2$ to $1 / 3$ of the sulfur found in domestic coal. Model compounds representative of coal organic sulfur species are diphenylsulfide, benzothiophene. dibenzothiophene, and thianthrene. Although mercaptans, aliphatic sulfides, and disulfides are present in coal, the hetero-aromatic sulfur compounds are found in predominating concentrations (43). The heterocyclic sulfur compounds are recalcitrant to most chemical desulfurization processes and represent the species expected to be most resistant to microbial attack.

Expensive chemical desulfurization processes are not as limited by the internal inaccessibility of organic sulfur as are the biological processes. Even at the small particle sizes effective in the biological removal of inorganic sulfur, much of the organic sulfur is inaccessible to the microbiai enzymes responsible for the oxidation of the model organic sulfur species. Only the sulfur compounds residing at the surface of the particle would be vulnerable to enzymatic attack.

The metabolism of condensed thiophene compounds in the environment is not well known. Few microorganisms have been characterized as dibenzothiophene (DBT) oxidizers, but those that do are strongly oxidative. Most of the research conducted to date has been oriented toward the potential application of the DBT degrading microorganisms in removing organic sulfur from petroleum, with some reports on coal biodesulfurization. DBT degradation has been demonstrated to be a product of cometabolism; and for some microorganisms, DBT may serve as the sole carbon, energy, or sulfur source. The rate of its metabolism is lowered when lighter. less carbon-condensed aromatic compounds are available to the bacteria. Bailey et al. (5) showed that when the benzene series of compounds are present, the disappearance of DBT is inhibited. 
Microbial desulfurization processes have been reported since 1935 when Maliyantz described the bacterial desulfurization of petroleum with the concomitant accumulation of hydrogen sulfide. In 1950 and 1951, Strawinsky patented procedures for microbial desulfurization. In order to reduce carbon loss, i.e. petroleum BTU loss, the former patent involved a two step oxidation and reduction procedure. Pseudomonas, Alcaligenes, and Bacillus species initially converted the sulfur compounds in petroleum to oxidized inorganic forms. Desulfovibrio sp., of the sulfatereducing bacteria, reduced the oxidized sulfur to sulfide. Desulfovibrio desulfuricans was used in 1953 in a reductive procedure patented by Zobell. Kirshenbaum patented a new procedure in 1951 utilizing Thiobacillus thiooxidans, Thiobacillus thioparus, and Thiophyso volutans io convert sulfur in petroleum to water soluble inorganic forms, especially sulfates. The attempted microbial desulfurization with Arthrobacter sp. by Isenburg in 1961 showed little success (44).

Yamada et al. (43) reported on the isolation and identification of DBT-utilizing bacteria. Ideally, they sought bacteria that would oxidize the DBT without the loss of hydrocarbon. Their intent was to apply the bacterial system in petroleum desulfurization. Six DBT active strains were isolated, including Pseudomonas fragii. Two new taxonomic strains were named: Pseudomonas abikonensis and Pseudomonas jianii. DBT utilization was evident in the culture medium when brightly colored ring-fission products were formed. Two water soluble degradation products were also found. One was an aromatic compound with sulfur, phenolic, and enolic hydroxyl groups; and the second was an aromatic with an enolic hydroxyl group and a mercaptan group.

Nakatani et al. (35) described culture conditions optimal for DBT oxidation by Pseudomonas abikonensis and Pseudomonas jianii. The mineral-salts meat extract base was supplemented with DBT dissolved in light oil. Dissolving the DBT in light oil enhanced the oxidation process. The DBT degradation products had absorption maxima at 395 and $470 \mathrm{~nm}$. Since a correlation was observed between optical density and aqueous sulfur content, soluble sulfur concentration was determined spectrophotometrically. Meat extract as a nitrogen source was optimal at a concentration of $0.4 \%$, with DBT at $10 \%$, a $\mathrm{pH}$ of 7.3 , and a temperature of $28{ }^{\circ} \mathrm{C}$. Vigorous aeration was favorable for DBT conversion. A $40 \%$ conversion ratio was attained within a period of 3 days. Optical density, representing growth, peaked on the second day.

Kodama et al. (27) reported on the isolation and identification of oxidation products by Pseudomonas jianii. Five water soluble organic sulfur compounds were detected as degradation products of DBT. Three of these compounds were identified: 3-hydroxy-2-formylbenzothiophene, dibenzothiophene-5-oxide, and 3-0xo-2(3'hydroxy-thionaphthenyl-(2)-methylene) dihydrothionaphthene. Ultraviolet spectra, infrared spectra, and nuclear magnetic resonance data were used in the identification of the isolated products.

Kodama et al. (26) reported further identification of the DBT oxidation products and proposed an oxidation pathway for DBT. The newly identified compounds were trans-4(2-(3-hydroxy)thionaphthenyl)-2-oxo-3-butenoic acid and the second as the hemiacetal form of the first. 
Kodama (25) reported that DBT was oxidized by resting cells of Pseudomonas jianii in the presence of lactate or glycerol as energy sources. This finding agrees with the assessment of DBT oxidation as a phenomenon of co-metabolism. Induction of the DBT oxidizing enzymes occurred in the presence of compounds containing benzene rings having no side chains, such as DBT, naphthalene, and anthracene. Kodama concluded that DBT was practically unusable as a carbon source for energy and without a co-substrate, like lactate or glycerol, could not induce specific enzymes.

Sagardia et al. (36) reported that Pseudomonas aeruginosa PRG-1 degrades benzothiophene (BT) and related compounds. Oxidation of the BT was measured spectrophotometrically by the disappearance of the $225 \mathrm{~nm}$ peak. The oxidation pathway was not elucidated, but it was suggested to be similar to that reported by Kodama. The organism was isolated from oilcontaminated soil. BT as a sole nutritive source would not support growth. Yeast extract was required for BT oxidation to occur. As in Yamada's DBT research, the BT was dissolved in light oil and added to a basal-salts yeast extract medium. The oil-aqueous system reduced the toxic effects of the substrate.

Hou and Laskin (16) reported on the oxidation of DBT by Pseudomonas aeruginosa ERC-8. Degradation products appeared as red pigments within the bacterial cells. The products identified were 4(2-(3-hydroxy)-thionaphthenyl)-2-hydroxy-3-butenoic acid. The second compound was a tetradecane ester of the first compound with an hydroxylated hydrocarbon moiety. DBT was not degraded unless $n$-paraffin was supplied in the enrichment screening medium. The paraffin apparently acted as the energy source. The DBT degradative enzyme action of Pseudomonas aeruginosa ERC-8 attacked only the benzene ring and did not alter the sulfur moiety.

Laborde and Gibson (31) reported on the metabolism of DBT by the mutant Beijerinckia B8/36 in the presence of succinate. The two initial water soluble degradation products that accumulated before ring-fission products appeared were: (+)-cis-1,2-dihydroxy-1,2-dihydrodibenzo-thiophene and dibenzothiophene-5-oxide. The organisms were cultured at $30^{\circ} \mathrm{C}$ in 10 -liter quantities of a mineral-salts medium supplemented with $0.2 \%$ succinate and $0.05 \%$ DBT. Air was supplied at 12 liters per minute: The culture was stirred at $600 \mathrm{rpm}$. Yellow-ring fission products were observed but not identified (30).

Chandra et al. (9) reported on the microbial removal of organic sulfur from coal. Following the screening technique reported by Yamada et al. (43) an unidentified mixed bacterial culture was isolated exhibiting DBT utilization where DBT was the sole carbon source. A coal sample was ground to 240 mesh and suspended in a mineral-salts beef extract medium $(\mathrm{pH} 7.5)$ at a concentration of $6.6 \%$. The coal suspension was inoculated with $5 \mathrm{ml}$ of a culture containing $10 \mathrm{E} 9 \mathrm{cells} / \mathrm{ml}$ and incubated on a rotary shaker for 10 days at $30^{\circ} \mathrm{C}$. Sterile coal was shown to lose $17.9 \%$ organic sulfur following bacterial treatment and unsterile coal lost $14.9 \%$. Activity of the culture on coal previously treated to remove the inorganic sulfur was not reported. 
Finnerty (13) reported on the degradation of DBT by a mixed-culture bacterial system. The sulfur-containing aromatic compcunds DBT, BT, thioxanthine, thianthrene, and benzene disulfide were oxidized but would not serve as a sole source of energy, carbon, or sulfur. The culture converted $97 \%$ of the DBT to water-soluble compounds within 24 hours. The degradation products w'ere identified as 1,2-dihydroxy-dibenzothiophene, 3-hydroxy-2-formyl-benzothiophene, trans-4(2-(3-hydroxy)-thionaphthenyl)-2-oxo-3-butenoic acid and an unidentified product It was found that DBT was oxidized by Pseudomonas putida, which would grow on naphthalene as a sole carbon and energy source. Observing that the degradation products of DBT from different bacterial strains were similar, and in some cases the same, Finnerty was led to examine and determine whether the genes coding for DBT oxidation were located on plasmids. It was discovered that the plasmid containing the genes for naphthalene oxidation also contained the genes for DBT oxidation. No taxonomic identification of the mixed-culture system was reported.

Jerusik (21) working with Finnerty, reported the tentative identification of the microorganisms in the inixed culture responsible for oxidation of DBT. The Gram-negative rod was tentatively designated as an Acetobacter sp. and the Gram-positive coccus as a member of the Micrococcaceae. The possible environmental impact of the DBT degradation products was studied using nonspecialized and specialized bacteria. Little toxic effect was observed when Shigella flexneri, Pseudomonas aeruginosa, or Escherichia coli were cultured in a liquid medium supplemented with DBT degradation products at $90 \%$ concentration. No change in the lag or logarithmic phases was observed, although the stationary cell mass did decrease. E. coli continued to grow in the presence of the cell products after attaining the stationary phase, suggestive of diauxic growth. The exact nature of the observed stimulation was not determined.

Eckart et al. (12) reported on the isolation of bacteria exhibiting desulfurizing activity on crude Romashkino oil. The bacterial strains were isolated from oil polluted water, soil, and remnants in oil tanks. DBT was used as the model organic sulfur species in the screening media. All strains were aerobic, strongly oxidative, and tentatively identified as species of Pseudomonas. The most active strains were capable of removing 50 to $55 \%$ of the sulfur within 5 days. The incubation was carried out in discontinuously running laboratory fermentors. There was no mention of applying the cultures to desulfurize coal.

Kurita et al. (29) reported the isolation of a bacterial culture that reductively degraded thiophene, producing hydrogen sulfide. The anaerobic culture was isolated from oil well sludges or crude oil reservoir bottoms. The thiophene decomposing bacterial cells were Gram-negative rods that grew optimally at $\mathrm{pH} 7.2-7.8$ at $38^{\circ} \mathrm{C}$ in a nutrogen or hydrogen environment. Polypeptone was required for growth. Hydrogen sulfide production was enhanced by the addition of $\mathrm{FeSO}_{4}$. Cellfree extracts of the culture catalyzed the production of $\mathrm{H}_{2} \mathrm{~S}$ from thiophene when supplied with methyl viologen in hydrogen gas. The culture did not utilize thiophene as a sole source of carbon, sulfur, or energy. Cripps (11) reported the isolation of a Flavobacterium sp. capable of using thiophene-2-carboxylate as a sole source of carbon, energy, and sulfur for growth. The sulfur atom of the thiophene nucleus was oxidized to sulfate and accumulated in the culture medium. 
Arrowood (3) described a bacterial isolate designated OC7-A, a naturally occurring soil microorganism which degraded DBT. OC7-A, found in oil samples collected around an oil well slush pond near Oil City, Louisiana, was tentatively identified as a species of Arthrobacter. Desulfurization by $\mathrm{OC7}-\mathrm{A}$ occurred in nature at $25-28{ }^{\circ} \mathrm{C}$ and $\mathrm{pH}$ of 7.0 . It required relatively low cost nutrient additives of secondary carbon sources. Coal samples with a total sulfur content of $5.1 \%$ were treated with $\mathrm{OC} 7-\mathrm{A}$ in $1 \%$ and $5 \%$ slurries. A calculated percent organic sulfur lost from coal was reported as 25.78 in 48 hours. The levels of organic sulfur reduction varied with the slurry concentration and the added carbon source. Succinate as an added carbon source showed the highest level of organic sulfur reduction. As a model organic sulfur compound, Arrowood also studied desulfurization of DBT by OC7-A using Hutner's vitamin free-mineral base; $18 \%$ organic sulfur reduction was found. An AE mineral-salts solution gave even better results. In determining whether co-metabolism would enhance organic sulfur degradation, a secondary carbon source was added. Napthalene was found to be inhibitory while yeast extract showed a reduction of $18.67-24.43 \%$.

The ambient conditions and the effectiveness of organic sulfur removal from coal by the organisms reported by Arrowood, especially the naturally occurring OC7-A, show promise for an economically feasible large-scale process of coal cleaning.

Isbister and Kobylinski (20) found what they called a unique desulfurizing microorganism. This organism, designated $\mathrm{CB} 1$, is a DBT degrading organism that was developed by mutagenically altering the DNA of the naturally occurring parent organism. The parent organism degraded DBT minimally. CBI was initially grown in a basic mineral-salts medium. CB1 reduced organic sulfur in a bench model coal reactor at $\mathrm{pH} 7.0$ over a temperature range of $25-35^{\circ} \mathrm{C}$ for 48 hours. The treatment process was then moved to a continuous pilot plant capable of treating 1000 to 2500 pounds of coal per day. Using ${ }^{14} \mathrm{C}-\mathrm{DBT}$ and ${ }^{35} \mathrm{~S}-\mathrm{DBT}$, the action of CB1 in DBT was traced. $C B 1$ was found to be different than other microorganisms that oxidize DBT, because it released 2,2 di-hydroxybiphenyl instead of breaking the carbon ring to yield 3-hyroxy-2formylbenzothiophene. Cleaned coals containing approximately $90 \%$ organic sulfur were used in the initial research to bypass problems associated with organic sulfur analysis. The total sulfur content of these coals was determined using the Fisher Total Sulfur Analyzer before and after treatment. The organic sulfur content was reduced $18-28 \%$ when treated with CB1. When run of the mine coals were used with CBI treatment, the organic sulfur removed varied from $25 \%$ to $34 \%$. The variations in the data may be attributed to differences in particle sizes (desulfurization increases as particle size decreases), surface characteristics of the coal (desulfurization is inhibited by surface oxidation), or differing amounts of thiophene sulfur in the coals. Using a direct method of organic sulfur determination, which involved energy-dispersive $x$-ray microanalysis combined with scanning election microscopy (EDS-SEM), pulverized coal of 140 mesh was tested for organic sulfur content before and after treatment with CB1. The reduction in organic sulfur was $32.9 \%$ to $34 \%$. Initial cost estimates for enough medium to produce the microorganisms capable of treating 1 ton of coal was $\$ 117$. Further studies showed that at a much lower level of microorganism dose and using a less expensive carbon source, the medium cost estimate was reduced to $\$ 2.34 /$ ton. The overall cost estimate, depending on whether the final product was dried or used with $30 \%$ moisture, was calculated to be $\$ 25.50$ or $\$ 21.09$ per ton of product coal. Of this cost, $\$ 11.39$ was estimated as the cost/ton for organic sulfur removal. 
Murphy et al. (34) used the microorganism Sulfolobus acidocaldarius to reduce sulfur from coal. They adapted the organism to grow on high sulfur coal without the addition of nutrients. They believe that a 50-60\% reduction in organic sulfur is possible in 3-6 days when the coal used was 200 mesh, temperature $55-80^{\circ} \mathrm{C}$, and $\mathrm{pH} 1-2$. The estimated cost was given at $\$ 10-14 /$ ton or about $\$ 12$. S. acidocaidarius must have oxygen to be viable so air must be pumped or stirred in. S. acidocaldarius also utilizes the $\mathrm{CO}_{2}$ in air as its carbon source. Surfactants were added with varying results, from increased to decreased efficiencies.

Kargi and Robinson (23) also used Sulfolobus acidocaldarius to oxidize sulfur in treated coal. They found that $S$. acidocaldarius used $\mathrm{Fe}_{2}{ }^{+}$and reduced sulfur as energy sources. They used coal of 100-150 mesh at a temperature of $75^{\circ} \mathrm{C}$ and $\mathrm{pH} 2.5$. Initially a double strength mineralsalts medium was used. Yeast extract, $\mathrm{FeCl}_{3}$, and other nutrients were added as needed. When the yeast extract was added, both the rate and the amount of sulfur reduction decreased. When the initial coal was $11 \%$ total sulf:yr, $15.6 \mathrm{mgS} /(\mathrm{L} \mathrm{h})$ was removed. When the total sulfur was $4 \%, 3.1 \mathrm{mgS} /(\mathrm{L} \mathrm{h})$ was removed. On the average, there was a total sulfur removal of $40 \%$. Total sulfur was determined using the Eschka method. Inorganic sulfur was determined using standard methods of ASTM. Organic sulfur levels were found by subtracting the inorganic sulfur content from the total sulfur content.

Monticello et al. (33) conducted a study that linked plasmids to the oxidation of DBT. They used plasmids of two strains of Pseudomonas that oxidized DBT. Each of the plasmids has a molecular weight of approximately $55 \times 10^{6}$. The products of the DBT oxidation appeared to be identical to products of other DBT reducing microorganisms, substantianing their findings.

Vaseen (41) reported that Thiobacillus ferrooxidans may be used to reduce organic sulfur from coal under certain conditions. It requires a temperature of $20-35^{\circ} \mathrm{C}$ and a $\mathrm{pH}$ of $1.2-2.5$. This $\mathrm{pH}$ is very corrosive so moving parts must be minimized. For effective sulfur reduction, the coal must be pulverized to a uniformly-reduced particle size. Oxygen is a requirement of $T$. ferrooxidans, it may be sparged or added through agitation. Thiobacillus ferrooxidans also gets needed carbon from the $\mathrm{CO}_{2}$ in the air. Vaseen believed that with a bioreactor he had designed. 100,000 metric tons of coal with $2.3 \%$ total sulfur could be processed in a year.

Kublek and Clark (28) reported that mutagens of Escherichia coli degraded thiophene and several other organic and inorganic sulfur compounds. These mutants can hydrolize DBT on a minimal medium of yeast extract, peptone, and $0.5 \%$ glucose at $\mathrm{pH} 7.0$. Mutant generations of E. coli were tested in an effort to produce an efficient thiophene degrader. 


\section{Objectives}

In the past twenty years, genetic engineering and recombinant DNA work with bacteria has created the potential for altering microorganisms to perform new and different metabolic reactions. One area that has more recently received attention is the use of bacterial plasmids, extrachromosomal entities, in mediating the parent cells to metabolize difficult, recalcitrant substrates. One of these substrates is the sulfur-containing heterocyclic organic compounds found in coal, coal tars, and crude oil. Plasmid-mediated degradation of dibenzothiophene (DBT) by Pseudomonas species has been reported by several workers as referenced in the above section on Background of organic sulfur removal. Plasmid-mediated degradation also has promise for application to several species of bacteria that live in the environments of coal mining operation areas, coal mines, and in acid-mine drainage from such areas.

Based on the information to date, the following objectives and approaches were pursued to accomplish the removal or reduction of organic sulfur from coal by biodesulfurization with selected microorganisms in precombustion treatments.

\section{Subtask 4-1: Desulfurization with OC7-A}

Objectives and methodology in Subtask 4-1 were to utilize the bacterial isolate reported by Arrowood (3), OC7-A, to reduce the organic sulfur in DBT and coal, in a series of laboratory experiments designed to enhance the levels of organic sulfur removal found in Arrowood's work. Substrate modification and co-metabolic additives were screened to determine the best combinations for maximum organic sulfur reduction. (Note: While this objective existed in the original proposal, difficulties in observing any organic sulfur removal from coal with this culture arose shortly after the commencement of the project. Work with OC7-A then ceased and isolation and identification efforts shifted to other cultures).

\section{Subtask 4-2: Search for New Biodesulfurizing Microorganisms}

Objectives and methodology in Subtask $4-2$ were to screen soils, coals, waters, and acid-mine drainage samples in a search for new microorganisms capable of removing organic sulfur from coal/water slurries. Shake-culture techniques were used to screen large numbers of samples to detect the microbial populations containing organic sulfur oxidizers. Techniques employing enrichment and isolation procedures reported by other researchers $(3,33)$ were used to search for microorganisms that remove organic sulfur from coals. Emphasis was given to the autotrophic bacteria in order to reduce the need for expensive substrates, since this group of bacteria utilize $\mathrm{CO}_{2}$ or simple organic compounds as carbon sources. A part of this subtask was also concerned with techniques for maintenance of the active bacterial organic sulfur oxidizers once they had shown potential for use in coal biodesulfurization. 
Subtask 4-3: Plasmid-mediated Techniques

The main objective and methodology of Subtask 4-3 involved the use of plasmid mediation of the most promising and most active organic sulfur oxidizers. By using the procedures reported by Kado and Liu (22) and Monticello et al. (33), a search for plasmids coded for organic sulfur oxidation was made. Some effort was planned for determining whether cell-free extracts could be used in biodesulfurization as effectively as whole cell preparations. In order to determine the role of plasmids in organic sulfur removal, a program of screening the selected isolates for extrachromosomal DNA was planned to determine which parent cells were most productive of plasmids. The final phase of Subtask 4-3 was concemed with regulation of organic sulfur oxidation by the plasmid-mediated strains for riaximum performance in biodesulfurization of selected coal samples prior to attempts at continuous bench-scale treatment of coal.

The report on this Task as received from the subcontractor, the University of Mississippi, is presented as Attachment B to this Final Report.

\section{Task 5. Project Management and Reporting}

This task consisted of coordination of all tasks, procurement of supplies and equipment. maintenance of ledger of expenses, record keeping of results, preparation of reports and publications.

It should be noted that shortly after the initiation of the project, Dr. Joseph Femandes leit Louisiana Tech University. The project management then shifted to Dr. Brace Boyden who was also in the Department of Chemical Engineering. In February, 1990, Dr. Boyden also left the university and was replaced by Dr. Gary Zumwalt in the Department of Petroleum Engineering and Geosciences. Dr. Zumwalt served as the Project Manager and Principal Investigator unil the arrival of Dr. Bill Elmore in May, 1990-a newly hired Assistant Professor of Chemical Engineering. Dr. Elmore then served as PM and PI throughout the remainder of the 36-month project period and the subsequent 12 -month, no-cost, contract extension.

The following account of the work accomplished in this project generally follows a task-by-task chronology of events proceeding in a task-by-task analysis. Task 2 (Coal Procurement and Preparation) was expanded in scope (with DOE Project Manager approval) under the direction of Dr. Elmore during the 12-month, no-cost extension obtained in the latter stages of the project. While originally intended as a preparation step only for the subsequent study of microbially removing the organic sulfur fraction, the microbial pyrite and sulfate removal (Subtask 2-2) became the subject of research focus with the intention of enhancing the pyritic removal process. Analytical procedures (Task 3) were conducted at Louisiana Tech and are also presented. The microbial studies for isolating and identifying microorganisms capable of removing organic sulfur were conducted jointly by Louisiana Tech and the University of Mississippi. 


\section{LITERATURE CITED}

1. Angle, C., W. Leung, R. Mikula, and H. Hamza, "Sulfur Characterization of Eastern Canadian Coal for Optimization of Beneficiation Process". In Y. A. Attia (ed.), Processing and Utilization of High Sulfur Coal. Proceedings of the First International Conference on Processing and Utilization of High Sulfur Coals, Elsevier, New York, 68-88, 1985.

2. Annual book of ASTM standards. Part 26-Gaseous Fuels, Coal and Coke. ASTM D 2492-79.

3. Arrowood, Michael J., "Isolation of DBT-Oxidizing Microorganisms for Application in Coal Desulfurization", (Master's thesis, Louisiana Tech Universiry), Ruston, Louisiana, 1983.

4. Attia, Y. A., and M. A. Elzeky, "Biosurface Modification in the Separation of Pyrite from Coal by Froth Flotation". In Y. A. Attia (ed.), Processing and Utilization of High Sulfur Coal. Proceedings of the First Intemational Conference on Processing and Utilizing High Sulfur Coals, Elsevier. Niew York. 673-682, 1985.

5. Bailey, N. J. L., A. M. Jcbson, and M. A. Rogers, "Bacterial Degradation of Crude Oil: Comparison of Field and Experimental Data", Chemical Geology 11:203-221, 1973.

6. Beier, E., "Removal of Pyrite from Coal Using Bacteria", In Y. A. Atita (ed.), Processing and Utilization of High Sulfur Coal. Proceedings of the First International Conference on Coal, Elsevier, New York, 653-672, $198 \Sigma$.

7. Birks, L., Electron Probe Microanalysis, 2nd edition, Wiley-Interscience, New York, 1971.

8. Carrington, A., and A. McLachlan, "Introduction to Magnetic Resonance", Harper \& Row, New York.

9. Chandra, D., P. Roy, A. K. Mishra, J. N. Chakrabarti, and B. Sengupta, "Microbial Removal of Organic Sulfur from Coal", Fuel 58:549-550, 1979.

10. Chiou, K., and O. Manuel, "Chalcogen Elements in Coal and Their Redistribution in Combustion Products". In Y. A. Attia (ed), Processing and Utilization of High Sulfur Coal. Proceedings of the First International Conference on Processing and Utilization of High Sulfur Coals, Elsevier, New 'ork, 1985.

11. Cripps, R. E., "The Microbial Metabolism of Thiophene-2-carboxylate", Biochem. J. 134:353-366, 1973. 
12. Eckart, V., W. Heike, J. Bauch, and H. Gentzsch, "Mikrobielle Entschwefelung von Erdol und schweren Erdolfraktionen 1. Untersuchugen zur Mikrobiellen aeroben Entschwefelung von Romaschkinoroherdol". ("Mineral Desulfurization of Petroleum and Heavy Petrolum Fractions 1. Studies on Microbial Aerobic Desulfurization of Romashkino-crude Oil) Zbl. Bakt. II. Abt. 135:674-681, 1980.

13. Finnerty, W. R., "Microbial Desulfurization and Denitrogenation", Symposium on Microbial Processes for Metals Accumulation and Sulfur/nitrogen Removal from Fuels, Second Chemical Congress of the North American Continent, San Francisco, California, 1980.

14. Franklin, T. J., "Search for Inorganic Sulfur-oxidizing Microorganisms for Application in Coal Desulfurization, (Master's thesis, Louisiana Tech University), Ruston, Louisiana, 1983.

15. Genuit, W., J. Boon, and O. Faix, "Characterization of Beech-milled Wood Lignin by Pyrolysis-gas Chromatography-photoionization Mass Spectrometer", Anai. Chem. 59:508-513, 1987.

16. Hou, C. T., and A. I. Laskin, "Microbial Conversion of Dibenzothiophene", Develop. Industr. Microbiol. 17:351-362, 1976.

17. Hubner, T. F., E. Ras, and N. W. F. Kossen, "Design and Scale-up of a Reactor for the Microbial Desulphurization of Coal: A Kinetic Model for Bacterial Growth and Pyrite Oxidation", Laboratory of Bioengineering Department, Dept. of Chemical Technology, Dept. Univ. of Technology, Julianalaan. 67, 2628 B.C. Delft, The Netherlands.

18. Hubner, T. F., N. W. F. Kossen, P. Bos, and J. G. Kuenen, "Design and Scale-up of a Reactor for Microbial Desulphurization of Coal: A Regime Analysis", Laboratory of Bioengineering, and Laboratory of Microbiology; Delft Univ. of Technology, Delft, The Netherlands.

19. Hubner, T. F., N. W. F. Kossen, P. Bos, and J. G. Kuenen, "Modelling Design and Scale-up of a Reactor for Microbial Desulphurization of Coal", First Symposium on Biohydrometallurgy, Cagliari, Italy, 1983.

20. Isbister, J. D., "Microbial Desulfurization of Coal". In Y. A. Attia (editor), Processing and Utilization of High Sulfur Coal. Proceedings of the First International Conference on Processing and Utilizing High Sulfur Coal, Elsevier, New York, 1985.

21. Jerusik, R. J., "The Microbial Metabolism of Sulfur-containing Hydrocarbons", (Ph.D. Dissertation. University of Georgia), Athens, GA, 1979.

22. Kado, C., and S. Liu., "Rapid Procedure for Detection and Isolation of Large and 
23. Kargi, F., and J. M. Robinson, "Microbial Desulfurization of Coal by Thermophilic Microorganism Sulfolobus acidocaldarius", Biotech. and Bioeng. 26:2115-2121, 1982.

24. Karr, C., "Analytical Methods for Coal and Coal Products", vols. I, II, and III. Academic Press, Inc., New York, 1978.

25. Kodama, K., "Induction of Dibenzothiophene Oxidation by Pseudomonas jianii", Agric. Biol. Chem. 41:1193-1196, 1977.

26. Kodama, K., K. Umehara, K. Shimzu, S. Nakatani, Y. Minoda, and K. Yamada, "Identification of Microbial Products from Dibenzochiophene and Its Proposed Oxidation Pathway", Agric. Biol. Chem. 37:45-50, 1973.

27. Kodama, K., S. Nakatani, K. Umehara, K. Shimizu, Y. Minoda, and K. Yamada. "Microbial Conversion of Petro-sulfur Compounds, Part III. Isolation and Identification of Products from Dibenzothiophene", Agric. Biol. Chem. 34:1320$1324,1970$.

28. Kublek, B., and D. Clark., "Microbial Removal of Organic Sulfur from Coal (Degradation of Sulfur Containing Heterocyclic Compounds), Final report, DOS/FE/60339-T21 DE85-018429, July 1, 1984-June 30, 1985.

29. Kurita, S., T. Endo, H. Nakamura, T. Yagi, and N. Tamiya. "Decomposition of Some Organic Sulfur Compounds in Petroleum by Anaerobic Bacteria", J. Gen. Appl. Microbiol. 17:185-198, 1971.

30. Laborde, A. L., "Initial Reactions in the Microbial Metaoolism of Dibenzothiophene and Nanhthalene", (Ph.D. Dissertation, The University of Texas at Austin), Austin, TX, 1979.

31. Laborde, A. L., and D. T. Gibson, "Metabolism of Dibenzothiophene by a Beijerinckia species", Appl. Environ. Microbiol. 17:185-198, 1977.

32. Maijgren, B., W. Hubner, K. Norrgard, and S. Sunduall, "Determination of Organic Sulfur in Chemically-cleaned Coals by Scanning Electron Microscopy and Energy Dispersive X-ray Spectrometer", Fuel 62:1076-1078, 1983.

33. Monticello, D. J., D. Bakker, and W. R. Finnerty, "Plasmid-mediated Degradation of Dibenzochiophene by Pseudomonas species", Appl. Environ. Microbiol. 49:750-760, 1985.

34. Murphy, Julie, et al, "Coal Desulfurization by Microbial Processing". In Y. A. Attia (ed.), Processing and Utilization of High Sulfur Coal. Proceedings of the First International Conference on Processing and Utilizing High Sulfur Coal. Elsevier, New York, 1985. 
35. Nakatani, S., T. Akasaki, K. Kodama, Y. Minoda, and K. Yamada, "Microbial Conversion of Petro-sulfur Compounds Par II. Culture Conditions of Dibenzothiophene-utilizing Bacitria", Agric. Biol. Chem. 32:1205-1211, 1968.

36. Sagardia, F., J. J. Rigau, A. Marinez-Lahoz, F. Fuentes, C. Lopez, and W. Flores, "Degradation of Benzothiophene and Related Compounds by a Soil Pseudomonas in an Oil-aqueous Environment", Appl. Microbiol. 29:722-725, 1975.

37. Spencer, D., Research and Development Status Repor, EPRI Journal. 37-47, 1984.

38. Straszheim, W., R. Greer, and R. Markuszewski, "Direct Determination of Organic Sulfur in Raw and Chemically Desulphurized Coals", Fuel 62:1070-1075, 1983.

39. Thompson, R., "Trace Element Concentrations in Louisiana Lignite". Symposium on Biological and Chemical Removal of Sulfur and Trace Elements in Coal and Lignite, Lousiana Tech University, Ruston, Louisiana, 1982.

40. Van Dyck, P., S. Torok, and R. Van Grieken. "Enhancement Effect in X-ray Fluorescence Analysis of Environmental Samples of Medium Thickness", Anal. Chem. 58:1761-1766, 1986.

41. Vaseen, V. A., "Commercial Microbial Desulfurization of Coal", In Y. A. Attia (ed.), Processing and Utilization of High Sulfur Coal. Proceedings of the First Intemational Conference on Processing and Utiizing High Sulfur Coal. Elsevier. New York, 1985.

42. Wrathall, J. A., and E. E. Peterson, "Desulfurization of Coal Model Compounds and Coal Liquids", University of California, Laivrence Berkeley Lab., Pub. No. LBL-8576.

43. Yamada, K., Y. Minoda, K. Kodama, S. Nakatani, and T. Akasaki, "Microbial Conversion of Petro-sulfur Compounds Part I. Isolation and Identification of Dibenzothiophene-utilizing Bacteria", Agric. Biol. Chem. 32:840-845, 1968.

44. Proceedings of Symposium on "Biological and Chemical Removal of Sulfur and Trace Elements in Coal and Lignite," November 11-12, 1982, Louisiana Tech University, Ruston, Louisiana. 


\section{ATTACHMENT A}

Attachment A contains a chronological description of Task 2--Coal Procurement and Preparation and Task 3--Analytical Procedures for Total Organic Sulfur in three Appendices. The contents of the Appendices are as follows:

Appendix I covers the project period from August 1, 1988 to March 15, 1989. Task 2 was conducted primarily as a "service" task for preparing coal for organic sulfur removal studies. Initial work consisted of setting up detailed procedures for coal pretreatment (e.g. microbial depyritization) and storage. EDS-SEM equipment troubles slowed establishment of Task 3. A transition occurred in the Project Management and Principal Investigator positions from Dr. Joseph Fernandes through Dr. Brace Boyden to Dr. Gary Zumwalt.

Appendix II covers the project period from March 15, 1989 to March 15, 1990. During this stage of the project, Tasks 2 and 3 were completed as per the original contract requirements. Project Management and Principal Investigator responsibilities again changed in May, 1990 from Dr. Gary Zumwalt to Dr. Bill Elmore--a new faculty member entering the Chemical Engineering Department. A complete presentation of the work for analytically measuring organic sulfur by EDS-SEM is provided in the thesis, "Advanced Scanning Electron Microscopy and Energy Dispersive Spectroscopy Techniques for Sulfur Analysis in Coal", Sandeep Sayal, M.S.Ch.E, Louisiana Tech University, May, 1991. This thesis is available through the Louisiana Tech University library.

Appendix III covers the project period from March 15, 1990 to April 20, 1992. While Tasks 2 and 3 had been completed, an ongoing literature survey revealed the need for additional research into the depyritization process, the findings of which are contained in the thesis, "Studies and Methods for Increasing the Desulfurization Activity of Thiobacillus ferrooxidans on Bituminous Coal", David Krueger, M.S.Ch.E., Louisiana Tech University, August, 1993. This thesis is also available through the Louisiana Tech University library. 
ATTACHMENT A

APPENDIX I

Activity from Project Initiation (August 1, 1988) to March 15, 1989 


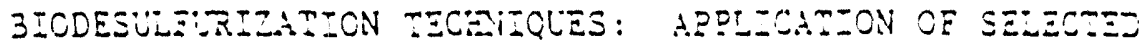 \\ YICRCCRGAVISITS FOR ORGAVIC SULFUR REXOVAL FRCM COALS}

Projec= Report from August 1, 1988, to September 16, 1988

\section{Task :: Projec: Planning}

The drazt oi the work plan was prepared and submitted to tzo on Ausus= 10, 1988. Znpur Erom T?O into the dzas= pan is included in the atsached copy.

Task 2: Coal ?rucurement and Papararion

A sample of $\because$ Z: $\vdots$ rois No. 6 cal (IBCS? $\%$, ::01600) has jeen reza:yed from Z:Zircis rological Survey. Crizination information has been

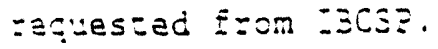

\section{Subrasic 2-:: Grinding. Sieving, and Storage}

3al1-mili grincer (ceramic with stones, Paul 0 . Abbe, Inc. 131343)

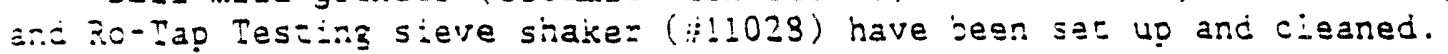

E'ystem for Coa- Storzge in a Vireogen Enyizorment

To pravent oxidation rasctions in tiae cra- samples, ve induca a

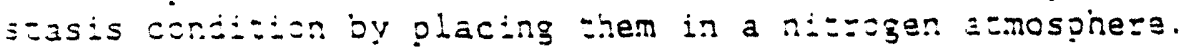

The system consists of a dessication cinaniner, a vacilun pump, a nitrogen souz:a, three valves, and a pressure gauge as shown in Eigure 1. [A "T" connector is threaded into a connection on the side of the dessicator. Connectad to the brancies of the "?" are a valve and tubing leading to a vacuum pump, and a pressure gauge and valve with tubing leading to a nitrogen cylinder and regulator. Also in place between the valves is a pressure release valve.]

\section{Procedure for Storage}

The coal samples are placed in looseiy capped vials in the chamber and the lid is sealed airtight. Aiz is removed by opening the vacuum valve and running the vacuum oumo for five minutes. The valve is closed and the nitrogen valve is opened to fill the chamber with 1.5 psi of nitrogen. This is repeared once to slusin out remaining oxygen, if any.

After one hour at 1.5 psi the nitrogen is released and the lid is removed. The vial caps are quickly iigntened and the chamber is resealed. The ait is again removed and replaced with 1.5 psi of nitzogen. 
Subtask 2-2: Microbial Pyrite and Sulfate Removal

Samples $0 Z$ acid mine waters were collected fron poncs near ine Ande-ex Resources coal mine at Madisonville, Kentucky. Shaker ILasks are being set up to determine the operating conditions of either pura or mixed cultures of Thiobacillas ferrooxidans, such as medium type and stzength, pH, and leacining time, to remove at least $90 \%$ of the pyrite suliur from coal.

Task 3: Analytical Procedures for Total Organic Sulfur

\section{Subtask 3-1: Characterization}

ASTM procedures of moisture, ash, total sulfur, pyritic sulEur, sulfate sulfur, heating value and volatiles are being set up. A set of suliur/coal calibration samples have been received. Acsuracy and reprojucijility of the above procedures will be determined by using tine szandards.

\section{Subtask 3-2: Ouality Assurance/Ouality Conc=01}

QC/QA plan prepared by Dr. John Rowley is attached for approval.

\section{Subtasid 3-4: MiczoscoDic Analyses}

The Eirst morth was dedicated to acuuizing a complere ser of conz:zis and calibrating equipment. A set of sulphur/coal calibrarion sampies ranging from $1.05 \%$ sulphur to $4.39 \%$ sulphur was acquizad $\mathrm{E}$. LiCj. Mineral calioration samples for iron sulfide have been ordered. A Zeiss vitrinite reflectance microscope was received from Mobil Oil Corporation. This microscope was set up and the process of calibrating it has begun. The scanning electron microscope was cleaned and rebuilt, and the energy dispersive $x$-ray spectrophotometer was calibrated.

Task 4: Organic Sulfur Removal

\section{Subtask 4-1: Desulfurization with OCA}

Strain OC7A was delivered by Joseph B. Fernandes (Project Manager) to Dr. Ward as a suspension of cellular material kept for several years in a frozen state (at Louisiana Tech University). Routine suriace piating revealed that several apparently different organisms were present in the culture. Each of the co-contaminants were isolated and studies were begun on each to determine if indeed it had OC7A, and if it (or one or more of the other strains) still would degrade DBT as desczibed by Arrowood. 
Subtask 4-2: Isolation and Sczeening Tests for 45 Pathray Zacteria Versus DBT

About tro dozen apparently unique bacterial isolates were derived Erom ivo sources of reatiered coals and from one sourca of weathered motor oil from a duno. Serial dilutions of derived isolates yielied piara cultures containing scattered, isolated colonies. Developed colonies were sprayed with a $1 \%(w / v)$ ethanolic solution of DBT inich, a tzez evaporation of the solvent, left a thin coating of crystalline DBT ove: the colonies and the agar surface. Controls consisted of coinnies sara:ed with erhano: only or unsprayed cultures. Aiter incubation at $30^{\circ} \mathrm{C}$ For $4-0$ hours, $: 0-12$ hol:s, 24 hours, 48 hours, and 120 hours, the piates were tested for lons-wavelength UV fluorescence to indicate Eormation of bipheny I Eom DBI via the 4S Pathway. Several DBT-coated culzuras showed flucrescence from the colonies, but so did the concrols o Each of these Ealse positive isolates. No tested isolate exinibited ilucrescence that couid be attributed to DBT degradation. A series of isoiations and sczeening of new organisms derived from difierent source samples collected from a variety of weathered coals or petroleum deposits has just begun. Tesing of new methods of screening isolates for is ac:ir:z: has aiso begun.

The process of establishing the ASTM D 516 method for determination of sulfare ions has jeen starzed. Standard reagents were prepared and Eicelity of calibration curves are being rested using a Spectronic 70 specz=opinotometer.

DE. Ward worked full time on the project during the first two weeks of August (the planned beginning date for the project to be Augus 1 , iogs) with his salar: paid from another account, which he plans to reimbuse Excm the subcontzact acsount when it is activated (The University of :ississipoi academic year contzacts began during mid-August). The Selay in funding of the subcontract has created probiems with obtaining personnel to work on the project. Dr. Ward was able to empioy tro gradute students par: time during September by "borzowing" from other accounts, which he will need to reimburse.

Dr. Ward had planned for the project to be funded earlier in the year, allowing him to work on the project full time during the sumer months to get the research off to a solid start. He received no zelease tige from his academic year duties, thus he now cannot devore as much time to the project as he would wish. He had planned to have empioyed a fuli-time postdoctoral research associate to begin in August or September, so that the work could continue without interfuption. However, because of the delay in funding, the timing was such that he could not make a monetary commitment to a prospective postdoctoral associate, wino was forced to accept another position. He advertised the pos:doc:oral research associate position during August by direct national mailing to a few hundred universities. Every applicant was expected to complete degree requirements by the end of this ( period. He has offered the position to one of the applicants, and hopes that he can have her on board no later than January 1989. 
Task $\vdots$ Project Maragement and Reporting

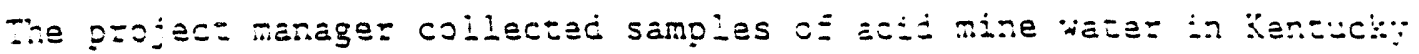
a.ci $\equiv$ tended the Contzactor's Review Yeeting in is jugust 11, 1988. Status reports of other researciness in the area of remcral of organic sulEur and individual discussions with peers iers use iul for a $300 \mathrm{~d}$ start of the project. Enzouta co Tyson's Corner, Yienna, the projecs manager stopped on Augus= 11 and August 12,1988 , at Yorjantown to meet peers attending the Consortiun for Coal Liqueraction Science. Participated in the coal workshop "3icprocessing ca coals" at Tyson's Corre: E=cm August is to August 18, 1988. Enroute to Fistor, iouisiana, colieczed soil and reathered coai sampies in Vizjinia anc

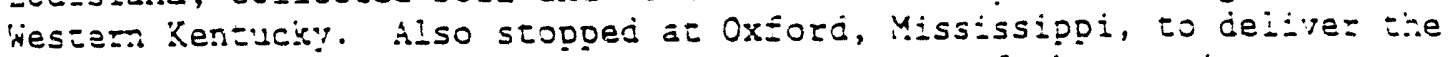
saries to or. Ward and to review the contents c the meetings.

Dr. Bcycen anc Dr. Zunwait began their tasks on Septembe: $\therefore, 1938$. Cre zasearch assistant was hized on September 1,2988 , and is ictising on Task 3 with Dr. Boycen. Arother research assistant (her wages providec jy -ouisiana Teci University as natching) began working on the projecs Sez=ember 8. Tro szucient workers started work on Task 2 on Septembez 3

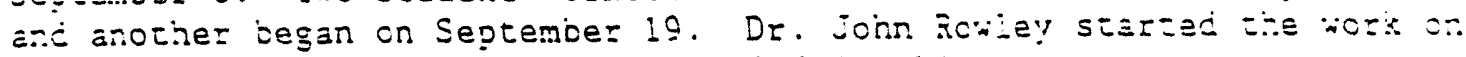
QC. a and his working drate is included in this zepore. 

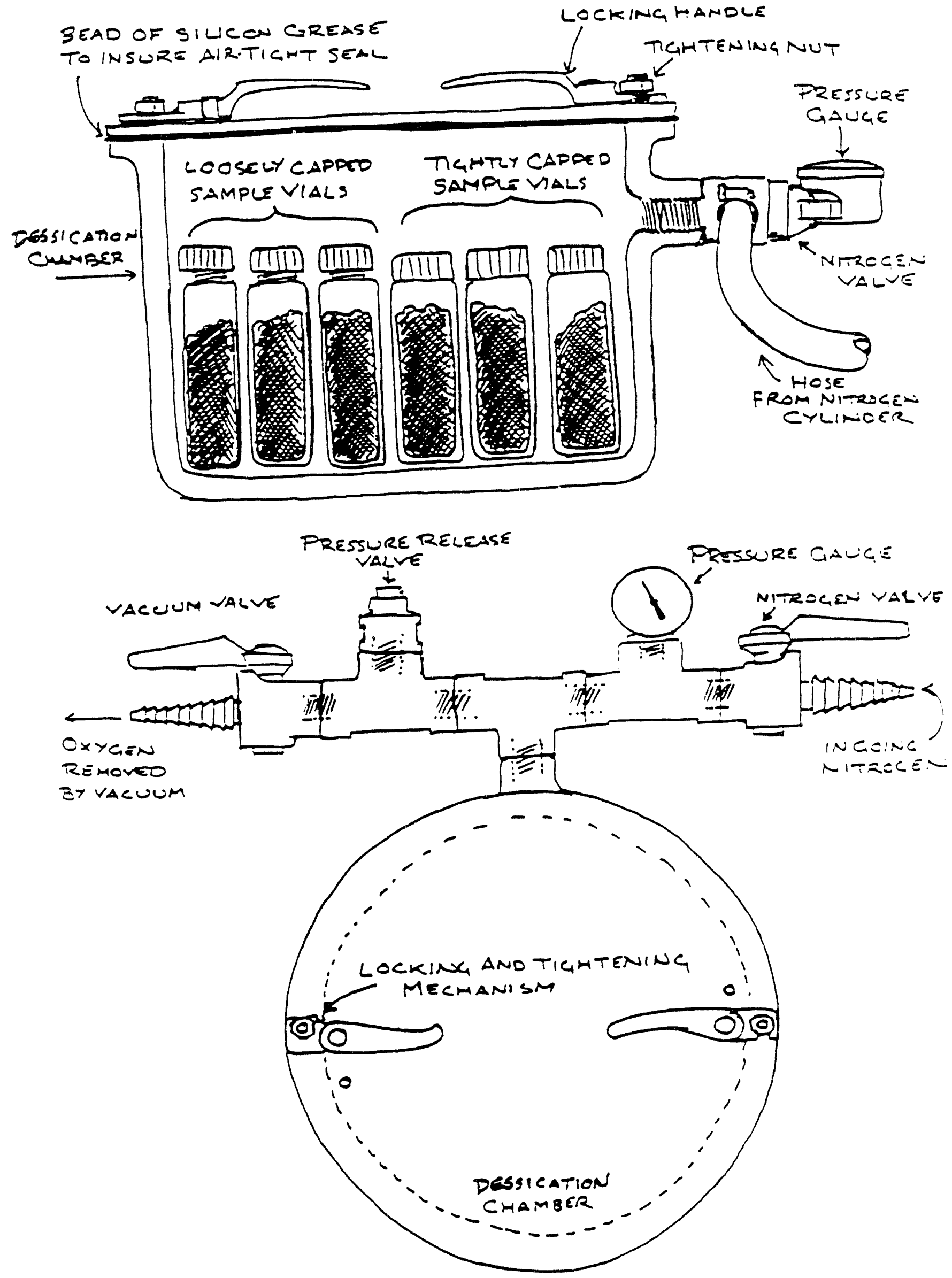

FIGURE ONE: SYSTEM FOR COAL STORASSE In A NITROSEN EUVIRONME.T' 
A corzectec Ezoject Elan with hours cemarazes as gez tie categories of labor, task, and month for each yeaz o the ticrojec= was forwazjed Decemcer 13, 1988. This Task sholli therefore de completec.

2 COAL PROCUREMENT AND DREPARATION

\subsection{Grinding, sieving, and Storage}

More IIIinois $\# 6$ coel is being grounc (200 mesi) anc sto=ฏ uncer nitzogen. Grinding will continue until sevezal golucis aza stored for use throughout the duratior of the groject.

\subsection{Microbial Pyrite and Sulfate Removal}

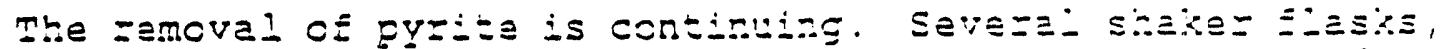

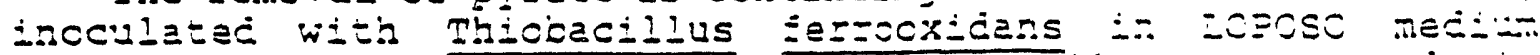

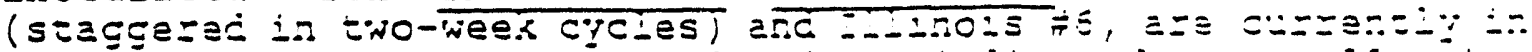

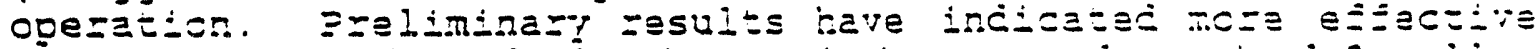

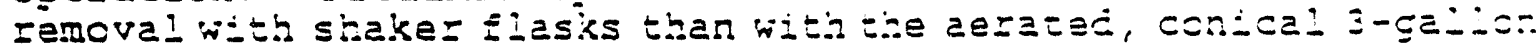
reacsor.

3 AYAIYTICAI PRCCEDURES ECR TOTAL ORGAYC SULEUE

\subsection{Charac:erization}

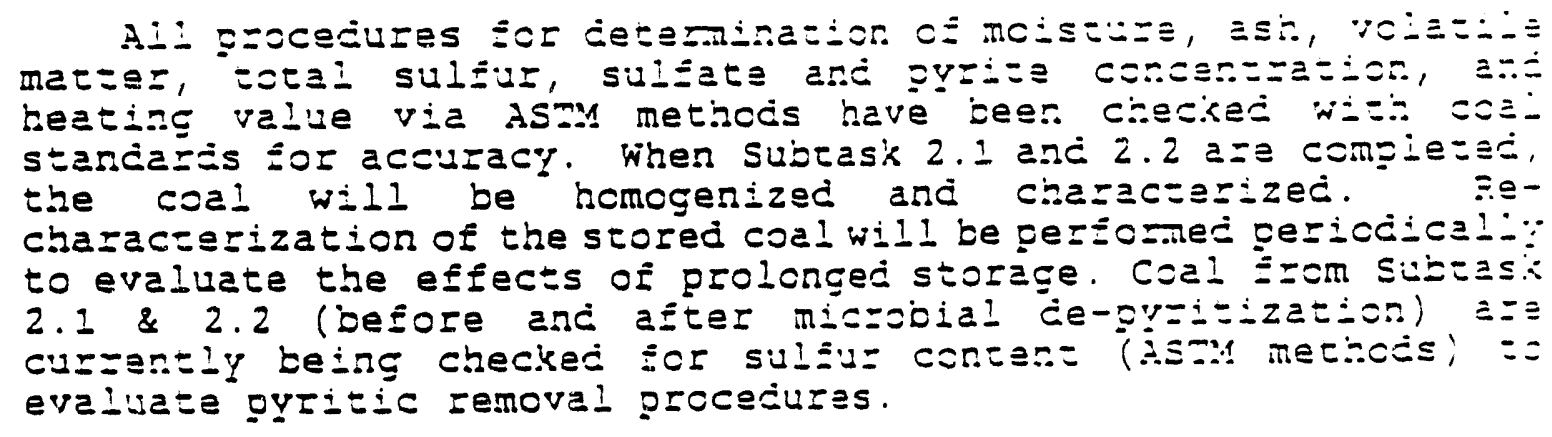

3.2 Quality Assurance/Cont=ol

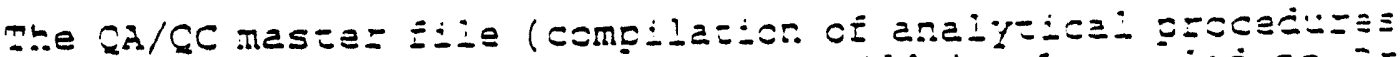

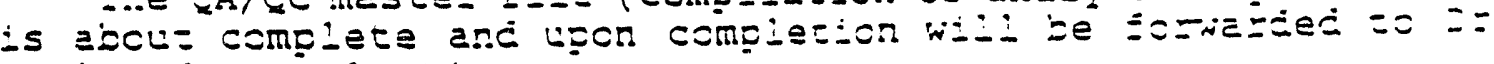
sowiey soz evaiuation. 


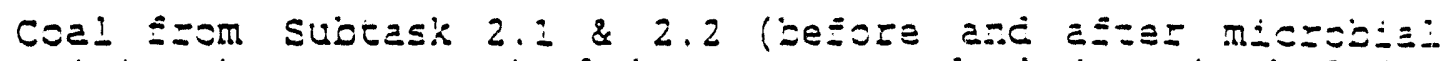

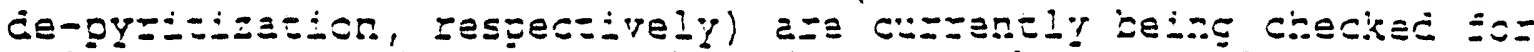

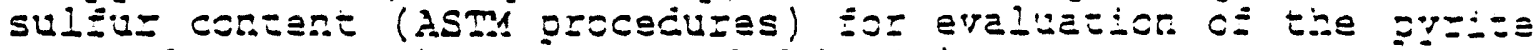
zemoval grscsss (on an as nesced bas

3.1 Microscopic Analysis

\subsubsection{EDS-SE.K}

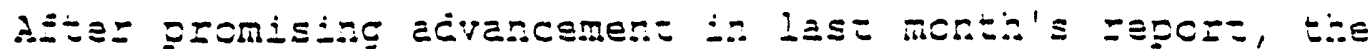

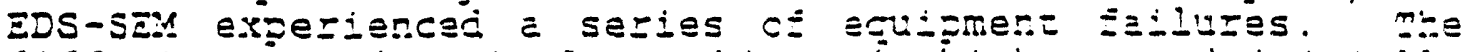
cizzus -on pume (

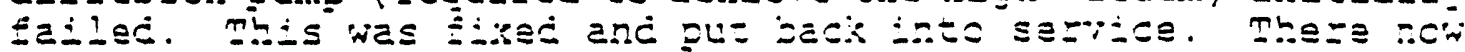

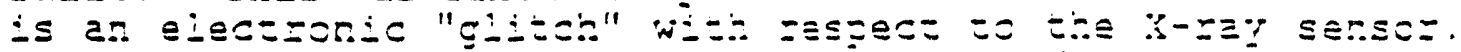

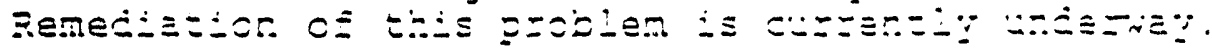

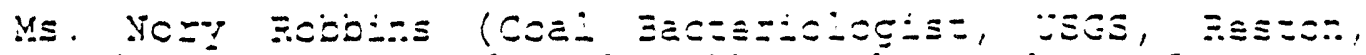

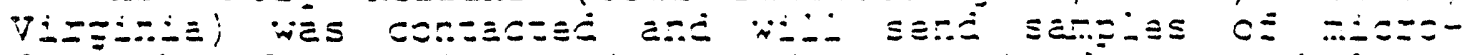

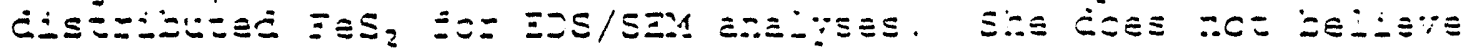

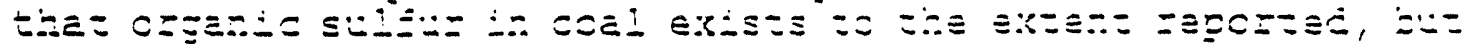

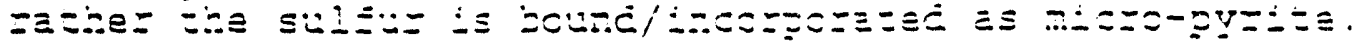




\section{PROJECT PLANNING}

This Task was complered as oi $12 / 13 / 88$.

2 COAL PROCUREMENT AND PREPARATION

\subsection{Grinding, Sieving, and Storage}

Ten pounds of Illinois $\# 6$ coal are ground, homogenized and siored under nitrogen. Arrangements are being made to procure quantities of Kentucky $\$ 11$ and Pittsourgi $\$ 8$ coais. Sulfur contents are such in the Illinois $\div 6 \mathrm{coal}$ (see below) ihat higher suliur conrents are desired.

\subsection{Micsobial Pyrite and Sulfate Removal}

Treatment of the Illinois $\# 6$ coal for pyrite and sulfate removal is proceeding. Some delay was encountered cue to inactive (i.e. old, lysec, few viable cells) cultures of Thiobacillus fermooxidans and Thiobacillus thiooxidans. Yew cultures were ootaired From Dr. Stevens ar the Univers:-y of Mississip̣i as well as Exr. ATCC.

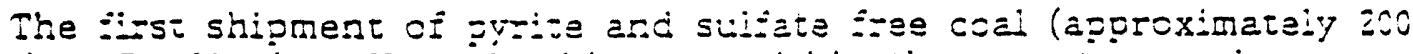
grams) to Dr. 'Nard at U.M. Sholld ccsur withis the rext two weeks. Design arc consiruction is currently uncervay to increase our treatmer: capacity to remove pyritic ard sulizte suifur. Immeciare pians will uti:ia 20 liter containers anchcred :o a reciprocal shaker bed. Each container is

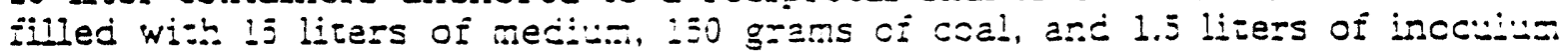
of the zforamentioned orgarisns. Zlans zor an even larger reactor sysis:

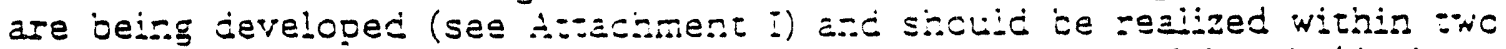

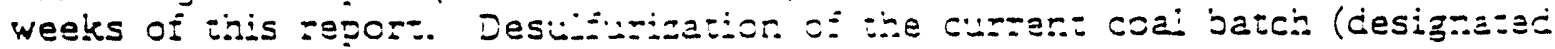

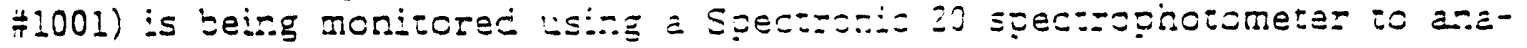
lyze for suijate release.

3 ANALYTICAI PROCEDURES FOR TCTAL CRGANIC SUIFUR

3.1 Characterization

A typical proximate analyses of the Illinois $\# 6$ under nitzogen storage before pyrite and sulfate renoval is as follows:

\begin{tabular}{|c|c|c|}
\hline Total Sulsur: & $3.39 w \tau \frac{1}{3}$ & $-1-0.05 w 2 \%$ \\
\hline Pyrite Sulfur: & 1.59 wts & $+1-0.04 w 2 s$ \\
\hline Sulfate Sulfur: & 0.25 wtร & $+1-0.02$ \\
\hline Organic suliuz: & 1.55 wtร & $+1-0.05$ \\
\hline Moisture: & 8.98 wT & $-1-0.09$ \\
\hline Voiatiles: & 37.8 & $+1-0.6$ \\
\hline Ash: & 9.25 wts & $-1-0.13$ \\
\hline
\end{tabular}


These aralyses could change sighidy as initiai tests were concuc:ad on coai betore : w was compietely homogerized. Caloric vai'ue of ine csa:

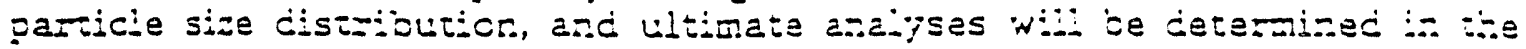

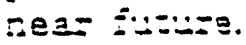

\subsection{Qualizy Assurance and Contzol}

All of ine analytical procecures have been Forwazied to Dr. Rowiey for zeview. Arisciments of iwo aporoved grocedures (as examples) are

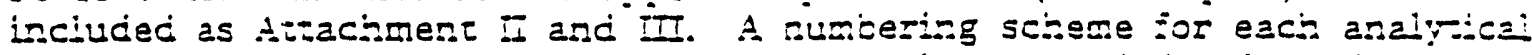

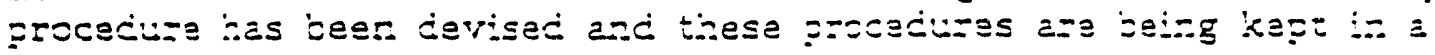
central :ise.

\section{3}

3.4 Micsescepic Analysis

\subsubsection{EDS-SEM}

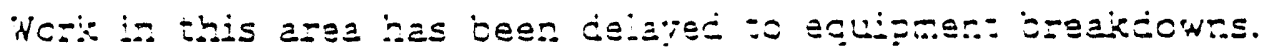

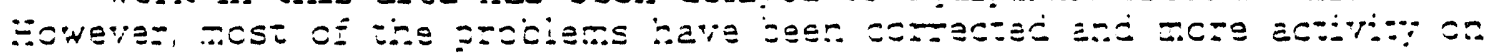

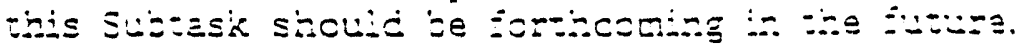


With gide arm cuerailon

$\tilde{\infty}$

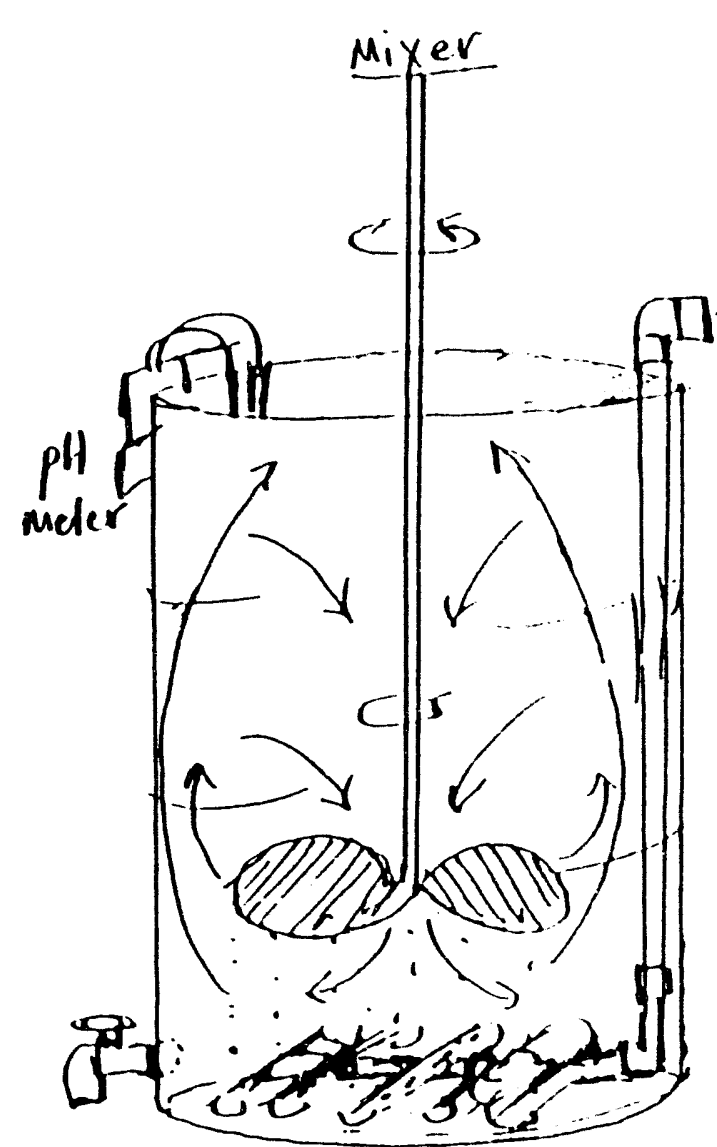

Cheri o stat

Reactor

for the aeration/mixin. and suspension of coal slurry -

[De-pyritization]

Constant Temp Also continual $P^{H}$ neonitaring

55 gap

poly propylene tank
* Also the side arm can be perforated, but the compressor would have to provide enough pressure to produce even aeration.

Al Iallunent | 


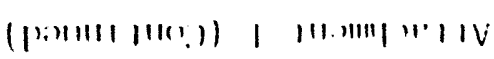

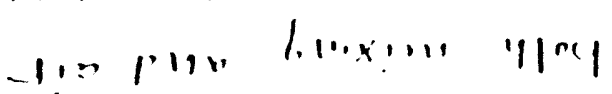

$$
\begin{aligned}
& \text { ag bu!s"in ing sex!n } \\
& \text { lilly!ssod - pu!) for }
\end{aligned}
$$

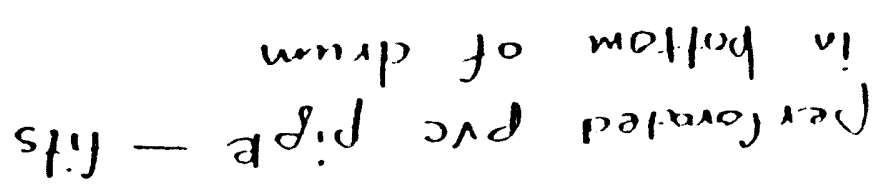

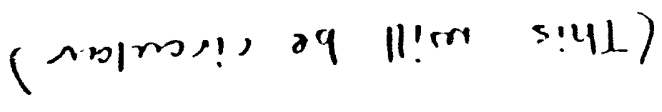

a fold jo pno adid

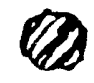

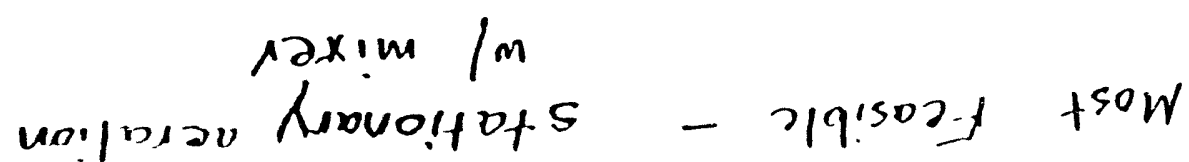
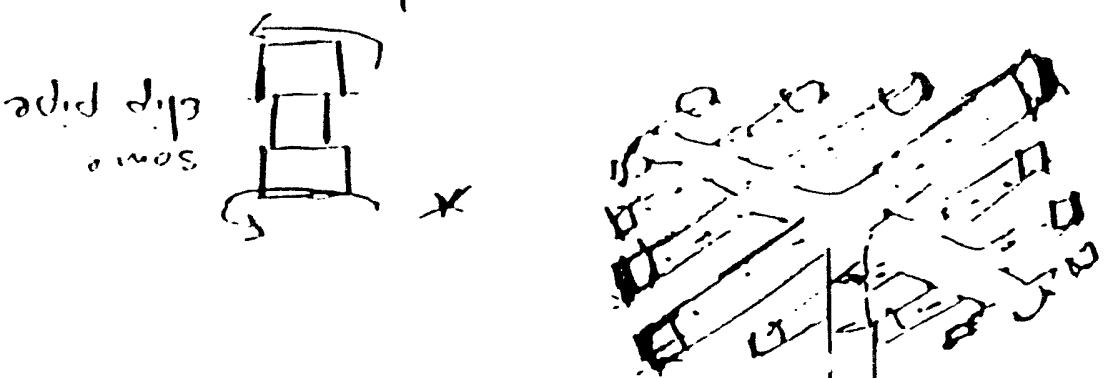

and $2 x+-1$

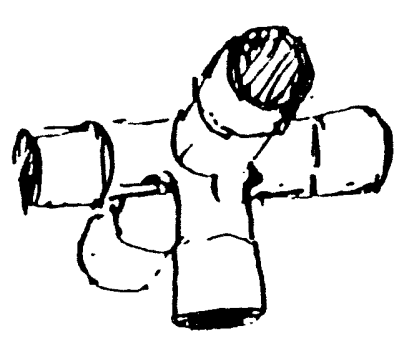

nossondwos 


\section{QCIQA PROGRAK}

LOUTSLANA TECH UNTVERSITY

DOE COAL BIODESULFURZATION IECHNTQUES:

APPLICATION OF SEIECTED MICROORGANISMS FOR ORGAVIC

SULFUR REMOVAL FROM COAL

\section{$D E \cdot A C 22-88 P C 3854$}

IECENTC.AI PROCEDURE REVIEW FORY

PROCEDURE DESIGNATION TD-201, 2ev,0: Procedure for Adiabatic

Calorimetar

REVIEW DATE lavamber 20, 1988

REVIEWER Jonn C. Rowley

COMMENTS

\section{DISPOSIION}

APPROVED $\underline{V}$ DISAPPROVED APPROVED CONDTHONALIY

CONDITIONS TO BE VET FOR APPROVAL

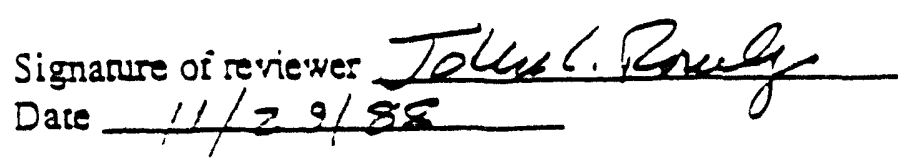

Now: See tvoo and sucoested number / designator system. 


\section{Atiachment II (Continued)}

\section{BROCDDURR ?OR ADLABATTC COFORITETZR}

Read and understand ASTM Proceduze D $: 01 \xi-7 T$.

Turn on vater supply under counter.

Turn on vater heater, vater cooler, dist:1led water tank, master sontroiler, and calorimerer.

Set buret siopcock to dizec water througi buzet. Je sure hot ard coli vatar lizites cycle even when the tank camerature stabilizas. (s seconcsicycle see page 6 of Yanual No. 156).

\section{Loadine 3omb}

Place preignited stainless steel c=jeibie on bajance and iaze weigre.

place sample pellet in cricible and note veight.

Install $10 \mathrm{e}$ of fizing wize on the bomo head electzodes as sincwn on pags 5 of opezalions sanual.

Placa crutile in Fing with the wize in concace with sample.

Piper 1 wi of dissilied watar into botsan of bomb.

put top on bomo, hand :ighten sing ard liose value.

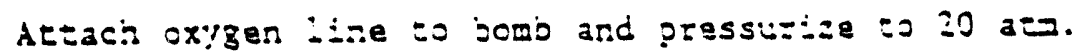

Release pressure in line with tog8 ie ard gmove line.

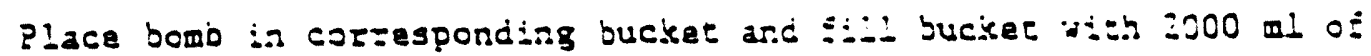
disc:iled wacer

Open calorimeter by raising therpomece: (pull black bali) and releas:ris (pull black ball and lift) cover and slide to : ighe.

Place filled bucker in opening and acsacin wises to elecs=odes. Close cover and lower ehermometers.

\section{Srandardization}

Load bomb with benzoic acid pellet and piaca in calorimeter. Ser toggie suitches on Kastar Cont=olier to Ref., Stand., and $3 \pi J / i j$.

Press reset, then start and respond to lizhes.

CAL. ID. renuizes a number sor the bomb and bucker combination--! or 2.

SAMPLE ID is a number for chis ran. 
SAMpla iT. is the weight in 8 ams of benzolic acid.

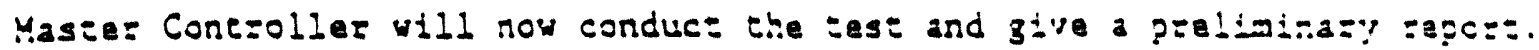

After the seport is printed, remove the bowo and slowly reisase the pressure. Open the bomb and ringe the inside with rechyl red solution ints a bexikaz.

Titrate this solution t:11 the red coler disappears.

Mulipiply the ml. used by 10 to get ac:i corsection.

Measure the length of unburned wize on the card. This is the wise corsiction.

Pross Sampie ID, its numeral, and Encaz.

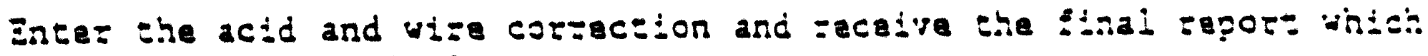
contains the energy equivalent.

Average ten enezzy equivalent gins tor sach bowb and buciar comoinaz:or.

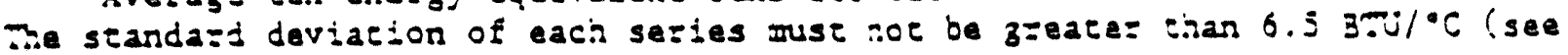

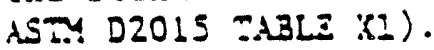

Check standardization at least once a sonth if the new standard value

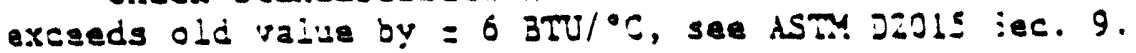

Inpur the average of the enerzy equiraine Eor each jomb and buciet

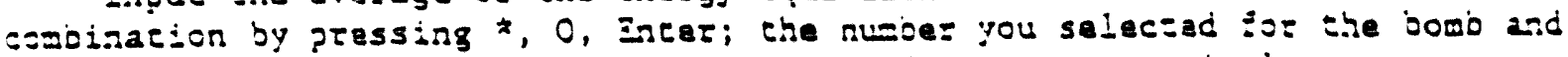
bueset combinat:on, Inter; and the corresponding enezyy equiralent.

\section{inning a Samoie}

Use the peliet press to make a coa: pe:-er $\vdots=0 m: g=2 m 0 \vdots$ coal, and loac the bomb as previously desciibed.

Set the toggle switches to Ref., Det. and $3 T U /$ Ib.

Press reser and start.

Respond to lighes - CAL. DD and SAMPLi iEIGT!.

After preliminary repors is printed, open bomo, titzate concent and geasure wire.

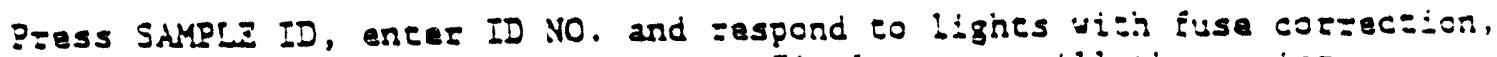
: sulfur of sample, and acid corzection. : inal geport will then print.

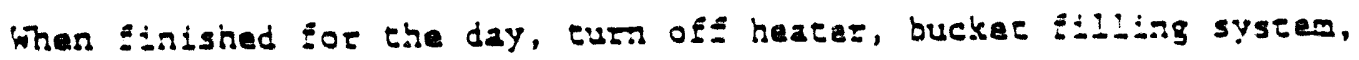
calorimeter and water supply.

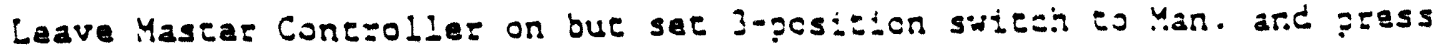
star= to go to standby stacus. 


\section{Azaciment is (Continued)}

i:-ic:. Rev.s

Novemcer $1 !$

Page 3 of $j$

Duplicate results should not be considered suspec unless they diffez by pore than $503 T U / 1 b$, dry basis. 
QC/QA PROGRAM

LOUTSIANA TECI UNTVERSTYY

DOE COAL BIODESULFURZATION TECFNIQUES:

APPLICATION OF SEIECTED MICRCORGANISMS FOR ORGANIC SULFUR REMOVAI FROM COAL

DE-AC22-88PC3854

TECINICAI PROCEDURE REVIEW FORM

PROCEDURE DESIGNATION T2-n02, 2ey n: Micrabial Oyrite and Suliate

Qemoval

REVIEW DATE Yovamber 20,1088

REVIEWER John C. ROWieV

COMMENTS

\section{DISPOSTICN}

APPROVED $\checkmark$ DISAPPROVED

APPROVED CONDTIONALLY

CONDIIONS TO BE MET FOR APPROVAL

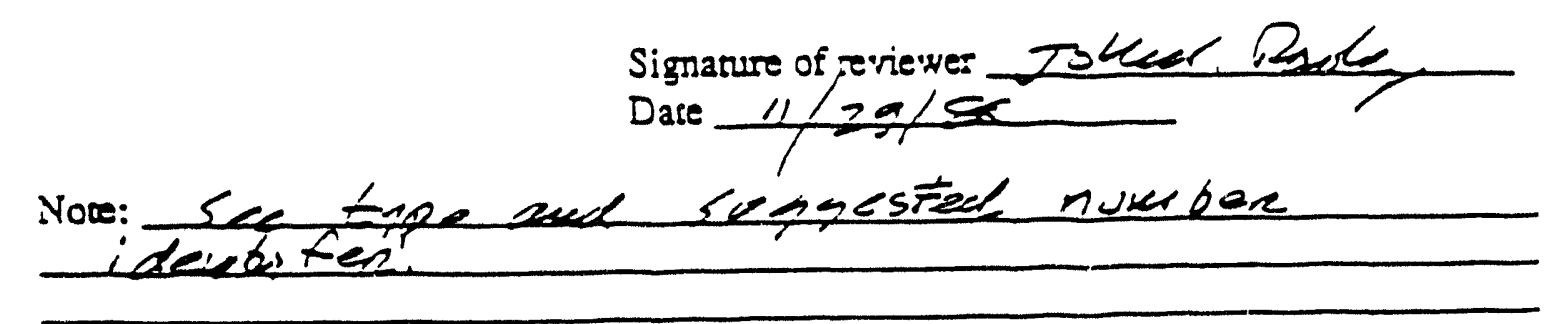


MICROBIAL TRITE AND SULEATE REYOVAL

Samples of acid mine water and pond =ud S=om Madisonville, Kencucky, weze set up in shake flaskes of IS? mediun to screen for izon-oxidizing and inorganic sulfur utilizers. Incibation was at room temperature on a reciprocal shaker at 100 shakings/min unt:- the medium showed an orangebrown color. ?lates of IS? agaz weza stzeaked from the flaskes showirg the pressure of $i=0 n-o x d d i z i n g$ and inorganic sulfur utilizers to determine the backerial types. Plates of ISP agaz were also streaked directiy from the acid mine water samples and the pond $\lambda$ used to detect inorganic sulfur urilizers. 


\section{hLzaciment III (Continued)}

\section{VETEOD II \\ BPCCESSING TEEATD COAL SAMETES --

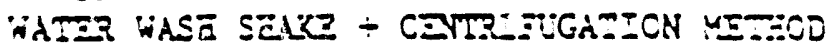

1. Shaike sazpies vigorousiy as in 11 , Meched $I$.

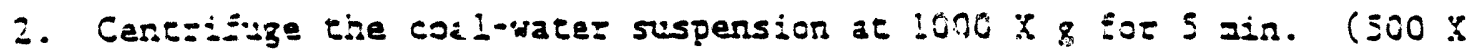
nay also vork.)

3. Aspizaze or decant the supezmatant.

4. Resuspend the pellet in vater and Eilter as in 17 , yethod I.

5. Izans:ez sample as in 18, Method I Sor doging.

6. Izars:ez sample Sor araiysis as in 19 , Method I. 
DVIFCNRERTAL SAMPIZ IVRETORY

Lou1stana Iec:

Samie

Number

1

2

3

4

5

6

T

3

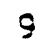

10

11

12

13

14

$\vdots 5$
Iroe

SoiI

So:s

Soi:

So::

Liquis

İฺุ:

iquis

$\because: \div \div: \div$

L̇ดui:

Liquisd

Weathezed ligrite

Heachezed ligni=e and soi:

bi:isizise inzonise

Soi:

So::

\section{Site Taken I=00}

Eighway 1 at $1 / 2$ anle soust of Vivian at a eanic baesery storage azea (O1I C $:=y$ )

1/2 mil norsh of highway 2 on higiway 1 at new taris batsary storage area ( $0: 1$ CIEY)

Same as abcve but $5=0 \mathrm{~m}$ old batiezy sistage area ( 0 : (ity)

Siucige pit on higiway 2 , $\sqrt{E}$ of Vivian, 1 alle before Caddo laise (011 CiEy)

011 pit on the same sita as samples 2 and 3 (011 Cizy)

Same site as sample ! Sare site as sample ? Same size as sampie $;-(0:-: \vdots: \because)$

Same site as sampie 4 Same site as sample 5$]$

Dolet Eil: in Yanstield, La.

Dolet Eill in Mans:ieid, La.

Dolet E:1: mise, $\bar{Z}-z$ =arige, Mansíieid, La.

Oil seepage in CaijEsrnia

(Califor.ia statea

Universi:y, Nor:hside)

E=om 2.5 pi gond, Kencüch? 
Sample

Nimber

16

17

13

19

20

21

22

23

24

25

25

27

28

29

30

31

32
Froe

Sile Taken $I=0 m$

Heachered coal

-.- Andelex

Liquid

Liquid

İqquid

Liquid

Liquidi

Liquid

İq̣u:d

Soi1

Soil

So:-

Soil

Soil

Soil

Soil

Soi1

Soil
Near pond in sample 15

PE 2.6 pond, Zentucky

pe 2.34 ponc, Zentucloy

1/2 mile south of I-io on Indiana Ewy. 42

Tentuely Eivy. 813 Zxit 37

Active slusey pood is Renrucky

Runof: of ?eabody stzi? aine slus:y

1/2 mile sousit of I-70 on Indiana Exy. i2

Bor Sulfur Seriags Colorado

Eot Sulfur Sorings

Colorado

Eor Suls:u= So:iags

Colorado

Eot SulËz= Sorings Colorado

got Sulfur Sorings Colorado

Bot Sulfur Spriags Coloracio

Pressboard ? Zane (Dr. Boyden)

Chevron Oii ReIinezy, Zor: Afthur, Texas -- hest Lagecr Condui= Banis

Cherron Oi: ReÉinezy, Eo:= Arthus, Texas -- 166 Tark hoid 
Sample

Number

33

So:1

34

35

36

37

38

39

40

41

42

43

44

45

46

47

48
Troe

Site Taken ?:00

Cherson O1l Refinezy, Por:

Arthur, Texas - 47 PE

Manifold Conduit
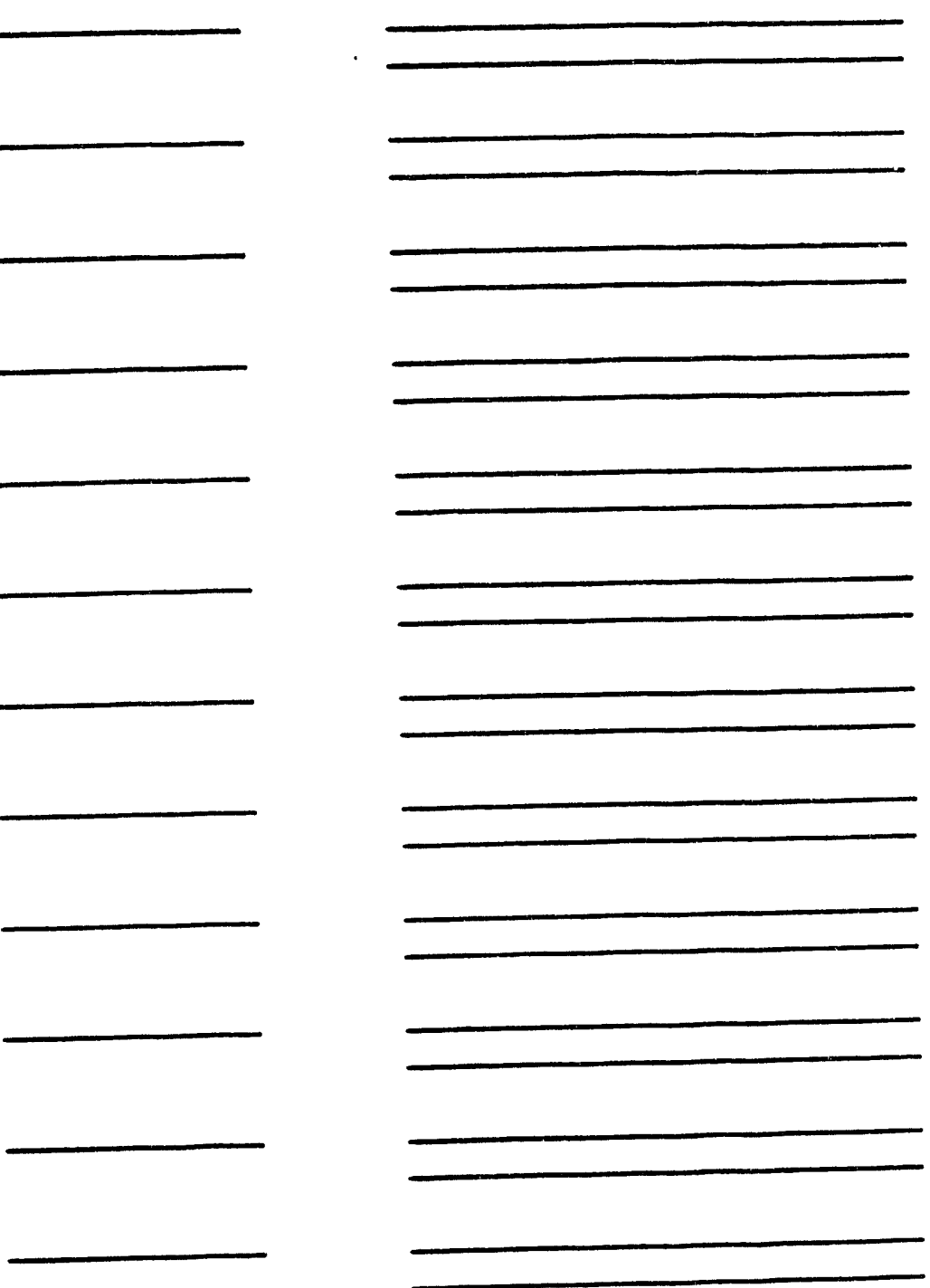


\author{
ATTACHMENT A \\ APPENDIX II \\ Project Activity from March 15, 1989 to March 15, 1990
}




\section{PROJECT PLANNLNG}

Task Completed.

2 COAL PROCUREMENT AND PREPARATION

\subsection{Grinding, Sieving, and storage}

Additional Illinois coal (From Illinois Geological Surn

101) has been procured, ground to 200 mesh, homogenized, asu stored under nitrogen atmosphere. This coal is in acdition to what was previously on hand fron a previcus coal shipment. Analyses on the new coal will be in suissequent reports.

\subsection{Microbial Pyrite and Sulfate Removal}

Microdial reactors have been set ue for the removal of pyritic sulitu. Cultures empioyed for this purpose include ATCC Thiobacillus thiooxicars and Thiobacillus jersooxidans, and a mixed environmentai cilivire exinciac f=om a South Ane Fcan mining site, cenoted Sero de Pasco. The first bat:of "depyritized" coal was sent to $U$. of Mississipoi, with approximately $90 \%$ of the residen pyrite removed. Adciticnal shipments will be made as the coal becomes available.

\section{ANALYTICAI PROCEDURES FOR TOTAL ORGANIC SULEUR}

\subsection{Characterization}

Additional characierization will be forthcoming on the coal recentiy ground and zut under nitrogen. These analyses will inciuce a suliur oreakdown, ess, volatiles, moisiure, BTU content, and a $C: 3: N: 0$ breakicwr. The efiec:s of storage on this coai will aiso be monitored by same accre analyses.

\subsection{Quality Assurance and Control}

All of tise analyrical procedures have been reviewed anc aptroves i $=y$ Dr. Rowley) and incorporated into the centrai inie.

\section{3}

\subsection{Microscopic Analysis}

\subsubsection{EDS-SEM}

Work involving the use of this techricue for the direct anaiysis of organic sulfur in coal is continuing. The present areas of empiasis are: (1) sample preparation, (2) optimum magnification, and (3) minimiza:ica c: the number of required shots. With respec: to sampie preparation, ise traciticnal 24-hour epoxy mounting has been replaced by a pelletiza:ion. prececure. A sample of homogenized, 200 mesi coal is compressec uncie: several thousand psi into an one-haif inci diameter peilet. The suriace of the peilet appears "glassy" to the eye and, undez nagnification, grovices a reasonably planer suriace in which crystalline pyrite can be icentized (and therefore avoided). A view grapin of a cepresentative suliace has been inciuced with the areas of pyrite isolated. Resciut:or was losi when the view grapi is phorocopied, however, the crysiali:ne pyate can be icientified by locking for signs of a cysialline metzix. e.z. st=aight edges, triangular areas, cubics, er cetera. 


$$
\text { EDS - SEM }
$$

Parameters: veltage $15 \mathrm{ev}$

$$
\text { TCA } 30^{\circ}
$$

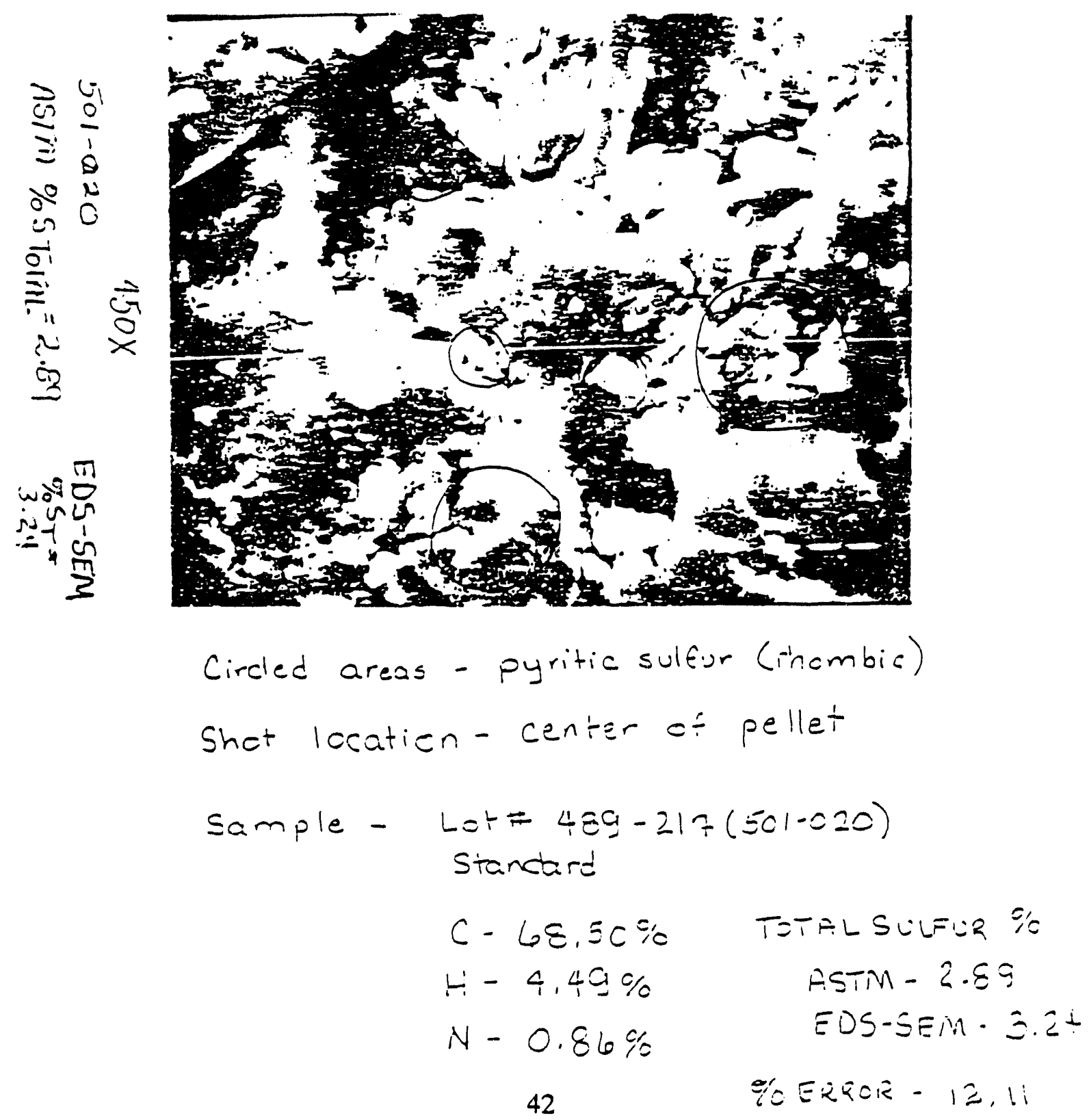


1 PROJECI PI HNNING

Task Conpleted.

2 COAL PRCCUREYENT AND PRIPARATION

2.1 Grinding, Sieving, and Storage

Of the approximate 15 lbs of mlinois $\div 6$ csal originally grounc to -200 mesh and scored under nitrogen, approximately 6 lbs are still to be depy-:tired via Thiobacillus sp. The coals (both Mlinois basin coals) being ut:lized in ine project include lots 1002 and 1003 as defired below:

\begin{tabular}{|c|c|c|c|c|}
\hline Concorent & int? & $\begin{array}{r}\text { Lot } \neq 1002 \\
\text { Deviaticr }-i- \\
\end{array}$ & $n=\frac{3}{3}$ & $\begin{array}{c}\text { lot } \$: 003 \\
\text { Deviatice }-1 \\
\end{array}$ \\
\hline Totai Sui_ur & 3.72 & 0.06 & 4.22 & 0.10 \\
\hline Pyritic Suliur & \multicolumn{2}{|c|}{ pending } & 0.85 & 0.01 \\
\hline Sulfate Sulfur & 0.27 & 0.02 & 0.16 & 0.02 \\
\hline Organic sulfur (via ciff̈.) & \multicolumn{2}{|c|}{ pending } & 3.21 & 0.10 \\
\hline Volatiles & 41.5 & 0.7 & $5 i .1$ & 0.30 \\
\hline Asin & 10.2 & 0.1 & $10 . \equiv 1$ & 0.19 \\
\hline Moisture & 8.98 & 0.09 & 11.38 & 0.29 \\
\hline Carbon & 64.91 & 0.97 & \multicolumn{2}{|l|}{ percirg } \\
\hline Fydrogen & 4.82 & 0.20 & \multicolumn{2}{|l|}{ percing } \\
\hline Nitrogen & 0.71 & 0.01 & \multicolumn{2}{|l|}{ pescing } \\
\hline Oxygen (ria diff.) & \multicolumn{2}{|c|}{ pencing } & \multicolumn{2}{|l|}{ perding } \\
\hline Eeating jalue $\left(B T U / I b_{m}\right)$ & 12,950 & 48 & $\because 2,245$ & $\equiv 8$ \\
\hline
\end{tabular}

\subsection{Miczobiai Pyrite and Sulfate Remcvai}

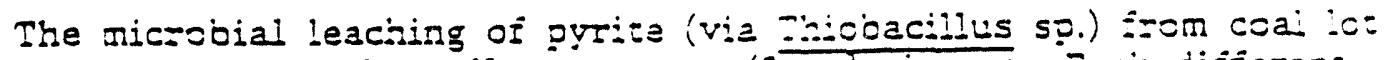
i002 is via a series of 5 gailon reaciors ( 2 ivis silury). Eaci difierer: batch is jeroted as 10024, 1002B, et cerera. Becuuse of the smaller batches, final ultimate and proximate analyses will not be performec un:: the coal is treated, recombined, and homogenized. However, the reacior used for depyritizing coal lot 1003 is aporoximately 50 gallons and can tza: up to 10 lbs of coal per batch (a typical batch lasting anywhere from 2 is 3 weeks). The large size of the 1003 batches allows the economic (ult:mate/proximate) analyses of each reacsor voilume or throughput.

Some of 1002 coal was left on an ex:=a week (batcin 1002A) to rencve essentiaily all of the pyrite. This coal is for use as one of the siandaris for EDS/SEM analyses. As a result of csal 1002A being used in this nanner, corfoborative ultimate/proximata anaiyses of this coal was sought through a commercial laboratory (copies inciuced). The anaiyses of $1002 . A$ were as Ellows (moisture.fiee): 


\begin{tabular}{|c|c|c|c|c|}
\hline \multirow[b]{2}{*}{ Comporent } & \multicolumn{2}{|c|}{$\begin{array}{l}\text { Our Araiyses: } \\
\text { lot } \# 1002 \mathrm{~A}\end{array}$} & \multicolumn{2}{|c|}{$\begin{array}{l}\text { Commercial Testing ias: } \\
\text { lot } \neq 1002 \mathrm{~A}\end{array}$} \\
\hline & $N=\frac{9}{5}$ & Deviaticr -1- & & \\
\hline Total Suifiur & 2.35 & 0.02 & 2.46 & $0 . \vdots 0$ \\
\hline PपTitic Sulfu= & 0.39 & 0.01 & 0.05 & 0.05 \\
\hline Sulfate Sul:u & 0.17 & 0.01 & 0.18 & 0.02 \\
\hline Organic sulfur (via difï.) & 2.59 & 0.04 & 2.23 & 0.17 \\
\hline Volatiles & 37.72 & 0.3 & $-\cdots-$ & $-\cdots$ \\
\hline Ash & 3.91 & 0.09 & 9.14 & 0.30 \\
\hline Moisiu=e & 2.90 & 0.09 & 2.97 & $\cdots-\cdots$ \\
\hline Carbon & 58.78 & cenci:=s & 68.78 & 0.30 \\
\hline Hydrogen & 4.77 & Eec:ing & 4.77 & 0.07 \\
\hline $\mathrm{Nit}=c g e n$ & $\therefore .49$ & ze:cisis & 1.19 & 0.05 \\
\hline Oxygen (via diff.) & 13.36 & perding & 13.36 & $-\infty--$ \\
\hline تeating Value (3TU/1 $\left.b_{m}\right)$ & $: 1,902$ & 13 & $\cdots$ & \\
\hline
\end{tabular}

3 AYALYMCAI PROCEDURES ECR TOTAI ORGANTC SULEUR

\subsection{Characterization}

YLC: of the coal characierization is included in the aoove sections. Zowever, ancther experimen: which was of interest with respec: to sulfacalyses was that of clean::g (or not cleaning) the coal after treatment with micoacillus sọ. For $\mathrm{m}$ ?

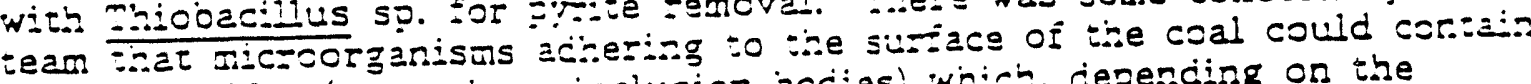
internai suifur (cr perhaps :nclusicn vccies) which, depending on the cegree ine coal was washed, could ał̌ec ite suifur anayses. In Julys

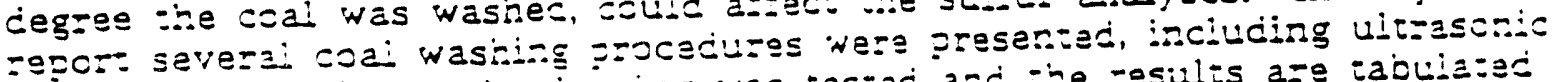

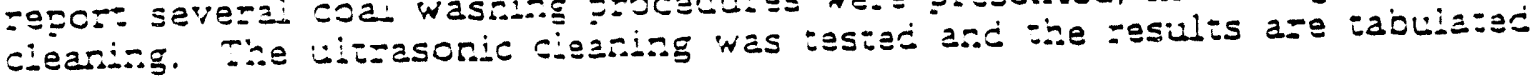
selow:

$$
\text { Resuiss of Ultzascric Cleaning }
$$

\begin{tabular}{|c|c|c|}
\hline $\begin{array}{l}\text { Suifur Content } \\
\text { (Wet, mass } \frac{\text { W }}{\text { (Wet }}\end{array}$ & $\begin{array}{l}\text { Moisiure } \\
\text { (mass o ) }\end{array}$ & $\begin{array}{l}\text { Sulfur Conter } \\
\left.\text { (Dry, mass } \frac{\rho}{\jmath}\right)\end{array}$ \\
\hline
\end{tabular}

$\begin{array}{llll}\text { Before Washing } & 2.50=0.06 & 4.20=0.23 & 2.71=0.06 \\ \text { After Washirg } & 2.33 \pm 0.03 & : 6.5 z=0.65 & 2.79=0.03\end{array}$

Eased on this procecure (and the lac: that the coal was so througing? washec), we detecied no discerracie dišerence jetween washed and unwasied coal with respec: to sulfur analyses.

3.2 Quality Assurance and Control

All of the analyticai grocectures haye jeen reviewed and aporoved Dr. Rowley) and incorporated into the cental :ile. 


\subsection{Microscopic Analysis}

\section{4.: EDS-SE.M}

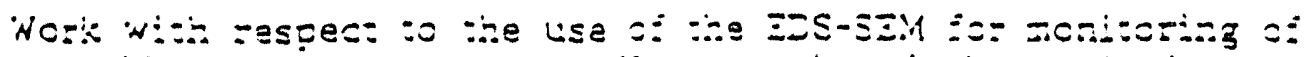

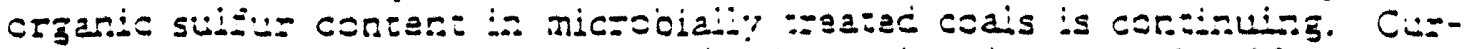

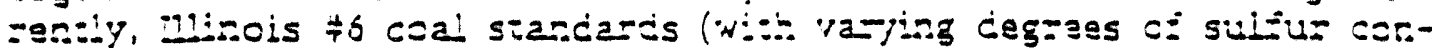
tenc) are jeing incorporated into a siandard liorary. Siandards are oreparec by removireg essentially ail ci the resicent pyt:ee fron the coai via the use of Thiobacillus sp. and inus circimventing any problems asscciated with the possiole preseres of nics-pyrite. Coal sampie 1002.4 is one of the coals to be used as a siandari.

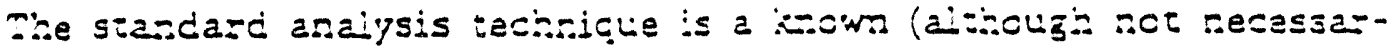

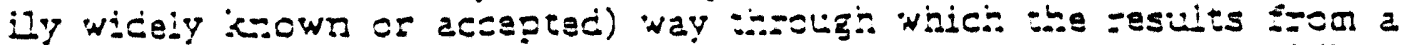

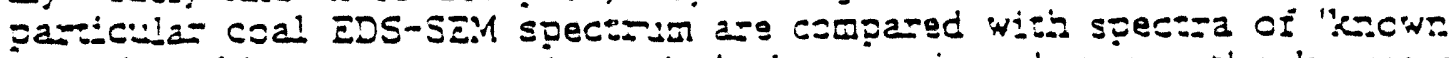
orgaric sulfur conteris. A siatisicai conpariscn between the knowr arci

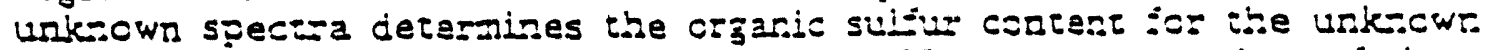
sample. The closer the unknown crgaris suifur cortan to that of tise libra-y siandard, the nore acsura:e ihe aralysis. Coriererce with II. Warer straszinein (wiro did consicerzile worie with inis iechniculu in is 2h.D. siudies) at the recent Pit:sju-ji conierence has ielped corsicier-

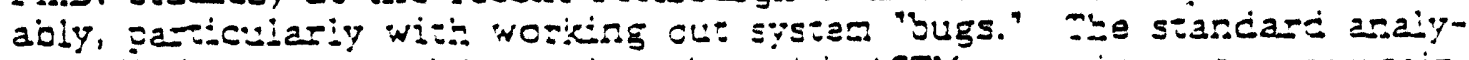

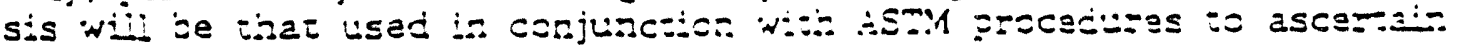

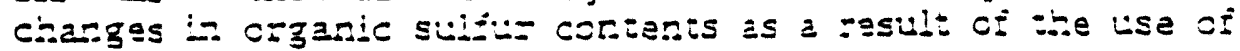
envizorrental isclases. 


\section{COMMERCIAL TESTING \& ENGINEERING CO.}

CENERAL OFIICZS. 919 SOUTH MIGHLANO AVE.. SUITE 210.a. LOMBAAO. IL.INCIS 80148 - $13121993.93 C 0$

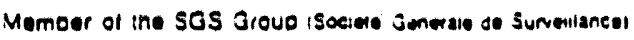

Septembe: 2,1989

DEASE tOORESS ALL COARESPCNCENCE TC 151 :AMES SRIVE 'NEST. $51.2 C S E$. 'A TCOB TELETCNE: :S04) 467.9322 TEIER: 4 BOtis CTE

- LCUISTHNa TzCZ UNITZRSETY

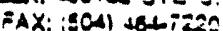

P. $0.30 \times 10348$

RUSTON id 71272

BRUCZ B. BOYDEA
Sample identification by

LA. TXCI

P.0. $12=111$

Iind of sanple 32-4111 20E COAL PROJ3C:

reported to us SUBUITTSD SAMPLE

Sample taken at RUSTON, Li.

Sample taten by unkroin

Date sampled -...-

Date receiped August 23,1989

Analysis Report Ho. $89-54726$

\section{STORI PROXTART - TLITATE AHALTSIS}

As Receized Dr Basis

\section{Loisture \\ * Carjon \\ 7 Bydrogen \\ * Nitrogen \\ * sulfur \\ * asb \\ * Oxggen (diff)}

$B+a / 1 b$

$$
\begin{array}{r}
2.97 \\
66.74 \\
4.63 \\
1.45 \\
2.39 \\
8.87 \\
12.95 \\
\hline 100.00
\end{array}
$$

$\operatorname{cxcex}$ $\cos x$

63.78

4.77

$2 .+9$

2.16

9.14

13.36

100.00

$\operatorname{cosex}$

ans $\cos x$

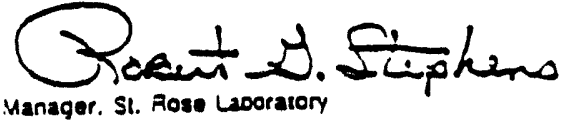




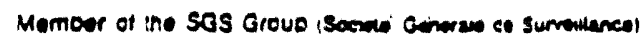

\author{
PLEASE ACOAESS ALL CCARESPGNCE!ICE :C:

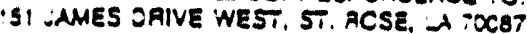 \\ TELEPUCNE: SON1 167.3320 \\ TESEX: 460139 CTE UI \\ FAX: (son) 4Q6itizo \\ September 15,1989 \\ LOUISTANA TECH UNIVEREIT"? \\ ?. 0 . $30 \pi: 0343$ \\ RUSTON LA $7: 272$
}

RE: SUBMITIED SAYPLE IDETTIFIED AS 32-4111 DOE COAL PROJECT

P. O. พO. 12-9111

SGS/CTE IILE: $89-54726$

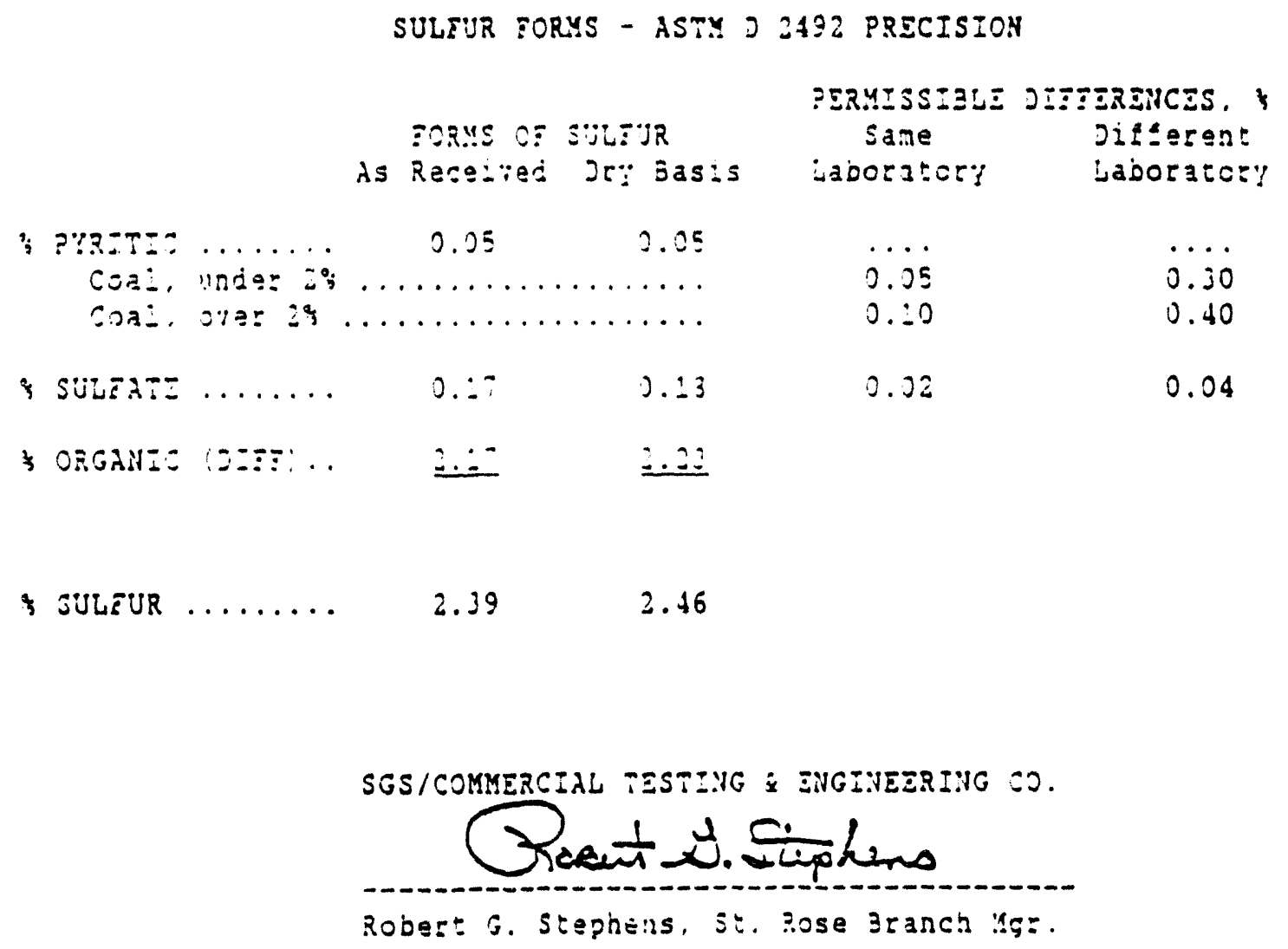

PMeJ 
PLEASE AOORESS 41 CERFESPCNCENCE TC:

ISI JAMES JRIVE NEST. ST. ACSE : $A$ iXa7 TELEPHCNE: (SOA) 1675322 TE! EX: 16013 C.E U FAX: (501) 164,1200

Septembe: 16,1983

LOUISIANA TECI UNIVERS:?"?

P. $0.30 \pi: 0348$

RUSTON LÀ T1272

RE: SUBMITTED SAMPLE IDEKTIYIED AS 32-\$111 DOE COAL PROJECT

P. O. NO. 12-9111

SGSICTE IIIE: $89-54726$

ULIIMATE ANALTSIS - ASTY D 3176. TABLE 3 PRECISION

ULTEXATE AHALTSIS

As Received D!" Basis

; MEIJTURE $\ldots \ldots \ldots$

4 G.A.ZON ........

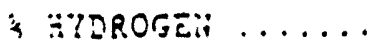

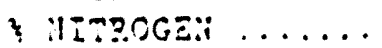

'i süz̈? .......

Ga:, uncer 24

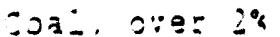

$\because 2 x: 9$

53.73

4.77

$\therefore .49$

2.45
PERMISSIBLE DIEZERENCES, औ

same

iaboratory

$\cdots$

0.30

0.07

0.05

....

0.05

0.50

0.20

0.30

0.50
Dif:eran:

Laborator!
. . .

$\ldots$

$\ldots$

$\cdots$

$\cdots$

0.20

0.20

0.50

0.50

$\therefore .00$

\& $\lambda \mathrm{Sit} \ldots \ldots \ldots \ldots$

3.37

9.14

fo carjonates present

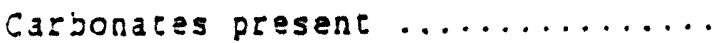
Coals 1: th nore than $12 y$ asi
$\ldots \ldots$

contzining carbonates and

pyci:es

S OXYGEV (DIEI) ... $\frac{12.95}{100.00} \quad \frac{13.36}{100.00}$

SGS/COMMERCEAL TESTEHG \& ENGINEERING CO.

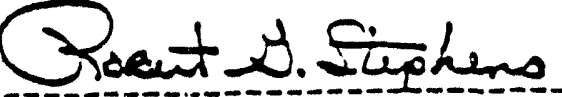

Robert 3 . Stephens, St. Rose Branch ig:.

PMCD

OVER DO BRANCM LABORATORIES STAATEGIC: TDEWATEA AND GREAT UKES 


\section{PROJECI PIANINTNG}

Task completed.

2 COAL PROCUREMENT AND PREPARATION

\subsection{Grinding, Sieving, and Storage}

Task completed.

\subsection{Micsobial Pyrite and Sulfate Removal}

The removal of pyritic sulfur from aporoximately 16 is 18 its $0:$ =:ncis $\# 6$ coal (200 mesis) via the Thiobacillus 50. is completed. Two csai lets of Ilinois $\$ 6$ wers used, lot 1002 and lot 1003 . As the coal was treatec by batches, eaci batch was desigrated by lot auncer followed by a let:az; e.z. the Irst batch of 1002 treated with Thicbacillus sp. was desigmated $1002 .$. subsequent barches 3 , C, et cetera. The or-ginal plan was to use severa: batches and at ine end homegenize all the batch juns. Fowever, $: 2$ particular csal batch was needed for immeciate luse, complete analyses inere aiso periornec on that batc:.

\section{ANAIYTICAI PROCEDURES EOR TOTAL ORGANIC SULEUR}

\subsection{Characiezization}

To daie, a synopsis of ije treatment of the coals is presented jeis:

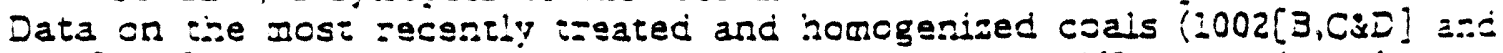

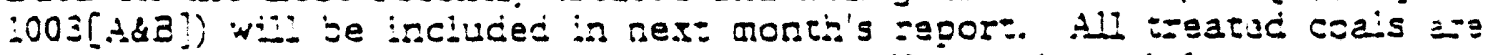

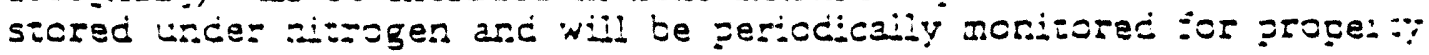
changes. 


\begin{tabular}{|c|c|c|c|c|c|c|c|c|}
\hline & \multicolumn{2}{|c|}{1002} & \multicolumn{4}{|c|}{ Lot/Barci Numicers $1002(\mathrm{B \& C})$} & \multicolumn{2}{|c|}{$1002(3, C \times D)$} \\
\hline & $w t \frac{0}{s}$ & $S D^{2}$ & $w t \frac{9}{5}$ & SD & wt? & SD & wrs & $S D$ \\
\hline Total Sulfur & $3 . \pi$ & 0.06 & 2.85 & 0.02 & 2.84 & 0.08 & & \\
\hline $\begin{array}{l}\text { Pysitic Sul- } \\
\text { fyr }\end{array}$ & 0.94 & 0.01 & 0.09 & 0.01 & 0.38 & 0.21 & & \\
\hline $\begin{array}{l}\text { Sulface Sul- } \\
\text { fur }\end{array}$ & 0.30 & 0.02 & 0.17 & 0.01 & 0.28 & 0.01 & & \\
\hline $\begin{array}{l}\text { Organic Sul- } \\
\text { fur (via di二- } \\
\text { ference) }\end{array}$ & 2.48 & 0.09 & 2.59 & 0.04 & 2.58 & 0.20 & & \\
\hline Volaties & 41.5 & 0.7 & 37.12 & 0.3 & $\mathrm{NA}^{3}$ & VA & & \\
\hline Asin & 10.2 & 0.1 & 8.91 & 0.09 & VA & NA & & \\
\hline Moistize & 8.98 & 0.09 & 2.90 & 0.09 & 23.26 & 0.2 & & \\
\hline Carjon & 69.18 & 10.97 & 68.78 & 0.3 & Y. & NA & & \\
\hline Eydragen & $\$ .03$ & 0.2 & $4.7 i$ & 0.07 & $\mathrm{NA}$ & $\mathrm{NA}$ & & \\
\hline Nit=sgen & $1.5 i$ & 0.01 & 1.19 & 0.05 & $\mathrm{NA}$ & $\mathrm{NA}$ & & \\
\hline $\begin{array}{l}\text { Oxyger: (ria } \\
\text { diference) }\end{array}$ & 10.26 & $\$ .34$ & 13.20 & 0.33 & $V A$ & NA & & \\
\hline $\begin{array}{l}\text { Eear:is } \\
\text { Vaiue, } \\
\text { Bü/Ib }\end{array}$ & 13,229 & $5 j$ & $\therefore, 902$ & 12 & $\mathrm{NA}$ & $\mathrm{N} \div$ & & \\
\hline
\end{tabular}




\begin{tabular}{|c|c|c|c|c|c|c|}
\hline & \multicolumn{4}{|c|}{$\begin{array}{c}\text { Lor/Barcis Numbers } \\
1003 \mathrm{~A}\end{array}$} & \multicolumn{2}{|c|}{$1003(A \& B)$} \\
\hline & $w t \frac{o}{\partial}$ & $S D^{2}$ & $w \tau \%$ & SD & $w \tau^{\circ}$ & SD \\
\hline Total Sulfur & 4.22 & 0.10 & 3.23 & 0.03 & & \\
\hline Py:itic Suizu= & 0.96 & 0.01 & 0.13 & 0.01 & & \\
\hline Sulfate Sulfur & 0.18 & 0.02 & 0.09 & 0.01 & & \\
\hline $\begin{array}{l}\text { Orgaric sulfur } \\
\text { (via difierence) }\end{array}$ & 3.08 & 0.10 & 3.01 & 0.05 & & \\
\hline Volatiles & 51.1 & 0.5 & 35.95 & 0.13 & & \\
\hline Ash & 10.51 & 0.19 & 8.86 & 0.31 & & \\
\hline Moisture & 11.88 & 0.19 & 12.38 & 0.34 & & \\
\hline Caricn & 69.00 & 0.3 & $68 . \pm 5$ & 0.3 & & \\
\hline Eyciroger: & 5.12 & 0.07 & 4.38 & 0.07 & & \\
\hline Nitrogen & 1.49 & 0.05 & 1.33 & 0.05 & & \\
\hline $\begin{array}{l}\text { Oxygen (via di:- } \\
\text { ference) }\end{array}$ & 9.66 & 0.71 & 13.34 & 0.76 & & \\
\hline $\begin{array}{l}\text { Fearing Vaice, } \\
\text { BIU/1b }\end{array}$ & 12,547 & $60^{\circ}$ & & & & \\
\hline
\end{tabular}

: 11 w $t^{3}$ are or a moisture Kree basis.

2Stanciars deviation.

3Not anaiyzes.

\subsection{Quaity Assurance and Control}

All of the analycical procedures have been previcusly approved by t:e Quality Assurance Officer, Dr. John Rowley. Moreover, to assure concirues accuracy of analytical results, periodic analysis have been routinely farred out to other labs for verification. Two such laboratories included Comme:cial Tesing \& Engineering Co. of St. Rose, LA (used routinely for ultimates; and Gueipi Chemical Laboratories ltd. of Cntario, Canacia. To dare our in-house analyses bave been well within acceprable inter-laboratory dasa reporting.

\section{3}

\subsection{Microscopic Analysis}

Stucies during this quarer have concentated on developing and using a sianciarless analysis (as oppcosec to a siandard analysis) to monitor organic sulfur removal. The coais in use, two IIlinois $\$ 6$ coals 1002 \& 1003, have been cleaned of pysite to where ihat remaining consitutes approximately 0.10 percent by weight; sesider suifate ranges from 0.10 is 0.20 percent. This translates (via the dï̈erence formlia) into an orgaric sulfur content of ca. 2.5 to 3.0 wto. 
Because of the special nature of Cur coais, the EDS-SEM standart analysis (as deineated in the iiterature) was considered ico laborious (scrsidering the number of samples involved) and periaps not the optimum route to pursue or duplicate. A standardless analysis on the other hand offered wore Ilexioility. This procedure however for coal sulfur analysis has yet to be developed; to his end, we have nade signizicant progress.

Extensive EDS-SEM aralyses have ceen made on coal :002, before (E: g- $^{-}$ ure 1) anc aiter pyrite removal (Eigure 2). In Zigure ${ }_{\text {, }}$ ISS anaiyses are presented flom leit to jigin, down the page, by decreasing angnificaticns.

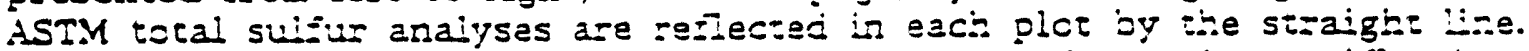
The average percent sulfur anc stancard deviation for eaci magnification is presented in tise bottom piot. As expecied, the average deviation decriased proportionally with decreased magnification. One would expec the average sulfur concentzation to be more of an "average" as the area of excitation is increased. In the spot moce, wrere the area of excitation is suall (or the

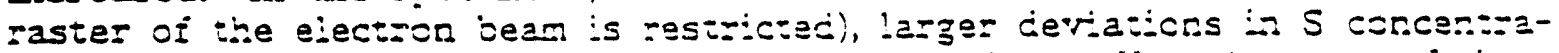
tion were expecied and this was zeriec:ed experimentaily is nore oi ite

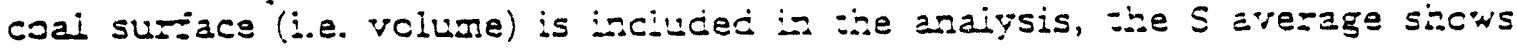
less tencency to vary dzasticaiy.

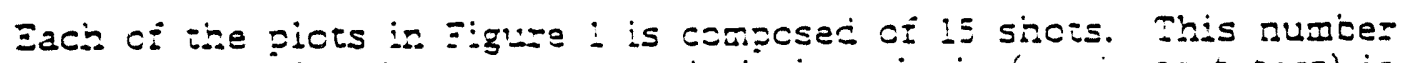
was random in cicice, however, a siatisicai anaiysis (sïcerss t-tesi) is

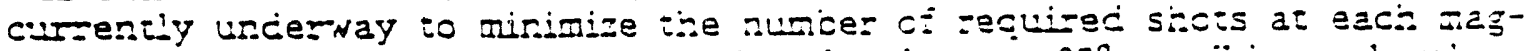
aification to jail within acsepted AsTM levais a: a 953 corizcerce levei.

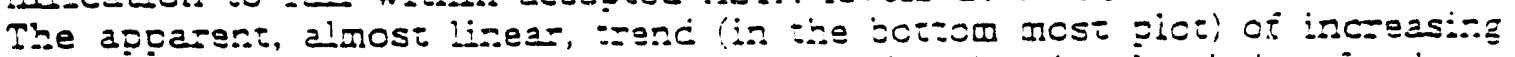

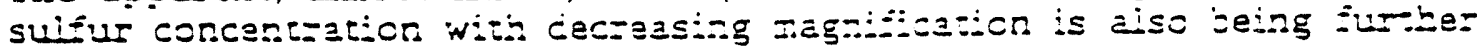
eiuciciatec.

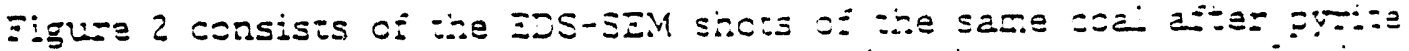

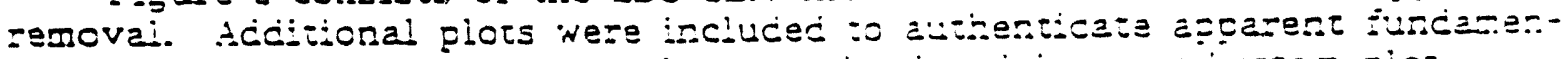

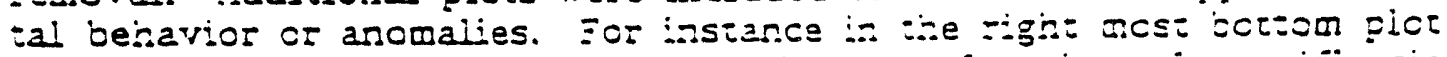

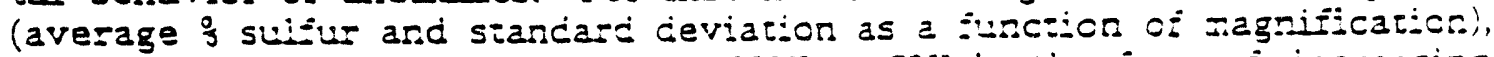
there appeared to be a trend $:=0 m 220 \mathrm{X}$ to $70 \mathrm{X}$ in the form of decreasirs sulfur concentration with decreasing nagnification. Lowever, furcher ir.restigation (i.e. additional shots) revealed no such behavior. ?lots contain:-g just 5 points are other examples of reruns at particular magnifications.

Athough the causes anc effects are by no means itmly esibilisine (cr for that matier, the decucicns and hypotheses congcsed), what sar. ie said of the data in Figures 1 and 2 to date is this:

¿. As expected, there is less sinciar deviation (" in tie data as the magnification is decreased or tie volume i= crai] of excitation is increased.

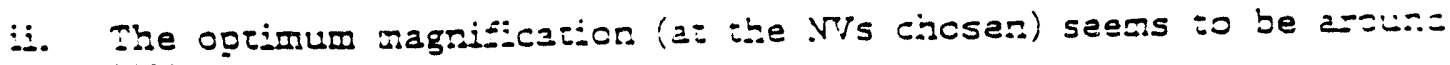
$320 \mathrm{x}$. 
i:i. The mosi aprocos VTs, although originaily couposed isso iso - 3C

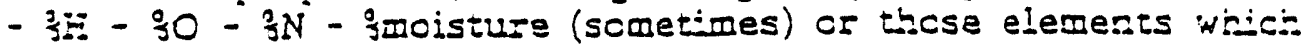
EIS cannor detac: without a special window, seem to csfospcred sissely with the persent asi (see coal analyses). Fowever, ins is ar early suppositior.

iv. Ea-iy indicaticrs soni-g that ine stancariess anaiysis is $\equiv$

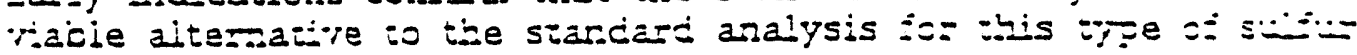
aralysis in csai.

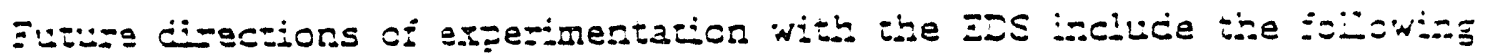
coscers:

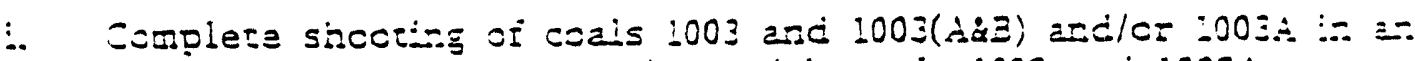
azalogous iasticr as was done with coais 1002 and 1002.1 .

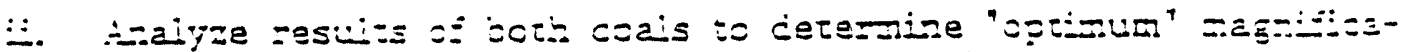

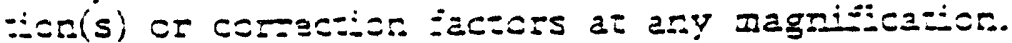

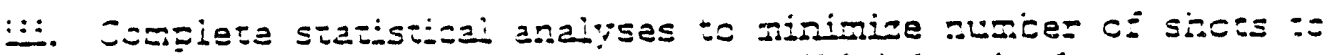

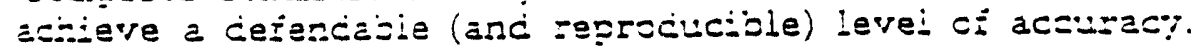

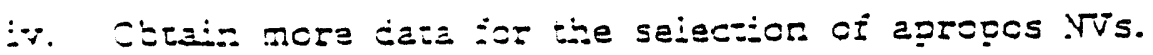

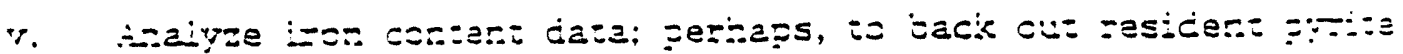
s=ะces:t=az:er?

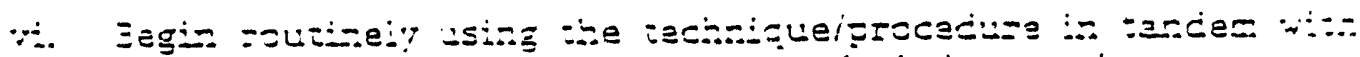

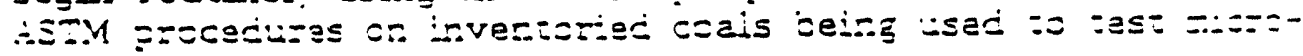

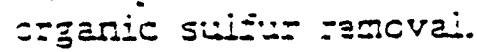




\section{COMMERCIAL TESTING \& ENGINEERING CO.}

GENERAL CFFICES. 1919 SOUTH HIGHLANO AVE.. SUITE 2:0-3. LOMBARO. ILLINOIS 60148 •13121953.9300

Wemoer or the Şs GroLo Suciele Generale se Survemance

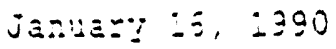

PLEASE ACORESS ALL CORAEEFG:ICENICE -O :Si JAMES DRIVE WEST. ST. FCSE. $-\mathrm{A}$ T 70087 TE:EX: 150135 CTE

FAX: (ECA) 4fLI-i220

LCUIEEATA TECH UNEYERSITY

?. 0 . 30.8 10348

RUSTON LA $7: 272$

Sample identificaticn by

LA. TEC:.

SAXIE IDENTIEIED AS: :CO23CD

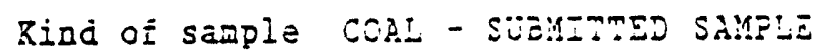

reported to us

Sample taken at UNKisonit

Sample taken by UNKMCin

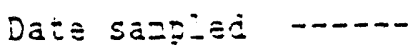

Date receited januar: 2, 2000

Analysis Report No. 38-57390

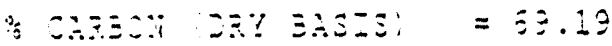

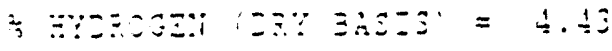

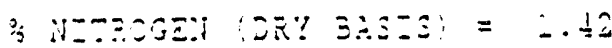

Aesoectully suomitiod.

COMMEACIAL TESTING 3.ENGINEEPING Cこ

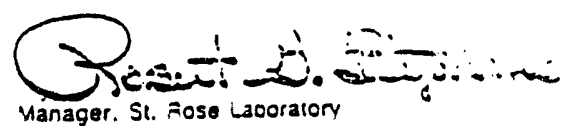

CVEF 40 SRANCH LABORATORIES STAATEGICALL $\checkmark$.

TOENATER AND GREAT LAKES POR: 54 IEA LOAOING FACILITIES

Criginal Cas" Nacermarved For Ycur Drolec:ion 


\section{COMMERCIAL TESTING \& ENGINEERING CO.}

GENERAL OFFICES. 1919 SOUTH HIGHLANO AVE. SUITE 210-8. LOMBARD. ILLINOIS 60148 • 13121953.9300

Memoer of the SGS GrCuD (Societe Generale ce Surretiance)

January:ó, 1990

LOUISIAHA TICA UNIVERSE"Y

?. 0 . BCK 10348

RUSTON I.Z 71272
PLEASE AOCFESS ALL COFARESPCNCENICE TO

ISI JAMES DRIVE 'NEST. ST. ROSE. LA TCOBT TELEPHCNE: :SC4) $167.5 \equiv 22$

TE: $\cong X: 460135$ CTE UI

Fix: $(504) 464-i 220$
Sample identification by

LA. IIC:.

SAMPIE IDENTIEIED AS: LOCZIO

Kind of sample COAL - SUEYITIED SAMPLE

reported to us

Sample taken at UNXYOWN

Sample taken by UNKNowis

Date sazpled -----

Date received January 2, 1990

Analysis Report No. 3Q-37引Q

\& CAREOH (DKY BASIS! = 30.

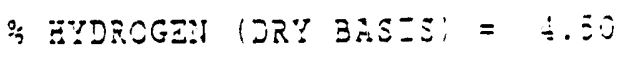

\% NITROGEN (DRY BASES; = :.2E 


\section{TASK 1 Project Planning}

Task complete.

\section{TASK 2 Coal Procurement and Preparation}

\subsection{Grinding, Sieving, and Storage}

Task complete.

Funre: We have ordered 20 pounds of Illinois $\div 6$ (IBC-101). Half or this coal will be homogenized, ground to pass through a $=200$ sieve, anc rehomogenized. Five pounds each will be ground to $30 / 0$ and $100 / 0$.

2.2 Microbial Pyrite and Sulfate Removal

Task complete.

The removal of pyritic sulfur from Illinois $\# 6$ and the Freepor: coal is completed.

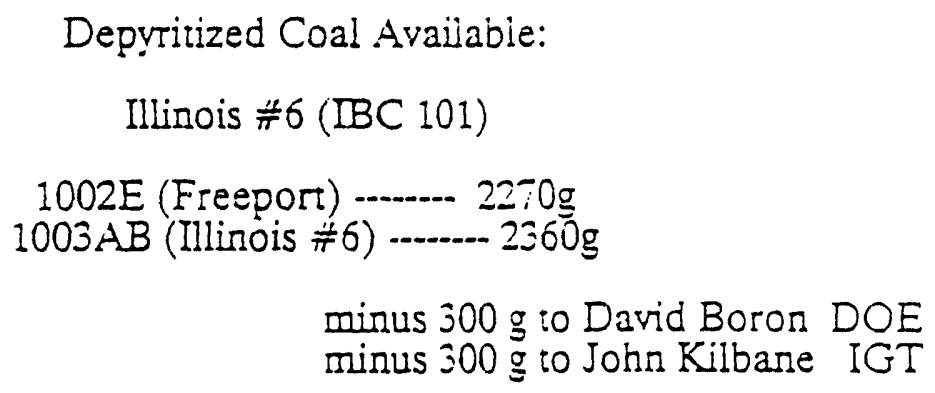

Fundre: Depyritized coal will be available as batch removal continues.

1. The large reactor will be started with $200 / 0$ coal. Tnis batch should be available by April 30, 1990.

We will run a mass balance with a degeneration curve while monitoring pH, temperature, and bacteria count.

2. Efforts to optimize the batch reaction should generate additional depyritized coal. The resultant coal by-product may vary in grain size. Two small (5 gal.) reactors have been construcied to tesi reactor conditions. The first two runs of these small reactors $(s i)$ will be used to compare the efficiency of reactor sizes.

sr1 Duplicate large reactor run discussed above.

sr2 Control run without bacteria to evaluate oxidation of coal matrix. The next runs will be used to evaluate the effects of coal size on the efficiency of depyritization. 
TASK 3 Analytical Procedures for Total Organic Sulfur

3.1 Characterization

Analyses of the stock and depyritize coal are included in Table 1. Further analyses of the most recently treated coal (1002E) await the return of carbon analysis from the commercial laboratory. These analyses will be available for the next report. All treated coals are stored under nitrogen.

3.2 Quality Assurance and Control

We continue to run multiple samples to check in house accurac/ as prescribed by Quality Assurance Officer, Dr. John Rowley. Moreover, to assure continued accuracy of analytical results, periodic analysis have been routinely farmed out to other labs for verification. To date, our in house analyses have been well within acceptable inter-laboratory data reporting. Commercial analyses of carbon, hydrogen, and nitrogen are included in Appendix A.

\subsection{Microscope Analysis}

We finished basic data collection with the SEM/EDS sysiem this lasi quarter. Most of our efforts have been dedicated to statisical analysis of these data. Our first concern was to find a siatistical measure that fit the disirioution of our data. We analyzed the data for normal, lognormal, truncated lognormal, maximum-minimum uniform, and standard uniform disirioution. The result of these analyses for the two end points and a middle value are included in Table 2. We used a Kolomogorov-Smirnov $(\mathrm{K}-\mathrm{S})$ tesi to evaluate the fit of each of our data sets to these distributions (Table 2). Our data is best described as having a normal or lognormal distrioution. Normal and lognormal plots ot spot mode anc $100 \mathrm{X}$ are included in Figure 1.

Once we had a reasonable representation of our data disiribution, we wer: able to ask how many sampies were necessary to predict the mean with a $9 \vdots$ percent certainty to fall within ASTM tolerances. We ran student "t" test on. each distribution. Again the results for spot mode, $100 \mathrm{X}$ and $30 \mathrm{X}$ are reported (Table 3 ). These analyses suggest that four to five spectra should predict the mean within ASTM tolerances as long as we keep the magnification at or below $100 \mathrm{X}$ (Figure 2). 
Table 1. Batch Analyses of Microoial Depyritized Coal

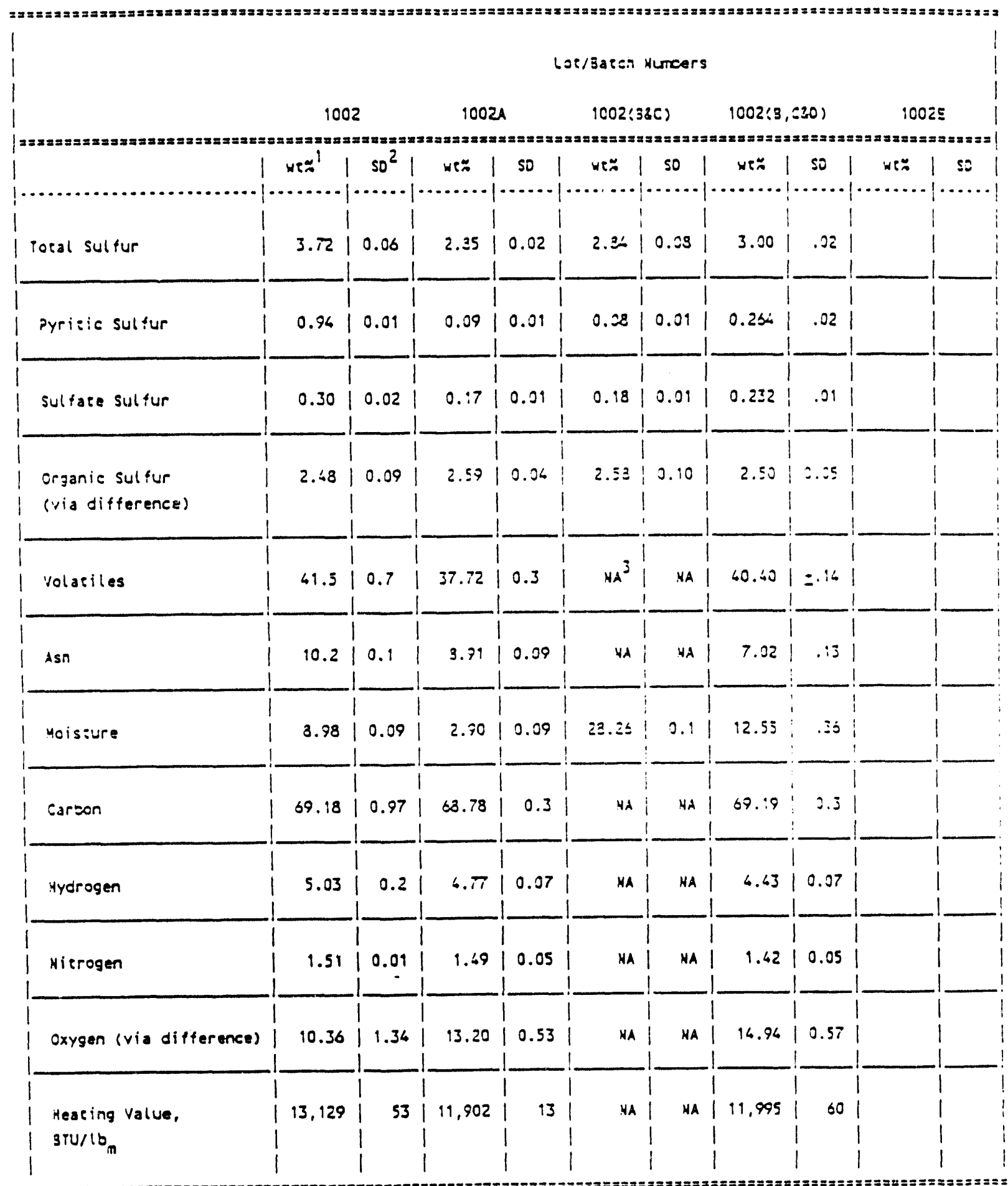

\footnotetext{
${ }^{1}$ 1! wez are on a moisture free basis.

2 standard ceviacion.

3 yor analyzed.
} 
Table! (cont'd) Batch Analyses of Whicobial Depyritized Coal

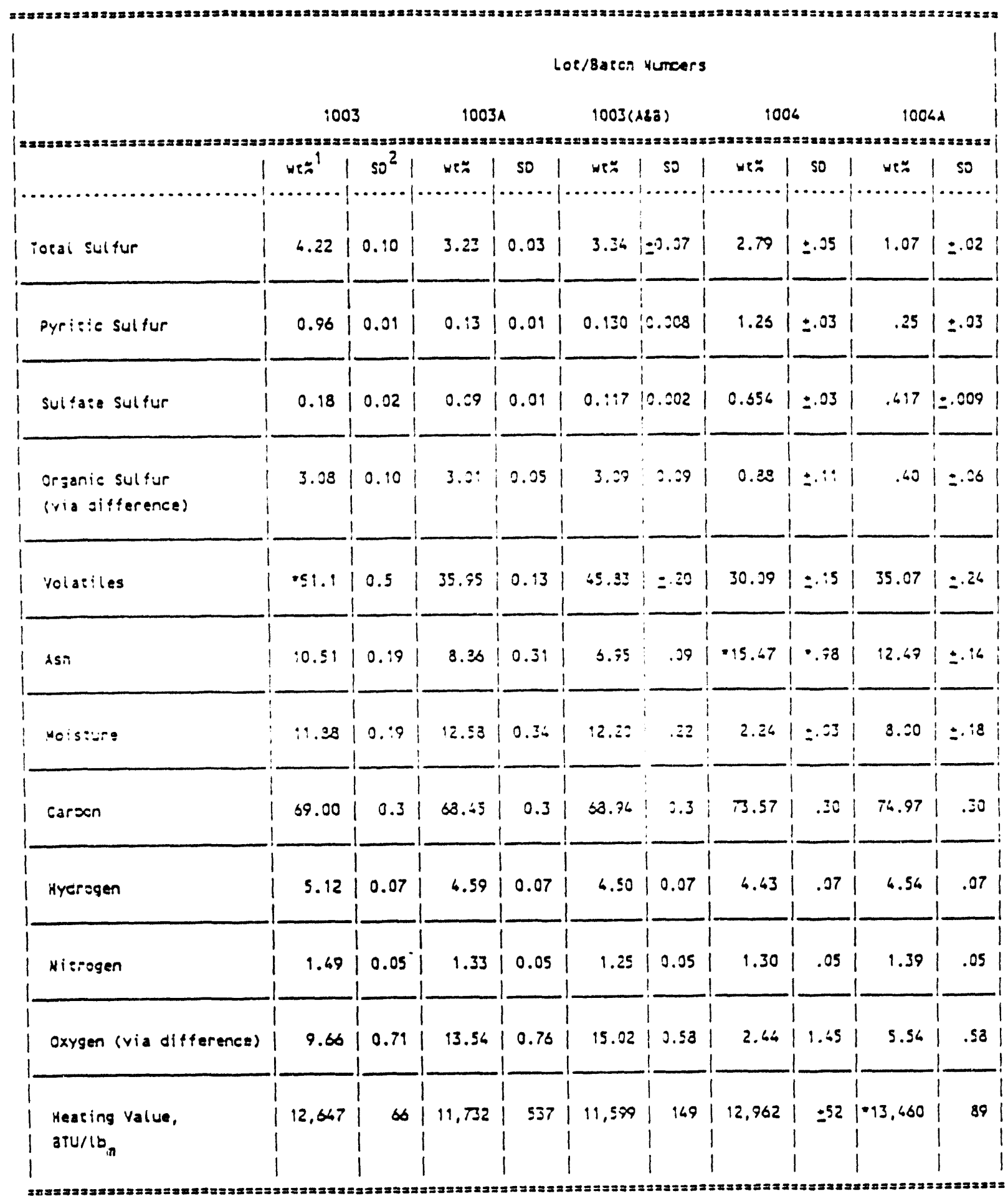

'All we: are on a noisture free basis.

2standard deviation.

3 Yor analyz=0.

- Contirmed. 
Table 2. Statistical Tesi of Best Fit of SE.M/EDS Data

A. Spot Mode

$\begin{array}{llllll} & \text { Normal } & \text { Lognormal } & \begin{array}{c}\text { Truncated } \\ \text { Lognomal }\end{array} & \begin{array}{c}\text { Maxlike } \\ \text { Uniform }\end{array} & \begin{array}{l}\text { Sampdata } \\ \text { Uniform }\end{array} \\ \text { Mean } & 3.4687 & 3.4230 & 0.0355 & 3.6400 & 3.4637 \\ \begin{array}{l}\text { Variance } \\ \text { Stand. Dev. }\end{array} & 0.3470 & 0.0282 & 0.0303 & & \\ \text { Range } & 0.580 & 0.1680 & 0.1741 & 2.3314 & 2.0405 \\ \text { K-S test } & 0.125202 & 0.094013 & 0.095132 & 0.213848 & 0.136609\end{array}$

B. Magnification $=100 \mathrm{X}$

Normal Lognomal $\begin{array}{lll}\text { Truncated } & \text { Waxike Sampda:a } \\ \text { Lognomal Liform Liform }\end{array}$

$\begin{array}{llllll}\text { Mean } & 1.4573 & 4.4511 & 0.0466 & 4.4300 & 4.4573 \\ \text { Variance } & 0.0591 & 0.0030 & 0.0033 & & \\ \text { Stand. Dev. } & 0.2431 & 0.0547 & 0.0573 & 0.8914 & 0.9421 \\ \text { Range } & 0.168889 & 0.168461 & 0.16346 \vdots & 0.175320 & 0.127 i 33 \\ \text { K-S test } & 0.51\end{array}$

C. Magnification $=30 \mathrm{X}$

Vormal Lognomal $\begin{array}{lll}\text { Truncated } & \text { Maxiike } & \text { Sampcata } \\ \text { Lognomal Liform } & \text { Lniform }\end{array}$

$\begin{array}{llllll}\text { Mean } & 4.8613 & 4.8564 & 0.0510 & 4.9200 & 4.8613 \\ \text { Variance } & 0.0527 & 0.0022 & 0.0024 & & \\ \text { Stand. Dev. } & 0.2296 & 0.0467 & 0.0491 & 0.8457 & 0.7954 \\ \text { Range } & 0.183656 & 0.174524 & 0.174998 & 0.268807 & 0.197294 \\ \text { K-S test } & 0.1758\end{array}$


Table 3. Student "T' Tolerance Test of Normal Disiribution of SEM/EDS Data

Sample $\#$

A. Spot Mode

Tolerance $=0.3469$

Normal distribution

Lognormal distribution

Doubly truncated lognormal distribution

Uniform distribution using maximum likelihood

Uniform distribution using sample data

$\begin{array}{ll}= & 15 \\ = & 15 \\ = & 16 \\ = & 13 \\ = & 12\end{array}$

B. Magnifica:ion $=100 \mathrm{X}$

Tolerance $=0.4457$

Normal distioution

Lognormal distribution

Doubly truncated lognormal distribution

Unifom disiribution using maximum likelihood

Uniform disi:ibution using sample data

$=5$
$=\quad 5$
$=6$
$=6$
$=6$

C. Magnification $=30 \mathrm{X}$

Tolerance $=0.4861$

Normal distribution

Lognormal distribution

Doubly truncated lognormal distribution

Uniform distribution using maximum likelihood

Uniform distribution using sample data

...-NOTE: 9999 indicates $>31$....

$\begin{array}{ll}= & 4 \\ = & 4 \\ = & 4 \\ = & 5 \\ = & 5\end{array}$ 
Figure 1. Statistical Analyses of SEM/EDS Sulfur Data
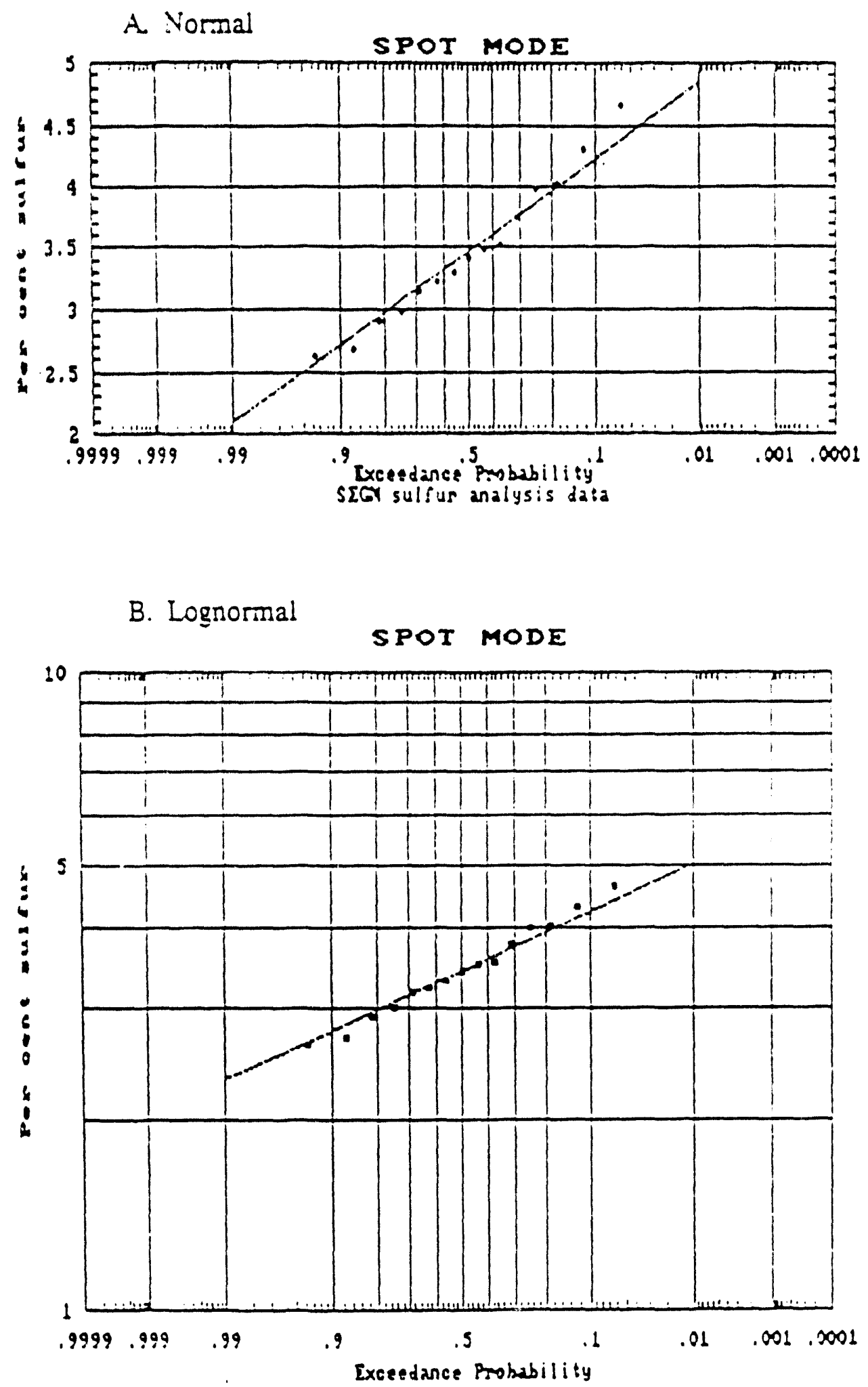

SICY sulfiur analysis data 
Figure 1 (cont'd) Statistical Aralyses of SEM/EDS Sulfur Data
C. Vormal

Magnification $=100$

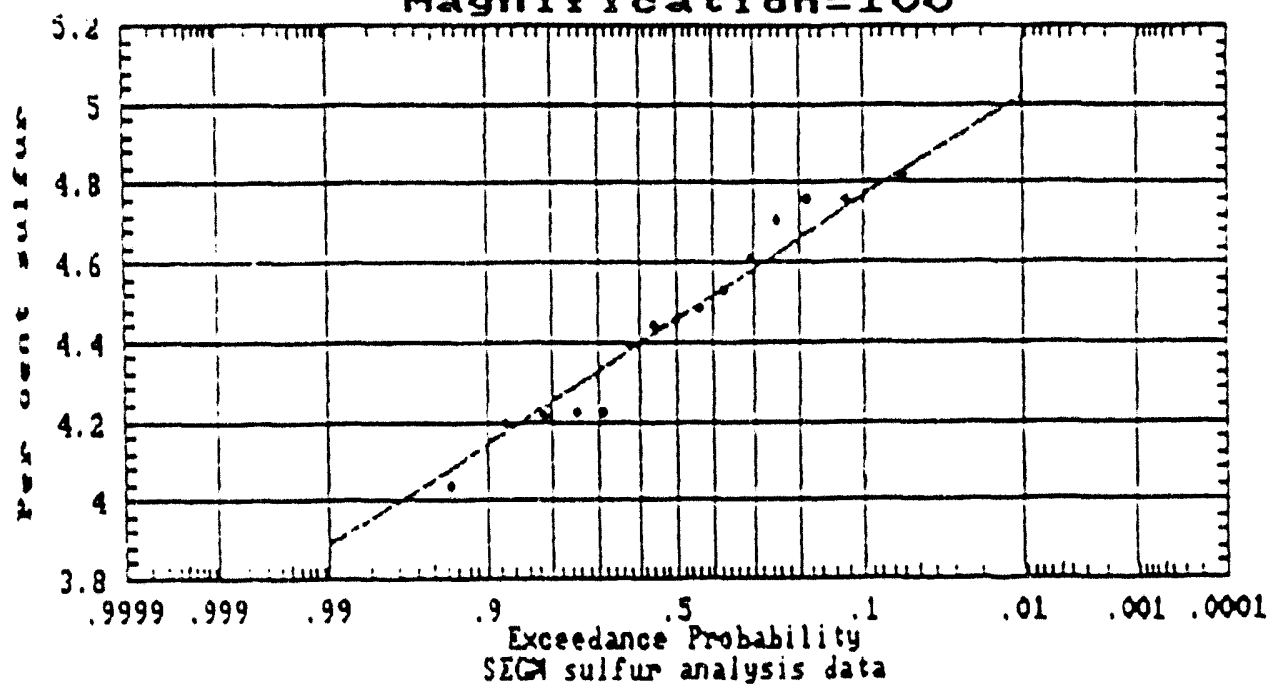

\section{Lognormal}

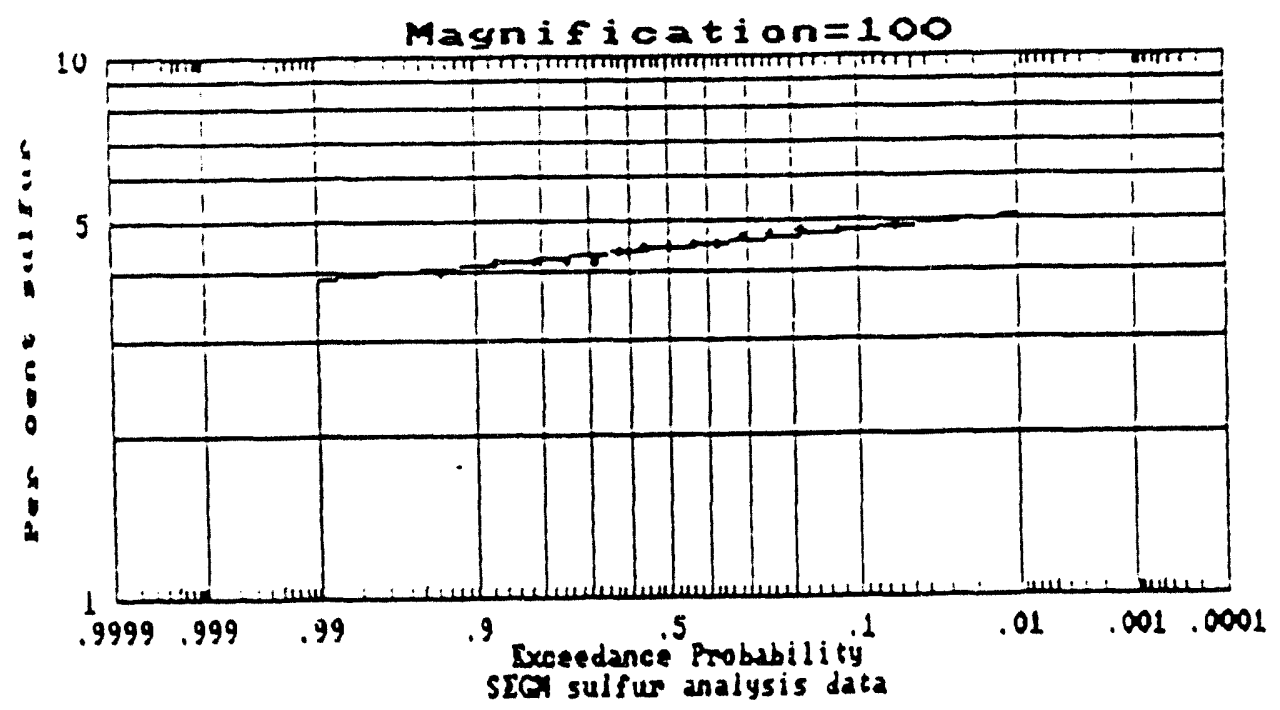




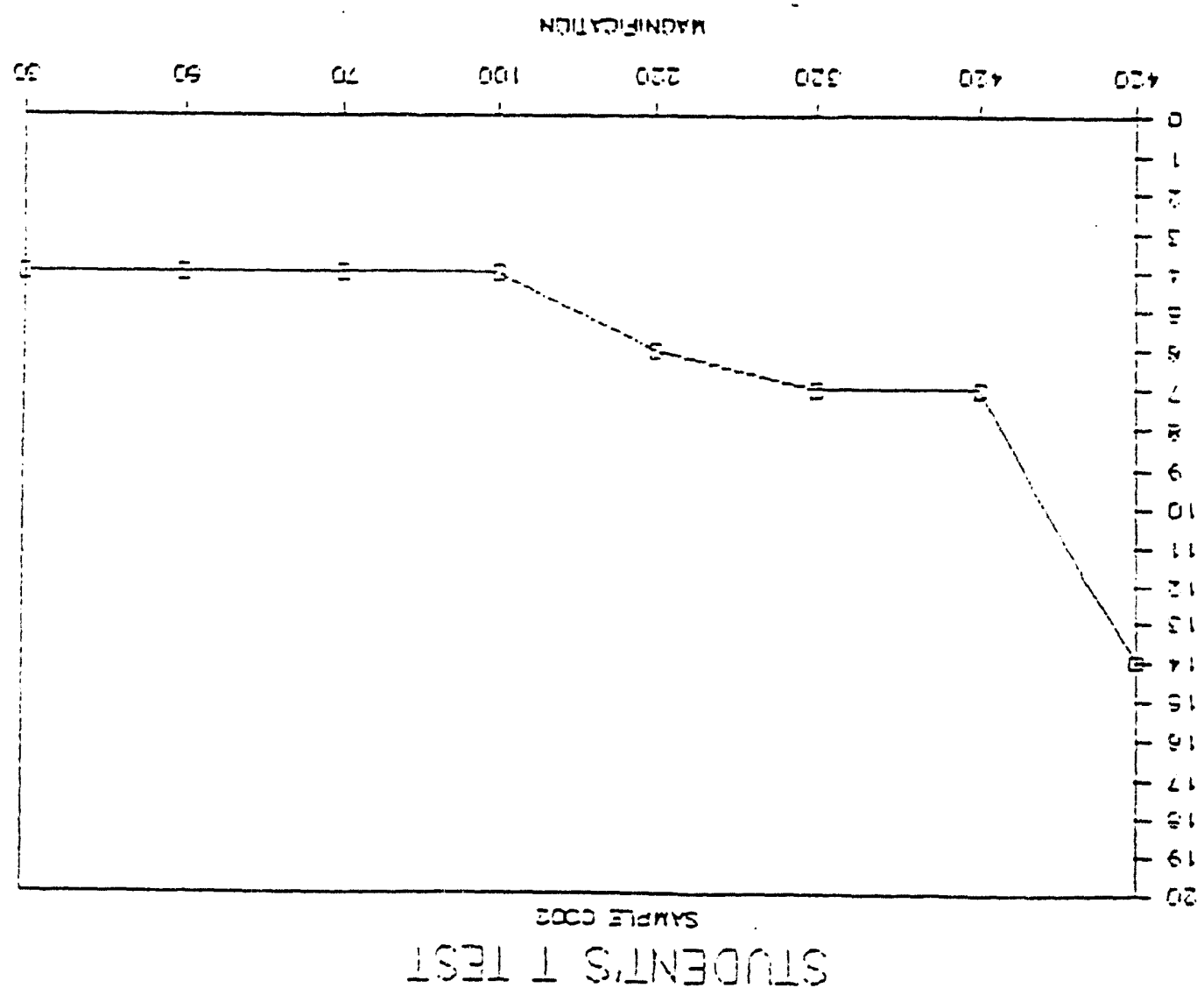


APPENDIX A 
January 16,1990

LOUISIANA TECH UNIVESSITY

P. $0.30 \% 10348$

RUSTON Lì 71272

Sample identification by

i... TEC:..

SAYYLE IDEYYIEIED AS: 10023CD

Rind of sample COAL - SUBMITIED SAMPLE

reported to us

Sample taken at UNRNowis

Sample taken by UNKNonit

Date sampled --.--

Date received januar: 2, 1990

Analysis Report No. $30-57390$

\& CARSOI (JRY ZASZS) = 53.19

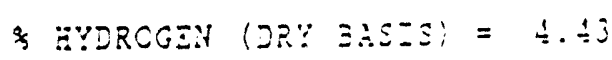

\& VITRCGEV (DRY BASES; = L.42

PLIASE AOORESS ALL CSARESPCNCENCE -

ISI AMMES SRIVE NEST. ST. PCSE. LT TCCS: TELEFHCNE: (SG,4) 467.5322 TELIEX: 160135 CTE $J 1$ FAX: $(504) \div 60, i \leq 2=$

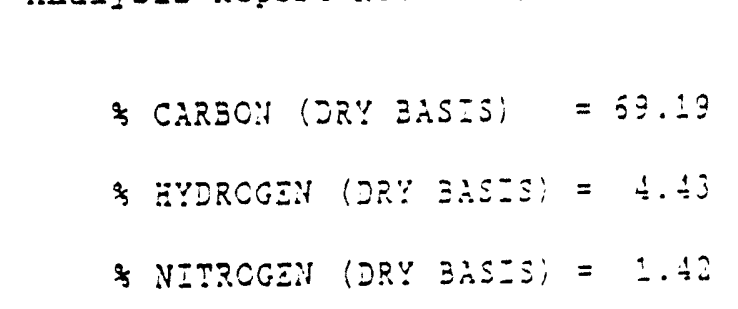

Rescec:fully SUzmurec.
COWHEAC:AL TESTING 3.SNGINEEAR:O =0

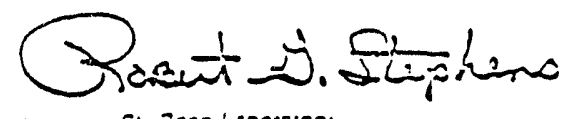

Manaçer. SI. Fose Lacoralory

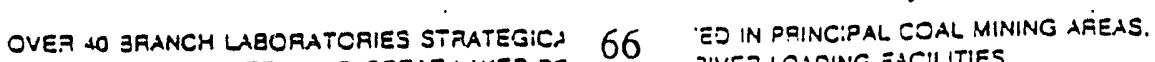

TIEWATER ANO GREAT UKES PC ........ IIVEA LOADING FACILTIES

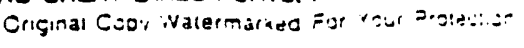


januaz:16, 1990

LOUISIANA TEC:̈ UNITERSERY

?. $0.30 \times 10348$

RUSTON Lก̀ 71272
PLEASE ACCAESS ALL CORAESPCNCENCE TU

ISI JAMES ORIVE WEST, ST. RCSE, 'A TCC8:

TELEPHCNE: (\$CA) 467.5522

TElEX: 160135 CTE UI

FAX: $(5 C 4)+64 ;-i 220$
Sampie identification by

i.r. TEC.̈.

SAYPLE TDEVTIEIED AS: $1003 \mathrm{AB}$

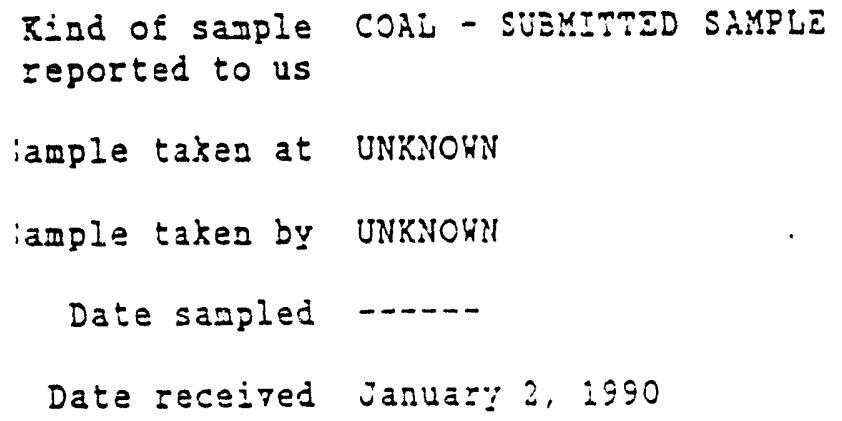

Analysis Report No. 39-5T:9I

\& CARBON (ZNY SASES) = 53.94

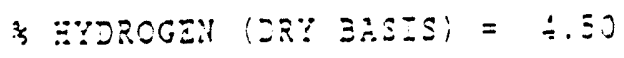

\& NITRCGEN (ORY ERSEST = -.25 


\section{COMMERCIAL TESTING \& ENGINEERING CO. GENERAL OFFICES: : 919 SOUTH HIGHLANO AVE.. SUITE 210.3. LCMEARO. ULINCIS 80148 • (312) 953.93CO}

xarci $\div 9, \quad 1990$

LOUISIAHS TECA UNIYERSIT?

P. $0.30 \% 10348$

RUSTON LA 71272

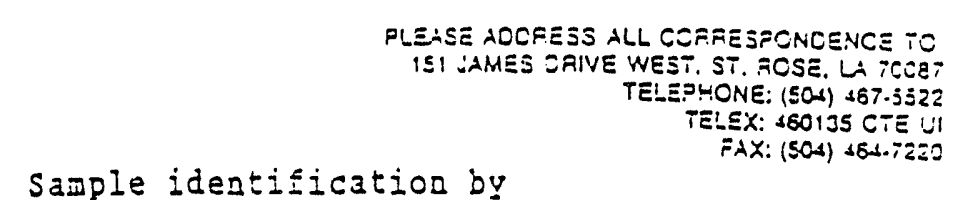

Sample identification by id.TEC:
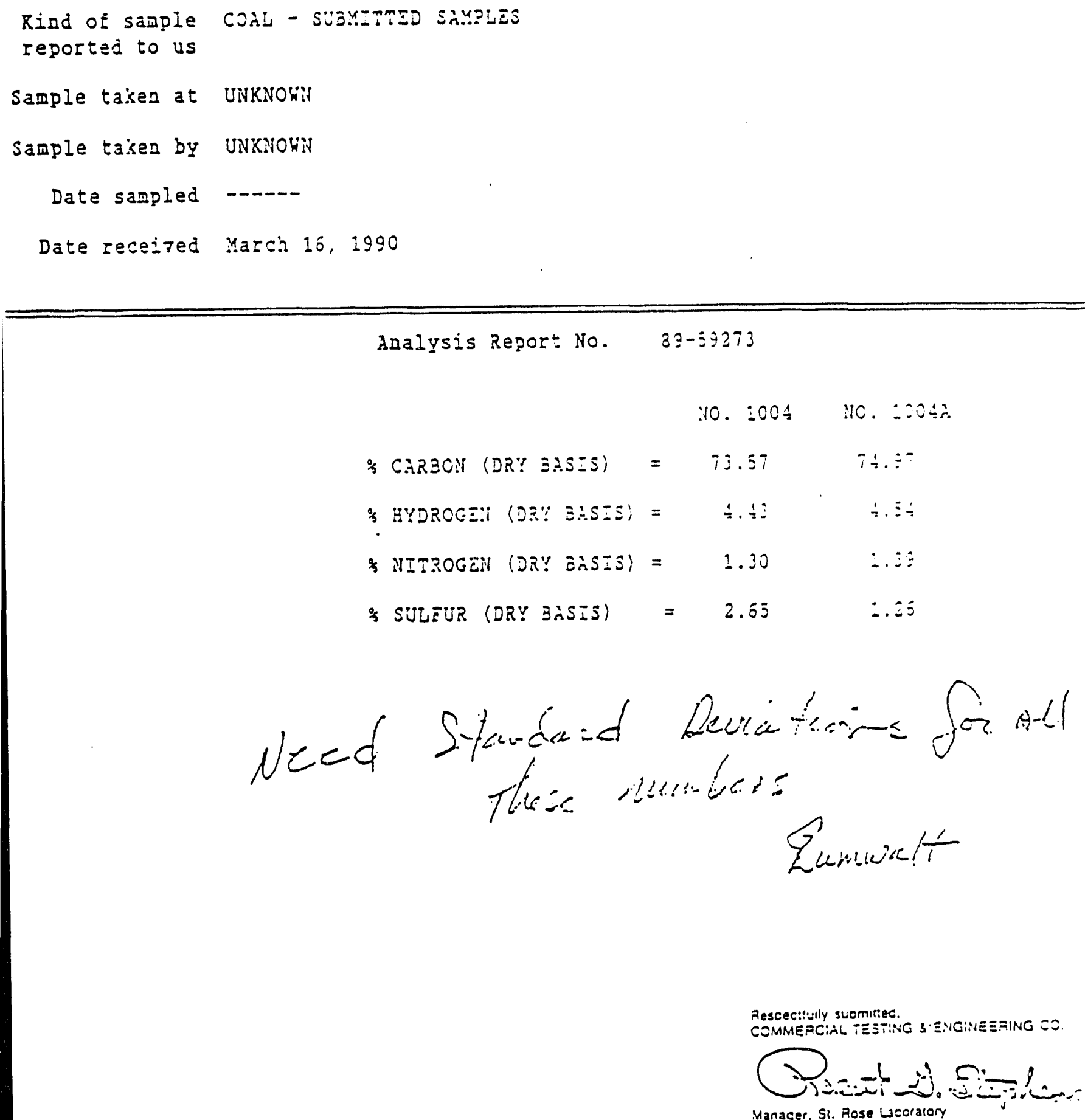

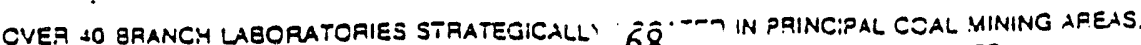
TIOEWATEA ANO GREAT LAKES PORT. 68 ER LOAOING FAC:LITIES 
ATTACHMENT A

APPENDIX III

Activity from March 15, 1990 to Project Completion (April 20, 1992) 


\section{INTRODUCTION.}

On May 21, 1990, Dr. Michael Hsieh and I formally assumed responsibility for the microbial coal desulfurization project. I will be serving as Project Director throughout the remainder of the contract period, while Dr. Hsieh is providing expertise in the area of biological coal treatment.

The following discussion summarizes the work done over the last quarter and outlines planned activities in the upcoming months in relation to the Tasks as outlined in the contractual agreement.

\section{TASK OVERVIEW.}

Task 1 - Project Planning.

Task Complete.

\section{Task 2. Coal Procurement and Preparation.}

\subsection{Grinding, Sieving, and Storage.}

Task Complete.

Current coal supplies (raw and depyritized) are being inventoried to determine amounts available for further treatment. All of the raw coal on hand (Illinois $\# 6$ IBC-101) is being ground to 200 mesh particle for subsequent cepyritization. As described in the April 20 report (Task 2.1 ) the remaining unground coal comprises approximately 10 pounds of the initial 20 pounds ordered. Portions of this lot of coal have previously been ground to 200 mesh and treated for pyrite removal (Batch Runs 1005A \& B) and are currently being tested for sulfur content.

Additionally, 20 pounds of Illinois \#6 IBC-101 have been ordered (arrival of this shipment is expected in July). This coal will be riffled and portions of the lot will be ground to various particle sizes (including $200 \mathrm{mesh}$ ) for future evaluations of the kinetic rates and extent of depyritization as a function of particle size. Literature sources have reported successful microbial attack upon pyritic inclusions on particles sized up to 60 mesh (Andrews et al., 1987). 


\subsection{Microbial Removal of Pyrite and Sulfate.}

Task complete.

Depyritization of Illinois \#6 (IBC-101) coal remains an ongoing procedure in order to provide a supply of depyritized coal for various organic sulfur removal studies. All analytic and coal handling procedures are currently under review to ensure reliability and continuity of the project with the recent change of personnel (including most of the staff of siudent workers conducting analytic procedures).

Previous depyritization runs for each of the three batch reactors (April and Way monthly reports, Task 2.2) are being analyzed for the extent of pyrite removal. The apparent cessation of microbial depyritization for Reactors $1005 \mathrm{~A} \& \mathrm{~B}$ is being investigated. For future batch runs, the operating conditions and parameters monitored will include agitation rate (rpm), pH levels, initial cell concentrations of inocula, inoculum sizes, etc. Close monitoring of batch runs offers the potential for conducting studies for developing a kinetic model describing the depyritization rate for the Thiobacillus consortium used in this project.

\section{Task 3 - Analvtical Procedures for Total Organic Sulfur.}

\subsection{Characterization.}

Task complete.

\subsection{Quality Assurance and Control.}

As with previous raw and treated coals, in-house analytical results will be checked periodically with outside lab testing.

\subsection{Microscope Analysis.}

Task complete.

Task 4 - Organic Sulfur Removal.

The following discussion outlines the activities and procedures which have been initiated as an effort to isolate organic sulfur utilizers. 
Forty-one samples of natural inocula, obtained from various sources including soils, slurry ponds, coals, and oil sludges (collected samples were refrigerated to minimize microbial activity) were inoculated onto 82 petri plates of screening medium, Trypticase Soy Agar with dibenzothiophene (DBT) added in solution. DBT was dissolved in glycerol and added to the medium to give a final concentration of $1 \mathrm{~g} / \mathrm{L} \mathrm{DBT}(0.1 \% \mathrm{w} / \mathrm{w})$. Inoculum dilutions were prepared by adding $1 \mathrm{~g}$ of sample to $4 \mathrm{~mL}$ of sterile, distilled water. For each sample prepared, streaks were made onto two plates, each with a different $\mathrm{pH}$ value $(2.4$ and 6.7, respectively). The plates at the lower $\mathrm{pH}$ were prepared to screen for strong acidophiles (considering the attractiveness of having an organism operating in the same $\mathrm{pH}$ range as Thiobacillus sp.). A control plate was prepared for the medium at $\mathrm{pH}$ 6.7. Of course, this procedure only screens for organisms that are capable of growing in the presence of DBT, though not necessarily utilizing it.

The plates were incubated a minimum of 72 hours at room temperature. Specific colonies showing strong growth were then selected from each plate. These colonies were again streaked onto fresh plates containing the same medium in order to purify the working culture and eliminate the presence of contaminants. Again, plates were incubated for a minimum of 72 hours at room temperature.

Organisms from the purified colony-separation plates were placed in a broth screening medium identical to the Tryptic Soy/DBT medium (but without agar)to produce a workable quantity of the purified strains. This procedure was carried out for each of the cultures isolated. These broth cultures were also incubated for at least 72 hours.

\section{Planned work.}

For each culture isolated, a preparation of $150 \mathrm{~mL}$ oi basal salts medium containing depyritized coal will be inoculated with $15 \mathrm{~mL}$ of seed cuiture from the Tryptic Soy broth culture. The basal medium with $3 \mathrm{~g}$ of coal will be added to a $250 \mathrm{~mL}$ Erlenmeyer flask, autoclaved at $121{ }^{\circ} \mathrm{C}$ for 15 minutes to sierilize the culture environment. The $15 \mathrm{~mL}$ of seed inoculum will be added following cooling of the autoclaved medium. Once inoculated, the flask will be placed on a shaker bed at an agitation rate of $180 \mathrm{rpm}$ and at room temperature (approximately $27^{\circ} \mathrm{C}$ ). The culture will be incubated in this environment for at least two weeks after which the coal will be filtered from the culture broth, treated for biomass removal from the coal particles, dried and analyzed for organic sulfur content. It is possible that the incubation period may have to be increased in order to observe significant changes in the sulfur content, provided that strong microbial activity is observed, and that supplemental medium additions may be necessary to prevent nutrient limitations over such a long incubation period.

For cultures which show positive results, the shaker bed inoculation procedure will be repeated. However, it is proposed that two samples be run for each positive culture -. one with glucose and one without to examine the potential of increasing the extent of microbial attack on organic sulfur in the presence of high energy substrates. Positive cultures can then be identified and characterized. 
Throughout this process, measures are being taken to maintain stock cultures in a viable state until they have been proven positive or negative in their ability to attack the organic sulfur fraction in coal. Regular transfers of cultures into similar, fresh medium will be carried out. Cultures which show positive performance will carefully be preserved with standard microbiological techniques (e.g. lyophilization, retrigeration, ultra-freezing, etc.) in addition to periodic transfer and incubation of stock cultures.

Finally, plans are underway for the construction of equipment which would enable iesting of these cultures in fed batch or continuous flow reactors. This will allow further optimization of process operating conditions.

Ancrews, G., M. Darroch, and T. Hannson, "Bacterial Removal of Pyrite from Concentrated Coal Slurries", Biotech. and Bioeng., 32:813-320, 1988. 
Table 1. Bacti Analyses of Microbial Depyritized Coal

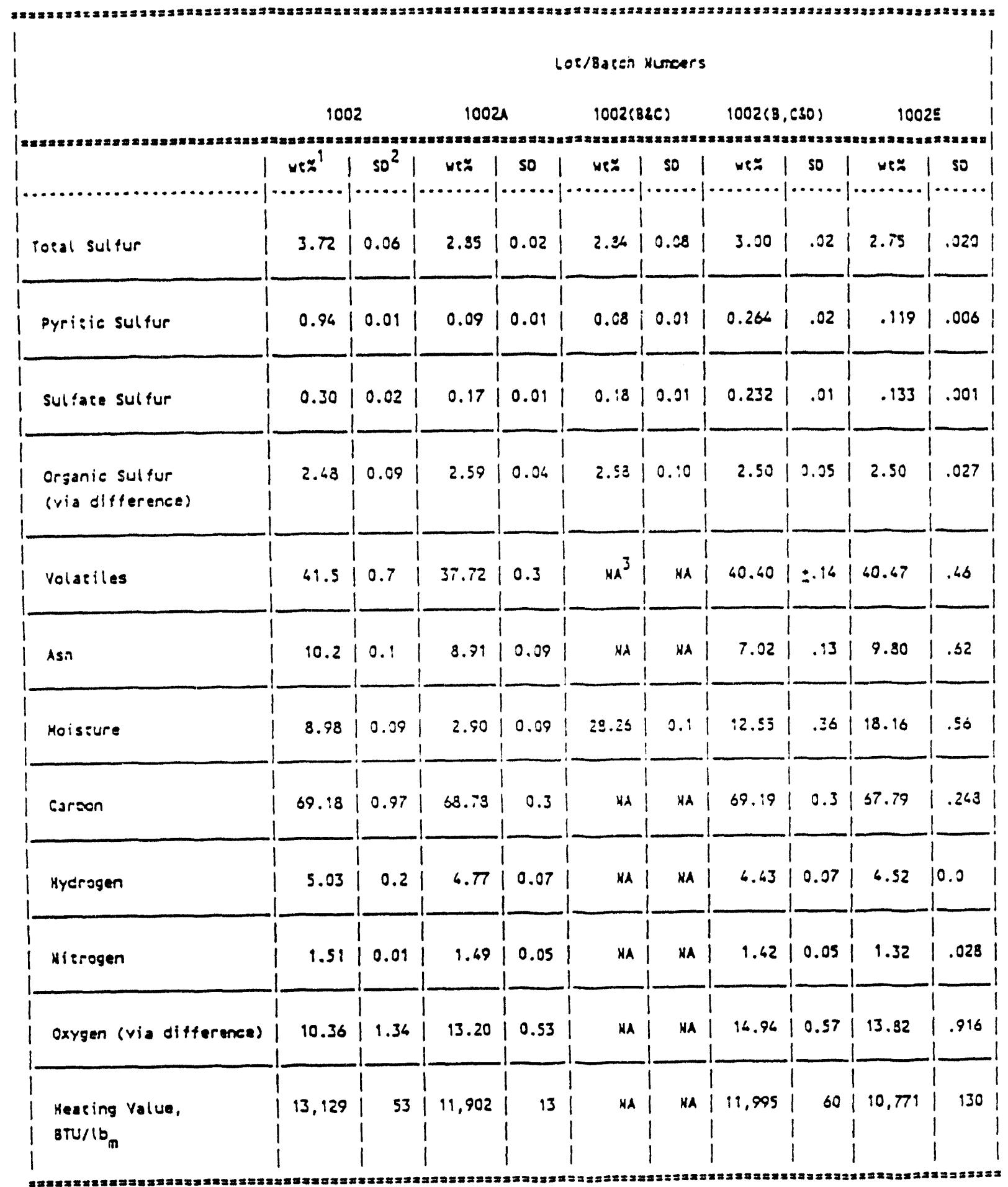

iAll we\% are on a moisture free basis,

2 standard deviation.

3 Hot analyzed. 
Table ! (coni'd) Batch Analyses of Microbial Depyritized Coal

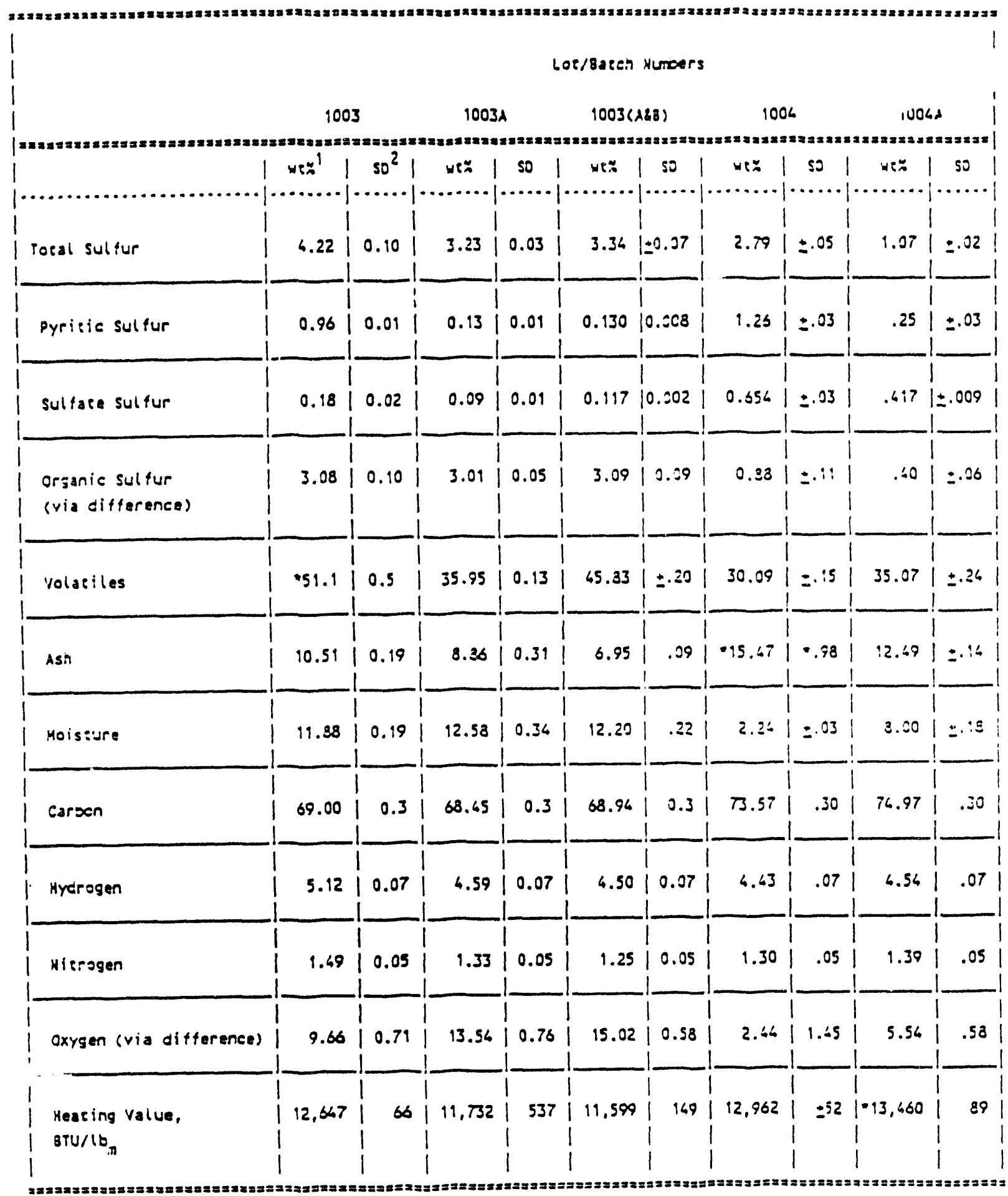

\footnotetext{
${ }^{A} 11$ wez are on a noisture free basis.

2 standard deviacion.

3 Hoe analyzed.

conit i med.
} 
TASK 3 Analytical Procedures for Total Organic Sulfur

\subsection{Characterization}

Task complete.

Final analyses of the stock and depyritized coal are included in Table 1. All treated coals are stored under nitrogen.

\subsection{Quality Assurance and Control}

To assure continued accuracy of analytical results, each of the depyritized coal samples were sent out to "Commercial Testing and Engineering Company". These final analyses are included in the Appendix A. To date, our in-house analyses have been well within ASTM acceptable error for inter-laboratory data reporting.

\subsection{Microscope Analysis}

Task complete.

Statistical analyses of the data sets for 1002 and 1002 a were completed. Our firsi concern was to find a siatistical measure that fit the disirioution of our data. We analyzed the data for normal. lognormal, truncated lognormal, maximum-minimum uniform, and standard uniform distribution. The results of these tesis are included in Tables 2 and 3 . We used a KolomogorovSmirnov (K-S) test to evaluate the fit of each of our data sets to these disiributions (also Table 2). While there is some variation, our data is besi described as having a normal or lognormal disirioution. Normal and lognormal plots for each data set are included in Figures 1 and 2.

Once we had a reasonable representation of our data distribution, we were able to ask how many samples were necessary to predict the mean with a 95 percent certainty to fall within ASTM tolerances. We ran siudent "t" tesis on each distribution to discern the minimum sample size. The results of these tesis are summarized in Tables 4 and 5 . These analyses suggesi that four to five spectra siould predict the mean within ASTM tolerances as long as we keep the magnification at or below $100 X$ (Figure 3 ). 
Table 2. Statistical Test of Besi Fit of SEM/EDS Data for C002

A. Spot Mode

$\begin{array}{llcll}\text { Normal } & \text { Lognormal } & \begin{array}{c}\text { Truncated } \\ \text { Lognormal }\end{array} & \begin{array}{l}\text { Maxlike } \\ \text { Uniform }\end{array} & \begin{array}{l}\text { Sampdata } \\ \text { Lniform }\end{array} \\ 3.4687 & 3.4230 & 0.0355 & 3.6400 & 3.4687 \\ 0.3470 & 0.0282 & 0.0303 & & \\ 0.5090 & 0.1680 & 0.1741 & 2.3314 & 2.0405 \\ 0.125202 & 0.094013 & 0.095132 & 0.213848 & 0.136009\end{array}$

B. Magnification $=420 \mathrm{X}$

Normal Lognormal

Truncated Maxlike Sampdata Lognomal Uniform Lniform

$\begin{array}{llllll}\text { Mean } & 3.7400 & 3.7228 & 0.0387 & 3.6650 & 3.7400 \\ \text { Variance } & 0.1342 & 0.0100 & 0.0108 & & \\ \text { Stand. Dev. } & 0.3664 & 0.1000 & 0.1038 & & \\ \text { Range } & 0.132631 & 0.150090 & 0.149428 & 0.181298 & 0.134533 \\ \text { K-S test } & 0.13691\end{array}$

C. Magnification $=320 \mathrm{X}$

Normal Lognorma!

Truncated Maxiks Samodaia Lognormal Lniform Liñorm

$\begin{array}{llllll}\text { Mean } & 3.8987 & 3.8805 & 0.0404 & 3.7600 & 3.3987 \\ \text { Variance } & 0.1461 & 0.0102 & 0.0110 & & \\ \text { Stand. Dev. } & 0.3822 & 0.1011 & 0.1050 & 1.5086 & 1.3239 \\ \text { Range } & & & & & \\ \text { K-S test } & 0.143063 & 0.159826 & 0.159167 & 0.221212 & 0.131221\end{array}$

D. Magnification $=220 \mathrm{X}$

Truncated Maxlike Samodata

$\begin{array}{llllll}\text { Mean } & 4.0667 & 4.0524 & 0.0422 & 4.0000 & 4.0667 \\ \text { Variance } & 0.1215 & 0.0076 & 0.0083 & & \\ \text { Stand. Dev. } & 0.3485 & 0.0873 & 0.0909 & 1.2571 & 1.2074 \\ \text { Range } & & & & & \\ \text { K-S test } & 0.094872 & 0.107409 & 0.106708 & 0.196591 & 0.137110\end{array}$


Table 2. Statistical Test of Best Fit of SEM/EDS Data for COO2 (Cont.)

E. Magnification $=100 \mathrm{X}$

Normal Lognormal Lognormal Uniform Uniform

$\begin{array}{llllll}\text { Mean } & 4.4573 & 4.4511 & 0.0466 & 4.4300 & 4.4573 \\ \text { Variance } & 0.0591 & 0.0030 & 0.0033 & & \\ \text { Stand. Dev. } & 0.2431 & 0.0547 & 0.0573 & 0.8914 & 0.8421 \\ \text { Range } & & & & & \\ \text { K-S test } & 0.168889 & 0.168461 & 0.168465 & 0.175320 & 0.127733\end{array}$

F. $\quad$ Magnification $=70 \mathrm{X}$

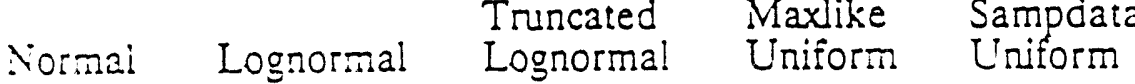

$\begin{array}{llllll}\text { Mean } & 4.5413 & 4.5361 & 0.0475 & 4.4750 & 4.5413 \\ \text { Variance } & 0.0504 & 0.0025 & 0.0027 & & \\ \text { Siand. Dev. } & 0.2245 & 0.0498 & 0.0521 & 0.9029 & 0.7775 \\ \text { Range } & 0.137861 & 0.128500 & 0.128954 & 0.261656 & 0.148673 \\ \text { K-S iesi } & 0.13786\end{array}$

G. Magnification $=50 \mathrm{X}$

Vorma! Lognormal Lognormal Uniform Uniform

$\begin{array}{llllll}\text { Mean } & 4.6800 & 4.6764 & 0.0491 & 4.7300 & 4.6800 \\ \text { Variance } & 0.0364 & 0.0016 & 0.0018 & & \\ \text { Stand. Dev. } & 0.1908 & 0.0403 & 0.0423 & 0.6629 & 0.6608 \\ \text { Range } & 0.195870 & 0.192029 & 0.192166 & 0.257184 & 0.181800 \\ \text { K-S test } & 0.50\end{array}$

H. $\quad$ Magnification $=30 \mathrm{X}$

Normal Lognormal $\begin{array}{ccc}\text { Truncated } & \text { Maxlike } & \text { Sampdata } \\ \text { Lognormal Uniform Uniform }\end{array}$

$\begin{array}{llllll}\text { Mean } & 4.8613 & 4.8564 & 0.0510 & 4.9200 & 4.8613 \\ \text { Variance } & 0.0527 & 0.0022 & 0.0024 & & \\ \text { Stand. Dev. } & 0.2296 & 0.0467 & 0.0491 & 0.8457 & 0.7954 \\ \text { Range } & 0.183656 & 0.17452 & 0.164998 & 0.268807 & 0.197294 \\ \text { K-S test } & 0.4 & \end{array}$


Table 3. Statistical Tesi of Besi Fit of SEM/EDS Data for C002A

A. Spot Mode

$\begin{array}{lccccc} & \text { Normal } & \text { Lognormal } & \begin{array}{c}\text { Truncated } \\ \text { Lognomal }\end{array} & \begin{array}{c}\text { Maxlike } \\ \text { Uniform }\end{array} & \begin{array}{l}\text { Samodata } \\ \text { Uniform }\end{array} \\ \text { Mean } & 3.0767 & 3.0214 & 0.0312 & 3.1650 & 3.0767 \\ \text { Variance } & 0.3727 & 0.0387 & 0.0412 & & \\ \text { Stand. Dey. } & 0.5105 & 0.1966 & 0.2029 & & \\ \text { Range } & 0.159655 & 0.129660 & 0.130650 & 0.167814 & 0.1149 \\ \text { K.S test } & 0.156554\end{array}$

B. Magnification $=420 \mathrm{X}$

Normal Lognormal $\quad \begin{array}{lll}\text { Truncated } & \text { Maxlike } & \text { Samodata } \\ \text { Lognormal } & \text { Uniform } & \text { Uniform }\end{array}$

$\begin{array}{llllll}\text { Mean } & 2.9127 & 2.9047 & 0.0299 & 2.8700 & 2.9127 \\ \text { Variance } & 0.0490 & 0.0060 & 0.0063 & & \\ \text { Stand. Dev. } & 0.2214 & 0.0773 & 0.0796 & 0.8229 & 0.7669 \\ \text { Range } & 0.147148 & 0.149854 & 0.149798 & 0.208681 & 0.141506 \\ \text { K-S test } & 0.14714 & & \end{array}$

C. $\quad$ Magnification $=320 \mathrm{X}$

Normal Lognormal Lognormal Uniform Liniform

$\begin{array}{llllll}\text { Mean } & 2.8433 & 2.8369 & 0.0292 & 2.8500 & 2.8433 \\ \text { Variance } & 0.0392 & 0.0048 & 0.0051 & & \\ \text { Stand. Dev. } & 0.1979 & 0.0696 & 0.0717 & 0.7314 & 0.6854 \\ \text { Range } & & & & & \\ \text { K-S test } & 0.113065 & 0.108833 & 0.108635 & 0.149610 & 0.149244\end{array}$

D. Magnification $=220 \mathrm{X}$

Normal Lognormal

Truncated Maxlike Sampdata Lognormal Uniform Uniform

$\begin{array}{llllll}\text { Mean } & 2.7993 & 2.7892 & 0.0287 & 2.8350 & 2.7993 \\ \text { Variance } & 0.0626 & 0.0077 & 0.0082 & & \\ \text { Stand. Dev. } & 0.2503 & 0.0878 & 0.0904 & 0.9486 & 0.8670 \\ \text { Range } & 0.178132 & 0.163942 & 0.164368 & 0.22093 \div & 0.172353 \\ \text { K-S test } & 0.153\end{array}$


Table 3. Statistical Test of Best Fit of SEM/EDS Data for C002.A (Cont.)

E. Magnification $=100 \mathrm{X}$

Normal Lognormal Lognormal Uniform Uniform

$\begin{array}{llllll}\text { Mean } & 2.6300 & 2.5965 & 0.0267 & 2.8550 & 2.6300 \\ \text { Variance } & 0.2086 & 0.0262 & 0.0278 & & \\ \text { Stand. Dev. } & 0.4567 & 0.1620 & 0.1667 & 1.5200 & 1.5820 \\ \text { Range } & & & & & \\ \text { K-S test } & 0.210258 & 0.182356 & 0.183168 & 0.369079 & 0.224146\end{array}$

F. $\quad$ Magnification $=70 \mathrm{X}$

Normal Lognormal Lognormal Uniform. Uniform

\begin{tabular}{|c|c|c|c|c|c|}
\hline $\begin{array}{l}\text { Mean } \\
\text { Variance } \\
\text { Stand. Dev. }\end{array}$ & $\begin{array}{l}2.4287 \\
0.2033 \\
0.4509\end{array}$ & $\begin{array}{l}2.3949 \\
0.0281 \\
0.1677\end{array}$ & $\begin{array}{l}0.0245 \\
0.0297 \\
0.1723\end{array}$ & 2.7050 & 2.4287 \\
\hline $\begin{array}{l}\text { Range } \\
\mathrm{K}-\mathrm{S} \text { test }\end{array}$ & 0.277763 & 0.238348 & 0.239409 & $\begin{array}{l}1.7257 \\
0.468074\end{array}$ & $\begin{array}{l}1.5620 \\
0.301794\end{array}$ \\
\hline
\end{tabular}

G. Magnification $=50 \mathrm{X}$

Normal Lognormal Lognormal Uniform Uniform

\begin{tabular}{|c|c|c|c|c|c|}
\hline $\begin{array}{l}\text { Mean } \\
\text { Variance } \\
\text { Stand. Dev. }\end{array}$ & $\begin{array}{l}3.3053 \\
0.0505 \\
0.2247\end{array}$ & $\begin{array}{l}3.2980 \\
0.0049 \\
0.0698\end{array}$ & $\begin{array}{l}0.0341 \\
0.0052 \\
0.0721\end{array}$ & 3.2250 & 3.3053 \\
\hline $\begin{array}{l}\text { Range } \\
\mathrm{K}-S \text { test }\end{array}$ & 0.136072 & 0.150225 & 0.149767 & $\begin{array}{l}0.9714 \\
0.259069\end{array}$ & $\begin{array}{l}0.7784 \\
0.162243\end{array}$ \\
\hline
\end{tabular}

H. Magnification $=30 \mathrm{X}$

Normal Lognormal Lognormal Uniform Uniform

\begin{tabular}{|c|c|c|c|c|c|}
\hline $\begin{array}{l}\text { Mean } \\
\text { Variance } \\
\text { Stand. Dev. }\end{array}$ & $\begin{array}{l}3.3327 \\
0.0043 \\
0.0656\end{array}$ & $\begin{array}{l}3.3321 \\
0.0004 \\
0.0197\end{array}$ & $\begin{array}{l}0.0345 \\
0.0004 \\
0.0204\end{array}$ & 3.3200 & 3.3327 \\
\hline $\begin{array}{l}\text { Range } \\
\text { K-S test }\end{array}$ & 0.142161 & 0.142538 & 0.142559 & 0.194696 & \\
\hline
\end{tabular}


Figure 1. Statistical Analyses of SEM/EDS Sulfur Data for CO02

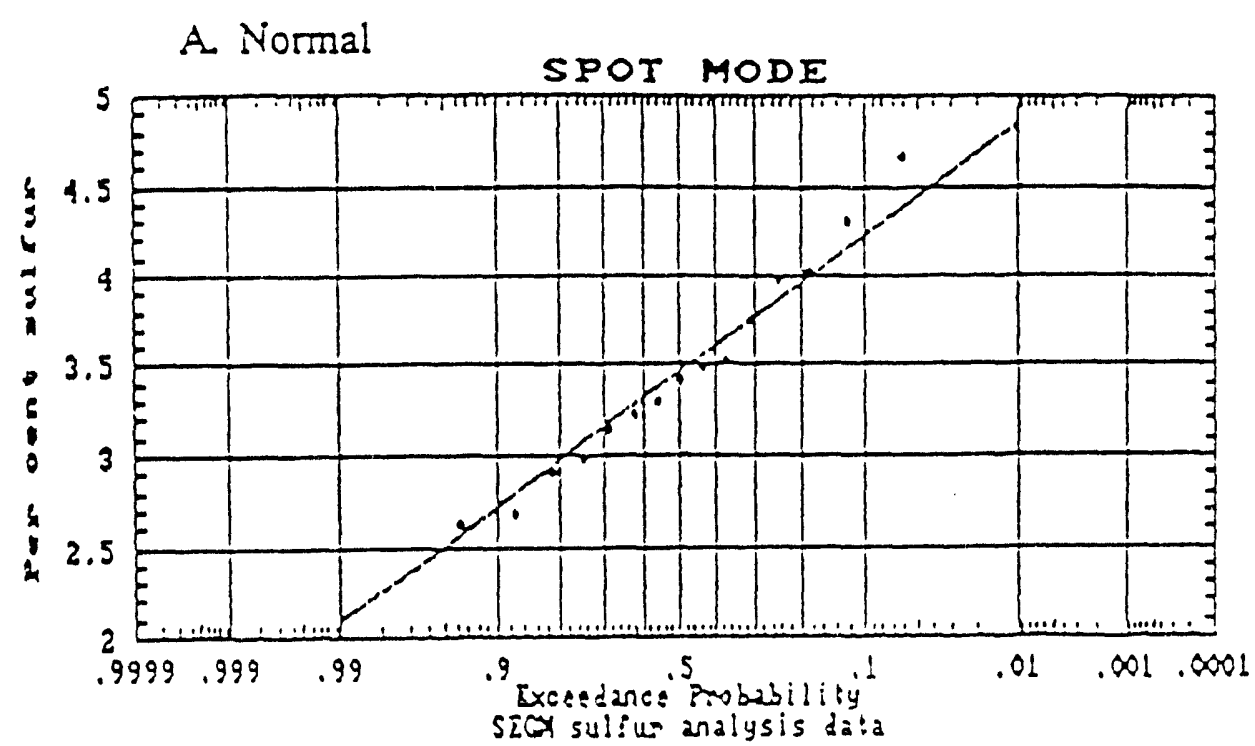

\section{B. Lognormal}

SPOI MODE

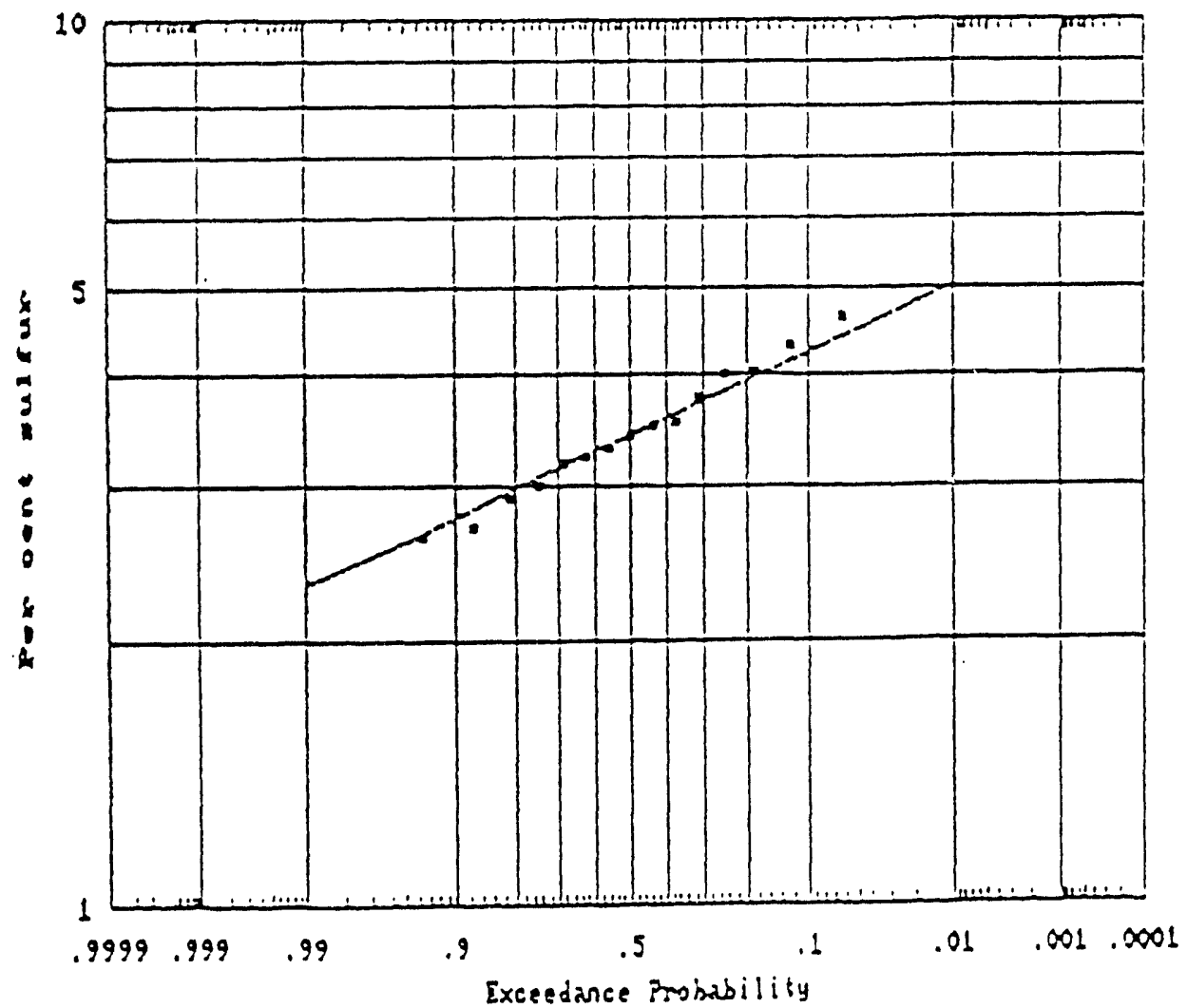

SICX sulfur asalysis data 
Figure 1. Statistical Analyses of SEM/EDS Sulfur Data for C002 (Cont.)

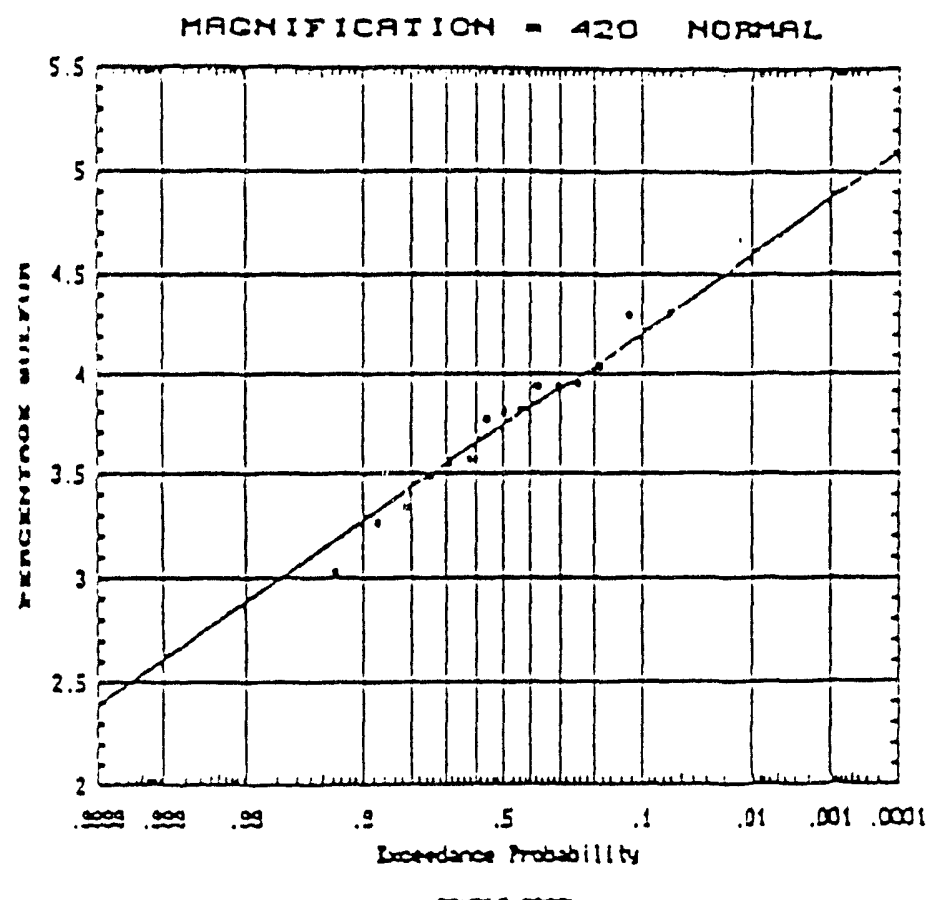

STris 002

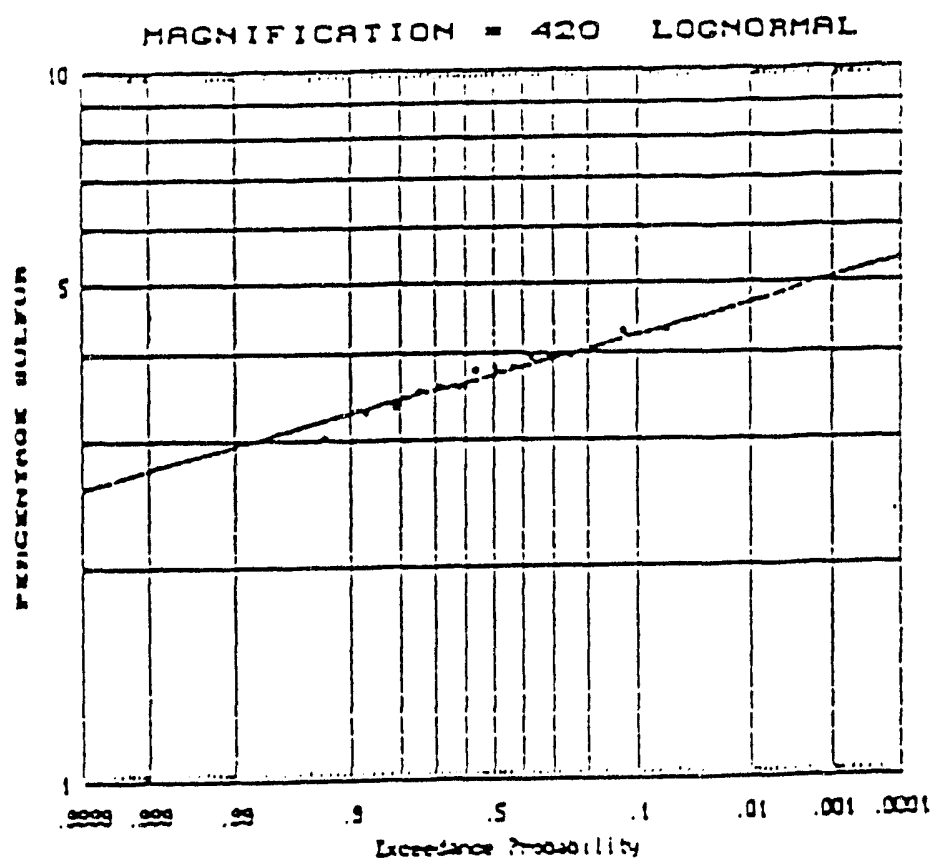

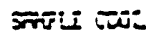


Figure 1. Statistical Analyses of SEM/EDS Sulfur Data for C002 (Cont.)
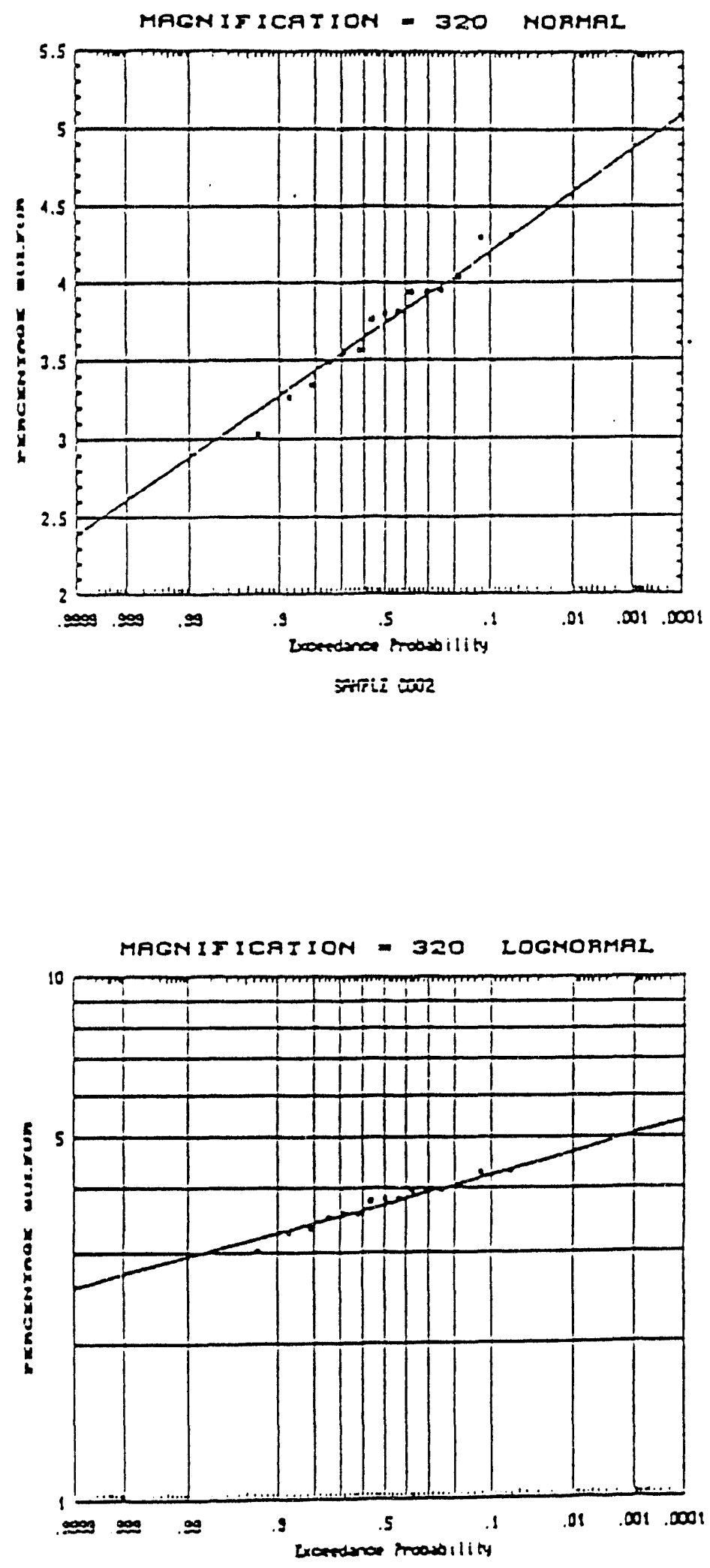

STRLi: 002 
Figure 1. Statistical Analyses of SEM/EDS Sulfur Data for C002 (Cont.)

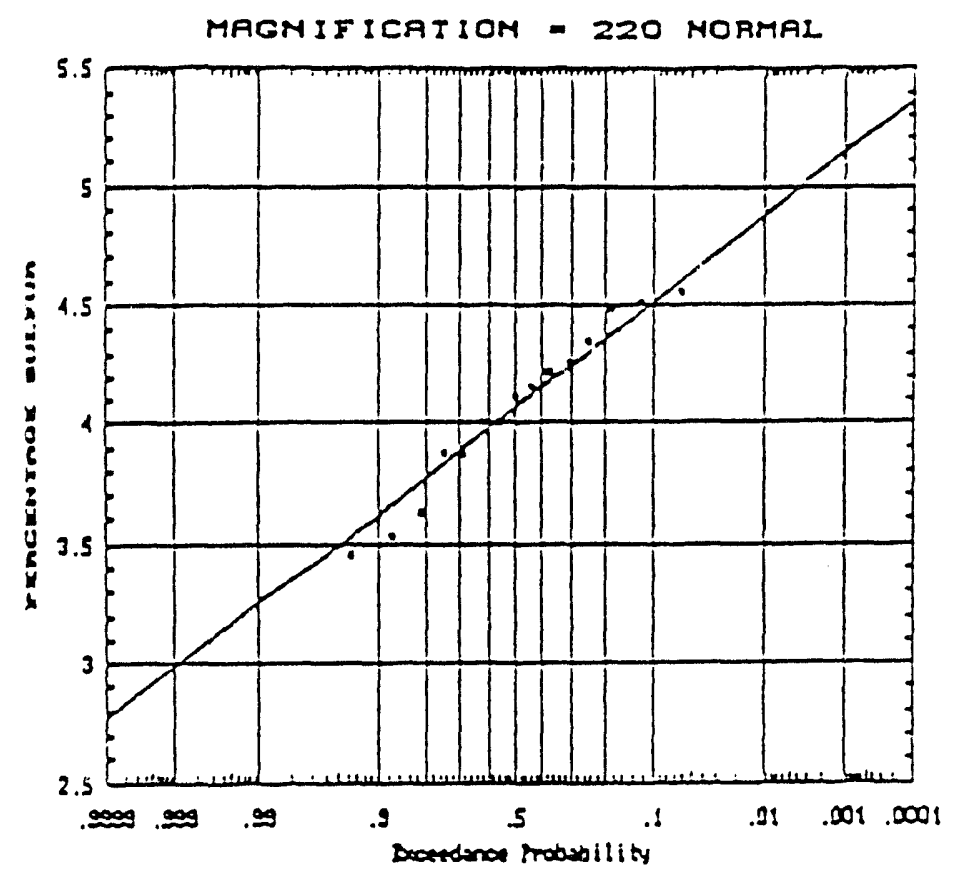

seris the

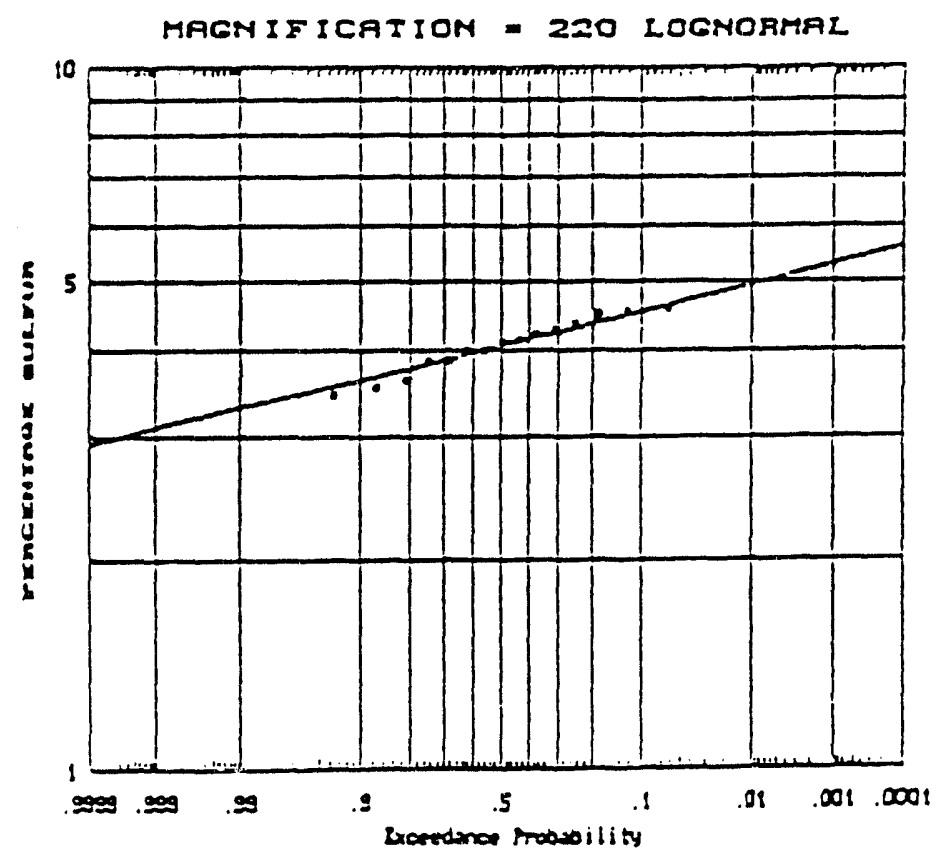

SAli 
Figure 1. Statistical Analyses of SEM/EDS Sulfur Data for CO02 (Cont.)

C. Normal

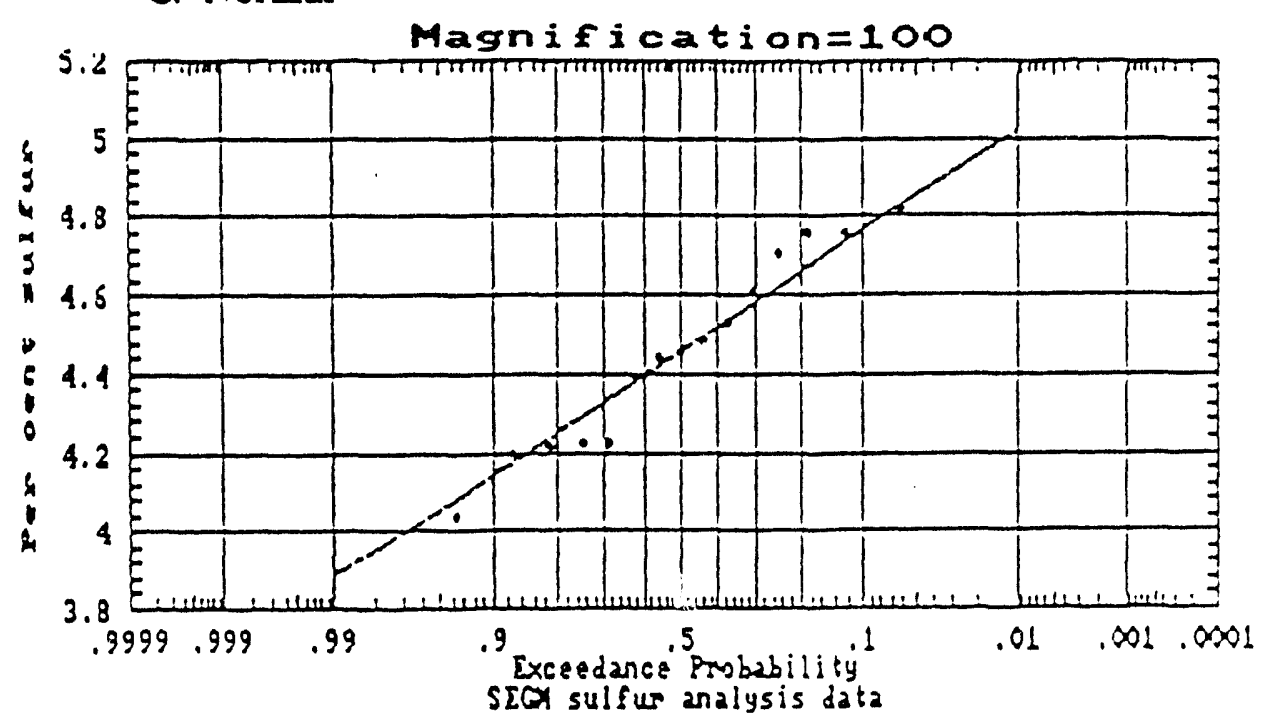

D. Lognormal

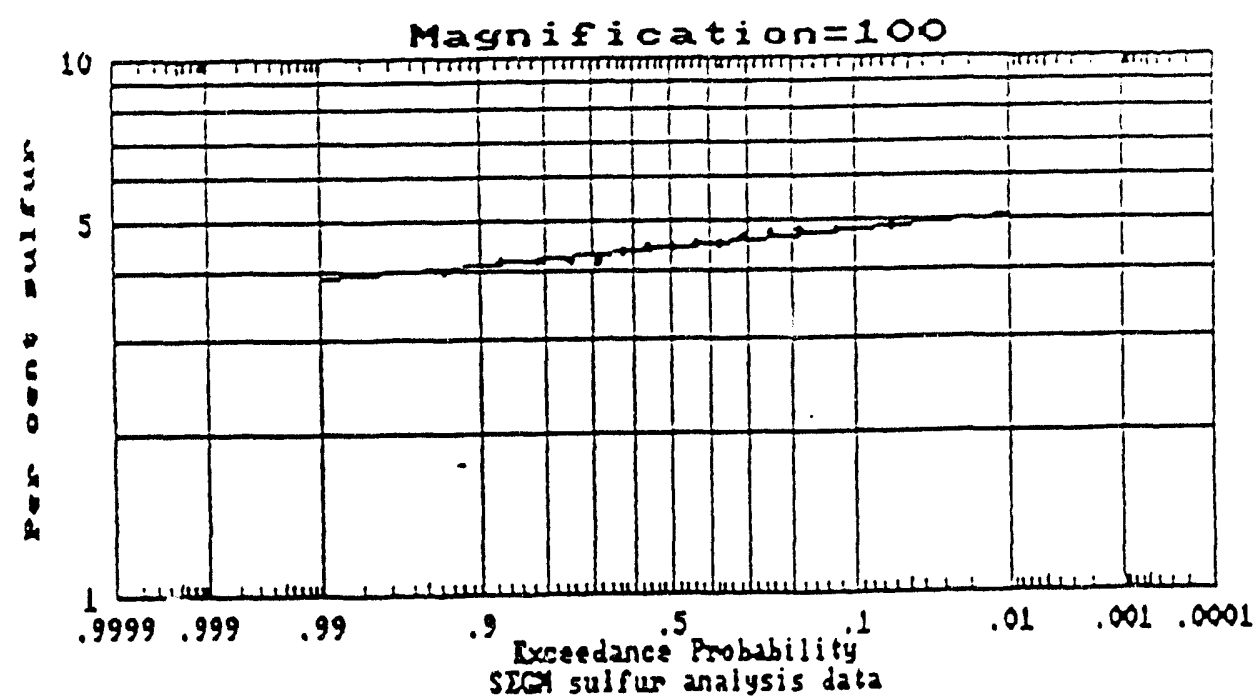


Figure 1. Statistical Analyses of SEM/EDS Sulfur Data for C002 (Cont.)

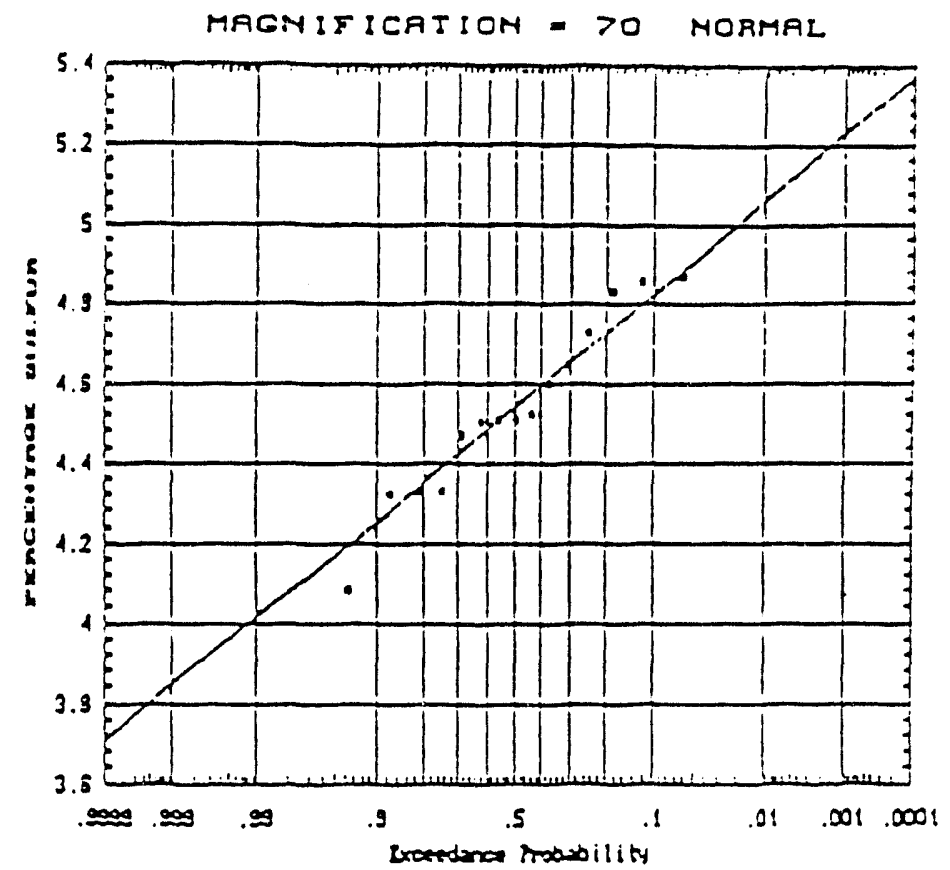

STats

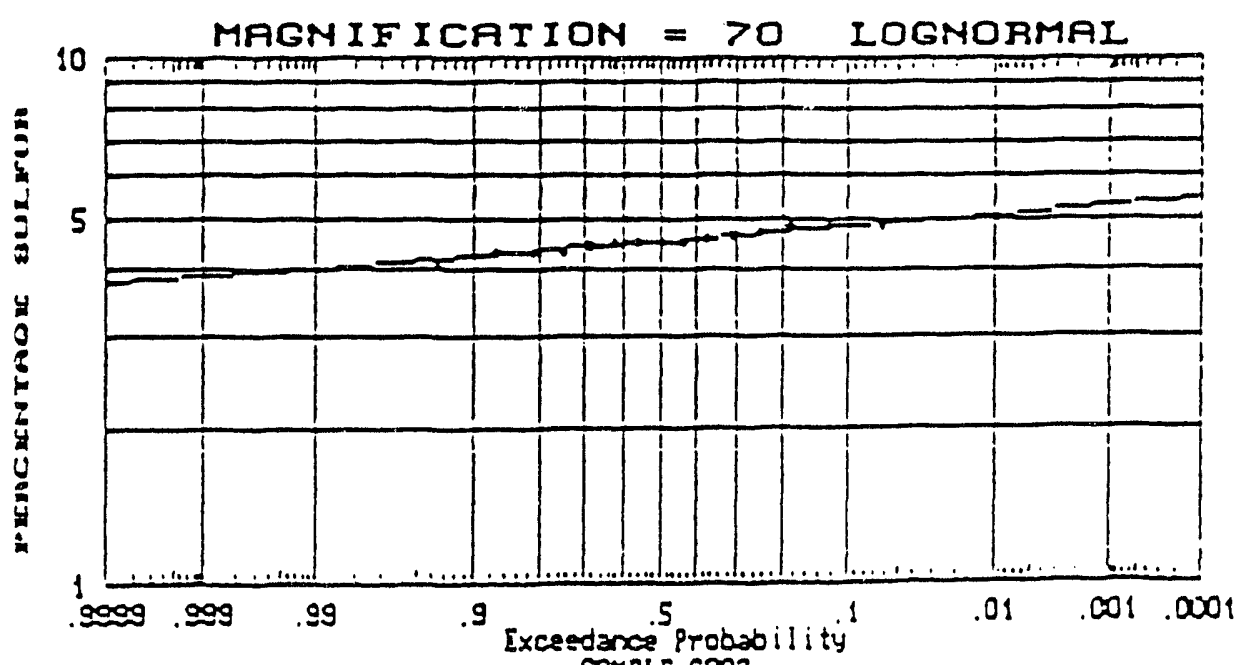

SPMPLI COOZZ 
Figure 1. Statistical Analyses of SEM/EDS Sulfur Data for C002 (Cont.)

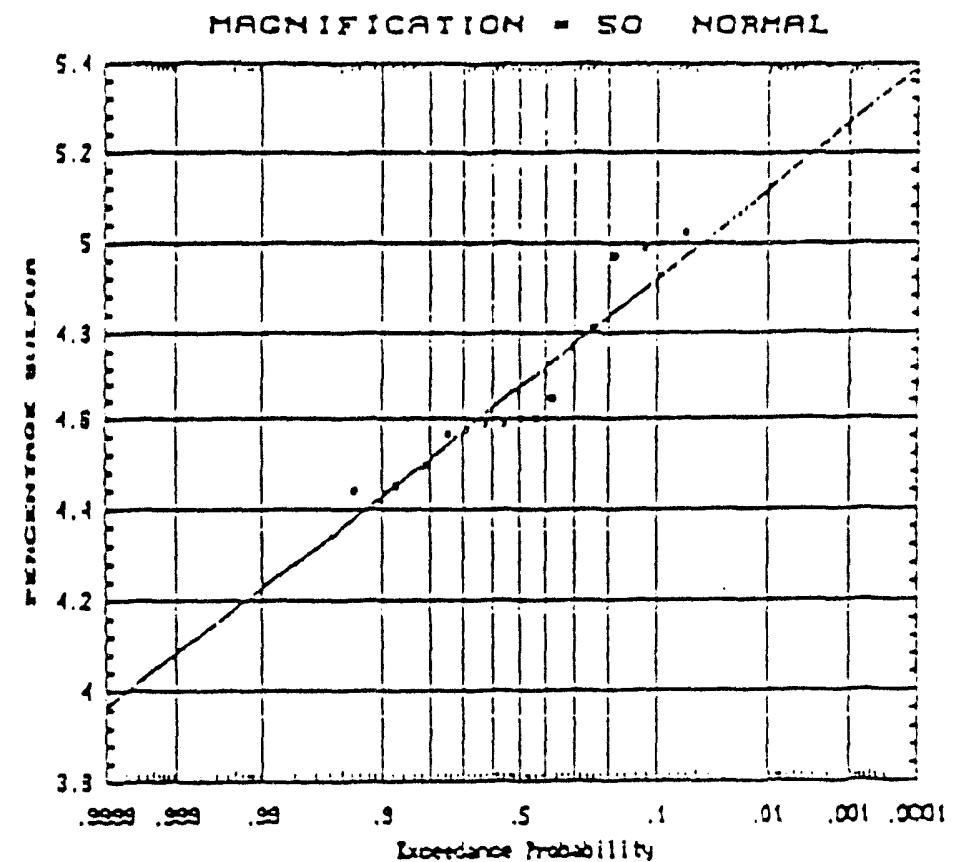

ERst

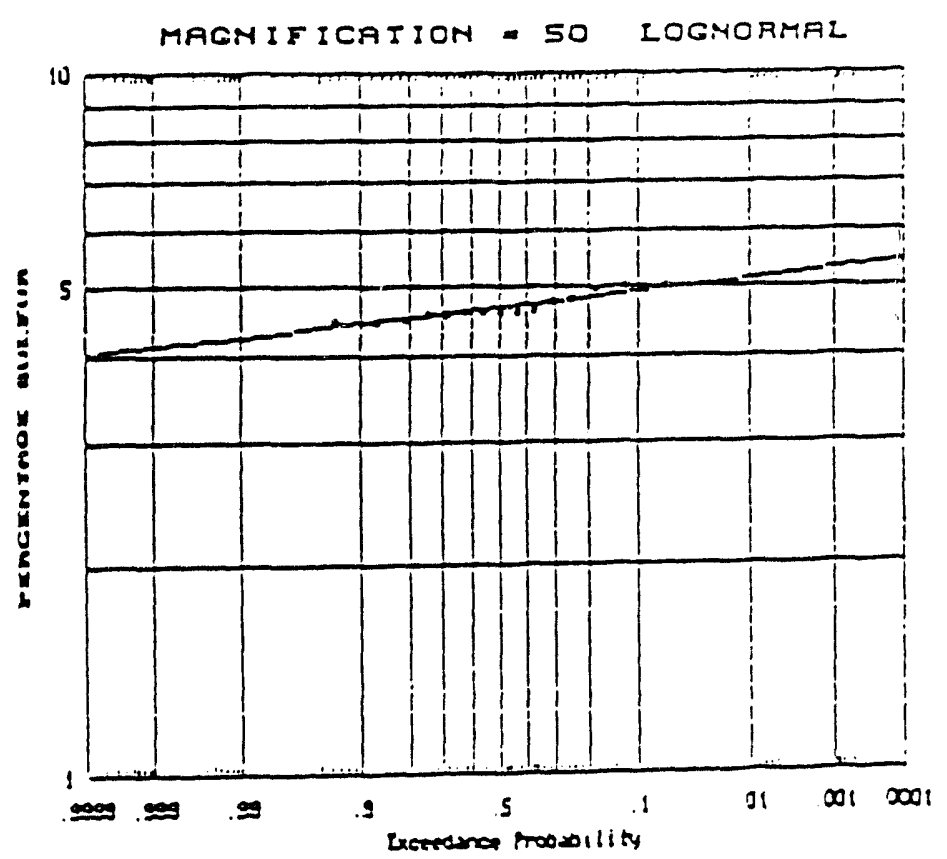

इ단 
Figure 1. Statistical Analyses of SEM/EDS Sulfur Data for C002 (Cont.)

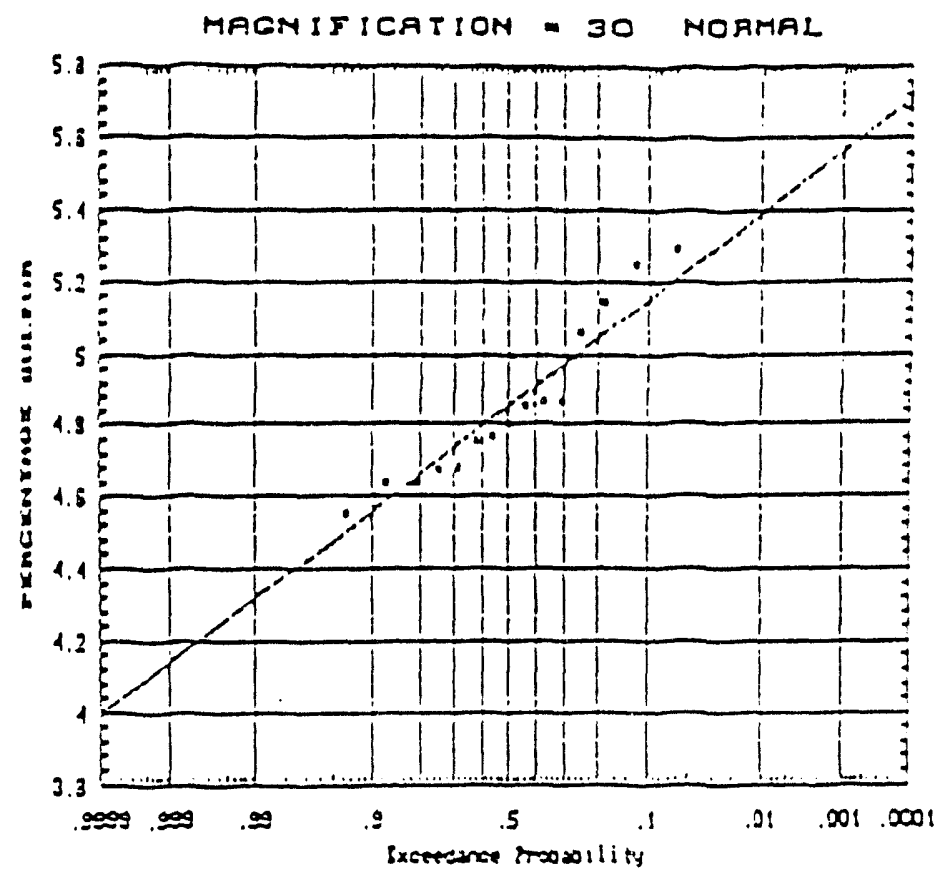

ForRLI TOS

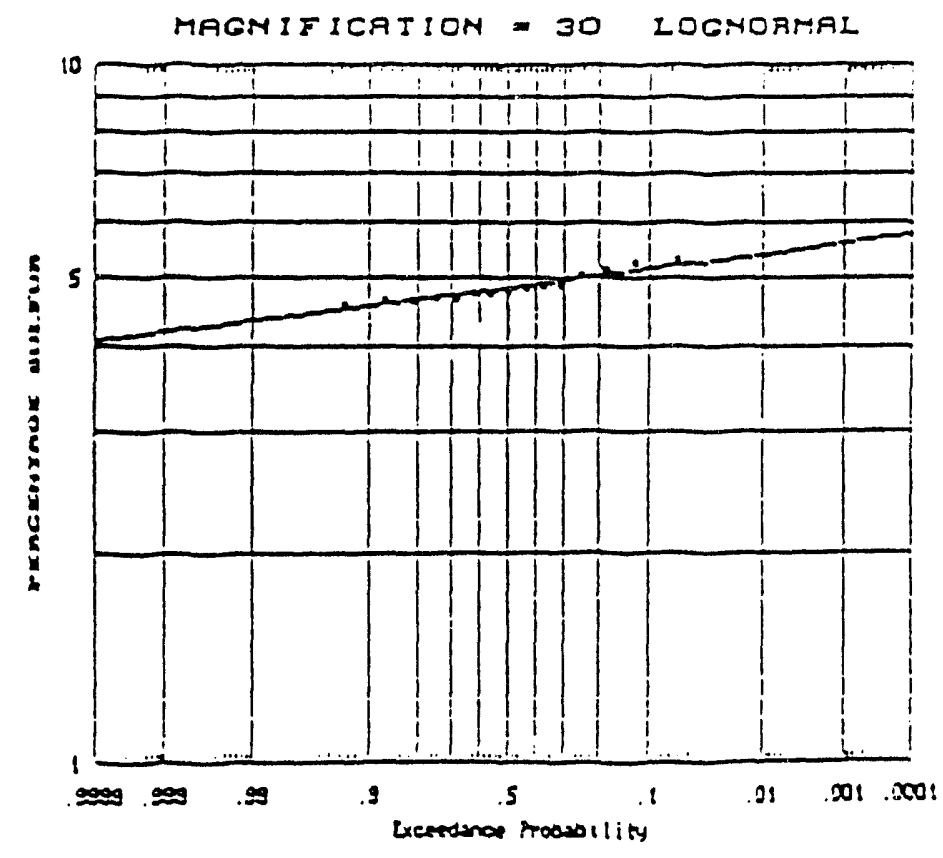

Fin: 
Figure 2. Statistical Aralyses of SEM/EDS Sulfur Data for C002A
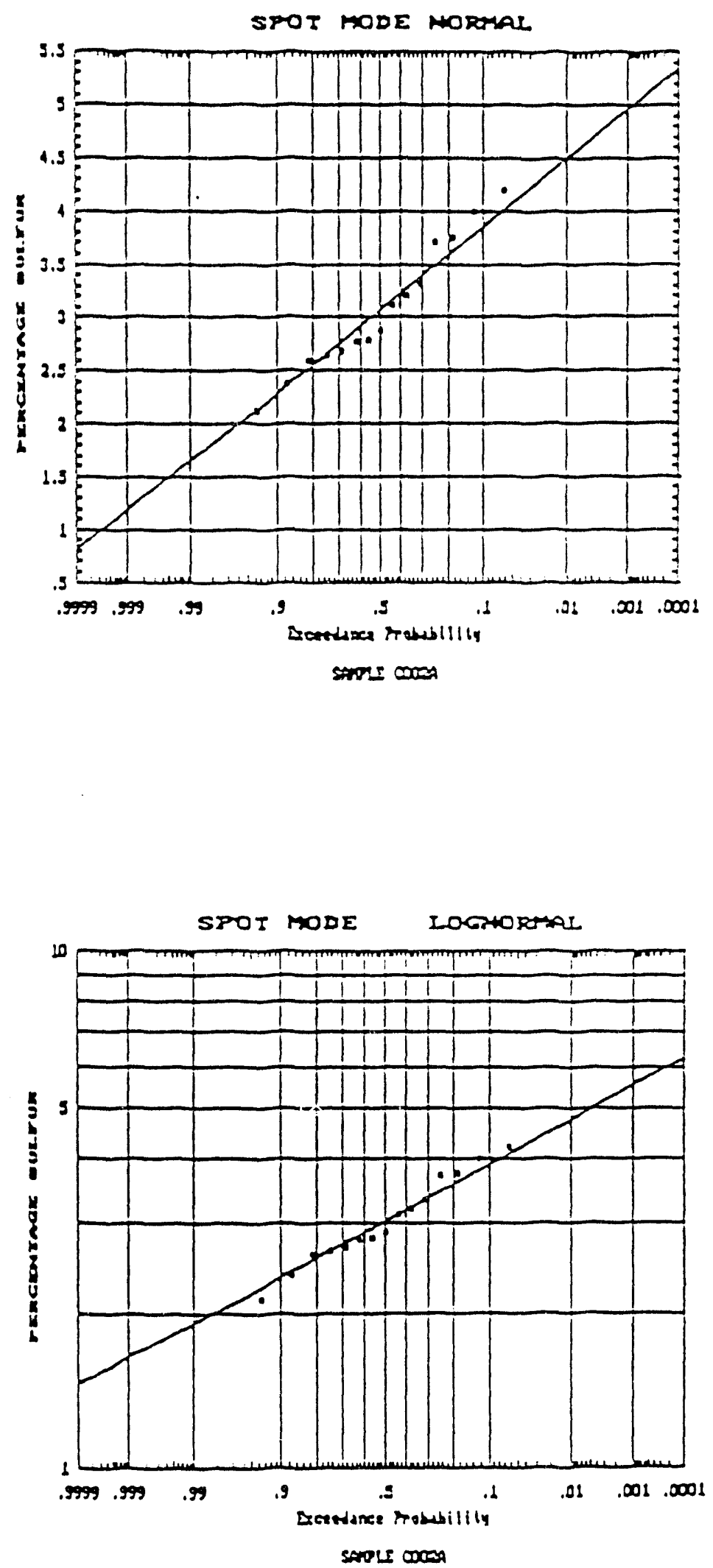
Figure 2. Statistical Analyses of SE.V/EDS Sulfur Data for C002.A (Cont.)
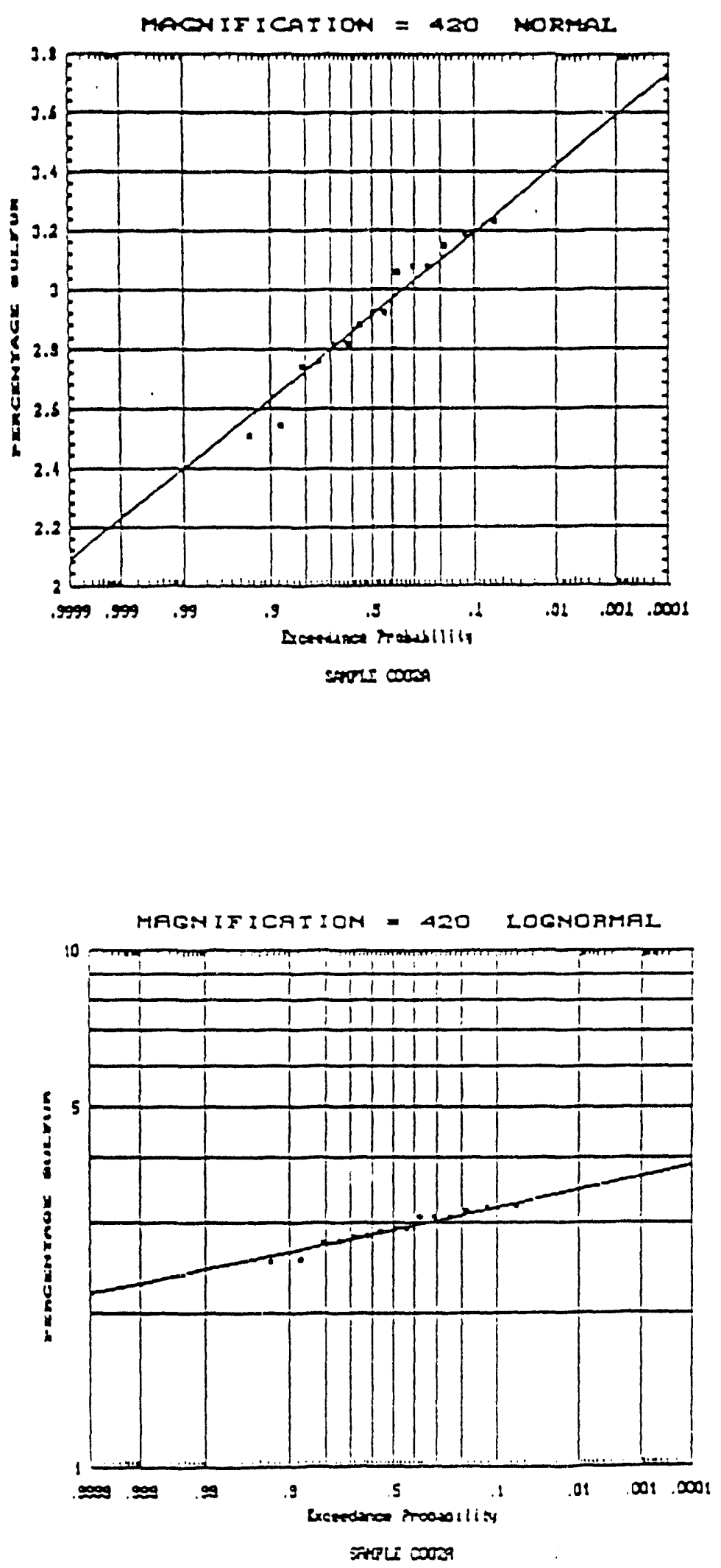
Figure 2. Statistical Aralyses of SEM/EDS Sulfur Data for C002.A (Cont.)

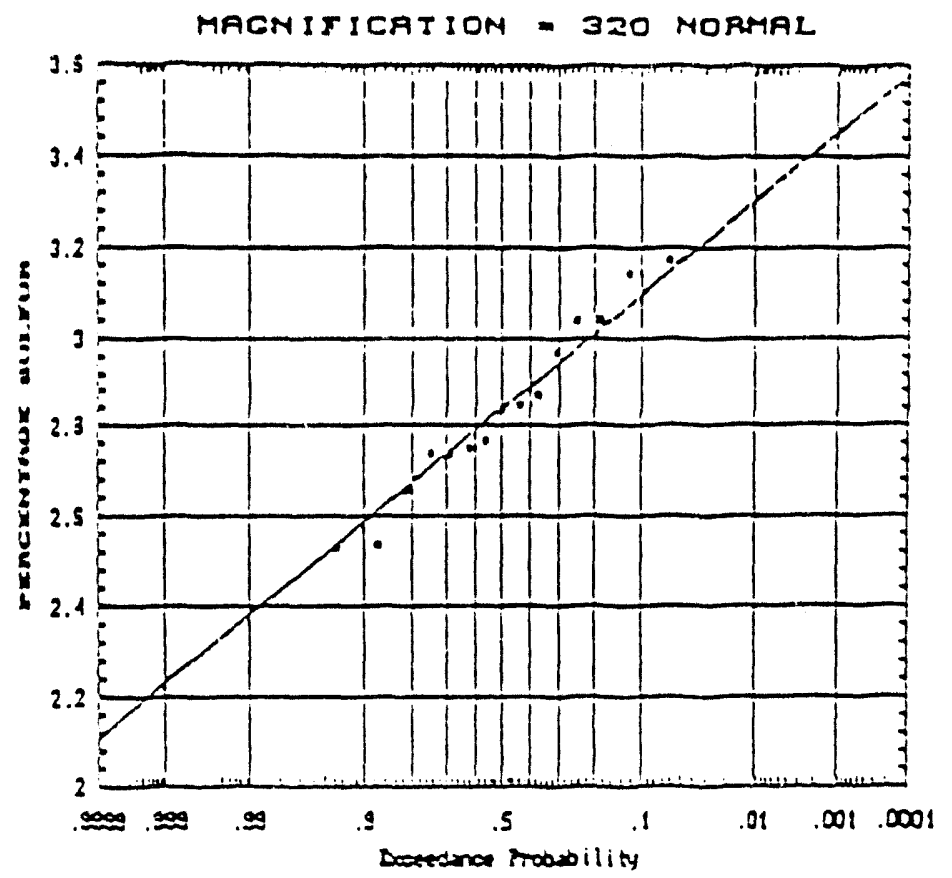

STOLI

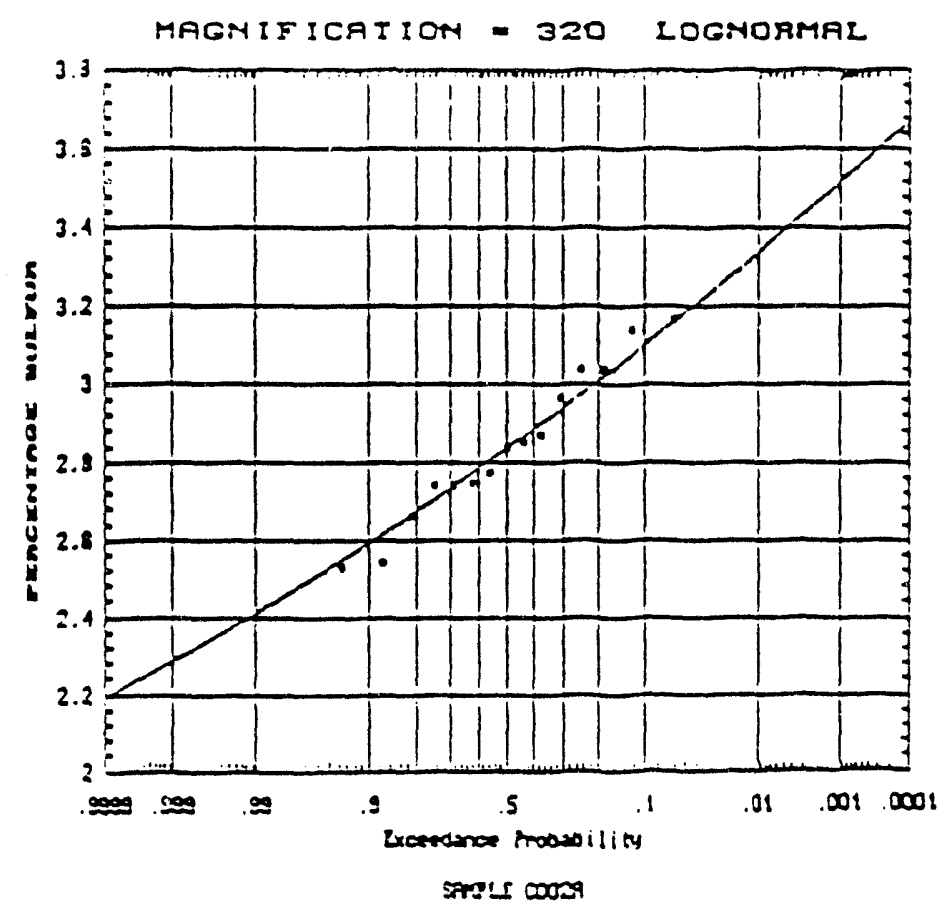



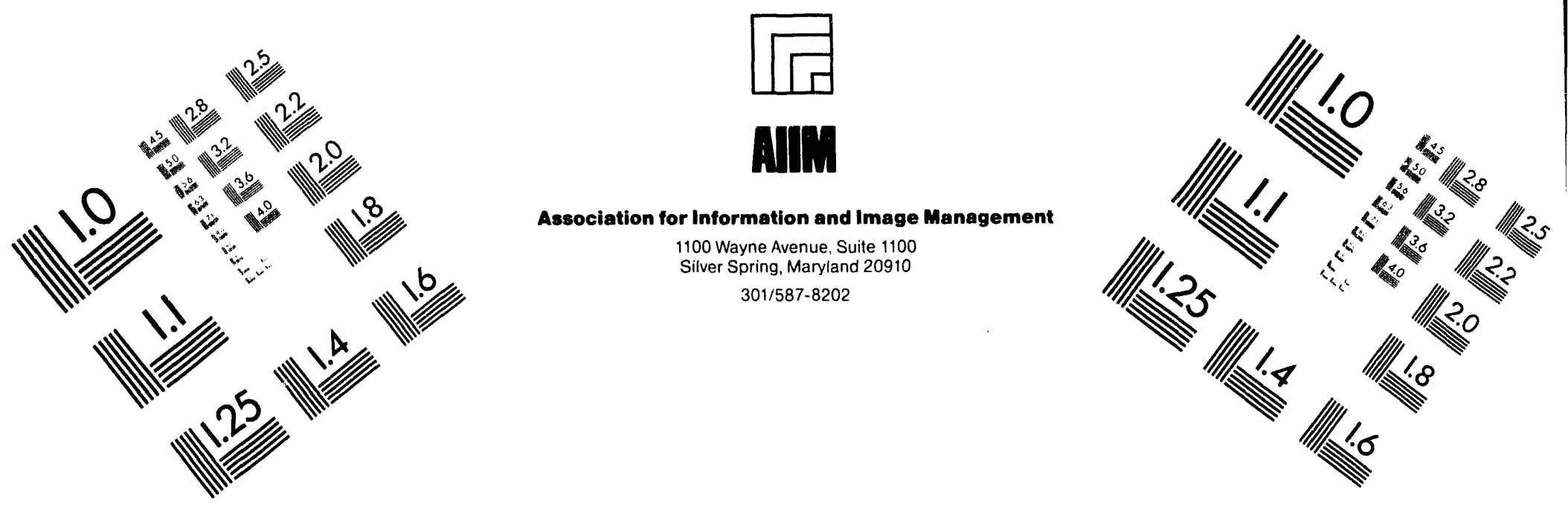

\section{Centimeter}

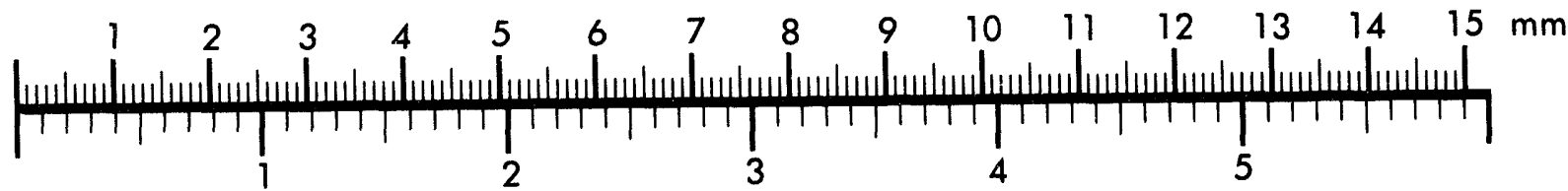

Inches
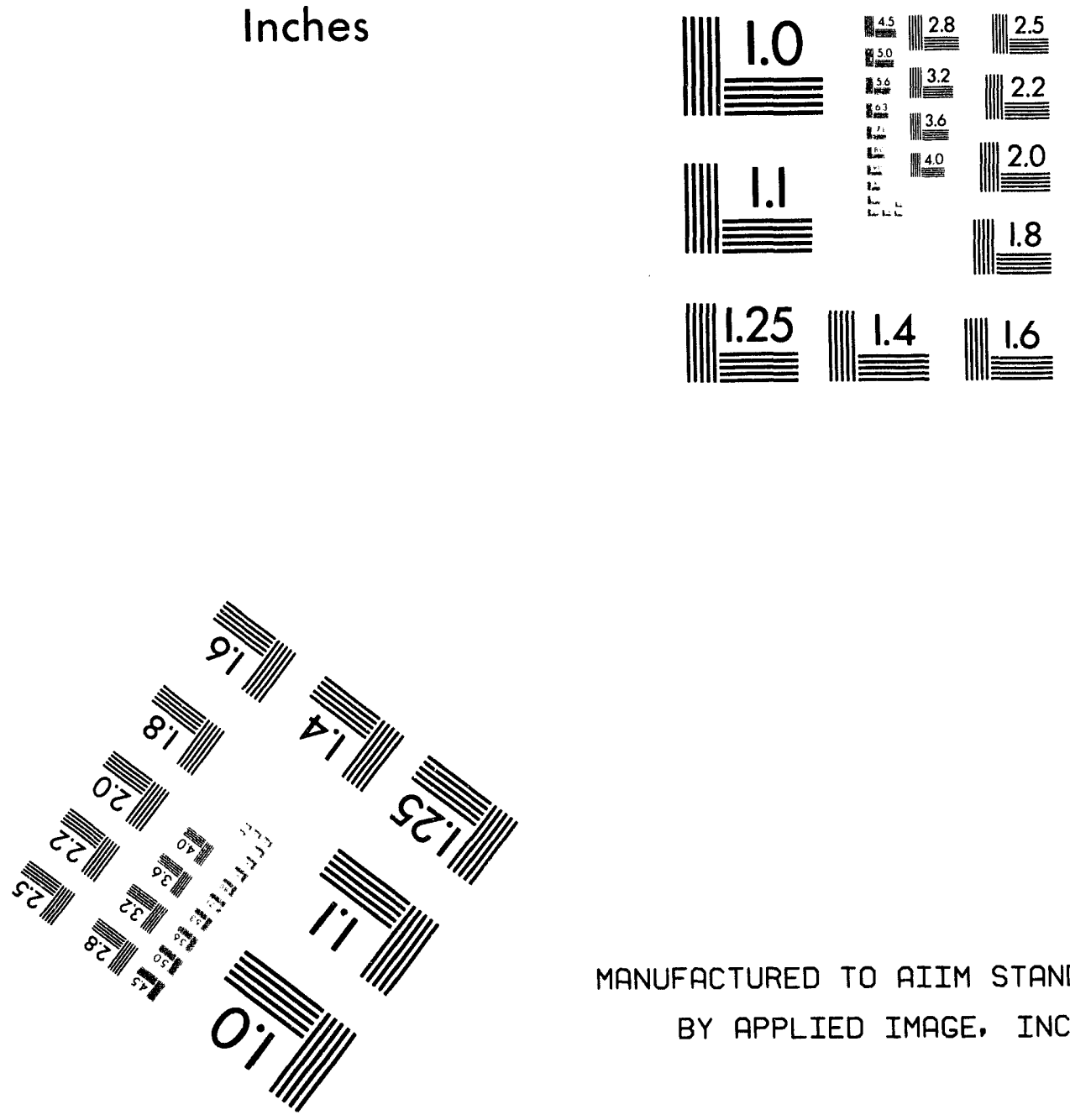

MANUFACTURED TO AIIM STANDARDS

BY APPLIED IMAGE, INC.

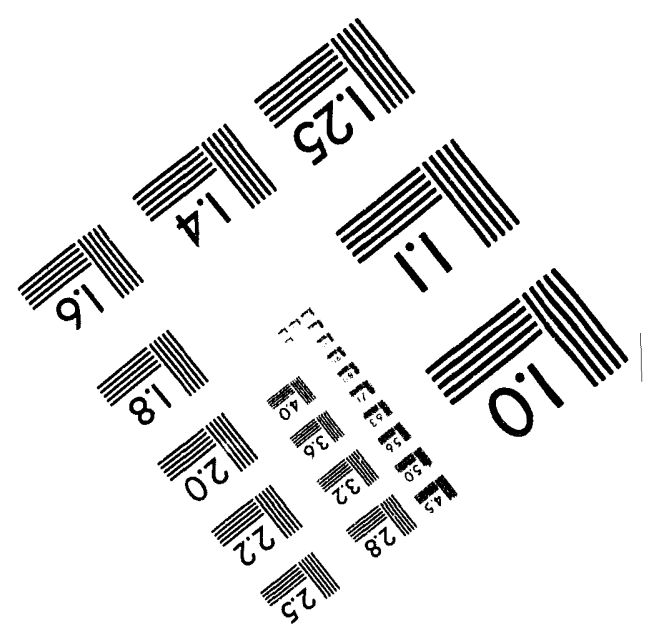



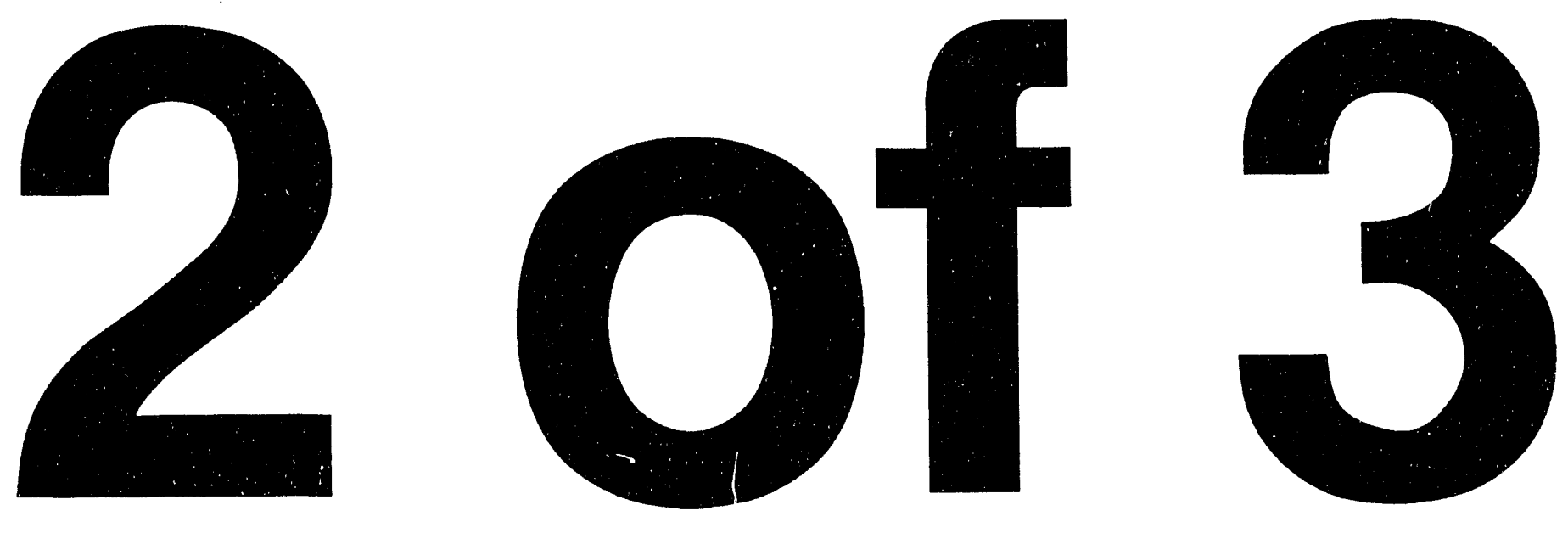
Figure 2. Statistical Analyses of SE:M/EDS Sulfur Data for C002.. (Cont.)

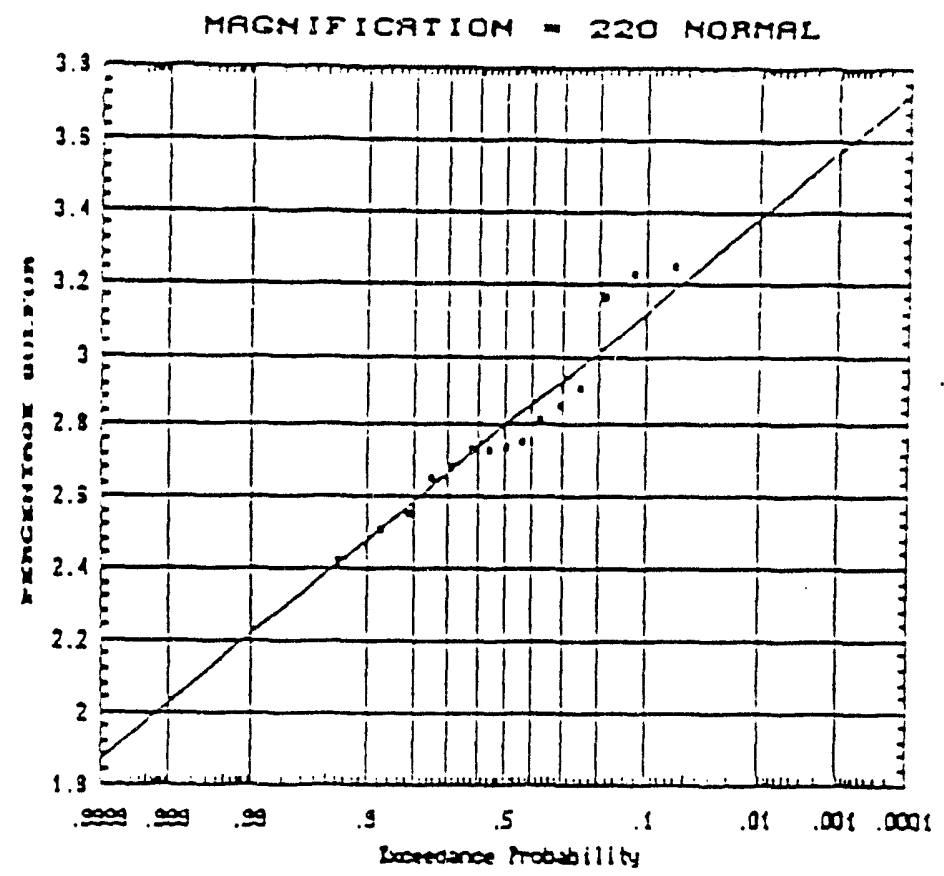

STILI 0029

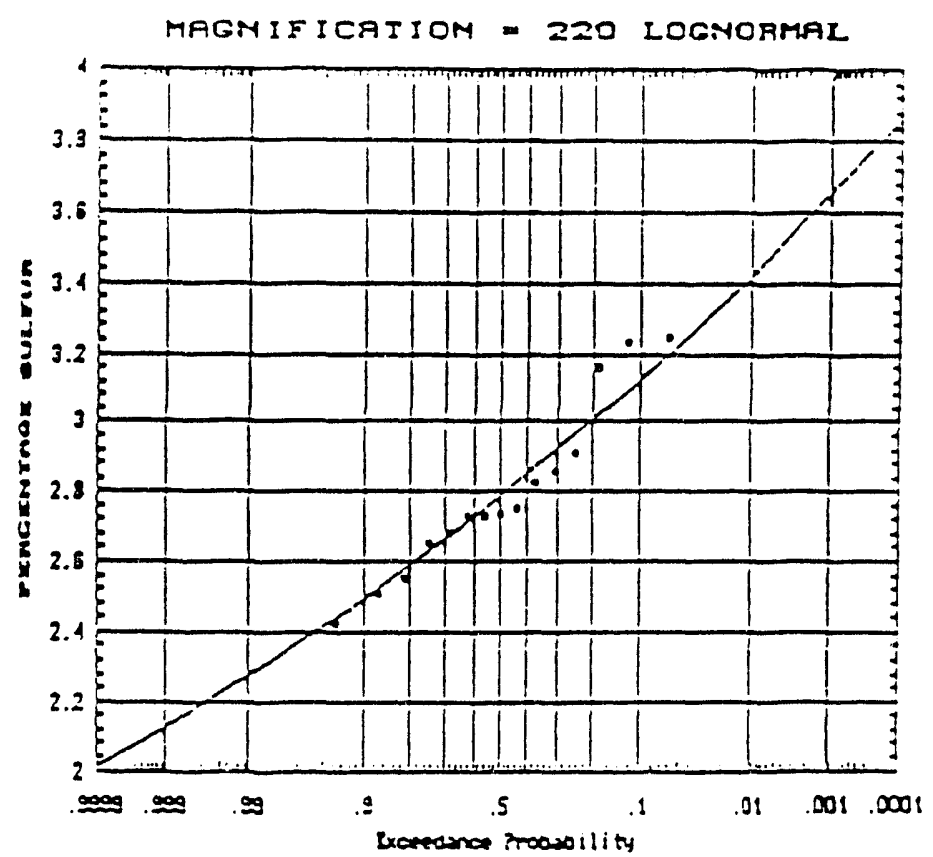

Dhesis 
Figure 2. Statistical Analyses oi SEVM/EDS Sulfur Data ior COC2A (Cont.)

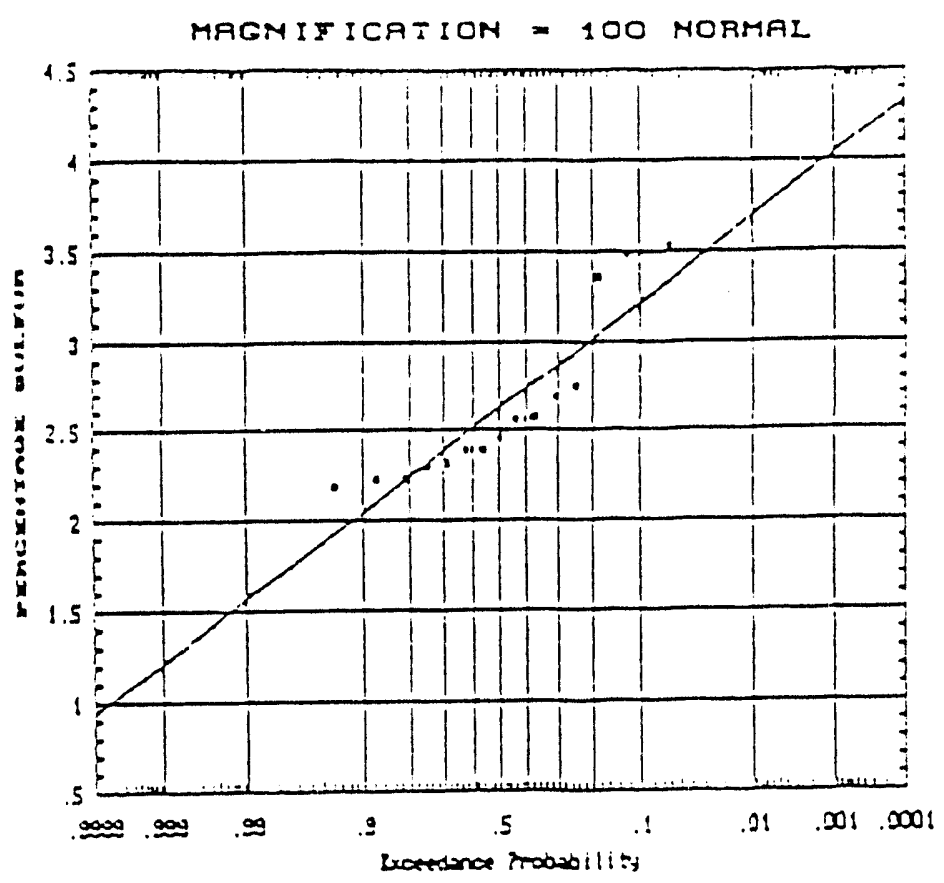

STRL

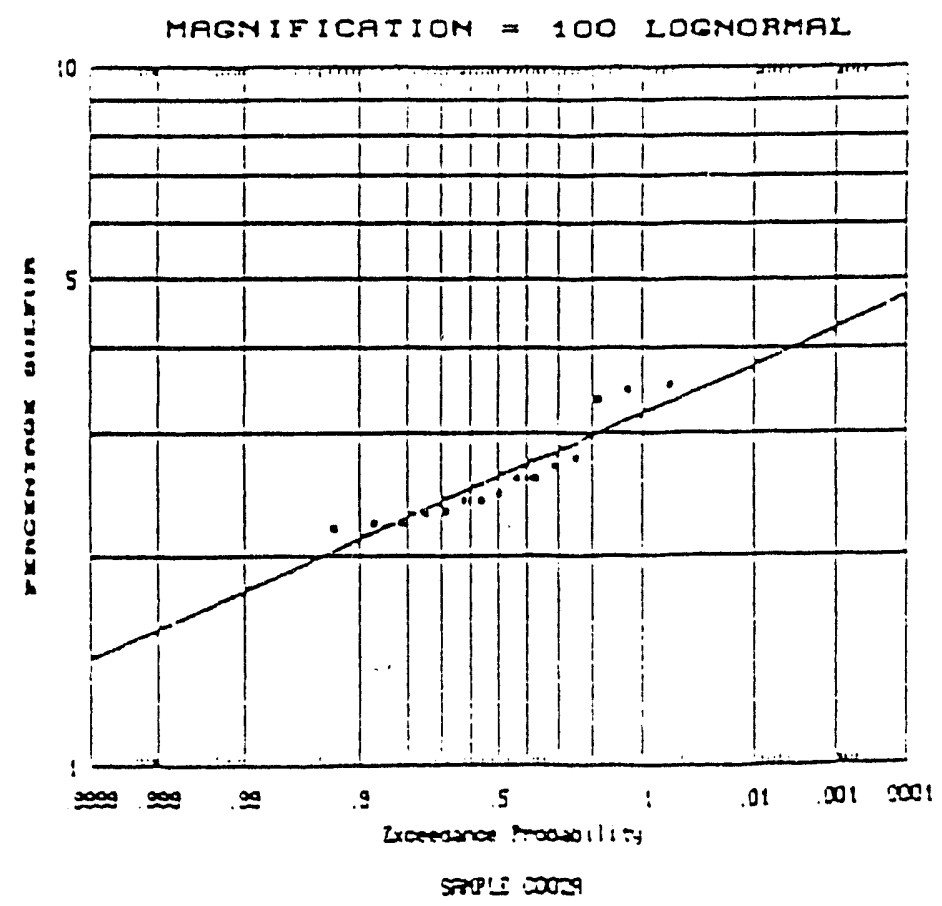


Figure 2. Statistical Analyses oi SE.V/EDS Sulfur Data for C002.\. (Cont.)
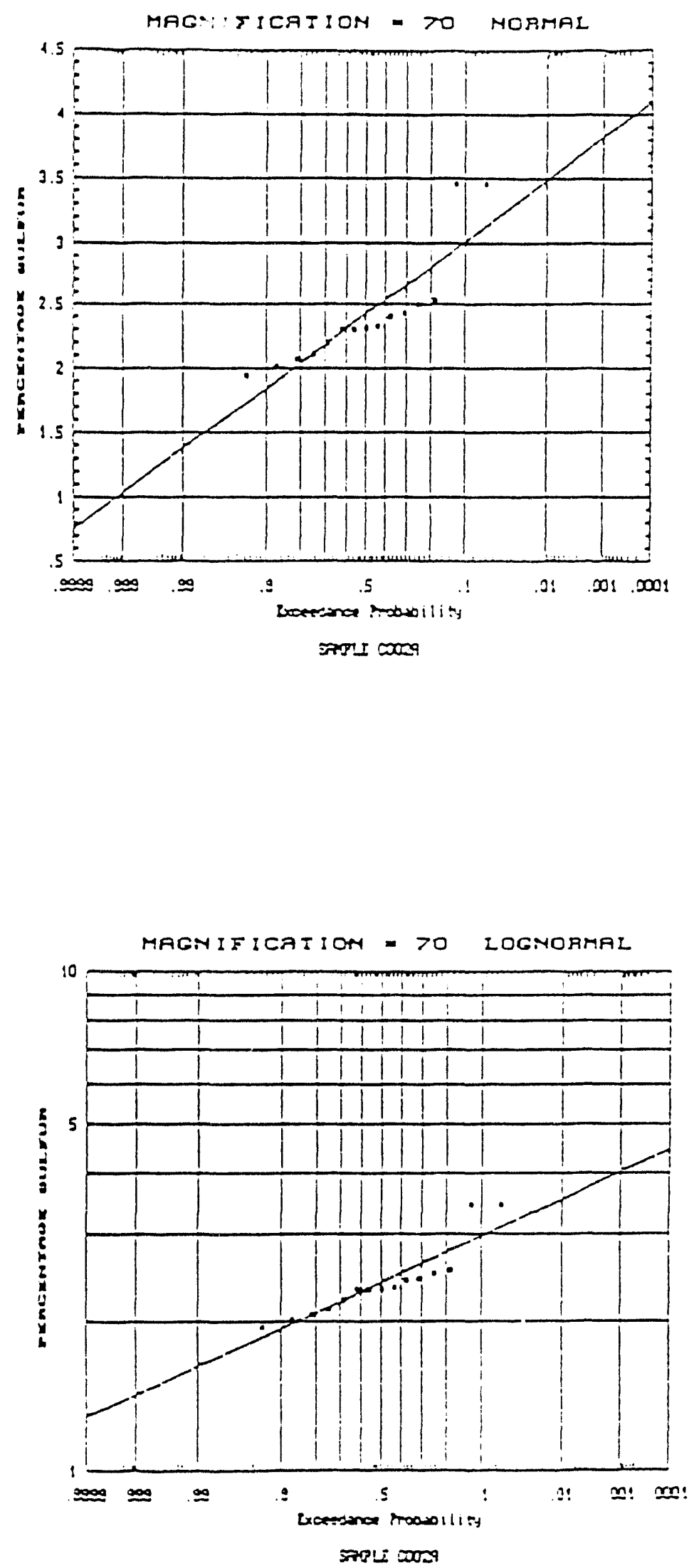
Figure 2. Satistical Analyses of SE:M/EDS Sulfur Data for CO02.A (Cont.)

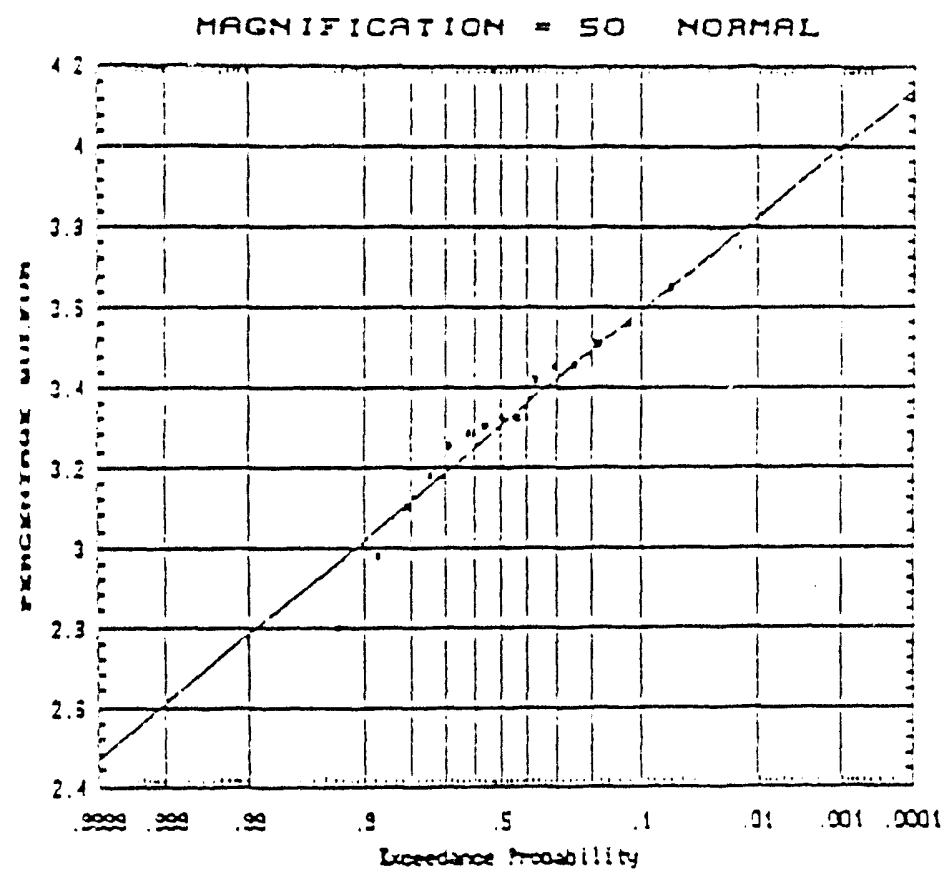

$\operatorname{sen} 15 \cos$

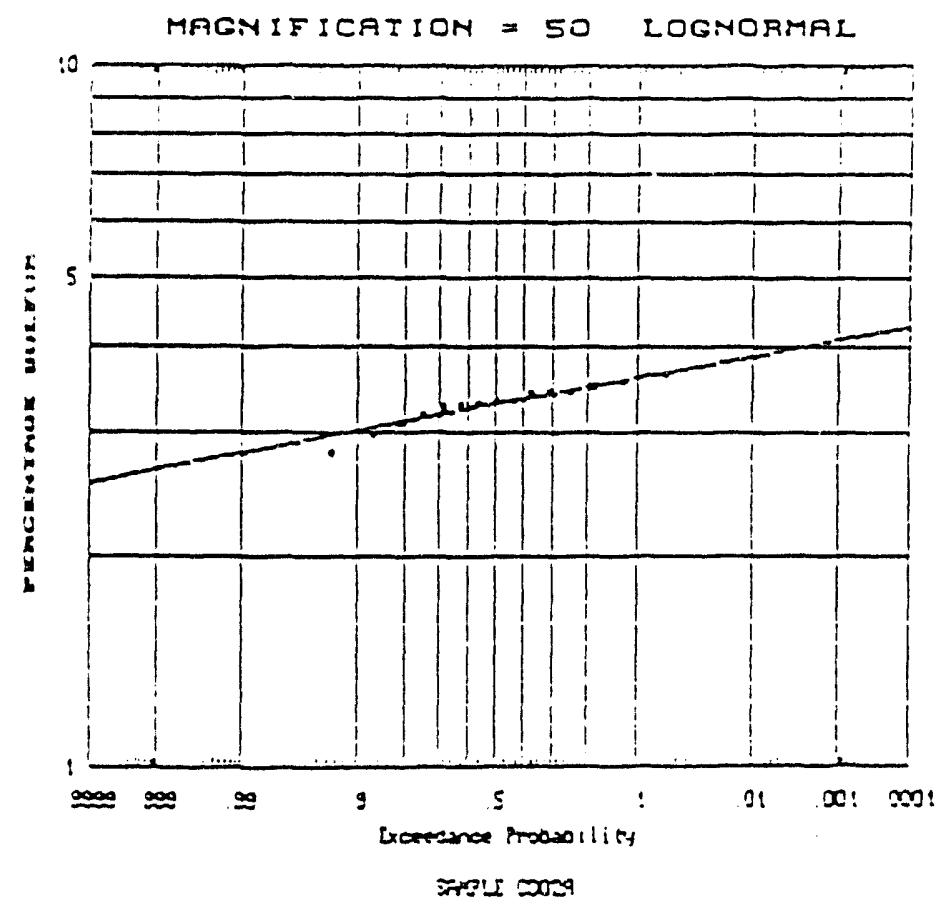


Figure 2. Siatistical Analyses of SE.M/EDS Sulfur Data for CO02.A (Cont.)
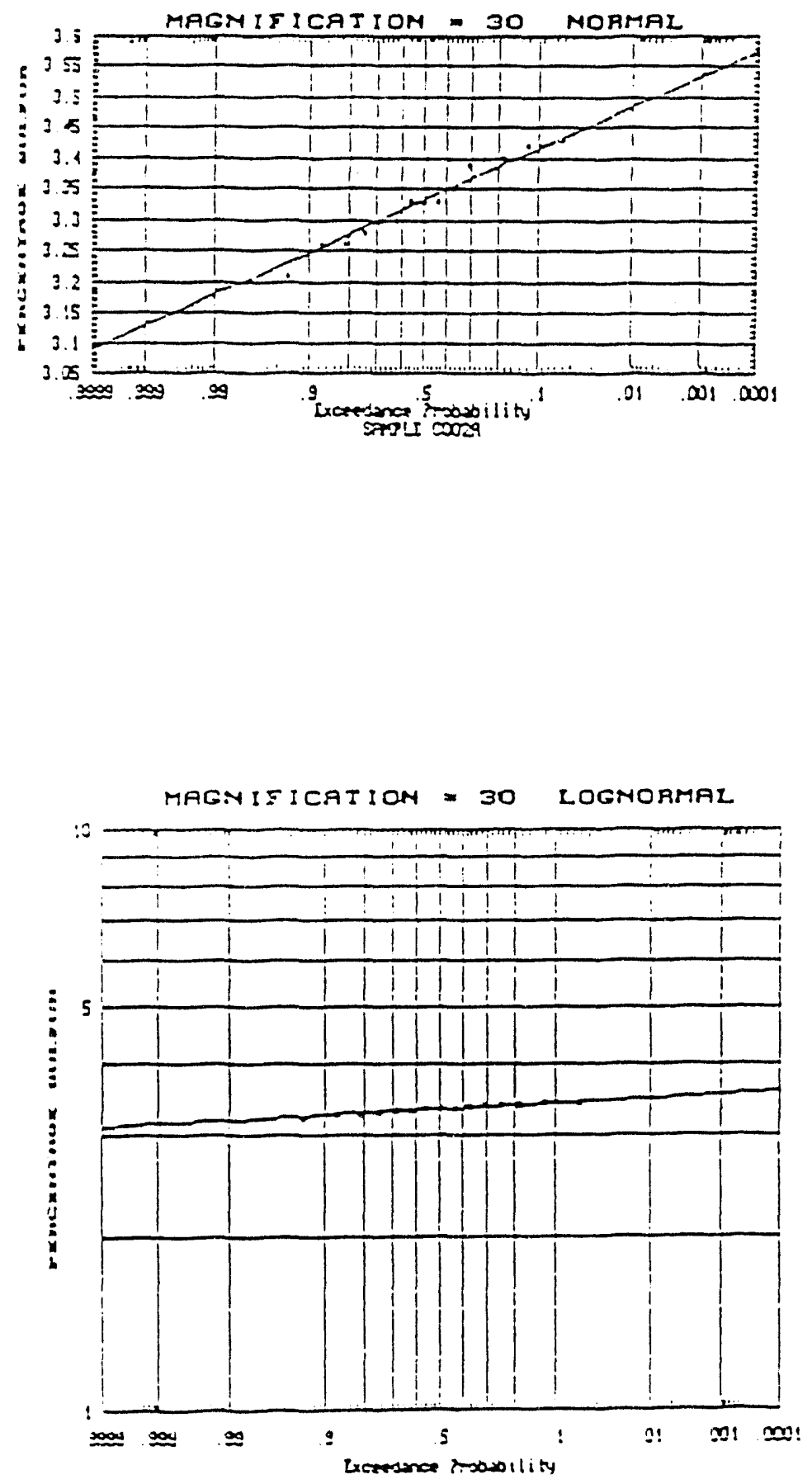

27sti 2000 
Table -. Scudent " $T$ " Tolerance Tesi oi Normal Distributicr:

of SEM/EDS Data icr CCO2

Sample \#

A. Spor Mode

Tolerance $=0.3469$

Normal distribution

Lognormal distribution

Doubiy truncated lognormal distrioution

Uniform distrioution using maximum likelinood

Uniform disirioution using sample data

$\begin{array}{ll}= & 15 \\ = & 15 \\ = & 16 \\ = & 13 \\ = & 12\end{array}$

B. Magnifica: : 0 $=420 \mathrm{X}$

Tolerance $=0.3740$

Normal distizioution

Lognormal distribution

Doubly :runcated lognormal distrioution

Uniform cistribution using maximum like!incoc

Uniform distribution using sample data

$\begin{array}{ll}= & 7 \\ = & 8 \\ = & 3 \\ = & 9 \\ = & 8\end{array}$

C. Magnificat:on $=320 \mathrm{X}$

Tolerance $=0.3890$

Normal distribution

Lognormal distribution

Doubly truncated lognormal distribution

Uniform distribution using maximum like!ïnood

Uniform distribution using sample data

$\begin{array}{ll}= & 7 \\ = & 8 \\ = & 8 \\ = & 9 \\ = & 8\end{array}$

D. Magnification $=220 \mathrm{X}$

Tolerance $=0.4067$

Normal distribution

Lognormal distribution

Doubly truncated lognormal disiribution

Uniform distribution using maximum likeiinocd

Uniform distribution using sample data

$=\quad 6$
$=\quad 7$
$=\quad 3$
$=\quad 7$ 
Table 4. Sudent "T' Tolerance Test of Vormal Distribution

Of SE.M/EDS Data ior COOZ (Cont.)

Sample :

E. Magnifica:ion $=100 \mathrm{X}$

Tolerance $=0.4457$

Normal distribution

Lognormal distribution

Doubly truncated lognormal distrioution

Uniform distribution using maximum likelïnood

Uniform distribution using sample data

$\begin{array}{ll}= & 5 \\ = & 5 \\ = & 5 \\ = & 6 \\ = & 6\end{array}$

F. $\quad$ Magnification $=70 \mathrm{X}$

Tolerance $=0.4540$

Normal disirioution

Lognormal distrioution

Douoly :runcated lognormal distribution

Uniform disiribution using maximum likelinood

Uniform distribution using sample data

$\begin{array}{ll}= & 4 \\ = & 4 \\ = & 5 \\ = & 6 \\ = & 5\end{array}$

G. $\quad$ Magnification $=50 \mathrm{X}$

Tolerance $=0.4680$

Normal distribution

Lognormal distribution

Doubly truncated lognormal distribution

Uniform distribution using maximum lixelinood

Uniform distribution using sample data

$\begin{array}{ll}= & 4 \\ = & 4 \\ = & 4 \\ = & 5 \\ = & 5\end{array}$

H. $\quad$ Magnification $=30 \mathrm{X}$

Tolerance $=0.4861$

Normal distribution

Lognormal distribution

Doubly unncated lognormal distrioution

Uniform distrioution using maximum likelïncod

Uniform disirioution using sample data

$\begin{array}{ll}= & 4 \\ = & 4 \\ = & 4 \\ = & 5 \\ = & 5\end{array}$ 
Table 5. Student " $T$ ' Tolerance Tesi of Viormal Distrioution

of SE.M/EDS Data for CCOz.A

Sample $\ddot{*}$

A. Spor Mode

Tolerance $=0.3076$

Normal distrioution

Lognormal distribution

Doubiy truncated lognormal distribution

Uniform distribution using maximum like!inood

Uniform distribution using sample data

$\begin{array}{ll}= & 19 \\ = & 20 \\ = & 21 \\ = & 13 \\ = & 13\end{array}$

B. Magnification $=420 \mathrm{X}$

Tolerance $=0.2912$

Normal distrioution

Lognormal disiribution

Doubly truncated lognormal cistrioution

Uniform distrioution using maximum like!incod

Uniform disiribution using sampie data

$\begin{array}{ll}= & 6 \\ = & 6 \\ = & 6 \\ = & 7 \\ = & 7\end{array}$

C. Magnification $=320 \mathrm{X}$

Tolerance $=0.2843$

Normal distribution

Lognormal distribution

Doubly truncated lognormal distribution

Uniform distribution using maximum likelihood

Uniform distribution using sample data

$\begin{array}{ll}= & 5 \\ = & 6 \\ = & 6 \\ = & 7 \\ = & 6\end{array}$

D. Magnification $=220 \mathrm{X}$

Tolerance $=0.2799$

Normal distribution

Lognormal distribution

Doubly truncated lognormal distrioution

Uniform distrioution using maximum likelïncc

Uniform distribution using sample data

$=7$
$=\quad 7$
$=\quad 8$
$=\quad 8$ 
Table 5. Student "T' Tolerance Tesi of Normal Distrioution

of SE.W/EDS Da:a for CO02.A (Cont.)

Sample \#

E. Magnification $=100 \mathrm{X}$

Tolerance $=0.2630$

Normal disiribution

Lognormal distribution

Doubly truncated lognormal distribution

Uniform distribution using maximum likelihood

Uniform disiribution using sample data

$\begin{array}{ll}= & 15 \\ = & 15 \\ = & 15 \\ = & 12 \\ = & 12\end{array}$

F. $\quad$ Magnification $=70 \mathrm{X}$

Toierance $=0.2428$

Normal distrioution

Lognormal distribution

Doubiy inncated lognormal distribution

Uniform distribution using maximum likelinood

Uniform distribution using sample data

G. Magnification $=50 \mathrm{X}$

Tolerance $=0.3305$

Normal distribution

Lognormal distribution

Doubly truncated lognormal distribution

Uniform distribution using maximum likelihood

Uniform distribution using sample data

$$
\begin{aligned}
& =5 \\
& =6 \\
& =6 \\
& =6 \\
& =6
\end{aligned}
$$

H. Magnification $=30 \mathrm{X}$

Tolerance $=0.3330$

Normal distribution

Lognormal distribution

Doubly truncated lognormal distrioution

Uniform distribution using maximum like!inood

Uniform disiribution using sample data

$\begin{array}{ll}= & 3 \\ = & 3 \\ = & 3 \\ = & 4 \\ = & 4\end{array}$ 
Biodesulfurization Techniques: Application of selected Microorganisms for Organic sulfur Removal from Coals

\author{
Louisiana Tech University \\ Contract NO. DE-AC22-88PC88854 \\ Quarterly Report \\ Report No. PETC-9-90 \\ Report Period: June 21, 1990 \\ Sept. 20,1990
}

\title{
INTRODUCTION
}

Depyritization and general screening procedures for potential microbial organic sulfur utilizers have continued throughout the past quarter. Sample analyses and associated reporting have been delayed somewhat as a result of new student technicians replacing the former work group and the loss of the departmental secretary.

The ongoing work which has been conducted during the past quarter is summarized in the following discussion.

\section{TASK OVERVIEW}

Task 2 - Coal procurement and Preparation.

\subsection{Grinding, Sieving, and storage.}

The twenty pound shipment of IBC-101 (to be designated Lot 1007) has been received, riffled and placed storage. The inert gas used as a blanket for storage has been changed from nitrogen to argon as per the discussion at the 6th Annual coal contractors Conference. This coal is being ground to $200 \mathrm{x} 0$ mesh for use in the future as needed.

2.2 Microbial Removal of Pyrite and sulfate.

Task complete.

In order to compare the effects of Loposo medium (the supporting medium for Thiobacillus so. for depyritization) on the degree of depyritization in batch culture, a run was conducted in three flasks, each with varying initial conditions. 
Table 1 shows the initial conditions set for each flask. The operating conditions for each batch culture were identical with 50 grams of $200 \times 0$ coal carefully measured into each flask.

\section{Table 1. Batch Reactor Initial Conditions}

Description

Medium

Temp. ${ }^{\circ} \mathrm{C}$

$\mathrm{Rx} \cdot \mathrm{pH}$

$\%$ coal slurry $\underline{1}$

water only

25

2.5

5 $\underline{2}$

3

LOPOSO Only

25

2.5

5
2.5

LoPoso - organisms

25

5

As presented, $1000 \mathrm{ml}$ of water and $50 \mathrm{~g}$ of $200 \mathrm{X} 0$ mesh coal (ra'n coal $\# 1005$ ) were added to Flask 1 . Flask 2 received Loposo medium (composition presented in Table 2) and coal. The thira flask, in addition to Loposo medium and 50 grams of coal, received a $10 \% \mathrm{~V} / \mathrm{V}$ inoculum of Thiobacillus so. The culture inoculum consisted of equal volumes (50 mL each) of Thiobacillus thiooxidans and Thiobacillus ferrooxidans. Each of these cultures have been maintained in their respective ATCC media as specified in earlier reports. This $100 \mathrm{~mL}$ inoculum was added to $900 \mathrm{~mL}$ LOPOSO medium.

\section{Table 2. LOPOSO Medium constituents}

\section{Component}

$\mathrm{NH}_{4} \mathrm{Cl}$

$\mathrm{KH}_{2} \mathrm{PO}_{4}$

$\mathrm{MgCl}_{2} \cdot 6 \mathrm{H}_{2} \mathrm{O}$

$\mathrm{KCl}$

$\mathrm{CaCl}_{2} \cdot 2 \mathrm{H}_{2} \mathrm{O}$

$\mathrm{NaCl}$

\section{Comnosition (a/L)}

0.63

0.10

0.85

0.10

0.008

0.123

Upon inoculation of Flask 3 , the three flasks were placed in a constant temperature environment $\left(T=25^{\circ} \mathrm{C}\right)$ on stirring plates witi agitation rates between $200-400 \mathrm{rpm}$. 
Each reactor $\mathrm{pH}$ was monitored periodically and maintained at 2.5 with $1.5 \mathrm{~N} \mathrm{NaOH.} \mathrm{Table} 3$ presents the periodic "preadjustment" $\mathrm{pH}$ values for tile three flasks.

It should be noted that after $\mathrm{pH}$ measurement, the $\mathrm{pH}$ of each flask was returned to $\mathrm{pH}=2.5$.

Table 3 . $\mathrm{DH}$ Values as $\geq$ Function of Time.

$\begin{array}{cccc}\text { Time (hrs) } & \text { Elask } & \text { Elask 2 } & \text { Flask 3 } \\ 0.0 & 2.60 & 2.52 & 2.51 \\ 24.5 & 2.45 & 2.41 & 2.31 \\ 95.5 & 2.70 & 2.33 & 2.12 \\ 121.5 & 2.68 & 2.17 & 2.21 \\ 168.5 & 2.54 & 2.15 & 2.19 \\ 336.5 & 2.37 & 2.13 & 2.10 \\ 480.5 & \text { experiment discontinued } & & \end{array}$

As indicated in the representative data of Table 3 , the pH dropped significantly in both Flask 2 with LOPOSO and Flask 3 with IOPOSO plus organisms. On day 14 (hrs=336.5), a slurry sample estimatec to yield approximately 5 grams of coal was removed from each of ti:e three flasks for subsequent sulfur anaiyses. These analyses have yet to be conducted. Upon discontinuation of the experiment, the coal slurry was filtered, wash with distilled water to remove organisms, and dried for sulfur analyses.

Attempts to close the mass balance have met with several difficulties. The initial coal samples weighed into each of the three flasks were carefully measured to 50 grams per flask. However, in trying to effectively wet and mix the coal into the medium, considerable "dusting" occurred with the likely loss of some coal to the atmosphere. Additionaliy, coal sampling during the experiment incurred some coal loss through adherence to the sides of filtration equipment, filter paper, etc. In summary, the post-experimental coal weights are as follows (with 50 grams as the initial weight for each flask):

$\begin{array}{llll}\text { Flask } 1 \text { (water only) } & -44.7 \mathrm{~g} \\ \text { Flask } 2 \text { (LOPOSO) } & -45.4 \mathrm{~g} \\ \text { Flask } 3 \text { (LOPOSO+BUGS) } & -46.1 \mathrm{~g}\end{array}$

The post-experimental dry coal weights presented above were obtained by drying the washed coal slurzies in an air flow oven 
until no measurable mass change occurred $(+/-0.01 \mathrm{~g})$.

This experiment will be repeated with planned improvement in coal handling procedures. Sulfur analyses will be forwarded as obtained.

An additional batch reactor has been started for depyritizing a sizeable amount of coal. For this batch run (designated Experiment 10051A), a 5\% slurry of $200 \mathrm{X} 0$ mesh coal was prepared in LOPOSO medium--1275 grams of coal in 25.5 liters of medium. The $\mathrm{pH}$ was adjusted to 2.5 with a reaction temperature of $30^{\circ} \mathrm{C}$ and an agitation rate of approximately $200 \mathrm{rpm}$. The coal slurry was inoculated with 1 liter of $2 \%$ coal slurry, previously inoculated with equal volumes of Thiobacillus ferrooxidans and Thiobacillus thiooxidans. Additionally, approximately $150 \mathrm{~mL}$ of each Thiobacillus pure culture were added to ensure the viability of the inoculum.

Samples have been obtained on a regular basis and reactor $\mathrm{pH}$ monitored closely. Sulfur analyses are forthcoming as students complete training in the analytical area.

Task 3 - Analytical Procedures for Total Organic Sulfur.

3.1 Characterization.

Task complete.

3.2 Quality Assurance and control.

Cross whecks of in-house analyses periodically conducz三d.

\subsection{Microscopic Analyses.}

Task complete.

\section{Task 4 - Organic sulfur Removal.}

As described in the Quarterly Progress Report for March-June, 1990, cultures from raw inocula sources have been placed in basal salts medium with depyritized coal and allowed to incubate at $27^{\circ}$ $C$ with an agitation rate of $180 \mathrm{rpm}$ for approximately 14 days. Upon completion of the incubation period, the coal samples were filtered and washed to remove biomass, air-dried, and stored in a dessicator for sulfur analysis. These samples will be analyzed for total sulfur and compared to the total sulfur values for the depyritized coal used as a source for the experiment.

cultures for which the sulfur analyses show significant changes will be further subjected to testing. 
Sulfur analyses for the cultures tested will be completed as students gain proficiency in the necessary analytical methods.

Work to construct a system of reactors and a temperature controlled cabinet which would allow better control of process parameters in microbial coal desulfurization studies has been delayed in order to concentrate on new staff orientation and training and to set up and monitor the batch depyritization reactor. 
Biodesulfurization Techniques: Application of Selected

Microorganisms for Organic Sulfur Removal from Coals

\author{
Louisiana Tech University \\ Contract No. DE-AC22-88PC88854
}

Quarterly Report

Report No. PETC-12-90

Report Period: September 21, 1990

December 20, 1990

\title{
INTRODUCTION
}

The ongoing work which has been conducted during the past quarter is summarized in the following discussion.

\section{TASK OVERVIEW}

Task 2 - Coal Procurement and Preparation.

2.1 Grinding, Sieving, and Storage.

The rwenty pound shipment of IBC-101 (Lot 1007) has been ground to 200X0 mesh. riffled and placed storage. An additional twenty pound shipment (Lot 1008) has been received. It will be ground to various mesh sizes for future studies.

2.2 Microbial Removal of Pyrite and Sulfate.

Task complete.

During this past quarter, experimentation was conducted in order to compare the effects of LOPOSO medium (the supporting medium for Thiobacillus SD. for depyritization) on the degree of depyritization in batch culture. Analysis of the samples for the completed experiment is underway. 
Table 1 shows the initial conditions set for each flask. The operating conditions for each batch culture were identical with 50 grams of $200 \times 0$ coal carefully measured into each flask.

Table 1. Batch Reactor Initial Conditions

$\begin{array}{lccc}\text { Descriotion } & \underline{1} & \underline{2} & \underline{3} \\ \text { Medium } & \text { water only } & \text { LOPOSO only } & \text { LOPOSO + organisms } \\ \text { Temp. }{ }^{\circ} \mathrm{C} & 25 & 25 & 25 \\ \text { Rx. pH } & 2.5 & 2.5 & 2.5 \\ \text { T. coal slurry } & 5 & 5 & 5\end{array}$

As presented, $1000 \mathrm{ml}$ of water and $50 \mathrm{~g}$ of $200 \times 0$ mesh coal (raw coal \#1005) were added to Fiask 1. Flask 2 received LOPOSO medium (composition presented in Table 2) and coal. The third flask, in addition to LOPOSO medium and 50 grams of coal, received a $10 \% \mathrm{v} / \mathrm{v}$ inoculum of Thiobacillus $\mathrm{SD}$. The culture inoculum consisted of equal volumes (50 $\mathrm{mL}$ each) of Thiobacillus thiooxidans and Thiobacillus ferrooxidans. Each of these cultures have been maintained in their respective ATCC media as specified in earlier repors. This $100 \mathrm{~mL}$ inoculum was added to $900 \mathrm{~mL}$ LOPOSO medium.

Table 2. LOPOSO Medium Constituents

Component

$\mathrm{NH}_{4} \mathrm{Cl}$

$\mathrm{KH}_{2} \mathrm{PO}_{4}$

$\mathrm{MgCl}_{2} \cdot 6 \mathrm{H}_{2} \mathrm{O}$

$\mathrm{KCl}$

$\mathrm{CaCl}_{2} \cdot 2 \mathrm{H}_{2} \mathrm{O}$

$\mathrm{NaCl}$
Composition (g/L)

0.10

0.85

0.10

0.008

0.123 
Upon inoculation of Flask 3, the three flasks were placed in a constant temperature environment $\left(T=25^{\circ} \mathrm{C}\right)$ on stirring plates with agitation rates between $200-400 \mathrm{rpm}$.

Each reactor $\mathrm{pH}$ was monitored periodically and maintained at 2.5 with $1.5 \mathrm{~N} \mathrm{NaOH}$. Table 3 presents the periodic "preadjustment" pH values for the three flasks. $\mathrm{pH}=2.5$.

It should be noted that after $\mathrm{pH}$ measurement, the $\mathrm{pH}$ of each flask was returned to

Table 3. DH Values as a Function of Time.

$\begin{array}{cccc}\text { Time (hrs) } & \text { Flask 1 } & \text { Flask 2 } & \text { Flask 3 } \\ 0.0 & 2.60 & 2.52 & 2.51 \\ 24.5 & 2.45 & 2.41 & 2.31 \\ 95.5 & 2.70 & 2.33 & 2.12 \\ 121.5 & 2.68 & 2.17 & 2.21 \\ 168.5 & 2.54 & 2.15 & 2.19 \\ 336.5 & 2.37 & 2.13 & 2.10 \\ 480.5 & \text { experiment discontinued } & & \end{array}$

As indicated in the representative data of Table 3, the $\mathrm{pH}$ dropped significantly in both Flask 2 with LOPOSO and Flask 3 with LOPOSO plus organisms. On day 14 (hrs=336.5), a slurry sample estimated to yield approximately 5 grams of coal was removed from each of the three flasks for subsequent sulfur analyses. These analyses have yet to be conducted. Upon discontinuation of the experiment, the coal slurry was filtered, wash with distilled water to remove organisms, and dried for sulfur analyses.

Attempts to close the mass balance have met with several difficulties. The initial coal samples weighed into each of the three flasks were carefully measured to 50 grams per flask. However, in trying to effectively wet and mix the coal into the medium, considerable "dusting" occurred with the likely loss of some coal to the atmosfhere. Additionally, coal sampling during the experiment incurred some coal loss through adherence to the sides of filtration equipment. filter paper, etc. 
In summary, the post-experimental coal weights are as follows (with 50 grams as the initial weight for each flask):

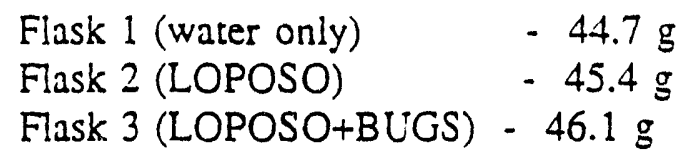

The post-experimental dry coal weights presented above were obtained by drying the washed coal slurries in an air flow oven until no measurable mass change occurred $(+/-0.01 \mathrm{~g})$.

An additional batch reactor was started for depyritizing a sizeable amount of coal. For this batch run (designated Experiment 10051A), a 5\% slurry of $200 \mathrm{X} 0$ mesh coal was prepared in LOPOSO medium--1275 grams of coal in 25.5 liters of medium. The $\mathrm{pH}$ was adjusted to 2.5 with a reaction temperature of $30^{\circ} \mathrm{C}$ and an agitation rate of approximately $200 \mathrm{rpm}$. The coal slurry was inoculated with 1 liter of $2 \%$ coal slurry which had been grown for approximately two weeks, previously inoculated with equal volumes of Thiobacillus ferrooxidans and Thiobacillus thiouxidans. Additionally, approximately $150 \mathrm{~mL}$ of each Thiobacillus pure culture were added to ensure the viability of the inoculum. The microbial activity of the $2 \%$ coal slurry as detected by a decrease in the pyrite percentage had not been verified by analysis at the time the 25.5 liter batch was started. Therefore, the additional pure cultures of Thiobacillus sp. were added to ensure an ample bacterial cell concentation to initiate depyritization.

Samples were obtained on a regular basis and reactor pH monitored closely. The iniriai and final pyritic sulfur analyses are presented below in Table 4.

\section{Table 4. Pvritic Sulfur as a Function of Time for the 5\% Coal Slurrv.}

Time (davs)

0

76
To Pvrite

$0.638+/-0.028$

$0.393+/-0.005$

As seen in Table 4, only approximately $38 \%$ of the pyritic sulfur was removed over a rache: extended reactor operating period. The extent of this period ( 76 days) results from the absence of sulfur analyses for the samples obtained throughout the batch operation. This is due to an ongoing training of new student workers. This coal will be retained for subsequent "retreatment" at a later date.

It should be noted that the solids concentration for this batch was higher (5\%) than for batches of coal treated previously $(2 \%)$. During the treatment of this batch of coal, samples of the slurry were periodically examined for the presence of cells. Though cells were detected, the determination of microbial depyritizing activity could not be made in the absence of sulfur analyses.

Another batch of raw coal is currently being treated in a manner identical to the methocs 
presented above. However, the solids concentration for this batch has been set at 2\%. Progress is being made in obtaining reliable sulfur analyses from the lab thus allowing for closer monitoring of reaction progress for this batch.

Task 3 - Analytical Procedures for Total Organic Sulfur.

\subsection{Characterization.}

Task complete.

3.2 Quality Assurance and Control.

Cross-checks of in-house analyses periodically conducted.

\subsection{Microscopic Analyses.}

Task complete.

\section{Task 4 - Organic Sulfur Removal.}

Procedures for the selection of definitive sulfur utilizers from the list of isolates presented in monthly progress Report No. PETC-10-90 are being developed with a focus on promoting organic sulfur utilization through the application of mutagenesis techniciues to these cultures. 
Biodesulfurization Techniques: Application of Selected

2. croorganisms for Organic Sulfur Removal from Coals

Louisiana Tech University

Contract No. DE-AC22-88PC88854

Quarterly Report

Report No. PETC-3-91

Repor Period:

December 21, 1990

March 20, 1991

\section{INTRODUCTION}

The research activities which have been conducted during this time period are addressed below.

\section{TASK OVERVIEW}

Task 2 - Coal Procurement and Preparation.

2.1 Grinding, Sieving, and Stornge.

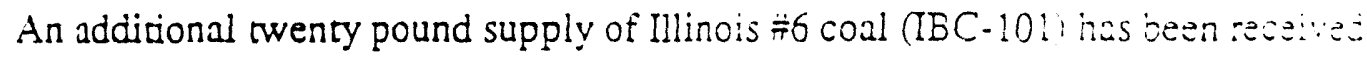
and is available for grinding as needed.

\subsection{Microbial Removal of Pyrite and Sulfate.}

Task complete.

A batch treatment for depyritizing a sizeable portion of coal is planned for the latter stages of the month. The reactor vessel which has been used previously is being altered in an attempt to increase the rate and extent of depyritization. The reactor has a 136 liter working liquid volume in which a $2 \%$ coal slurry (mass $\%$ ) will be mixed with LOPOSO medium and operated at a reaction temperature of $30^{\circ} \mathrm{C}$. The reactor impeller has been changed from a three-blade axial flow impeller to a four-blade axial flow impeller having a greater blade surface area and longer blade length (in an attempt to promote greater homogeneity in mixing). Addicionally, the inlet air source has been affixed to the bottom of the conical reactor vessel to inhibit setting of the coal particles. The successful operation of this reactor scheme will te followed with a detailed figure and description in subsequent monthly progress reports. 
Task 3 - Analytical Procedures for Totai Organic Sulfur.

\subsection{Characterization.}

Task complete.

3.2 Quality Assurance and Control.

Cross-checks of in-house analyses periodically conducied.

\subsection{Microscopic Analyses.}

Task complete.

Task 4 - Organic Sulfur Removal.

Task complete. 
Biodesulfurization Techniques: Application of Selected

Microorganisms for Organic Sulfur Removal from Coals

Louisiana Tech University

Contract No. DE-AC22-88PC88854

Quarterly Report

Report No. PETC-6-91

Report Period: Marsin 21, 1991

June 20, 1901

\section{INTRODUCTION}

The ongoing work which has been conducted during the past quarer is summarized in the following discussion.

\section{TASK OVERVIEW}

\section{Task 2 - Coal Procurement and Preparation.}

2.1 Grinding, Sieving, and Storage.

Task Complete. Ground coal (200 X 0 mesh. Illinois $\div 6$ IBC-101) has been placed under Argon storage awaiting depyritization treatment.

\subsection{Microbial Removal of Pyrite and Sulfate.}

Task complete.

A coal batch of approximately $1.5 \mathrm{~kg}$ is being treated for removal of pyrite a by I. ferrooxidans and I. thiooxidans mixed culture. Samples obtained during the treatment are awaiting analysis.

As the work at LTU has been comprised primarily of depyritization effors, an update in reviewing the literature is being conducted to search for areas in which new work may be pressed forward here. One area that has captured our attention is the employment of waterin-oil emulsions and reverse micelle processes for the enhancement of mass transfer between the coal substrate and microbial biocatalysts (Lee and Yen, 1990). This study looks promising for improving the total sulfur content of particulate coal, and our focus this next quarter will be toward possible contributions to this area of research. 
Task 3 - Analytical Procedures for Total Organic Sulfur.

\subsection{Characterization.}

Task complete.

\subsection{Microscope Analysis.}

During the spring quarter, one of our graduate students completed his master's thesis entitled, "Advanced Scanning Electron Microscopy and Energy Dispersive Spectroscopy Techniques for Sulfur Analysis in Coal". This document will be mailed under separate cover.

Task 4 - Organic Suifur Removal

The completion of the contractual agreement with Dr. Bailey Ward at the University of Mississipoi has brought this portion of the work to a close. This portion of the project's final repor should be forthcoming this summer and will be forwarded upon receipt. 
Biodesulfurization Techniques: Application of Selected

Microorganisms for Organic Sulfur Removal from Coals

Louisiana Tech University

Contrac: No. DE-AC22-88PCS8854

Quarterly Report

Report No. PETC-9-91

Repor Period: June 21. 1951

September 20, 1991

\section{INTRODUCTION}

The ongoing work which has been conducted during the past quarer is summarized in the following discussion.

\section{TASK OVER VIEW}

Task 2 - Coal Procurement and Prevaration.

\subsection{Grinding, Sieving, and Storage.}

Task Complete. All ground coal (200 X 0 mesh, Ilinois $\# 6$ IBC-101) which has been placed under Argon storage has now been treated for pyrite removal. Adcitional coal has been ground for the reverse micelle sucies currenty uncervay.

\subsection{Microbial Removal of Pyrite and Sulfate.}

Task complete.

During the past quarter, a coal batch of $1.8 \mathrm{~kg}$ (200 X 0 mesh, Ilinois \#6 IBC. 101) was treated for removal of pyrite by a $T$. ferrooxidans and $T$. Thiooxidans mixed culture. Samples obcained during the treatment were analyzed.

The batch reactor run for this experiment was comprised of a $5 \%$ coal slurry in LOPOSO medium (see Table 1 below for medium composition) and an inoculum of Thiobacillivs sp. (T. ferrooxidans and T. thiooxidans). The inoculum consisted of a 1 liter $2 \%$ coal slur: incubated for 48 hours prior to inocularion of the large batch reactor. In turn. the inoculum was prepared by inoculating the $2 \%$ coal slurry from $50 \mathrm{mls}$ each of the two Thiobacillus sp. stoci cultures. Prior to inoculation, air flow and agitation was established. The agitation rate was se: at approximately $200 \mathrm{rpm}$. 
Table 1. Composition of LOPOSO medium.

$\begin{array}{ll}\text { Comoonent } & \mathrm{g} / \mathrm{L} \\ \mathrm{NH}_{4} \mathrm{Cl} & 0.63 \\ \mathrm{KH}_{2} \mathrm{PO}_{4} & 0.10 \\ \mathrm{MgCl}_{2} \cdot 6 \mathrm{H}_{2} \mathrm{O} & 0.85 \\ \mathrm{KCl} & 0.10 \\ \mathrm{CaCl}_{2} \cdot 2 \mathrm{H}_{2} \mathrm{O} & 0.008 \\ \mathrm{NaCl} & 0.123\end{array}$

Prior to addition of the culture incculum, the contents of the batch reactor were allowed to equilibrate to the reaction temperature of $30^{\circ} \mathrm{C}$ and were adjusted to a $\mathrm{pH}$ of 2.5 . Samples were obtained regularly and $\mathrm{pH}$ was readjusted to 2.5 daily after inoculation.

As described in PETC Report No. PETC-8-91, samples which were obtained were allowed to sit until the coal particles sertled. Afterwards, the supernatant was decanted. The remaining coal was washed (with vigorous agitation) repeatedly with distilled water to remove microorganisms potencially adhering to the coal surface. This process was repeated three times after which the coal was filtered through a Buchner funnel under vacuum filtration. The coal fiiter cake was then dried in an air-flow oven at $105-110^{\circ} \mathrm{C}$ to complete dryness. With the subsequent encounter of some difficulties in starting up the Atomic Absorption Analyzer, the coal was allowed to equilibrate with laboratory air. Each of the samples were then teated together for pyritic sulfur determination and corrected for the presence of moisture in the laboratory air (6\% moisture) at the time of analysis. The percent moisture was determined by ASTM procedures for moisture in coal samples. The results of the pyrite analysis as obtained through atomic absorption techniques (described in ASTM Method D2492-84) are presented in Table 2 and Figure 1.

As seen in Figure 1, the percent (by mass) of pyritic sulfur dropped approximately $45 \%$ in the first 48 hours after inoculation. This was accompanied by a drop in reactor $\mathrm{pH}$ from 2.5 to approximately 2.1 . The reactor $\mathrm{pH}$ was corrected to 2.5 with $\mathrm{NaOH}$ and monitored daiiy thereafter. However, as seen from the data presented, the rate of depyritization slowed dramatically after this initial period. Reactor operation was continued to observe the apparent ultimate extent of depyritization. The lengthy reaction time largely negates the utility of this experiment. After approximately 43 days, the coal had experienced a mass percentage loss in pyritic sulfur of approximateiy $71 \%$ which is well below reported literature values for pyrite removal in excess of 90\% (Andrews and Maczuga, 1982; Hoffman et al, 1981). 
Table 2. Percent Pyritic Sulfur As a Function of Time.

\begin{tabular}{cc} 
Time (davs) & \multicolumn{0}{c}{ Pvrite (bv mass) } \\
\cline { 2 - 2 } 0 & 1.63 \\
2 & 0.90 \\
6 & 0.84 \\
8 & 0.84 \\
10 & 0.82 \\
13 & 0.71 \\
15 & 0.72 \\
17 & 0.53 \\
20 & 0.61 \\
22 & 0.64 \\
24 & 0.70 \\
27 & 0.65 \\
29 & 0.54 \\
31 & 0.50 \\
34 & 0.54 \\
36 & 0.68 \\
38 & 0.49 \\
41 & 0.45
\end{tabular}




\section{Fig 1. Percent Pyritic Sulfur With Time Raw Coal Batch \#1007.}

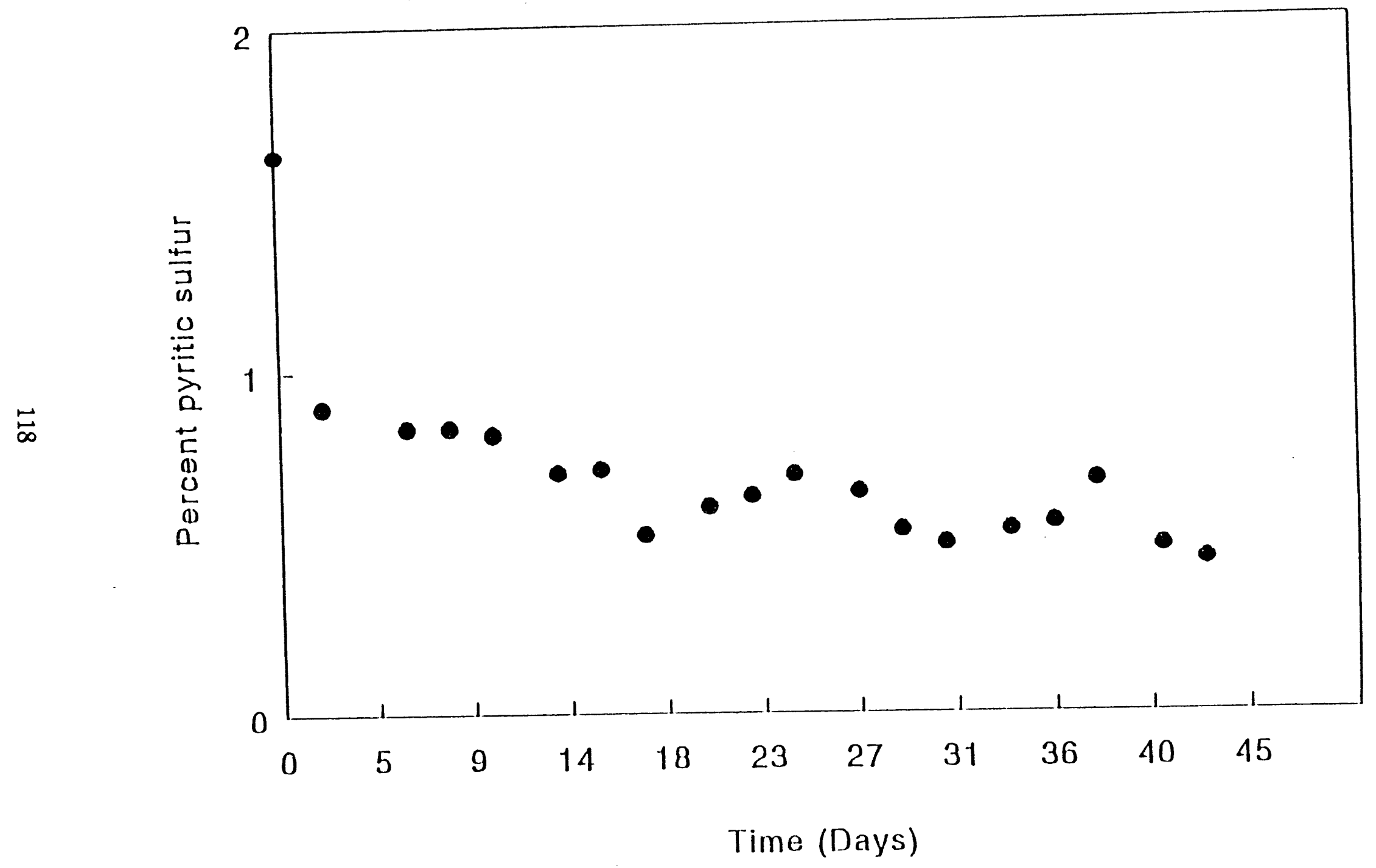


A number of factors have been cited as contributing to a decrease in miciobial pyrite oxidation including a decrease in $T$. ferrooxidans activity resulting from the release of organics into the aqueous phase (Eligwe, 1988); the precipitation of jarosite and iron oxides which inhibit bacterial activity through limiting oxygen mass transfer (Torma and Banhegyi, 1984); and the presence of competitive acidophilic bacteria contaminating the system. The latter bacterial contamination might have occurred in the batch run presented above through the use of nonsterile coal in the batch depyritization reactor. Such organisms may be resident upon the coal itself. In an effor to eliminate the possibility of such contamination, subsequent batches or coal will be autoclaved prior to addition to the medium--the sterilization of which is not practical with the current reactor design. To ensure the purity of our stock cultures, a plan of rapid seriai dilutions has been undertaken with gradual lowering of the $\mathrm{pH}$ from 2.5 to near 1.8 with each subsequent dilution in order to eliminate possible contamination of the stock cultures by acidophilic organisms.

Task 3 - Analytical Procedures for Total Organic Sulfur.

\subsection{Characierization.}

Task complete.

\subsection{Microscope Analysis.}

Task complete.

Task 4 - Organic Sulfur Removal

The contactual agreement with Dr. Baijey Ward at the University of Mississippi was completed during the second quarer of this year. The compilation of his results is underway and will be incorporated into the project final repor following completion of our no-cost contrac: extension. 


\section{LITERATURE CITED}

G. Andrews and J. Maczuga, Biotechnol. Bioeng. Symp. Ser., 12, 337 (1982).

C. Eligwe, Fuel, 67, 451, (1988).

M. R. Hoffman, B. C. Faust, F. A. Panda, H. H. Koo, and H. M. Tsuchiya, Appl. Environ. Microbiol., 42, 259, (1981).

A. E. Torma and I. G. Banhegyi, Trends in Biotechnol., 2, 13, (1984). 
Biodesulfurization Techniques: Application of Selected

Microorganisms for Organic Sulfur Removal from Coals

Louisiana Tech University

Contract No. DE-AC22-88PC88854

Quarterly Report

Repor No. PETC-12-91

Report Period: $\quad$ September 21, 1991

December 20, 1991

\section{INTRODUCTION}

As described in last month's repor, preparatory work for the reverse micelle study has continued with the rapid serial dilution of our Thiobacillus sp. stock cultures at a low $\mathrm{Ph}$ (approximately 1.8-2.0) to ensure a strong inoculum in a logarithmic growth phase.

Total sulfur analyses will be run on samples obtained from experimental work for the reverse micelle study. After relocating this equipment in a more convenient laboratory, several difficulties have been encountered in setting up and operating this equipment. These problems continue to be addressed this month.

The research activity conducted during the current reporting period is summarized below.

\section{TASK OVERVIEW}

\section{Task 2 - Coal Procurement and Predaration.}

2.1 Grinding, Sieving, and Storage.

Task Complete.

2.2 Microbial Removal of Pyrite and Sulfate.

Task complete.

In addition to the serial dilution procedures for preparation of Thiobacillus sp. stock cultures (which are continuing), a preliminary experiment for the comparison of organicphase, reverse-micelle depyritization to the typical aqueous phase culture has been initiated. The experimental set-up and procedures are described below. 
In this initial experiment, only Thiobacillus ferrooxidans was used in the various batch cultures. Stock cultures are maintained in Ferrous Iron Medium (composition shown in Table 1 below).

\section{Ferrous Iron Medium}

$\begin{array}{lr}\frac{\text { Part I (autoclavable) }}{1000 \mathrm{~mL} \text { dist. } \mathrm{H}_{2} \mathrm{O}} & \text { Part II (filter sterilizable) } \\ 0.50 \mathrm{~g} \mathrm{~K}_{2} \mathrm{HPO}_{4} & 500 \mathrm{~mL} \text { dist } \mathrm{H}_{2} \mathrm{O} \\ 0.50 \mathrm{~g}\left(\mathrm{NH}_{4}\right)_{2} \mathrm{SO}_{4} & 84 \mathrm{~g} \mathrm{FeSO}_{4} \cdot 7 \mathrm{H}_{2} \mathrm{O} \\ 0.50 \mathrm{~g} \mathrm{MgSO} \cdot 7 \mathrm{H}_{2} \mathrm{O} & 25 \mathrm{~mL} 1 \mathrm{~N} \mathrm{H}_{2} \mathrm{SO}_{4} \\ 3.14 \mathrm{~mL} \text { conc. } \mathrm{H}_{2} \mathrm{SO}_{4} & \end{array}$

Stock cultures are maintained in 250 Erlenmeyer flasks containing $200 \mathrm{~mL}$ of Ferrous Iron medium with parts I and $I$ mixed in the proportion of $144 \mathrm{~mL}$ and $36 \mathrm{~mL}$, respecively. The medium $\mathrm{pH}$ is adjusted to 2.5 through base $(\mathrm{NaOH})$ or acid $\left(\mathrm{H}_{2} \mathrm{SO}_{4}\right)$ as necessary prior to tansfer of the inoculum to fresh medium. The inoculum size is typically 10\% $\mathrm{v} / \mathrm{v}$ for stock culture maintenance.

For initiation of the reverse micelle experiment, one liter of Ferrous Iron mediun was prepared and adjusted to $\mathrm{pH} \mathrm{2.1.} \mathrm{To} \mathrm{it} \mathrm{was} \mathrm{added} 100 \mathrm{~mL}$ of Thiobacillus ferrooxidons inoculum from a 7-day old culture. After incubation at $28^{\circ} \mathrm{C}$ and $100 \mathrm{ppm}$ (agitation rate) for five days, the cells were harvested by centrifugation. The culture medium was spun down at 10 ${ }^{\circ} \mathrm{C}$ for 30 minutes at $5,000 \mathrm{rpm}$ (approximately 3,500 g). The cell pellet which was obtained was resuspended in $3 \mathrm{~mL}$ of distilled water (previously adjusted to 2.5). From this $3 \mathrm{~mL}$ ceil concentration, $1 \mathrm{~mL}$ was added to the reverse micelle formulation (described below), $1 \mathrm{~mL}$ was added to a control and the remaining milliliter was retained and resuspended in Ferrous Iron medium for stock culture maintenance.

The reverse micelle was prepared in a $2 \mathrm{~L}$ flask in the following manner:

- $500 \mathrm{~mL}$ light mineral oil

- $500 \mathrm{~mL}$ n-heptane

- $1 \mathrm{~mL}$ Tween 80 (surfactant)

- $1 \mathrm{~mL}$ bacterial suspension (described above)

- mixture agitated with a stiring bar for 1 hour 
After preparation of the reverse micelle system and the batch reactor controls, 20 grams of $100 \mathrm{X} 0$ mesh coal was added to each to form a $2 \%$ slurry. Table 2 presents each barch reactor condition.

\section{Table 2. Batch Reactor Description}

Fask No. 1 - Experimental reverse micelle system

Flask No. 2 - Control \#1 (reverse micelle without biocatalyst)

Flask No. 3 - Control \#2 (water @ pH=2.5 + $1 \mathrm{~mL}$ cells)

After each 2 liter flask had been prepared (as in Table 2), a stirring bar was placed in each for agitation and the media were autoclaved (prior to addition of the biocatalyst). Agitation was then accomplished by stirring plates in a temperature controlled cabinet (temp.= $\left.30^{\circ} \mathrm{C}\right)$.

Samples were obtained from each batch reactor every 12 hours with $50 \mathrm{mls}$ removed per sample. Each sample was filtered through a Whatman No. 1 filter under vacuum filtration. The aqueous phase sample, only, was washed with distilled water. The organic phase samples were not washed. All samples were then dried 12 hours in an air-ilow oven at $105^{\circ} \mathrm{C}$ and stored in a dessiceator awairing total sulfur analysis. This analysis will be provided as soon as current analytical equipment problems are resolved.

Task 3 - Analytical Procedures for Total Organic Sulfur.

3.1 Characterization.

Task complete.

\subsection{Microscope Analysis.}

Task complete.

Task 4 - Organic Sulfur Removal

Task complete. 


\section{Biodesulfurization Techniques: Application of Selected \\ Microorganisms for Organic Sulfur Removal from Coals \\ Louisiana Tech University \\ Contract No. DE-AC22-88PC88854}

Quarteriy Repor

Report No. PETC-3-92

Report Period: January 21, 1992

March 20, 1992

\section{INTRODUCTION}

The research activities conducted this month include the reverse micelle study (previous:y reported in Report No. PETC-2-92) and the initiation of related work conceming the growth characteristics of Thiobacillus SD. This experimentation is outlined below.

\section{TASK OVERVIEW}

\section{Task 2-Coal Procurement and Preparation.}

2.1 Grinding, Sieving, and Storage.

Task Complete.

2.2 Microbial Removal of Pyrite and Sulfate.

Task complete.

As described in last month's report, a second experiment for investigating the depyritization activity of $T$. ferrooxidans in a reverse micelle system was initiated this month. However, similiar difficulties experienced with the first experiment (as described in PETC Report No. PETC-1-92) were encountered and the experiment was discontinued. The investigation of the mixed-culture ( $T$. ferrooxidons/T. thiooxidans) depyritization activity is aqueous phase culture is continuing to ensure culture viability.

Additionally, an experiment has been started to investigate the effects of the organic phase upon desulfurization. A search of the literature has shown that the reverse mice:le alone (without organisms) removes sulfur to some degree. Studies are being initiated :0 investigate the degree of desulfurization with and without organic solvent presreatment. 
The capability of the heptane to remove sulfur will be reporied upon completion of this experimental work.

In order to examine the potential of reducing the lag phase in microbial growth and depyritization, a study is undenvay to investigate ce!lular activity in eariy exponential phase growth (as compared to later, stationary-phase growth).

Task 3 - Analytical Procedures for Total Organic Sulfur.

\subsection{Characterization.}

Task complete.

\subsection{Microscope Analysis.}

Task complete.

Task 4 - Organic Sulfur Removal

Task complete. 


\section{Biodesulfurization Techniques: Application of Selected \\ Microorganisms for Organic Sulfur Removal from Coals \\ Louisiana Tech University \\ Contract No. DE-AC22-88PC88854}

Monthly Report

Report No. PETC-4-92

Report Period: $\quad$ March 21, 1992

April 20, 1992

\section{INTRODUCTION}

The past month's research activities are reported below.

\section{TASK OVERVIEW}

\section{Task 2 - Coal Procurement and Preparation.}

2.1 Grinding, Sieving, and Storage.

Task Complete.

2.2 Microoial Removal of Pyrite and Sulfate.

Task complete.

Comparative experiments have been conducted to examine the effects of "seed culture" age, the presence of a surfactant (Tween 80 ) and pretreatment of the coal with nheptane on the rate and extent of desulfurization. These studies have been initiated as a resuit of attempts to formulate a reverse micelle system (as described in the literature) for improving the bacterial depyritization of coal. Problems with dispersion of the aqueous, microbial phase in the organic phase have resulted (discussed in previous reports) thereby prompting an investigation of several conditions associated with the reverse micelle system. These experiments are described below. Resulting experimental analysis will be provided as it becomes available.

\section{EXPERIMENT \#1}

Following the initial reverse micelle experiments, a standard test has been conducted to reexamine the ability of our $T$. ferrooxidans strain to remove pyrite from the Illinois $\# 6$ coal (200 X 0 mesh). The experiment was conducted in 2 liter flasks containing one 
liter of LOPOSO medium plus a nitrogen source $\left(0.6 \mathrm{~g} / \mathrm{L} \mathrm{NH} \mathrm{Nl}_{4}\right)$ and $20 \mathrm{~g}$ of coal for a $2 \%$ $(w / w)$ slurry. Flasks containing media and coal were autoclaved for 15 minutes at $121{ }^{\circ} \mathrm{C}$.

The bacterial inoculum consisted of a pure culture of $T$. ferrooxidans that had been growing for seven days at $30^{\circ} \mathrm{C}$ and $120 \mathrm{rpm}$ in modified $9 \mathrm{~K}$ medium with $30 \mathrm{~g} / \mathrm{L}$ $\mathrm{FeSO}_{4} \cdot \mathrm{TH}_{2} \mathrm{O}$ as the energy source. Typical cell concentrations of $10^{\wedge} 7 \cdot 10^{\wedge} 8$ cells $/ \mathrm{ml}$ wert achieved.

Cells were filtered from the $9 \mathrm{~K}$ medium using 0.2 micron filters. Cells were then resuspended by agitating the filter in $50 \mathrm{~mL}$ of distilled water at $\mathrm{pH} 2.5$ (adjusted by the addition of $1 \mathrm{~N} \mathrm{HCl}$ ). The resuspension of cells contained $10^{\wedge} 9-10^{\wedge} 10 \mathrm{cell} / \mathrm{s} / \mathrm{mL}$. Cell concentrations were obtained by the measurement of the optical density in a spectrophotometer and through correlation to actual cell concentrations for $T$. ferrooxidans cited in published sources.

The two-liter flasks were then inoculated with $25 \mathrm{~mL}$ of the bacierial resuspensions to produce approximately $5 \times 10^{\wedge} 7 \mathrm{cells} / \mathrm{mL}$ in the $2 \%(\mathrm{w} / \mathrm{w})$ coal slurry. Incubation was carried out at $30^{\circ} \mathrm{C}$ and $120 \mathrm{rpm}$ for 9 days.

The decrease in total sulfur was monitored with time by analysis on a LECO induction fumace. The experimental flasks removed approximately $75 \%$ of the pyritic sulfur in 10 days, while the control removed only approximately $10 \%$ of the pyritic sulfur.

\section{EXPERDMENT \#2}

The next experiment was identical to the one described above except that a $5 \%$ (w/w) coal slurry was used witt. a surfactant (Tween 80), and cells were harvested after only two days of incubation to obtain cells in logarithmic growth. The purpose of this experiment was to examine both the effect, if any, of the added suriactant and the seed culture age upon the rate and extent of depyritization. The number of cells per $\mathrm{mL}$ was not recorded because of the presence of fine iron particulates in the resuspension.

The experimental flasks (both with and without suriaciant) snowed a similar reduction of $40 \%$ in pyritic sulfur in 12 days as compared to the uninoculated control in whicis a sulfur removal of only $10 \%$ was observed. It should be noted that the total sulfur removed in the experimental flasks was significantly lower for a comoarable length of time than the experiment described above. It is likely that this is due, in part, to a lower cell count than in the previous, older culture.

\section{EXPERIMENT \#3}

In this experiment, $50 \mathrm{~g}$ of coal was washed for 8 hours in $100 \mathrm{~mL}$ of $\mathrm{n}$-heptane, ethanol, and distilled water at $30^{\circ} \mathrm{C}$ and $120 \mathrm{rpm}$ in 1 liter flasks. The washed coal was then filtered and dried ovemight in an air-flow oven at $110^{\circ} \mathrm{C}$.

The washed coal was then inoculated with cells harvested as before (Experiment \#1) from a 7-day old culture. The experiment was done in 1 liter flasks containing $500 \mathrm{~mL}$ of LOPOSO medium and $10 \mathrm{~g}$ of washed coal for a $2 \%$ (w/w) slurry.

The initial results indicate that, prior to bacterial inoculation, the n-heptane washed coal experienced a $15 \%$ reduction in pyritic sulfur while washing with ethanol and distilled water removed only about $1 \%$. After three days of incubation with the bacterial inoculation, the n-heptane flask showed about $30 \%$ pyritic sulfur removal as compared to only about $10 \%$ in the other two flasks (one with ethanol-washed and water-washed coal. respectively). 
In each of the experiments described above, it is assumed that 1) the sulfatic sulfur is solubilized upon contact of the coal with the medium and 2) the organic sulfur remains unaltered by the aforementioned treatments thereby leaving only the pyritic sulfur to be removed by bacterial action. This allows the use of total sulfur analysis as a means of following the depyritization of the coal. However, further investigation into the action of heptane (upon all forms of sulfur) is warranted and more detailed sulfur analyses may be required.

Future experimentation is planned as follows:

1) n-heptane removal of sulfur as a function of time

2) effects of other organic solvents (e.g. acetone, benzene, etc. for

removal of sulfur)

3) determination of the effect of each of the above treatments on $T$. ferrooxidans and $T$. thiooxidons activity in shake flasks

4) the acclimation of Thiobacillus cultures to FeS, use by the addition of small amounts of elemental sulfur to growing cultures.

Final Report.

Reporting on these results will be made in the May monthly report and the Project

Task 3 - Analytical Procedures for Total Organic Sulfur.

3.1 Characterization.

Task complete.

3.4 Microscope Analysis.

Task complete.

Task 4 - Organic Sulfur Removal

Task complete. 


\section{ATTACHMENT B}

Attachment B contains a complete, chronological description of Task 4--Organic Sulfur Removal, as conducted by Dr. Bailey Ward at the University of Mississippi. 


\title{
MICROBIAL EXTRACTION OF NONPYRITIC SULFUR FROM COAL
}

\author{
BAILEY WARD, Ph.D. \\ Principal Investigator
}

Environmental Microbiology Laboratories

Department of Biology

The University of Mississippi

University, Mississippi 38677

Principal Research Team

Joe E. Lepo, Ph.D.: Research Associate

Carol J. Stevens, Ph.D.: Research Associate

Ralph F. Purdy, M.S.: Research Assistant

\begin{abstract}
FINAL REPORT
Subcontract research in collaboration with Louisiana Tech University

Department of Chemical Engineering

U.S. Department of Energy Contract NO. DE-AC22-88PC88854
\end{abstract}

November 5, 1991 


\section{SUMMARY}

Several hundred bacterial cultures isolated from a variety of natural sites were tested for their ability to desulfurize selected model coal organos/ Ifur compounds. Initial focus was on detection of biodesulfurization of dibenzothiophene (DB'T) via a proposed pathway involving the intermediates, DBT-5-oxide, DBT-5-dioxide (-sulfone), and 2-(2-hydroxyphenyl)benzenesulfonic acid, from which removal of sulfate would give the produst, 2,2'-dihydroxybiphenyl. Severai screening methods initially were used to monitor desulfurization activity (on different organosulfur compounds): the Lehigh spray-plate assay (DBT), growing cell suspensions (DBT or DBT-sulfone), resting cell slurries (DBT or DBT-sulfone), or a sulfur-stress assay in which the only source of sulfur was organic (DBT or DBT-sulforie).

Numerous cultures produced colored "Kodama-type" products from DBT, but not from DBT-sulfone, via a carbon-destructive, non-desulfurizing pathway. Because the Kodama products interfered with detection of desulfurization activity, DBT-sulfone became the substrate of choice for subsequent screening assays. Although several cultures from a variety of sources exhibited activity (removal or disappearance from solution) on DBT-sulfone, no products were detected by the assays for which an inorganic-sulfur-sufficient medium was used.

Only two of our isolates, UMX9 and UMX3, and the strain IGT S-8, provided by the Institute for Gas Technology as a reference culture, would grow on DBT or DBT-sulfone as a sole source of sulfur under the sulfur-stress assay. Under sulfur-stress conditions, a desulfurized product was detected only for UMX9 and IGTS8. The desulfurized product was identified as 2-hydroxybiphenyl (2-phenylphenol). Biodesulfurization activity for all three organisms occurred only for growing cultures (vs. Washed, resting cell suspensions), and was depressed by free sulfate, although more so for UMX3 and IGTS8 than for UMX9. All three organisms exhibited similar biodesulfurization activity on a variety of organic sulfur substrates. Comparative tests on carbohydrate utilization (48 substrates using API CH kit) revealed that only UMX9 would grow on glucose, and that only IGTS8 would grow on L-arabinose. None of the three cultures exhibited good growth on DBT, DBT-sulfone, or 2-phenylphenol as sole sources of carbon, compared to growth on glycerol, and none produced Kodama-type colored products from DBT. Taxonomic studies (including MIDI analysis) revealed UMX3 to be similar to IGTS8, whereas UMX9 exhibited characteristically different features. All of the organisms exhibited Rhodococcus-like features. Assays of biodesulfurization activity as a function of temperature or $\mathrm{pH}$ revealed further differences between UMX9 and UMX3/IGTS8. Under optimized assay conditions for each organism, UMX9 exhibited ca. 30\% greater biodesulfurization activity than did IGTS8 and UMX3, which were about identical in activity.

Cultures UMX3 and UMX9 were tested for ability to grow on biodepyritized coal as sole source of sulfur, under the conditions of the sulfur-stress assay, with glycerol and glucose as carbon sources. Relative to appropriate controls consisting of growth medium plus coal only or medium plus cells only, both UMX9 and UMX3 exhibited better growth on coal as sole source of sulfur. Evidence of physical deterioration of the coal was noted for some biotreated samples. No data have yet been obtained on coal chemistry, thus we can only suggest that organic sulfur was removed from the coal.

\section{INTRODUCTION AND BACKGROUND}

Combustion of sulfur-containing fossil fuels results in the liberation of sulfoxides into the atmosphere where they react with water to produce sulfuric acids. Precipitation laden with the acids forms "acid rain", which poses a multitude of threats to the environment. The continued use of coals in general, and highsulfur coals in particular, will require technologies designed to eliminate or reduce sulfur emissions. Two approaches can be taken: elimination of sulfur from post-combustion gases or pre-combustion coal 
desulfurization, the latter being the subject of the present report. The predominant forms of sulfur in coals are 1) inorganic pyrite crystals existing as aggregates cloistered among, but not bound to, the organic coal matrix and 2) "organic" sulfur bound to carbon atoms. On the average, about one-half of the total sulfur in a "typical" coal is organic. The bulk of pyritic sulfur can be removed by a variety of chemical, physical, and biological technologies, but efficient methods for removing organic sulfur are lacking.

Because it would be desirable to remove coal organic sulfur without loss of fuel value, we proposed to search for bacteria capable of cleaving $C$-S bonds in model coal compounds or of coal itself. Previous reports $(1,2)$ already had established the potential for using bacteria to remove organic sulfur from coals, a process that will be called biodesulfurization in the present report. A pathway was proposed (2) for selective enzymatic cleavage of C-S bonds in thiophenic model compounds, with emphasis on

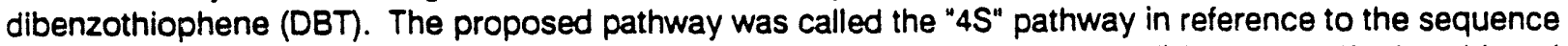
of sulfur oxidation via DBT-5-oxide, DBT-5-dioxide (-sulfone), 2-(2-hydroxyphenyl) benzenesulfonic acid, and liberation of free sulfate ion, resulting in the desulfurized product, 2,2 -dihydroxybiphenyl. A variant of the $4 S$ pathway leading to 2 -hydroxybiphenyl has been reported by Kilbane $(3,4)$. Another possible pathway of biodesulfurization has been suggested (5) in which ring cleavage accompanies or follows desulfurization, with benzene and derivatives occurring as transient intermediates. (The 4S pathway is illustrated in Fig. 1, App. 8) For effective biodesulfurization of fuel coals, the desired activity would be specific cleavage of the bonds of any sulfur bound to coal carbon. The fact of attendant ring cleavage of model compounds might be inconsequential inasmuch as such compounds likely do not exist in coal. That is, a microorganism that removes sulfur from DBT along with degradation of the parent substrate might only remove sulfur from coal.

Our objectives were to obtain one or more novel microbial systems that specifically desulfurized DBT or DBT derivatives (with or without ring cleavage, but with focus on 4S-type activity), to characterize the biodesulfurization activity and the organisms themselves, and to test the superior cultures on biodepyritized coal.

The project developed and matured over a period of about thirty months, with progress and noteworthy events chronicled in the forms of monthly and quarterly reports, and in three manuscripts published as proceedings $(6,7,8)$. Detailed and timely descriptions of methods, data collected, and interpretations appeared in the aforementioned reports, some or portions of which are appended to the present final report (in an approximately chronological sequence) to serve as references. For convenienc. (and to avoid having to rewrite that which already has been written) we will refer the reader to the Appendices for details of methodology, experimental rationale and setups, data, and results obtained as the project developed. This final report is presented as a chronology of events leading to a focus on the three (out of hundreds tested) organisms--cultures UMX3, UMX9, and IGTS8--that exhibited definite biodesulfurization, defined herein as

ability to grow on an organosulfur substrate as a sole source of sulfur. For convenience of reporting, details of new methodologies applied for the last few months of the project are presented in Appendix 7. This approach allows for a narrative description of general approaches with focus on important findings and interpretations. The project culminated with a presentation and manuscript (App. 8) for the Third International Symposium on Biotechnology of Coal and Coal-derived substances, Essen, Germany, Sepiember 23-24, 1991.

\section{PROJECT CHRONOLOGY}

We initially focused on isolating from natural sources bacteria that exhibited one or more of the reactions associated with the $4 S$ pathway. Because DBT is a common component of petroleum, we reasoned that sites of petroleum contamination might harbor bacteria capable of desulfurizing thiophenic compounds. We collected samples of weathered or fresh, refined or crude petroleum that had been mixed with soils or water in streams, ditches, or sumps near oil wells, pipelines, or storage or transfer facilities. At the time of the 
initiation of the project, we were aware that Professor Steven Krawiec of Lehigh University had reported (INEL Program Review, January, 1989 and personal communications;later published, ref. \#9) on the isolation from fuel-oil-contaminated soil of several (actually numerous) bacteria that gave evidence of production of $2,2^{\prime}$-dihydroxybiphenyl from DBT. Dr. Kraweic's apparent success reinforced our initial focus on collecting samples from oil-contaminated sites. We also collected samples from several sites where coals had been mixed with moist soils, and from an activated sludge wastewater facility.

Over the course of the project, several methods were tested as screening assays to detect and monitor biodesulfurization activity. Our desire was to use a rapid and simple regime that would allow for screening many isolates for $4 S$ activity. Initially, we tried the Lehigh spray-plate assay $(9 ; A p p .1,2)$ on a few hundred cultures, but found no convincing indications of (presumptive) $4 S$ activity (DBT-dependent production of fluorescent products). Unless stated otherwise, an inorganic sulfur-sufficient medium, designated 21C (App. 1, p.3; ref.10) was used for all assays. This was the medium formulation exactly as used by Professor Krawiec (9) for detecting $4 S$ activity for the Lehigh isolates via the spray-plate assay, thus we presumed that our use of the same formulation would yield good results in our hands.

Our initial lack of success using the spray-plate assay prompted us to secure cultures of several of the Lehigh University (Professor Steven Krawiec et al.) collection; these cultures had been reported to exhibit presumptive $4 S$ activity via spray-plate assay and in some cases to produce $2,2^{\prime}$-dihydroxybiphenyl (9). After consultation with Dr. Krawiec and his associate, Diane Dutt, to ensure similarity of techniques, we tested the Lehigh isolates $C_{18}, F 23, B 24, A 4, C 1, C 2, D 20, E 1$, and F14. It was our aim to use the Lehigh cultures as references to test our methodologies and analytical techniques; we wanted to be sure that we were not missing $4 S$ activity due to faulty techniques. A few of the Lehigh isolates did produce blue fluorescent products from DBT, but these same cultures also produced colored products, a phenomenon consistent with "Kodama" metabolism of DBT resulting in sulfur-containing yellow/orange/red products (11) which also fluoresce blue under short wavelength irradiation (12). After many trials and manipulations, we concluded that the spray-plate method did not allow us to differentiate between possible production of $4 S$ products and conspicuous production of Kodama products. In fact, all presumptive positive 4S activity was due either to confirmed Kodama products or to unidentified but undesulfurized products. In no case for any isolate. including the nine Lehigh isolates, did we detect a desulfurized product from DBT, although several isolates would remove DBT from solution. For these and subsequent experiments, we used thin-layer (TLC) and gas chromatography $(\mathrm{GC})$, and $\mathrm{GC} /$ mass spectrometry (GC/MS) to monitor or identify products. Refer to App. 1-5 for details of analytical protocols and to App. 3 and 5 for a description of our experiences with the Lehigh Plate Assay.

As we were testing the spray-plate assay, we also began to use shake-flask cultures to screen for biodesulfurization activity, both of crude or "raw" mixed cultures obtained directly from collected samples or of purified cultures. For these trials, we added DBT crystals to standard $21 \mathrm{C}$ medium inoculated with cells, then incubated cultures plus DBT-only and cell-only controls at $30^{\circ} \mathrm{C}$ (the standard temperature of all assays, uniess otherwise noted). Developed cultures were extracted with organic solvent (App.2 which was analyzed by $G C$ for amount of DBT remaining and appearance of $4 S$ products. We also compared growing cells (shake-flask) with resting cell suspensions. Appendix 3 contains descriptions of the analytical methods. We were not able to detect desulfurized products for any culture tested (although some DBT disappeared from the medium for some cultures). We encountered problems with interference by DBT crystals of celldensity (O.D.) measurements so we began using DBT-sulfone as a substrate because of its greater water solubility than DBT. We used a water-saturated DBT-sulfone $(0.166 \mathrm{mM}$ ) solution (no crystals) for subsequent tests. We reasoned that any organism capable of desulfurizing DBT via the $4 S$ pathway would also desulfurize DBT-sulfone. Although several cultures would readily remove DBT-sulfone from solution, in what appeared to be cometabolic reactions, we did not detect any products of possible biodesulfurization reactions. In short, we were not getting any evidence of desulfurization, only removal of the substrate. We should note here that we never were able to confirm biodesulfurization activity for any of the Lehigh isolates. Refer to App. 3 and 5 and ref. No. 6 and 7 for details. 
We also tested numerous cultures (that removed DBT or DBT-sulfone) for release of sulfate into the medium. We used at first the ASTM turbidimetric $\left(\mathrm{BaCl}_{2}\right.$ precipitation, App. 1) method then turned to ion chromatography (App. 5). We were not able to demonstrate significant increases in sulfate due to microbial activity on the thiophenic substrates; yet we had no real evidence that desulfurization was occurring. We wonder if cometabolic release of sulfate from organosulfur compounds in a sulfate-sufficient medium would indeed result in measurable increase in total sulfur. We became concerned that the presence of free sulfate in the culture medium might repress biodesulfurization activity. During this stage of the project we learned of Dr. John Kilbane's work at the Institute of Gas Technology (IGT). Dr. Kilbane described $(3,4)$ a "sulfur bioavailability assay" in which an isolate designated IGT S-8 would grow on DBT as a sole source of sulfur; the organism, identified by Dr. Kilbane as a Rhodococcus thodocrous, produced the product 2 hydroxybiphenyl, designated in the present report as 2-phenyiphenol. Thus IGT S-8 exhibited a variant of the proposed $4 S$ pathway. Dr. Kilbane sent a filtered (cell-free) supernatant prepared at IGT for us to analyze to provide independent confirmation of the biodesulfurized product, 2-phenylphenol. The supernatant was from a spent culture medium in which DBT had served as the sole sulfur source for IGT S-8 prepared at IGT. We confirmed (by UV spectral analysis, GC/MS, GC, and TLC) presence of 2 phenylphenol in the filtered supernatant. We realized that we had been devoting our efforts to the wrong approach for obtaining biodesulfurizing isolates. We modified our standard $21 \mathrm{C}$ medium by replacing all sulfate salts with chloride salts to yield a sulfur-free medium, which then was used for our Sulfur-Stress Assay, in which the only source of sulfur was DBT-sulfone (water-saturated solution) or other organosulfur substrates. Glucose and glycerol were provided as organic carbon sources to favor growth of a variety of organisms. Each trial consisted of three sets of culture-tube preparations containing $10 \mathrm{ml}$ of medium:

SET 1. DBT-sulfone + inoculum;

SET 2. inoculum only in sulfur-free medium;

SET 3. DBT-sulfone + inoculum + added sulfate $[0.166 \mathrm{mM}]$.

Cultures were considered to exhibit biodesulfurization when good growth occurred in SET 1 tubes and continued after several (five or more) successive transfers; with no to minimal growth in SET 2 tubes: and with good growth in SET 3 tubes which also allowed us to check for possible inhibition by the organosulfur substrate. All glassware was rinsed in $\mathrm{HCl}$ to remove residual sulfur. Measurements of optical density (O.D.) provided indications of cell growth. Culture extracts were analyzed by GC and GC/MS to monitor desulfurization activity (removal of organosulfur substrate and appearance of desulfurized product).

The reader here is referred to App. 7 and 8 for details of methodology and procedures for the latter phases of the project.

For time-course analyses of DBT-sulfone removal and appearance of 2-phenylphenol via sulfur-stress assays, we also used spectrometric UV scans to monitor and quantify biodesulfurization. Because DBT. sulfone and 2-phenylphenol gave distinguishable spectral peaks in the range $200-400 \mathrm{~nm}$, this method allowed us to monitor directly the aqueous, cell-free supernatants of test cultures (DBT-sulfone supplied as water-saturated solution of $0.166 \mathrm{mM}$ ). We used a Milton Roy Spectronic 1201 coupled to a computerized SpecScan program that allowed for curve area analysis and differentiation. Cultures were grown under sulfur-stress condtions, shaken in flasks at $30^{\circ} \mathrm{C}$, with $1.5 \mathrm{ml}$ samples withdrawn at time intervals. centrifuged at $10,000 \times g$ for $10 \mathrm{~min}$, then read directly via spectrometry.

Using the sulfur-stress assay, we retested most of our original isolates, including the Lehigh cultures. and several hundred cultures from the University of Alabama. Huntsville/ collection (isolated from superfund sites-Professor Alfred Mikell et al.). We also obtained IGT S-8 from IGT (Dr. John J. Kilbane) to serve as a reference culture. Of the first several hundred cultures tested, only IGTS8 grew on DBT or DBT. sulfone as a sole source of carbon. However, during subsequent trials, a mixed culture, designated UMX. exhibited positive activity on the sulfur-stress assay. The aforementioned filtered supernatant from IGT 
arrived in an apparently non-sterile container (the sample was faintly turbid), and we took no special aseptic precautions in handling the sample. We at once fractionated the sample, then extracted one fraction for analysis; the other fraction was dispensed to a non-sterile culture tube. Subsequent examination of the reserve fraction indicated the presence of cells, so we decided to attempt to culture them. Our interest was piqued by the presumption that the filtrate should have contained no free sulfur; no DBT was detectable by our GC or GC/MS analysis. Even if the solution contained a variety of bacterial cells, the lack of available sulfur should have prevented or at least severely restricted growth. However, organisms having a low sulfur requirement might at least survive the sulfur-stressed environment. A mixed culture derived (initially in $1 / 10$ strength tryptic soy broth) from the filtrate grew in the sulfur-stress assay on DBT-sulfone as sole source of sulfur and produced 2-phenylphenol (App. 5, Fig. 1). Our first thought was that IGT S-8 had slipped past the filter at IGT, and was present in the consortium. Examination of the consortium after growth on the sulfur-stress assay revealed a predominance of two pseudomonads along with several other organisms (App. 5). Upon separation and repeated tests of members of the consortium, only two isolates in pure culture, UMX3 and UMX9, grew well on the sulfur-stress assay. Analysis of extracts revealed that only UMX9 produced 2-phenylphenol, and that UMX3 did not produce a detectable product (App. 5,8). As evidenced by staining reactions, cell and colony morphology, and growth habit in liquid media, UMX3 appeared to be identical to IGT S-8, with the exception of lack of 2-phenylphenol in extracts of UMX3. The UMX9 appeared to be unllke either UMX3 or IGTS8 (App. 6). Thus, we concluded that IGT S-8 was not present in the consortium. The UMX cultures represented a fortuitous circumstance in which the original filtrate served as an enrichment and selection medium favoring the survival of organisms capable of desulfurizing the minuscule amount of DBT that must have remained in solution; or perhaps sulfur was being recycled from biomass. Our subsequent tests revealed that the nondesulfurizing members of the original consortium would grow in the sulfur-stress medium only when the desulfurizlers were present. Moreover, the nondesulfurizers usually were the dominant members of the consortia; indeed, desulfurizers were not apparent in the mix when it was viewed via microscopy, yet they could be isolated by serial dilutions and plate culture on sulfurstress media. We concluded that the desulfurizer(s) liberated excess sulfur from the organosulfur substrate. and that the other organisms scavenged the free sulfur, leaving just enough for survival of the desulfurizers.

Inasmuch as by this time the project was nearing final stages, and considering the fact that UMX 3 and UMX9 were the only isolates that we had obtained that exhibited biodesulfurization activity, we elected to concentrate our remaining efforts on characterizing these cultures in comparison to IGT S-8; the remainder of this report focuses on these activities, and the manuscript in App. 8 describes the results of our investigations.

Our objectives were to reveal additional taxonomic or physiological differences among the three organisms, and to compare the three with respect to biodesulfurization acthity. For these assays, we used the spectrometric method described earlier. Details of methodology are given in App. 7. Five replicate cultures were used for each experimental variable vs. each tested organism; data are reported as the mean of the five replicates, unless stated otherwise.

Taxonomic/physiological Studies. Our approach to taxonomic differentiation was to have the cultures analyzed by MIDI analysis (App. 7) and to apply the API carbohydrate utilization test to determine differences, if any, in carbohydrate metabolism. We also compared physiological responses of each culture with respect to ability to degrade and perhaps grow on DBT-sulfone or 2-phenylphenol, and checked each for production of Kodama-type products from DBT. Not only would differences in ability to degrade or utilize DBT-sulfone or 2-phenylphenol indicate genetic differences, but also would provide important information in assessing degree to which biodesufurization occurred. For example, if UMX3 rapidly degraded 2 . phenylphenol, then its mechanism of biodesulfurization of DBT-sulfone might be the same as that of IGTS8. with the additional capacity for ring cleavage. Moreover, biodegradation of 2-phenylphenol would obscure the actual rate of production. For these tests, we used spectrometric analysis and compared experimentals vs. controls vs. time of incubation. 
Kilbane (13) reported that the fatty-acid profile of IGT S-8 revealed Rhodococcus rhodocrous, thus we applied a similar technique to support our own taxonomic work. Our rationale for use of the API test was that because carbohydrate utilization likely represents metabolic pathways genetically distinct from biodesulfurization of thiophenes, such differences would reflect true taxonomic differences among the organisms. Moreover, Kilbane (personal communication) stated that IGT S-8 would not grow on glucose as a carbon and energy source.

We should note that none of the three cultures (UMX3, UMX9, or IGT S-8) produced "Kodama"-type colored products from DBT or DBT--sulfone, and no such products were detected by GC/MS.

The results of the MIDI analysis reported in App. 6 are not conclusive. Both UMX3 and IGT S-8 exhibited similar profiles, but none of the three cultures gave a good match with any organism in the library, including Rhodococcus rhodocrous and a variety of other species of Rhodococcus. We can now only state that UMX3 and IGT S-8 are obviously different from UMX9 and that all three exhibit Rhodococcus-like features.

Figures 2-4, App.8 contain representative time-course assays of growth, disappearance of DBT-sulfone, and appearance of 2-phenylphenol for each of the three organisms assayed under sulfur-stress conditions, with glycerol and glucose as carbon sources, and with DBT-sulfone as sulfur source.

When DBT-sulfone was supplied as sole carbon and sulfur source or 2-phenylphenol sole carbon only (with $0.16 \mathrm{mM}$ sulfate added), increase in cell density atter $120 \mathrm{~h}$ of incubation was about the same as occurred when no carbon source was added. Some reduction in both 2-phenylphenol and DBT-sulfone occurred for all three organisms. We attribute the slight increase in cell density to carryover carbon/energy source from the starter culture. Small decreases in DBT-sulfone of $0.04-0.05 \mathrm{mM}$ occurred for all three organisms, indicating some removal by the cells. Data and discussion are presented in App. 8.

The results of the API CH tests are presented in Table 5, App. 6. Culture UMX9 would grow on glucose, whereas neither UMX3 nor IGTS\& would do so, and only IGTS8 would grow on L-arabinose. Our working conclusion from the data available is that there are distinct taxonomic differences among the three organisms. UMX3 and IGTS8 appear to be closely related, with physiological differences exhibited in L. arabinose utilization and production of 2-hydroxybiphenyl. The UMX9 appears to be a quite different organism from the other two, yet it possesses the ability to desulfurize DBT or DBT-sulfone to 2 hydroxybiphenyl, and to utilize glucose as a carbon substrate.

Comparative Biodesulfurization Activities. We wanted to determine the differences, if any, that existed among the three cultures with respect to rate and degree of biodesulfurization under a variety of different conditions. We made time-course studies of cell density (O.D.) and disappearance of DBT-sulfone as functions of different carbon substrates (glucose or glycerol) or added sulfate to test for repression of activity. The results of first tests using the different carbon sources are presented in App. 6, Fig. 1 \& 2: the effects of added sulfate are described in Fig. 5-7, App. 8, which also presents a discussion.

We also tested each culture for effects of $\mathrm{Ph} 6,7, \& 8\left(30^{\circ} \mathrm{C}\right)$ and temperatures of $25,30,37, \& 41^{\circ} \mathrm{C}(\mathrm{pH}$ 7) on biodesulfurization to identify the best of each variable for each culture, then compared the three organisms under optimized conditions for each. These data along with discussion are presented in App. 8. The reader is referred to the manuscript of App. 8 for additional discussion, conclusions, and relevant references.

Tests on Coal. It was only near the end of the project that we had obtained biodesulfurizing strains, thus only a limited amount of work could be accomplished with coal. Details of the coal tests are presented in App. 6. Irı summary, UMX3 or UMX9 exhibited greater growth on biodepyritized coal as a sole source of sulfur than on control medium. Physical deterioration of the coal was evident after microbial growth. Glucose and glycerol were supplied, thus it is unlikely that the organisms were utilizing coal carbon.

We were not able to have chemical analyses done, thus we only can state that apparently the coal provided 
a source of sulfur; whether organic or not is not known now.

\section{SUBCONTRACT PROPOSAL TASK SUMMARY}

The subcontracted efforts were addressed to Task 4 - Organic Sulfur Removal of the Louisiana Tech proposal. The subcontract proposal Identified three Subtasks to be performed at the University of Mississippl. Our success at accomplishing each of these efforts is summarized below.

\section{Subtask 4.1 - Desulfurization with OC7-A}

Dr. Joseph Fernandes of Louisiana Tech supplied us with a culture identifled as OC7-A. The suspension contained several organisms, none of which appeared to be similar to OC7-A, and none of which exhibited any evidence of biodesulfurization. Further work under Subtask 4.1 was not warranted.

\section{Subtask 4.2 - Search for New Organisms}

The narrative of the preceding pages $1-6$, and the appended materials document our broad efforts and narrow success under this Subtask, which became the primary focus of the research.

We were disappointed that work with coal was limited, due to the fact that the project was almost at end and no additional funds for personnel, supplies, and services were available. As a major component of the overall project, personnel at Louisiana Tech were to provide organic-sulfur analyses using the SEM/EDX system at LTU, in addition to running other coal chemistry analyses on the biologically treated coals. Unfortunately, by the time that we had generated biotreated coals (biodepyritized at LTU), work at LTU had shifted to other focuses. Inasmuch as our funds were exhausted, we were unable to have the biotreated coals tested for amount and kinds of sulfur removed.

\section{Subtask 4.3 - Plasmid-medlated Techniques}

Louisiana Tech subcontracted separately with Dr. David Graves, Department of Chemistry, University of Mississippi, for the plasmid work to be done under this Subtask. Our own efforts focused on tests of cellfree extracts of UMX9 and UMX3 (prepared by nitrogen-decompression or French press rupture) revealed no detectable biodesulfurization activity. Some activity was detectable for the cell-particle fractions, but this was greatly reduced when equated with a comparable-biomass, whole-cell preparation. Further work in this direction was not done in favor of other efforts. A tentative conclusion is that the biodesulfurization activity is not mediated by extracellular enzymes.

Dr. Graves analyzed several of our isolates for plasmids during the first year of the project, but none of these ultimately exhibited true biodesufurization, thus the data were not relevant. Toward the end of the project, Dr. Graves tested UMX3, UMX9, and IGT S-8; no plasmids were identified, thus further work under this Subtask was not warranted. 


\section{REFERENCES}

1. Knecht, A.T. Jr. "Microbial oxidation of dibenzothiophene and its possible application in the desulfurization of coal and petroleum." Ph..D. Dissertation, Louisiana State University, Baton Rouge, 53 pages (1961).

2. Isbister, J.D., and E.A. Kobylinskl. "Microbial desulfurization of coal," In: Y. Attia (ed.), Coal and science technology: processing and utilization, p. 627-641. Elsevier/North Holland, Amsterdam (1985).

3. Kilbane, J.J. "Sulfur-specific microbial metabolism of organic compounds." Resources, Conservation, Recycling, 3:69-79 (1990).

4. Kilbane, J.J. "Blodesulfurization: Future prospects in coal cleaning." Proceedings: Seventh International Pittsburgh Coal Conference, pp. 373-382 (September, 1990)

5. van Afferden, M., S. Schacht, J. Klein, and H.G. Truper. "Degradation of dibenzothiophene by Brevibacterium sp. DO." Arch Microbiol. 153:324-328 (1990).

C. Ward, B., J.E. Lepo, F.R. Purdy, and C.J. Stevens. "Studies on biodesulfurization of model coal organosulfur compounds." Proceedings: First International Symposium on the Biological Processing of Coal, Orlando, Florida, P45-51 EPRI GS-6970 (May, 1990).

7. Lepo, J.E., R.F. Purdy, and B. Ward. "Microbial activity on model coal organosulfur compounds." Proceedings: Sixth Annual Coal Preparation, Utilization, and Environmental Control Contractors' Conference (Pittsburgh, Pennsyivania) pp. 226-233 (August, 1990)

8. Purdy, R.F., B. Ward, and J.E. Lepo. "Microbial extraction of sulfur from model coal organosulfur compounds". Proceedings: Third Symposium on Blotechnology of Coal and Coal-derived Substances, 23-24 September, 1991, Essen, Germany.

9. Krawiec, S. "Bacterial desulfurization of thiophenes." Developments in Industrial Microbiology. 31:103-114 (1990).

10. Guirard, B.V., and E.E. Snell. "Blochemical factors in growth." In: G. Gerhardt (ed.) Manual of Methods for General Bacteriology, American Society for Microbiology, Washington, D.C., USA (1981).

11. K. Kodama, K. Umehara, K Shimizu, S. Nakatani, Y. Minoda, and K. Yamada. "Identification of Microbial Products from Dibenzothiophene and its Proposed Oxidation Pathway." Agr. Biol. Chem. Vol 37, pp. 45-50 (1973)

12. Monticello, D.J., D. Bakker, and W.R. Finnerty. "Plasmid-mediated degradation of dibenzothiopherie by Pseudomonas species". App. Environ. Microbiol. Vol 49 (4):756-760. 1985

13. Kilbane, J. J. "Biodesulfurization: Future prospects in coal cleaning." Proceedings: Seventh Annual International Pittsburgh Coal Conference, University of Pittsburgh, Pittsburgh, Pennsylvania. USA (September, 1990). 


\title{
APPENDIX I
}

\author{
BIOLOGICAL SAMPLES \\ DBT-FLUORESCENCE SPRAY.PLATE ASSAY \\ CULTURE MEDIA \\ GAS CHROMATOGRAPHY METHODS \\ ASTM SULFATE ASSAY \\ LEHIGH UNIVERSITY CULTURES \\ SOLVENT EXTRACTION METHODS \\ CHROMATOGRAM OF ORGANIC SULFUR STANDARDS
}


Date: $3-3-89$

To: Brace Boyden, Interim Project Manager

Department of Chemical Engineering

Louisiana Tech University

Ruston, LA

Telephone: 318-257-2885 (LTU FAX No. 318-257-3356)

From: Bailey Ward,

Principal Investigator Research Associate

The University of Mississippi

Laboratory of Environmental and Applied Microbiology

Department of Biology

University, MS

Telephone: 601-232-7203

Re: Quarterly Report for the Period December 15, 1988 - March 15, 1989. Biodesulfurization Project.

\section{Personnel}

Beginning on January 1, 1989, Dr. Carol J. ("C.J") stevens joined the project as a Postdoctoral Research Associate. Dr. Stevens received her Ph.D. in Microbiology in December, 1988 from The ohio state University, where she studied the physiology of Thiobacillus ferrooxidans. Also on January 1, Mr. Mannish Petrekh, and on January 15, Mrs. Kathleen Odum began work on the project as research assistants.

Apparatus

During the last of January and first of February, two waterbath (culture) shakers and a Hewlett Packard Model 5890A gas chromatograph with Model $3396 \mathrm{~A}$ integrator were installed.

\section{screening for $4 \mathrm{~s}$ Bacteria}

Methods: Bacteria that were potentially positive for the $4 \mathrm{~S}$ pathway were screened by two methods. The first method was developed at LeHigh University by Dr. Steven Krawiec and his staff, the other was developed at INEL by Tom Ward and Diane Key. The Krawiec method involved growing bacteria on solid 2lC agar, spraying the plates with $38 \mathrm{DBT}(w / v)$ in ethyl ether, allowing the plates to dry, and then observing the plates under a $254 \mathrm{~nm}$ light source with the intention of observing the production of the Eluorescent compound 2,2'-dihydroxybiphenyl (Krawiec's staff claimed the results should be positive within 2 hours). The TTC assay involved growing bacteria on TTC agar that had first been sprayed with $3 \%(\mathrm{w} / \mathrm{v})$ DBT in ethyl ether. Those bacteria able to 
utilize the DBT produced an excess of electrons that were used to reduce the TTC dye to a red color and therefore produced red colonies. Bacteria unable to utilize DBT could not reduce the dye and produced white colonies. The red colonies were then transferred to TTC agar without DBT and were allowed to grow. The lack of excessive carbon source and hence electrons resulted in white colonies; red colonies were regarded as negative because the bacteria were not limited by the yeast extract.

Sample sources: Bacteria to be screened were isolated from the following sources: (a) the soil from a coal yard in Memphis, TN; (b) the soil contaminated with oil from an oil company in oxford, MS; (c) a natural crude-oil seepage site at Beaver Dam Creek, MS (these samples were obtained by a state agency in 1985 and had been stored; plans to obtain fresh samples have been hampered by flooding in the area); (d) airborne bacteria that contaminated medium containing DBT. Due to our inability to reproduce the positive results obtained by Krawiec's lab with their method, we also obtained some of their cultures (A4, B24, C1, C2, C18, D20, E1, F14, F23) to use as positive controls.

We made numerous unsuccessful attempts to obtain DBTdependent fluorescence (of presumed $4 \mathrm{~S}$ products) from microbial isolates obtained from our sample sources. We double-checked tc insure that our techniques conformed to those used by Dr. Steve Krawiec and his colleague, Diane Dutt at LeHigh University. We tested nine of Dr. Krawiec's isolates, but could not detect DEMdependent fluorescence from any culture using the three-percent diethyl ether solution of DBT described by the LeHigh team. During a series of exploratory tests in our lab, Dr. Stevens discovered that vivid DBT-dependent fluorescence occurred when a $0.1 \%$ solution of DBT in ether was sprayed onto developed colon:es of the LeHigh isolate strain C-18. This finding confirmed the reports by Dr. Krawiec. We note here that a very light coating of DBT gave the best results, e.g., the amount of DBT crystals deposited on the agar surface produced a barely detectable "sheen" when viewed at an angle under room fluorescent lighting. Table I presents our data on presumptive 45 and "Kodama" activity of the LeHigh cultures.

Details of our procedures are as follows: We used a "Chromist" (Gelman Cat. No. 15901) sprayer to deliver one short burst of DBT solution directly onto the agar surface (in a fume hood with $100 \mathrm{ft} / \mathrm{min}$ velocity air flow). The culture dish 1 id was replaced after about min of drying. Preparations were monitored at room temp. (ca $25^{\circ} \mathrm{C}$ ) from time "zero" at $15 \mathrm{~min}$ intervals up to 2 hours, or after incubation at $30 \mathrm{C}$ overnight. Fluorescence was monitored under a spectroline Model ENF-260C, $254 \mathrm{~nm}$ UV lamp (about $430 \mathrm{uW} / \mathrm{cm}^{2}$ at $15 \mathrm{~cm}$ ), with plates held at an angle at 5-6 cm from the lamp fitted to a spectroline Model CM-10 viewing cabinet. Subsequent tests using $0.1 \%$ DBT on the other LeHigh isolates resulted in detectable fluorescence by five of the nine tested. Some of the Lelligh isolates produced 
colored "Kodama"-type products, as did several of our own source sample isolates sprayed with 38 DBT. We cannot now explain why the LeHigh isolates did not exhibit 4S-type fluorescence when sprayed with $3 \%$ DBT. It is likely that the LeHigh team applied considerable less of the 38 solution than we applied using the commercial pressurized spray applicator. Yet we still do not see fluorescence for three of the LeHigh strains.

Media: Cultures were maintained and tested on the medium $21 \mathrm{Cl}^{2}$ prepared as described below:

stock solutions: (autoclaved) $50 \mathrm{~g} \mathrm{NH} 4 \mathrm{Cl} / 500 \mathrm{ml}$ water; $69.25 \mathrm{~g}$ $\mathrm{KH}_{2} \mathrm{PO}_{4} / 500 \mathrm{ml}$ water; $50.25 \mathrm{~g} \mathrm{Na} \mathrm{HPO}_{4} / 500 \mathrm{ml}$ water; (filtersterilized) $30 \mathrm{mg} g$ lucose $/ 100 \mathrm{ml}$ water. Vitamin stock (filtersterilized): $0.5 \mathrm{mg}$ biotin, $50 \mathrm{mg}$ nicotinic acid, and $25 \mathrm{mg}$ thiamine-HCl/ $50 \mathrm{ml}$ water; Hutner's mineral base (filtersterilized).

To prepare (per liter final volume):

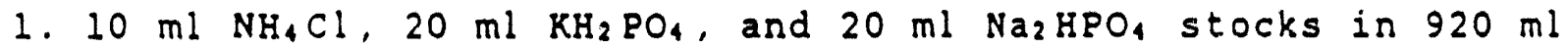
distilled water, autoclaved, then cooled.

2. The following Eilter-sterilized solutions are added aseptically to the solution from l. above: $20 \mathrm{ml}$ of trace metals (Hutner's vitamin-free trace metal mix), $1 \mathrm{ml}$ of vitamin $-i x$, and $10 \mathrm{ml}$ glucose. If solid medium is required, $15 \mathrm{~g}$ of agar is added prior to autoclaving. In certain circumstances, the glucose and vitamin mixtures are replaced by yeast extract.

TTC agar: This medium contained the same basal salts as the 2:C

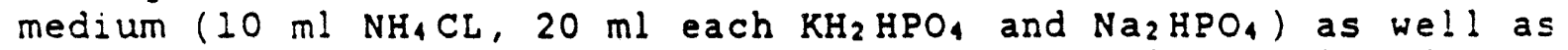
0.25 g yeast extract, $0.025 \mathrm{~g}$ triphenyltetrazolium cilorice (TTC), $15 \mathrm{~g}$ agar, and $930 \mathrm{ml}$ distilled water. The medium as autoclaved for $15 \mathrm{~min}$ at $121^{\circ} \mathrm{C}, 15 \mathrm{psi}$. When cool, $20 \mathrm{~m}$ ! of Hutner's trace metal $\mathrm{mix}$ were added.

The TTC assay indicated that several of the bacteria screened ( $S O C-3, S 2,54,58$, SOM1-17-1, SOM1-17-3a, SOM1-17-3b, SOM1-17-4, SOM1-17-5, SOM1-17-6a, SOM1-17-6b; Krawiec's cultures) were capable of utilizing DBT, but does not indicate if usage is via the Kodama or 45 pathways. These bacteria can be further screened by the $0.1 \%$ DBT fluorescence assay, determining the products of DBT degradation via GC, and possibly by measuring $\mathrm{SO}_{4} 2^{-}$release.

1 Guirard. B.V., and E.E. Snell. Biochemical Factors in Growth. In: Manual of Methods for General Bacteriology (G. Gerhardt, ed.). American Society for Microbiology (publishers), Washington, D.C. 1981 . 
Page 4 of 5

Analysis of DBT Degradation

Gas Chromatroqraphy

$\operatorname{DBT}(5 \% \mathrm{w} / \mathrm{v})$ in acetone was filter sterilized and $1 \mathrm{ml}$ aliquots were dispensed into sterile $125 \mathrm{ml}$ Erlenmeyer flasks. After drying overnight, $50 \mathrm{ml}$ of the $21 \mathrm{C}$ medium were added to each flask. The flasks were inoculated with $10 \mathrm{ml}$ of culture that had grown overnight in $21 \mathrm{C}$ medium: The flasks were then incubated at $300 \mathrm{C}, 125 \mathrm{rpm}$ for $48 \mathrm{~h}$. The DBT and hopefully its by-products were extracted by the following method. After prerinsing all glassware with chloroform, $0.5 \mathrm{ml}$ of 0.18 thianthrene was added to a $50 \mathrm{ml}$ centrifuge ( $1 / \mathrm{flask}$ ). The culture was added to the centrifuge tube, $9 \mathrm{ml}$ of chloroform were added to the flask and then transferred to the centrifuge tube. The tubes were inverted 50 times, centrifuged, and the organic layer saved. The tubes were extracted twice more with $8 \mathrm{ml}$ chloroform each time for a final total of $25 \mathrm{ml}$. Then 1 ul of the extract was injected into the gas chromatograph (FID detector, $15 \mathrm{ml} / \mathrm{min}$ He as the carrier gas, $10 \mathrm{~m} \mathrm{HP}-5$ column). Standard chromatograms have been prepared and preliminary trials have begun on assays for DBT bioconversions by the LeHigh cultures as well as some of the UM isolates.

\section{sulfate Assay}

The release of sulfate from DBT by microorganisms can potentially be measured using the ASTM turbidimetric method oE sulfate analysis. So far, we are still trying to determine the reprcducibility and detection limits for using this assay. Cultures are grown in $100 \mathrm{ml}$ of $21 \mathrm{C}$ media in $250 \mathrm{ml}$ Erlenmeyer flasks, incubated at $30^{\circ} \mathrm{C}, 125 \mathrm{rpm}$, for $48 \mathrm{~h}$. Samples are centrifuged and filtered to reduce turbidity. Then $50 \mathrm{ml}$ of the samp!e (or a diluted sample) are mixed with $12 \mathrm{ml}$ of gl $̈$ cerin (diluted $1: 1$ with water) and $5 \mathrm{ml}$ of $\mathrm{NaCl}$ solution ( $240 \mathrm{~g} \mathrm{NaCl}$, $20 \mathrm{~m}$ ! conc. $\mathrm{HCl}$ in 1 liter of water). The spectrophotometer is zeroed with the sample and then $0.3 \mathrm{~g}$ of $\mathrm{BaCl}_{2}-2 \mathrm{H}_{2} \mathrm{O}$ crystals are added and the sample stirred for $1 \mathrm{~min}$, then allowed to be static for $4 \mathrm{~min}$, then stirred for 15 seconds and the absorbance read at $390 \mathrm{~nm}$. The amount of sulfate present is determined by comparison to a calibration curve. The amount of sulfate used or released by the bacteria is determined by comparing the inoculated cultures to an uninoculated control. Thus far, the calibration curve is reproducible and it appears that the detection limits for sulfate used by pure cultures in $21 \mathrm{C}$ media may be within a useful range, provided that significant amounts of sulfate are released by DBT.

\section{UV spectrophotometry}

Attempts were made to determine if the degradation of DBT to $2,2^{\prime}$-dihydroxybiphenyl ( $0,0^{\prime}$-biphenol) could be followed using UV spectrophotometry. DBT was dissolved in tert-butanol (0.5\% to $0.0005 \% \mathrm{w} / \mathrm{v}$ ) and scanned from 350 to $250 \mathrm{~nm}$. Similar scans were 
done on biphenol solutions in tert-butanol. It was determined that although there was overlap of the two spectra, the DBT and biphenol spectra were dissimilar enough that decreases in the DBT concentration could be monitored. Increases in biphenol would have to be greater than about 108 to be detected. Following this premise, it should be possible to grow cultures in $21 \mathrm{C}$ media with DBT, extract the DBT, and determine decreases when inoculated media are compared to uninoculated controls.

TABLE I

Presumptive 45 or "Kodama" Activity of Nine Krawiec(LeHigh University) Bacterial Strains Tested at UM

Strain

activity2

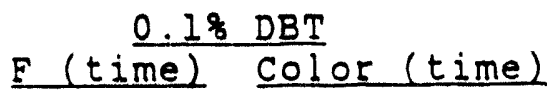

A 4

B2 4

CI

C2

C18

D20

El

F14

F23
$\mathrm{N}$

Y (18

$Y(18 h)$

$Y(15 \mathrm{~m}) \mathrm{N}$

$Y(15 \mathrm{~m}) \quad Y(18 \mathrm{~h})$

$Y(15 \mathrm{~m}) \quad Y(18 \mathrm{~h})$

$Y(18 \mathrm{~h}) \quad \mathrm{Y}(18 \mathrm{~h})$

$Y(18 h) \quad y(18 h)$

$Y(18 \mathrm{~h})$

$\mathrm{N}$

$Y(2 h) \quad N$
$3.08 \mathrm{DBT}$

$E$ (time) Color (time)

N

$Y(18 \mathrm{~h})$

$\mathrm{N}$

$\mathrm{N}$

N

$y(18 \mathrm{~h})$

N

$y(18 h)$

N

Y $(30 \mathrm{~m})$

N N

N $Y(6 h)$

N N

N N

IN none detectable; $Y=$ detectable; times in min. or hours (all colored products were orange). Strain Cl8 gave the most vivid fluorescence. 
Date: $4-7-89$

TELEFAX TRANSMISSION

To: Brace Boyden, Interim Project Manager

Departmen: of Chemical Engineering

Louisiana Tech University

Ruston, L:

Telephone: 318-257-2885

From: Bailey hard,

Principal Investigator

Carol J. Stevens,

Research Associate

The University of Mississippi

Laboratory of Environmental and Applied

Microbiology

Department of Biology

University, MS

Telephone: 601-232-7203

Re: Monthly Status Report, Biodesulfurization Project, Month of March, 1989 .

A. Studies or the Lehign University Isolates

Continued :ests revealed that the fluorescence ass $\because$ is sensitive to méium pH (using the 2lC yeast extract meisum described beloi). Best results were obtained at arounc pH 7 , with low activi=y below 6.5 , and with loss of detectabie fluorescence $a=\mathrm{pH} 7.5$ and inigher. The Hutner's vitamin-free stock solution zhanged from straw yellow to almost colorless when

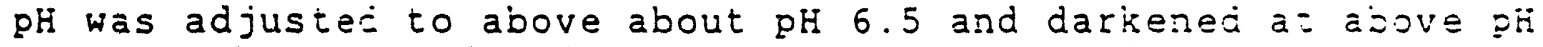
7.5. We have jiandoned tine use of glucose and the gurevitamin $\mathrm{mix}$ described $\equiv \equiv \mathrm{rlier}$ for 2IC. We now mix the three mazor sairs with $0.1 \%$ yeast extract, adjust the solution pH to 7.0 , add aga: at $1.5 \%$, then a:toclave. After the solution has coolec to about $55^{\circ} \mathrm{C}$, we add ت̈rtner's solution (adjusted to $\mathrm{pH} 7.0$ ). The medium supports good growth of many isolates and gives a low background fluorescence.

We have observed an interesting phenomenon for the LeHigh isolate c-18. To build up product concentration for extraction and assay of possible 45 products, we repeatedly sprayed $C-18$ colonies with C.18 DBT in ether; i.e., serial light app:ications were applied over a period of about 90 minutes. After about three applications, with concurrent fluorescence arounc the colonies, a disinct clear zone (clear of DBT crystals) developed around the colcry at about the location of the fluorescence. Colored (Kodama-type ?) products collected only on the colony surface. We ineerpret this observation to mean that the cells were producing extracellular enzyme(s) that converted tie crystalline DBT to colorless, noncrystalline (at least partially water soluble), Eluorescing product( $s$ ). 


\section{B. Search for New Isolates}

The P.I. collected a variety of crude-oil samples (fresh and weathered mixed with soil, decayed vegetation, or water in containment moats) from leaks and spills around pipelines and working or abandoned wells in oil fields in southern Mississippi and Al abama.

Several new isolates that exhibit DBT-dependent fluorescence were derived from the crude-oil samples. At least one of the new isolates appears to be a Bacillus sp, designated CIT-2, that produces fluorescence within about $30 \mathrm{~min}$ of $D B T$ application, but does not produce colored compounds after up to 72 hours of incubation. The lack of colored DBT-degradation products will facilitate sulfate assays read at near $400 \mathrm{~nm}$. Attempts to measure sulfate dynamics in cultures of strain C-18 (and other LeHigh isolates that produce colored compounds) were hampered by absorbance of the DBT-degradation products.

Research efforts now will focus on continued screening for new isolates, characterization of the new 4St strains, and on GC assays of new isolates to determine their ability to catalyze one or more of the proposed 45 pathway. Assays on sulfate rejection. Erom DBT also will be made. 
Date: 5-8-89

To: Brace Boyden, Interim Project Manager Department of Chemical Engineering Louisiana Tech University Ruston, LA Telephone: 318-257-2885
LTU Fax \#318-257-3356

UM Fax \#601-232-5453

From: Bailey Ward,
Principal Investigator
Research Associate

Carol J. Stevens,
The University of Mississippi
Laboratory of Environmental and Applied Microbiology
Department of Biology
University, MS
Telephone: 601-232-7203

Re: Monthly status Report, Biodesulfurization Project, Month of April, 1989.

Continued studies on the UM and LeHigh "4S+" isolates revealed that considerable variations in the fluorescence assay occur when attempts are made to obtain uniform and repeatable results. For reasons still unknown, the isolates (including the LeHigh $c-18$ strain) now do not yield good evidence of DBT-dependent fluorescence. For example, ether alone sometimes results in Eluorescent products, perhaps due to cell lysis or stimulation of release of fluorescing substances from the cells. There also are indications that some of the LeHigh cultures contain more than one organism. We are investigating methods to obtain consistent, believable results.

We now have screened (for DBT-dependent fluorescence) about three dozen samples of coal or petroleum materials. The Louisiana Tech group provided five samples collected from sludgepits, petroleum storage areas, coal mines, and the like. The UM samples were from coal yards, refined petroleum-contaminated soils, and crude oils. Only two samples of fresh crude oil mixed with water or soil yielded organisms that gave evidence of DBT-dependent Eluorescence, although we cannot obtain consistent results on subcultures of the isolates. The inconsistencies in the fluorescence screening method indicate a possibility that potential " $4 \mathrm{~S}+$ " isolates are being overlooked during routine screening.

We attempted unsuccessfully (via GC analysis of organic solvent extracts) to detect metabolism or transformation of DBT in liquid batch cultures or agar medium cultures of the UM and the LeHigh isolates. We also were not able to detect release of sulfate from DBT in liquid batch cultures of organisms (UM or LeHigh) 
Department of Biology

College of Liberal Arts University, MS 38677

(601) $232-7203$

Date: $7-10-89$

TELEFAX TRANSMISSION

To: Brace Boyden, Interim Project Manager (LTU Fax \# 318-257-2562)

Department of Chemical Engineering (UM Fax \# 601-232-5453)

Louisiana Tech University

Ruston, LA

Telephone: $318-257-2885$

From: Bailey Ward,

Principal Investigator
Carol J. Stevens,

Postdoctoral Research Associ $=2$

The University of Mississippi

Environmental and Applied Microbiology Laborator Department of Bioiogy

University, MS

Telephone: 601-232-7203

\section{SUMMARY}

We tested several solvents for improved efficiency of extraction of reference "4S" compounds from microbial culture media. Ethyl acetate proved to give acceptably efficient and consistent recovery of DBT, DBT-sulfone, phenylphenol, biphenyl. and biphenol. We now extract the culture medium first with ethyl acetate, evaporate the solvent, then redisolve the crystals is acetonitrile, which gives best results for GC analysis. The new extraction procedure revealed that our several different lots of DBT (Aldrich Chemical) contain DBT-sulfone and biphenyl, at abour $0.5 \%$ and $0.4 \%$ respectively, although different lots contais different amounts of the contaminants.

We applied the new assay procedure to several tests for "is" activity of pure cultures and mixed cultures lof unknchin composition) obtained from environmental sources. Some cultures degraded DBT and DBT-sulfone when these were added to the cultures in pure form. We have not yet obtained direct evidence of is pathway metabolism. The assay procedure and results of the firs: trials are described on the following pages. 
I. Procedure

a. $1.0 \mathrm{ml}$ of filter sterilized DBT $(12.5 \mathrm{mg} / \mathrm{ml}$ acetonitrile) was added to a sterile flask. This was dried to a residue.

b. $25 \mathrm{ml}$ of medium, were added to each flask (final DBT conc= $0.05 \%)$.

c. The flasks received a $10 \%$ inoculum and were then incubaced at $30^{\circ} \mathrm{C}, 150 \mathrm{rpm}$ for $48 \mathrm{~h}$.

d. After incubation, $12.5 \mathrm{ml}$ ethyl acerate were added to each flask. The flask was tightly capped and mixed by inversion - 50 times.

e. When the layers separated, the organic layer was saved.

f. Steps $d$ and $e$ were repeated. The two organic layers were combined (final volume : $25 \mathrm{ml}$ ) and allowed to dry to a residue.

g. The residue was resuspended in $1.0 \mathrm{mi}$ acetonitrile.

h. An internal standard $10.5 \quad m 1$ o $0.1 \%$ thianthrene acetonitrile) was added.

i. The samples were analyzed via GC : HF-5 column with helium $\equiv s$ the carrier gas $(15 \mathrm{ml} / \mathrm{min})$, FID detector at $280^{\circ} \mathrm{C}$, $0: 3 e n$ cemperature starting at $100^{\circ} \mathrm{C}$, final temperature $225^{\circ} \mathrm{C}, 10^{\circ} \mathrm{C}$ increase/min.

II. Assays for $4 \mathrm{~S}$ metabolism

Cultures: Lehigh strains, $C 18$ and $C 1$, UM strain Cit2B. These were chosen because C18 routinely, produces fluorescence and orange compounds when sprayed with DBT, C1 originally produced fluorescence but no orange compounds, and Cit2B fluctuates in its ability to produce fluorescence. Mixed inocula: Tinsley (crude oil sample), CIT (crude oil sample), and ECUTA (crude oil sample), TS (Alabama "tar sands" sample).

a. Organisms were incubated for $48 \mathrm{~h}$ in $21 \mathrm{C}$ medium $(0.5 \%$ benzoate. $\mathrm{pH} 7.0$ ) containing either $45 \mathrm{mM}$ DBT or $38 \mathrm{mM}$ DBTS (DBT sulíne), a final solution of $0.05 \% \mathrm{w} / \mathrm{v}$. The culcures were extracted with echyl acetate and analyzed via GC for products of the $4 \mathrm{~S}$ patinay.

b. Raw samples from 4 sources were incubated in $25 \mathrm{ml}$ of $21 \mathrm{C} \mathrm{medium}$ (0.5\% benzoate, $\mathrm{pH} 7.0$ ) into which $12.5 \mathrm{mg}$ of non-sterile DBI had been added. After the DBT had visibly disappeared from the Tinsley sample, the cultures were subcultured into similar media. When the DBT had again disappeared, $2.0 \mathrm{mi}$ were removed from each for subculturing and the remainder extracted with ethyl acetate and analyzed via GC. Colonies were isolated from the subcultur tested for fluorescence via the Lehigh spray plate method and for DBT utilization via the TTC assay. 


\section{Results}

a. When grown in liquid medium containing DBT, C18 produced an orange color; neither C1 nor Cit2B produced the orange color. No color was present with any of the cultures when DBTS was added to the medium. When grown with DBT, C18 showed a $32 \%$ decrease in DBT, while $C 1$ and $C i t 2 B$ showed no decrease. No change in other $4 S$ compounds was detected. When grown with DBTS, C18 showed a $36 \%$ decrease and $C 1$ an $18 \%$ decrease in the DBTS concentration but no changes in other $4 \mathrm{~S}$ compounds were detected. Ic appears, therefore, that in liquid medium C18 will utilize the Rodama pathway to degrade DBT. Although no color change occurred, it is also possible that $C 18$ and $C 1$ utilized the kodara pathway to degrade DBTS. Cit2B does not appear to utilize DBT or DBTS at all, and the flucuating fluorescence may be due to something other than the production of $4 \mathrm{~S}$ products.

b. Of the samples tested. Tinsley most readily used the DBT supplied. The subcultures turned orange, and GC analysis indicaced a 25\% decrease in DBT conc. None of the isolaces from the subcultures produced fluorescence when sprayed with DBT, or were positive for the TTC assay; however, this may be due to one of two things. Either the organisms responsible for the degradation of DBT were not isolated, or the organisms need to be in a mised consortium to synergistically utilize DBT. Bcrh of these possibilities are being examined further.

Work in progress and planned. Further tests are underway or planned to provide details of metabolism of " $4 \mathrm{~S}$ " compounds by selected pure cultures and crude inocula. Some culcures are being challenged with precleaned coal (from LTU) for lacer analysis of organic carbon content (at LTU). The ASTM sulfate assay is being reevaluated for effectiveness; the question is "car. we expec: :c be able to measure sulfate ion release from coal a DBT at $=$ ite concentrations of each that seem to be manageabie in growing bacterial cultures?. 
One $\mathrm{ml}$ filter-sterilized $4 \mathrm{~S}$ substrate (12.5 mg/ml acetonitrile)

Dried to residue in $125 \mathrm{ml}$ flask

$25 \mathrm{ml}$ growth medium (AS substrate $=0.05 \% \mathrm{~m} / \mathrm{v}$ )

Inoculated from growing cultures

(plus uninoculated controls)

Incubated at $30^{\circ} \mathrm{C}, 150 \mathrm{rpm}$ shaker bath

Tro extractions with $12.5 \mathrm{ml}$ ethyl acetate $=25 \mathrm{ml}$ pooled

Dried to residue

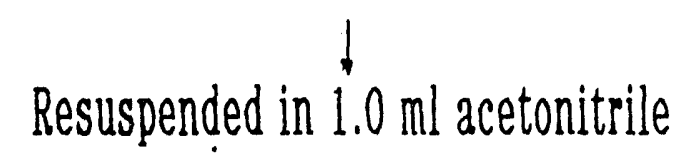

plus internal standard of $0.5 \mathrm{ml}$ of $0.1 \%$ thianthrene in acetonitrile

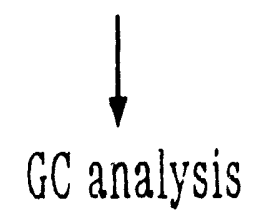




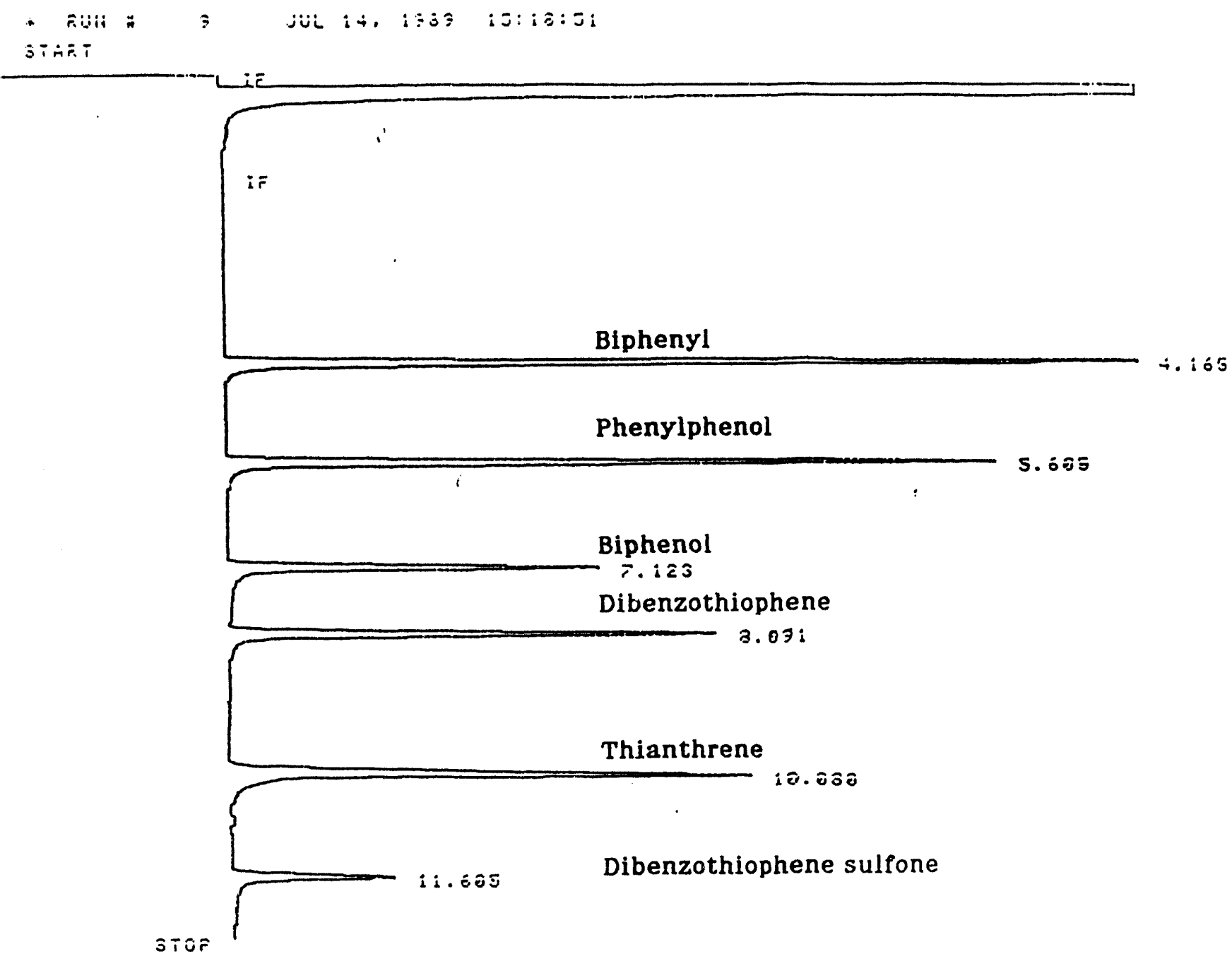

Standards in acetonitrile (12.5mg/m)); $\mathbb{P P} 5890 \mathrm{~A} \mathrm{GC,} \mathrm{HP} 3396 \mathrm{~A}$ integrator, $\mathbb{H P}-5$ column, He at $15 \mathrm{~m} / \mathrm{min}$, Inlet at $250^{\circ} \mathrm{C}, \mathrm{FDD}$ at $280^{\circ} \mathrm{C}, 100^{\circ} \mathrm{C}$ initial, $10^{\circ} \mathrm{C} / \mathrm{min}$ to $225^{\circ} \mathrm{C}$. 
1

\section{APPENDIX ||}

SUMMARY OF DBT SPRAY-PLATE ASSAYS

LEHIGH CULTURES AND KODAMA PRODUCTS

GC/MASS SPECTROMETRY

SULFUR-STRESS ASSAY 
Quarterly Progress Report, Biodesulfurization Project

Report Period: December 15, 1989 - March 15, 1990

1

(Submitted: March 12, 1990)

To: Dr. Gary Zumwalt, Imterim Project Manager

Department of Petroleum Engineering and Geosciences

Louisiana Tech University

Ruston, LA $71272-0046$

Telephone: 318-257-2885 Fax 318-257-2562

From: Bailey Ward, Ph,D.: Principal Imvestigator

Joe E. Lepo, Ph.D.: Research Associate

Frank Purdy, Graduate Research Assistant

The University of Mississippi

Laboratory of Environmental ilicrobiology

Department of Blology

University, MS 38677

Telephone: $601-232-7203$ Fax 601-232-7577

TASK-4 MICROBIAL ACTIVTY ON MODEL COAL ORGANOSULFUR COMPOUNDS

\section{A. History of Screening Assays}

During the past year, we have recovered from natural sources (crude oils and refined fuels mixed with sod or water) several individual or mixed cultures that gave one or more indications of the proposed " $4 S^{\text {" }}$ pathway. About one hundred samples taken from a varlety of locations were screened. The $4 \mathbf{S}$ indications were obtained by UV fluorescence via the Lehigh-type, spray-plate assay, or by capillary gas chromatography of extracts of growing cultures plus DBT or DBT-sulfone. Because of uncertainties about interference by colored "Kodama"-type products of DBT degradation, and by inability to obtain repeatable results, the spray-plate assays were suspended sometime about midsummer, 1989 . The report by Monticello et al. (Appl. Environ. Microbiol. Vol. 49 (4), p. 756, 1985) states that a yellow product of DBT degradation has a molecular ion of 178 and fluoresces blue under UV illumination. Another major product, orange in color, fluoresced purple under UV. These are primarily water-soluble compounds. We suspected that organisms that produced Kodama-type products would show blue/purple UV fluorescence due to the colored products, thus severely limiting the value of the assay for screening for $4 S$ products (phenylphenol or biphend) which also fluoresce blue/purple under UV. Moreover, it would seem that the Kodama products would be more likely to diffuse into the agar medium around the colonies, thus amplifying their interference, inasmuch as the Lehigh assay relies on fluorescence around the colony perimeter. We note also that we did not observe fluorescence on a colony, even when fluorescence was strong around the colony, even when much colored product covered the colony. Some colonies were autofluorescent, and some produced fluorescence around the colonies when sprayed only with ether. Moreover, such factors as medium composition, $\mathrm{pH}$, age of culture, DBT concentration, and some other unknown factors of laboratory personnel techniques seemed also to affect the spray-plate assay. However, we acknowledge that the assay should be usetul for $4 S$ organisms that do not produce interfering fluorescing compounds. and might also be applied to these latter organisms if one can differentiate between fluorescence of $4 S$ and colored products.

In our initial spray-plate assays (early in 1989) of nine of Dr. Steve Krawiec's (Lehigh) isolates, we observed UV fluorescence of only one culture (F23) that did not produce conspicuous colored products. Our main interest then was to use a known "fluoxescer (presumed then to be 4S-positive) to serve as a reference as we screened for new isolates. We chose Lehigh strain $C_{18}$ because it gave vivid and reliable DBT. 
dependent fluorescence; we note, however, that $\mathrm{C}_{18}$ also produces considerable amounts of colored product from DQT. It was only. later that we began to question the interference of the colored products (as related by $B$. Ward at the August 1989 workshop at the PETC Contractors' Review meeting).

We then focused on GC assays to screen for 45 -positive cultures. In brief, our assay consisted of incubating crude or purfiled cultures in shake-flask, liquid medium in the presence of DBT, followed by extraction in organic solvent (usually ethyl acetate), evaporation, then redissolving in acetonitrile for GC injection. A cocktail of pure compounds "ohenol, phenylphend, bipheny, DBT, and DBT-sulfone) along with an internal standard (phenanthrene) s sed to establish reference standards. At the time that we were testing the Lehigh isolates for UV fluorescence, we also attempted to detect 4 S products using the GC assay both by extracting directly from the agar-based, UV-fluorescing colonies, and by extracting from liquid-cutture media. We were not able to detect any evidence of 45 products by any Lehigh isolate. However, we suspect now that our techniques then were not properly tuned, and we believe that retrials will give different (better) results.

During the Autumn of 1989, we focused on refinement of techniques, development of reliable GC assays sensitive enough to detect small amounts of bloconversion of DBT to 45 products, initial trials on a lowtono sulfur bioassay (with DBT as sole sutfur source), and on isolation of new cultures that exhibited $4 S$ actlvity (via GC assay). We discovered that we were getting "ghost" peaks of $4 \mathrm{~S}$ compounds due to condensation and bleeding off in the injection port, and that cuttures that we thought were 4S-positive indeed gave no activity when retested under proper assay conditions. We subsequently obtained several indwidual or mixed cultures that produced weak to strong peaks that had retention times (RT) equal to or near those of DBT-sulfone, phenylphenol, and biphenyl. These cultures were derived from fresh crude oils from either the Tinsley (Mississippi), Ecuta (Mississippi), or Citronelle (Alabama) oil fields, or from weathered refined fuels (kerosene, oils) mixed with soil and coal particles (Smith OI Company, Oxford, Mississippi).

\section{B. Recent Screening Assays}

During the present report period, we first focused on studies of two cultures, one a mix of two seemingly different organisms (the "Ecuta" culture), the other a Bacillus-type isolate (designated "SOC-3" from a Smith Oil sample).

The Ecuta culture gave indications of 45 activity in that three (one weak one moderate, one strong) peaks were seen in the RT range between that of biphenyl and biphend; another strong peak occurred identical with the RT for DBT-sulfone. The Ecuta and Tinsley cultures also produce orange-colored, water-soluble products that we take to represent Kodama products. Some color also extracted into the ethyl acetate solvent used to recover possible $4 \mathrm{~S}$ compounds, and in the acetonitrile solution used for injection into the GC (these were especially obvious in the concentrated extract used for GC/MS analysis described in a following section). We presume therefore that Kodama products also exist in the solvent extract. We chose ethyl acetate (after tests on several solvents) because it gave good recovery of most " $4 \mathrm{~S}$ " compounds (polar to nonpolar) in a cocktall of standards extracted from cell suspensions and cell-free culture medium. For example, DBT, phenylphend, biphenol, and DBT-sutfone were extracted in ethyl acetate from cell suspension at $79.9 \%, 74.5 \%, 82.5 \%$, and $76.5 \%$ respectively. More recent tests indicate sonewhat better extraction percentages (from cell suspensions) with dichloromethane $(93.5 \%, 83.2 \%, 93.3 \%$, and 79.3\%, respectively for the same compounds. Bipheny was extracted at $39.0 \%$ and $47.6 \%$ in ethyl acetate and dichloromethane, respectively. Except for DBT-sulfone (83.9\%) efficiences in chloroform were less than those for ethlyl acetate.

The SOC 3 isolate is of interest because it readily removes DBT from culture suspension under either aerobic or anaerobic conditions. Moreover, SOC.3 does not produce colored Kodama-type products. However, we have not been able to detect 45 compounds using our standard GC analyses. Under anaerobic conditions, SOC-3 will readily metabolize either DBT or bipheny. which is a possible product of DBT desutiurization in the absence vi oxygen. However, no prodicts were detected. We are continuing to investigate the possibility that SOC-3 takes DBT through biphenty (withour accumulation) with concomitant rejection of sulfate. 
The aforementioned Ecuta extracts were analyzed by GC/MS, first during about September 1989 using an old instrument in the UM Chemistry Department. The resulting spectra indicated a sulfur-free product that we were calling DBT-sulfone. However, the mass spectra did not match our GC spectra as to retention times and number of peaks. so we were unable to determine that the sulfur-free product indeed was the one that we were calling DBT-sulfone. The other peaks near phenolphenol and biphenol appeared (by MS analysis) to contain sulfur. We prepared new samples of the Ecuta products, confirmed the presence of peaks for unknown products (including the "DBT-sulfone") via GC, and reanalyzed (during January 1990) using a new HP GC/MS system, equipped with a software-controlled identfica:ton package (with NBS library of spectra). Mass spectra were interpreted by faculty in the UM dept. of Chemistry. Figure 1 represents a gas chromatogram of the Ecuta extract along with a standard reference cocktall. Figure 2 consists of the mass spectrum of the same extract along with indwidual spectra for labeled peaks 1-3, and 6 (ion masses 150,164,178, and 200, respectively). We used the convention of comparing the peak (relative abundance) of the parent compound to that at plus two mass units, which if at $4 \%$ or greater of parent peak indicates the presence of sulfur atom (method prescribed by Dr. Norman Heimer, Professor of Chemistry, UM).

No ldentity now can be provided for the compounds of peaks 1 and 2 (< $30 \%$ match in the NBS library). The compound of peak 3 has an ion mass of 178, the molecular weight of 3-hydroxy-2. formylbenzothiophene, a colored Kodama product of DBT degradation, and Dr. Heimer acknowledged that the same compound could yield the observed mass spectrum (Fig. 2, peak 3 spectrum).

Analysis of the individual mass spectrum of the compound that had the same RT as pure DBT-sulfone (peak 6) revealed a possibility for the presence of two compounds, an abundant one with a molecular weight of 200 , the same as that of DBT-5-oxide, and a small amount of another with a molecular weight of 216, that of DBT-sulfone. Although we have not yet obtained a mass spectrum for pure DBT-5-oxide or for DBTsulfone (the GC/MS was not available for our use in time to include the data for this report), our spectrum for peak 6 matches that for DBT-5-oxide reported by van Afferden et al. (ACS, Div. Fuel Chem. Preprint Vol. 34(4): $561-572$ [1988]) with respect to ion mass fragmentation. DBT-5-oxide is a product reported to be produced by "Kodama" bacteria. We do not know if the ion mass at 216 represents the major parent compound (DBT-sulfone?). Professor lain Campbell (personal communication) suggested the possibility for formation of small amounts of DBT-sulfone from DBT-5-oxide via GC, whereas the reverse would not be the case. We have obtained DBT-5-oxide from P.R. Dugan and colleagues at INEL The pure DBT-5-oxide has a GC Rt equal to that of pure DBT-sulfone. During the next few weeks, we will gather more GC/MS data in attempts to resolve questions about Kodama vs $4 S$ products.

We now belleve that the GC peaks of the Ecuta culture extracts represent Kodama products or other derivattves of DBT with intact sulfur atom. It appears that a variety of sulfur-containing products of DBT are generated by microbial activity, and that some of these might give false-positive indications of $4 S$ compounds when extracts are analyzed by GC. We must note that we have analyzed via GC/MS only the Ecuta culture; we plan to retest (va GC/MS and other methods) several isolates, including some of the Lehigh strains, to determine the link between possible $4 S$ activity and Kodama activity. Our position for now is that routine GC analyses yield only presumptive evidence of $4 S$ activity, just as does the UV fluorescence plate assay.

We (in earller reports) described that which we belleved to be production of DBT-sulfone from DBT by several of our own as well as some of the Lehigh isolates. We based our belief on the presence of a GC peak with the same RT as DBT-sulfone. We note that all such isolates produced colored products, and it is possible that for these other isolates it is DBT-5-oxide rather than DBT-sulfone that is detected via GC. Moreover, we know now that the weak indications of production of phenylphenol, biphenol, or biphenyt for some cultures (as reported earlier) probably was the result of ghost peaks of residual, condensed pure compounds used to generate reference chromatograms. We must retest all such cultures by use of GC/MS (or by TLC/GC as described in the foilowing section) before we can make definitive statements as to $4 S$ activity. 


\section{New Approaches}

1

During the past few weeks, we have returned to studies of Lehigh isolates, as well as some of our own. Our aim is to reassess the spray-plate assay and to retest (via GC) the cultures for production of $4 S$ products. We especially want to address the issue of Kodama vs. 4S products as these relate to spray-plate fluorescence and detection of $4 S$ products via GC and GC/MS. We do not feel that routine screening and assays for $4 S$ acthity are warranted until we are confident that our assays will indeed detect and monitor true $4 S$ activity. Of special interest is a renewed imvestigation using the Lehigh strains C18, A4/B24 (suspected to be the same strain), and F23. C18 has received much attention in other laboratories (Lehigh University and North Dakota, for example) where the spray-plate fluorescence acthity is used as a putative $4 S$ genetic marker for gene cloning.

\section{Resting-cell Suspensions}

We have reconsidered our practice of incubating developing cells in the presence of DBT. Although we have not seen evidence that DBT uself is inhibitory to growth (at least for the organisms tested), we are aware that Kodama products are inhibitory to some organisms (Monticello, et al., cited preceding). It is probable that those cultures (most of ours) that produce colored products are growch-inhibited. It also is possible that $4 S$ products can be inhibitory, or that the same products can be metabolized by growing cultures. For generation, detection, and subsequent analysis of $4 S$ products, it is desirable to maximize cell. to-substrate (DBT) ratio, especially in consideration of the observations (J. Kabane, IGT) that desulfurization of DBT requires cell/substrate contact. We suggest also that addition of surtactants might enhance activity on hydrophobic compounds. Acldification of the culture suspension prior to extraction might also improve recovery of phenolic compounds. Our goal is to arrive at reaction conditions for maximal $4 \mathrm{~S}$ activity.

We are tuming to the use of resting-cell suspensions for screening assays. We will test effects of acidification on extraction efficiency of phenylphend, biphenol, and effects of different concentrations of synthetic surfactants (or microbially produced, as these become available) on DBT bioconversions.

We have tested one method whereby we spray DBT (in ether) onto the bottom of a glass culture dish. evaporate, then overlay the uniformly dispersed DBT film with a harvested cell suspension. The cells were grown up in complete nutrient medium, harvested by centrifugation, resuspended in a sulfur-free basal medium, layered (about $10 \mathrm{ml}$ in $100 \mathrm{~mm}$ diameter Petri plates) over the DBT film and incubated at $30^{\circ} \mathrm{C}$ for $24 \mathrm{~h}$. Following acidification with two drops of $6 \mathrm{~N} \mathrm{HC}$, the suspensions were extracted with ethyl acetate which then was evaporated; the residue was redlssolved in acetonitrile for GC analysis. We tested the Lehigh strains A4, D20, C18, and F23, as well as a few of our own isolates. The F23 rerain was the only one in previous tests that did not produce conspicuous colored products, but which did fluoresce via the sprayplate assay. We also retested A4, C18, F23, and our SOC 3 for DBT-dependent fluorescence via the sprayplate assay. Controls consisted of Cells only and for C18, cells also sprayed with ether only (no fluorescence).

Results.

1. When extracts of the resting-cell preparations were analyzed by GC, only one strain yielded a peak with a $4 S$ retention time, and that was strain C18 with a peak at the DBT-sulfone/DBT-5-oxide RT. Strain A4 produced several peaks but none matched a RT for a 4 S product C18, D20, and A4 produced colored products. Athough the extracts were tinted with yellow/orange color, these apparently were too dilute to be detected. We do not now know the identity of the C18 peak at DBT-sulfone/5-oxide, but we will apply GC/MS and TLC analyses in an attempt at identification.

2. Only one strain, C18, produced UV fluorescence via the spray-plate assay. Within $<5 \mathrm{~min}$ after application of DBT, the C18 colony and its immediate perimeter fluoresced bright blue. At the same time. yellow/orange pigments appeared in the fluorescing zones. After about 12 hours, both color and fluorescence had disappeared. And after 12 hours, no other strain showed fiuorescence or colored products. We note that we never have seen either $\mathrm{F} 23$ or SOC-3 produce colored products from DBT. However, A4 usually does produce colored DBT products, but in this spray-plate assay it did not, and it also 
did not fluoresce. Each culture was resprayed with the result that C18 again produced fluorescence and colored products, whereas no other culture produced either.

We note that the GC analysis of C18 extracts indicated either DBT-sulfone or DBT-5-oxide, and that of the two, only DBT-sulfone fluoresces blue under $254 \mathrm{~nm}$ ilumination. We ask... is the C18 spray-plate fluorescence due only to the colored products, or only to DBT-sulfone, or to both, or to neither? If the fluorescence is due to phenylphend or biphenol, then why haven't we been able to detect these $4 S$ products via GC analysis? (refer to C18 tests using TLC described in the next section). We will continue work to answer these questions for $\mathrm{C} 18$ and for other isolates. We will attempt to extract the $\mathrm{C}_{18}$ products from fiuorescing agar plates for analysis via GC or GC/MS. The described method will be used both for screening of crude cuttures and individual isolates, and for quantitative assays when known amounts of organosulfur substrates are added.

\section{TLC/GC}

We also have been exploring another method for screening for $4 S$ activity. Ouring the past several weeks. we have experimented with thin layer chromatography (TLC) as a means by which we can differentlate between Kodama (and other) products and $4 \mathrm{~S}$ compounds, and to recover the latter in relatively "clean" form for GC or GC/MS analysis. Tests with a variety of solvent moxtures and solid phases yielded preparations with which we can separate and visualize a variety of compounds of interest to our assays. including both colored and 45 products.

We tested the Ecuta extract (same preparation used for i ie aforementioned GC/MS data) using TLC, and observed that the colored products stayed with or near the solvent front, and fluoresced blue; we saw no evidence of DBT-sulfone, phenylphend, or biphend. We were unable to distinguish between DBT and UBT. 5 -oxide, which in pure forms had $R f$ values of 0.70 and 0.72 , respectively. With a diffferent solvent system, the colored compounds stayed behind the front and fluoresced blue.

We also tested via TLC the $\mathrm{C} 18$ extract (described above under Resting Cells, Results) that via GC showed a peak at the RT for DBT-sulfone/DBt-5-oxide, and also produced colored products. The colored products separated, with conspicuous blue fluorescence. We could not detect any $4 S$ compound other than the DBT substrate. We will continue to explore use of TLC to separate the compounds of interest and to provide a means by which the individual substrates and products can be recovered independently for GC or GC/MS analysis.

\section{Bloassays: Growth on DBT or DBT-sulfone as sole source of sulfur}

Rejection of sulfur in the form of suffate (or sulfite) accompanies the desulfurization of DBT via the proposed 4S pathway. Microbial cuttures incorporate sulfur (usually via suffate) into cellular biomass as they grow. A complete nutrient cutture medium provides an excess of sulfur (commonly as magnesium sulfate). If $4 \mathrm{~S}$ activity occurs independently of the avallability of free sulfur for growth, then the 45 -generated sulfate would enter the general pool of medium sulfate. Under conditions where sulfate would not be growth-limiting, it might be possible to measure the increased sulfate concentration in the growth medium relative to control cultures minus DBT, presuming of course that sufficient DBT desulfurization occurred. Under sulfurtimiting growth conditions, 4S-generated sulfur probably would be consumed as produced, and it is unlikely that sulfate release could be detected by analysis of the culture medium. However, one would expect to be able to measure increase in cellular biomass, relative to DBT-free controls, as a consequence of DBT desulfurization under sulfur-limiting growth conditions. Moreover, in a sulfur-fimiting environment, selection of DBT-desulfurizing strains might be tavored. Sulfur is required in relatively small quantities by most microorganisms, therefore growth on organosulfur compounds as sole source of sulfur probably will result in only small amounts of organosuttur desulfurization, with attendant production of desulfurized product that must be detected and quantified to substantiate $4 S$ activity. We are testing media formulations and experimental procedures for using microbial growth in low-to-no sulfur media for both screening and confirmation of desulfurization of model organosulfur compounds. Earlier and preliminary trials indicated that several complications must be resolved before the assay can be applied reliably. 


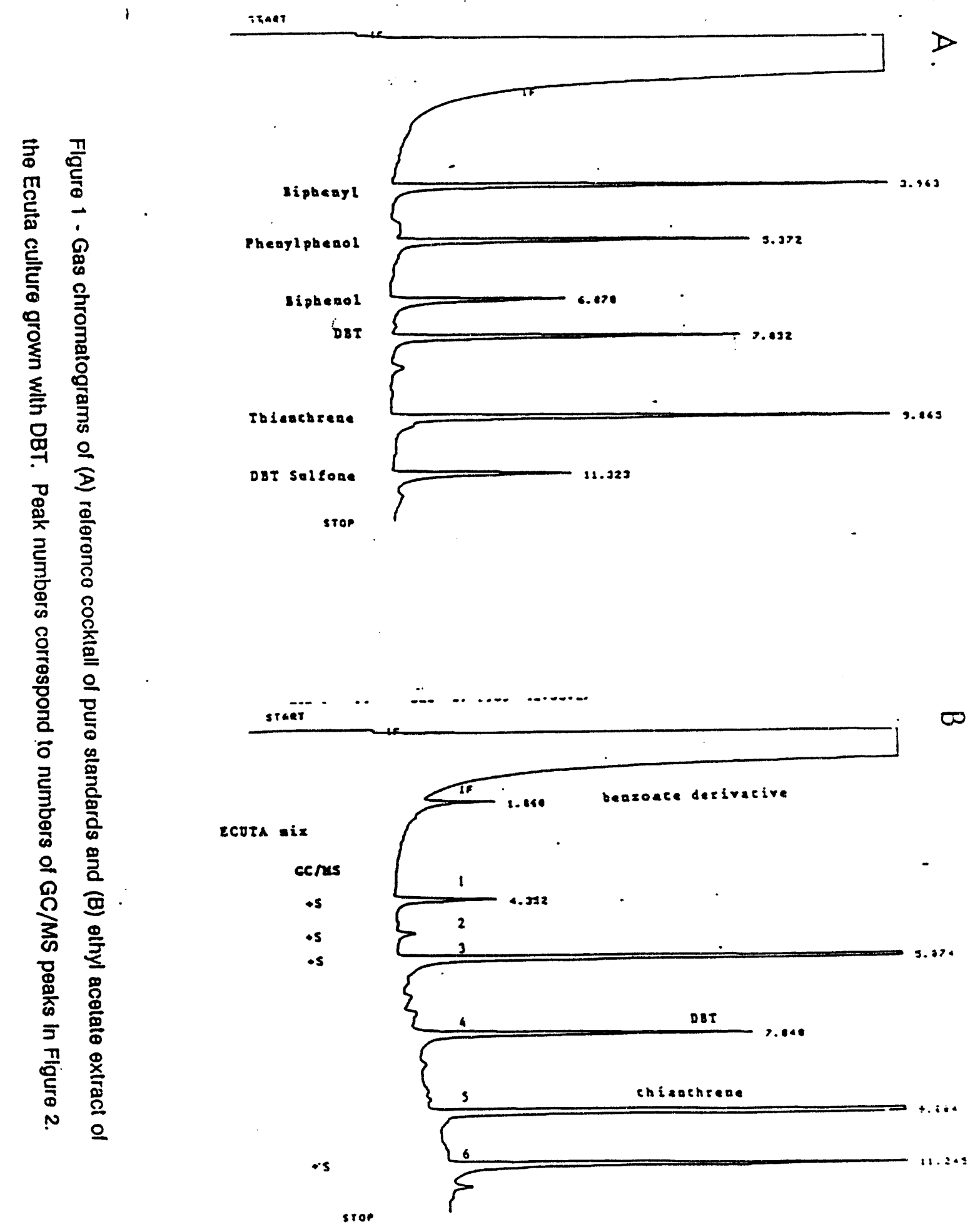




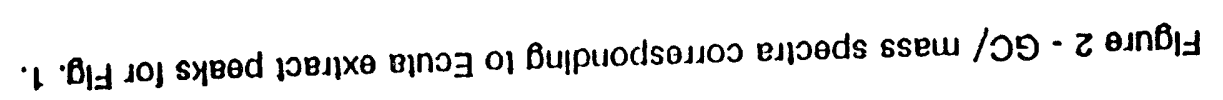

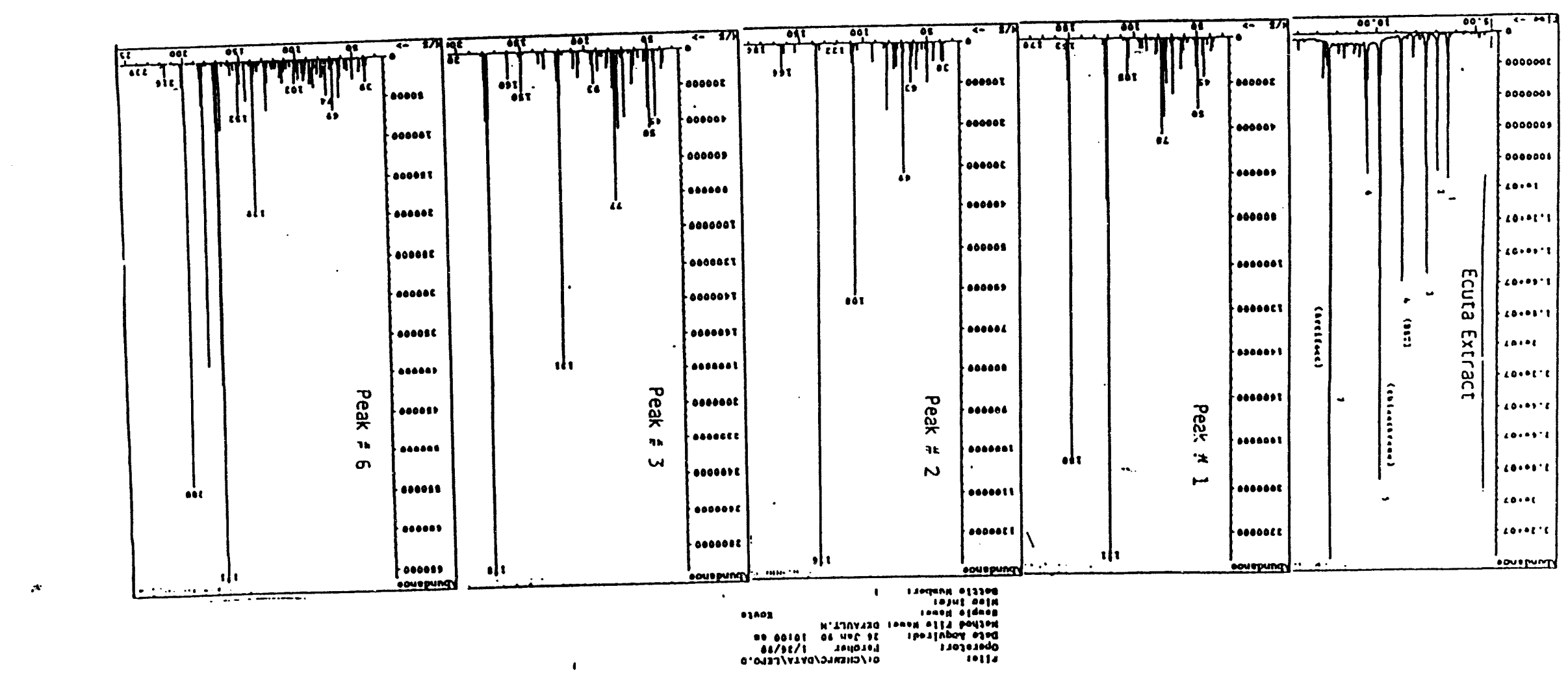


APPENDIX III

SOLVENT EXTRACTION EFFICIENCY

THIN-LAYER CHROMATOGRAPHY

GC/MS ANALYSIS 
Monthly Progress Report, Biodesulfurization Project

(Submitted: 12 April 1990)

To: Dr. Gary Zumwalt, Interim Project Manager

Department of Petroleum Engineering and Geosciences Louisiana Tech University

Ruston, LA 71272-0046

Telephone: (318) 257-2885 Fax: (318) 257-2562

From: Bailey Ward, Ph.D.: Principal Investigátor Joe E. Lepo, Ph.D.: Research Associate Frank Purdy, Graduate Research Assistant

The University of Mississippi

Laboratory of Environmental Microbiology Department of Biology

University, MS 38677

Telephone: (601) 232-7203 Fax: (601) 232-7577 
TASK 4-MICROBIAL ACTIVITY ON MODEL COAL ORGANOSOLFUR COMPOUNDS

\section{A. Screening Assays}

We are continuing to refine and improve the reliability of the resting cell assay in which diethyl-ether solutions of dibenzothiophene (DBT) or DBT sulfone are sprayed onto Petri plates; the plates with a thin film of crystalline compound are then overlaid with suspensions of the resting cells and incubated for 24 hours. Ethyl acetate extracts (acidified by the addition of 10 drops $6 \mathrm{~N} \mathrm{HCl}$ ) of these suspensions are being checked by GC for degradation products with particular attention being paid toward identification of putative "4S" compounds.

Tabulated below are percents of DBT sulfone utilized by resting cell suspensions various bacterial strains in our culture collection.

\begin{tabular}{cc}
\hline Strain & $\approx$ DBTS Removed \\
\cline { 2 - 2 } SL1 & 21 \\
SL2 & 39 \\
SI3 & $57 \star$ \\
SL4 & 43 \\
C18 & $50 \star$ \\
F23 & $46 \star$ \\
B24 & $61 *$ \\
SOC3 & $62 \star$ \\
Ecuta & 23 \\
Tinsley & $56 \star$ \\
& \\
\hline
\end{tabular}

* These values differed significantly from the amount of DBT sulfone extracted from control plates (i.e., plates that had not been incubated with cell suspensions) at $P>=0.05$ according to ANOVA. 
To determine whether the extraction efficiency of DBT or metabolic breakdown products might be improved by the disruption of cells, we subjected cell suspensions that had been incubated 24 hours on DBT sulfone plates to nitrogendecompression in a "Parr Cell Disruption Bomb".

Then effect of Parr Bomb treatment on the extraction efficiency of DBT sulfone was determined. Cell suspensions (approximately $5 \mathrm{ml}$ ) were held at $2000 \mathrm{psi}$ of nitrogen in the parr Bomb for 10 minutes after which the suspensions were brought to atmospheric pressure.

\section{C18 control}

$2.73 \mathrm{mg}$

$1.72 \mathrm{mg}$

$2.06 \mathrm{mg}$
C18 Normal Extr.

$1.04 \mathrm{mg}$

$1.17 \mathrm{mg}$

$1.35 \mathrm{mg}$
C18 Parr Extr.

$0.97 \mathrm{mg}$

$1.25 \mathrm{mg}$

$2.05 \mathrm{mg}$

Means were $2.09 \mathrm{mg}$ for the control, $1.18 \mathrm{mg}$ for the normal extraction procedure and $1.12 \mathrm{mg}$ for the Parr bombed cells; average utilization of DBTS by the cells of the two treatments was calculated at 43 and 46 percent, respectively.

Microscopic examination of Parr bombed suspensions showed that over $90 \%$ of the cells had lost their rod morphology. However, we found no significant difference in the extraction efficiency nor the DBTS utilization between Parrbombed suspensions and those that were not.

Thus we conclude that disruption of the cells is a superfluous addition to the procedure.

\section{B. Thin-Layer Chromatography}

The unambiguous and facile identification of intermediates in desulfurization or degradation of DBT is crucial to an understanding of microbial action on DBT. We have achieved the separation of several of these critical compounds using thin-layer chromatography (TLC) on silica gel plates.

DBT, DBT 5 oxide, and DBT sulfone were separable using a solvent system composed of hexane: n-butanol: glacial acetic acid: water in ratio of 20:20:5:1 by volume. Biphenol, 2phenylphenol, and biphenyl were separable using chloroform: acetic acid in ratio of $95: 5$. 
Compounds of interest:

List of compounds $(1 \mathrm{mg} / \mathrm{ml}$ in acetonitrile)

1. DBT (dibenzothiaphene)

2. DBT50X (DBT 5 oxide) $10 \mathrm{ul} / \mathrm{spot}$

3. DBTS (DBT sulfone)

4. BPOH (biphenol)

5. $2 \mathrm{PP}$ (2-phenylphenol)

6. BP (biphenyl)

Most of the compounds could be readily distinguished from the others by a combination of $R f$ values and fluorescence qualities. Silica gel plates were activated at $160^{\circ} \mathrm{C}$ for 1 hour or more. Chromatograms were developed for 1 hour, allowed to air dry and the compounds were visualized under short wave UV $(254 \mathrm{~nm})$.

Below are the results of a typical run using the hexane: butanol: acetic acid: water solvent system.

\begin{tabular}{cll}
\hline Compound & $\frac{\text { Rf }}{0.94}$ & Appearance \\
\hline 1 & 0.82 & dark $\star$ \\
2 & 0.92 & bright blue fluorescence \\
3 & 0.99 & dark, focused spot \\
4 & 0.99 & dark \\
5 & 0.99 & barely visible \\
6 & &
\end{tabular}

* The DBT 5 oxide (compound 2) showed two other spots at Rfs of 0.92 and 0.96 . The appearance and $R f$ values of these secondary spots, and our GC/MS analysis of this preparation leads us to conclude that it contains DBT and DBT sulfone as contaminants.

Below are the results of a typical run using the chloroform: acetic acid solvent system.

\begin{tabular}{cll}
\hline Compound & $\frac{\text { Rf }}{1}$ & Appearance \\
2 & 0.70 & bright blue fluorescence \\
3 & 0.70 & bright blue fluorescence \\
4 & 0.70 & bright blue fluorescence \\
$i 5$ & 0.85 & dark, slight ghost spots \\
6 & 0.90 & dark, gray \\
& 0.99 & dark, diffused
\end{tabular}

Note: Compounds $1,2,3$ are behaving as identical in appearance and $\mathrm{Rf}$; these have been run repeatedly from several sources with this solvent with the same result. 


\section{Gas chromatography/mass spectrometry}

"Positive" identifications of most of the critical compounds have been achieved using GS/MS analysis; the Hewlett-Packard software that includes the "NBS49K" library yielded identities between 90 and 99 percent match for DBT, thianthrene, biphenol, phenylphenol, and biphenyl. DBT sulfone and DBT 5 oxide continue to present problems for us: They have essentially identical retention times during chromatography, they may degrade to DBT prior to MS analysis, and the DBT 5 oxide standard probably has contaminants of DBT and DBT sulfone. Because DBT, DBT sulfone, and DBT 5 oxide can be separated by TLC methods it seems likely that we can clean up our DBT 5 oxide standard. Its mass spectral analysis can then be included into a custom library that we are building for our standard compounds against which unknown peaks generated from microbial activity on model compounds or depyritized coal can be compared.

The appended chromatograms and spectra for thianthrene and biphenol are typical of these analyses.

D. All strains in the culture collection have been preserved at $-80^{\circ} \mathrm{C}$ in glycerol to ensure genetic stability and replicability of experiments in which they are used.

E. A highly-specific and sensitive enzymatic assay for sulfate is being developed. 

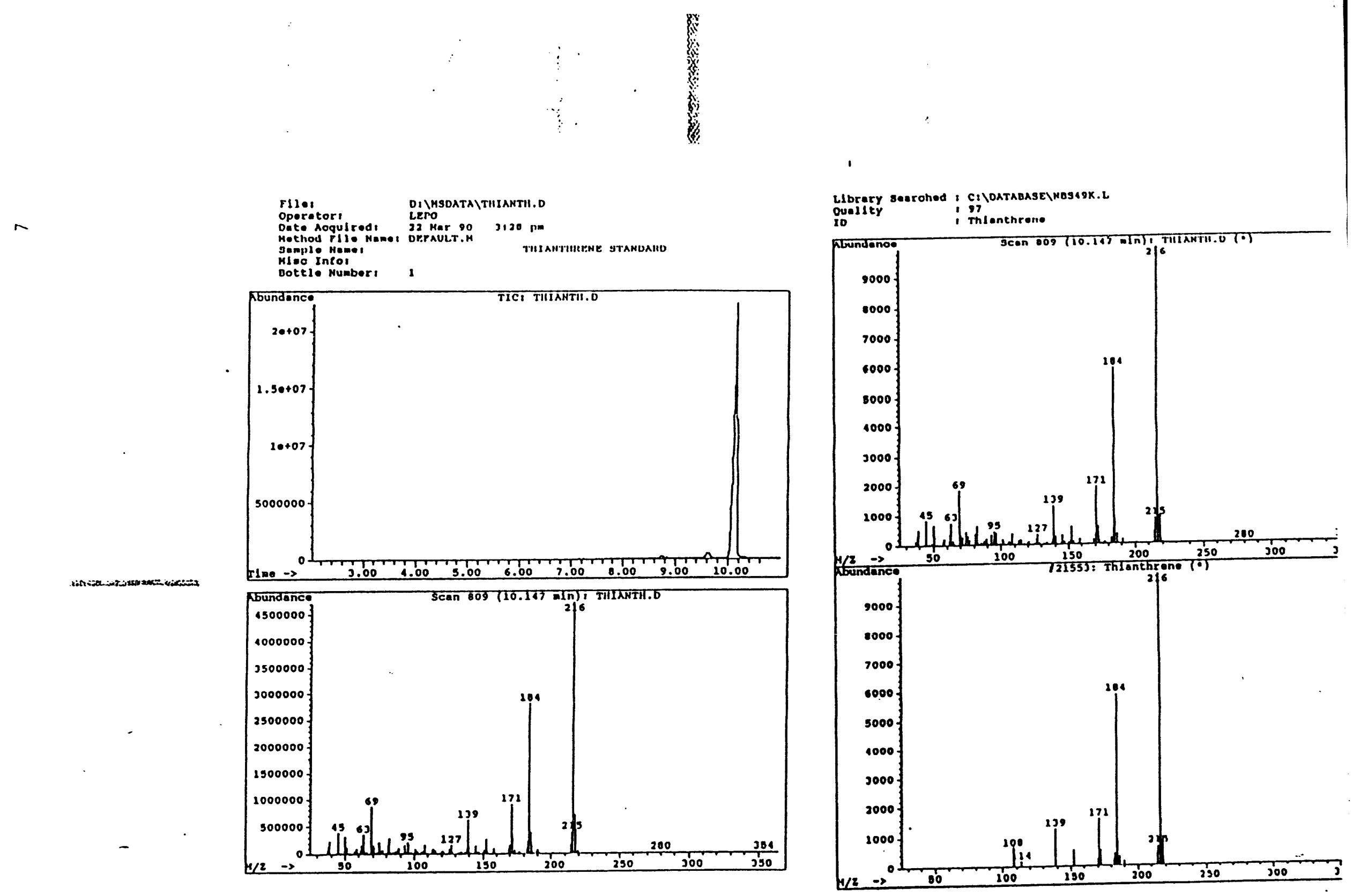


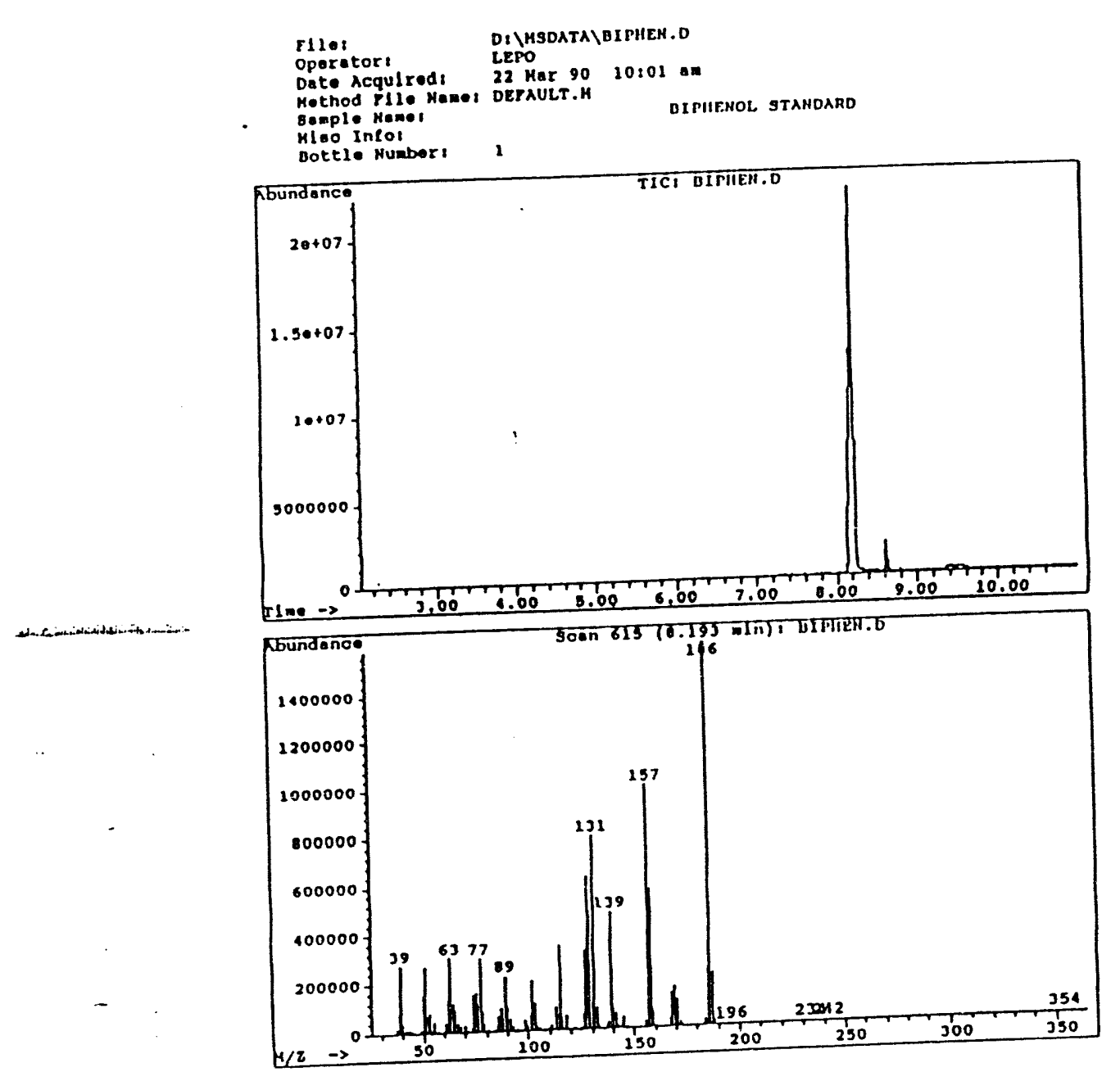

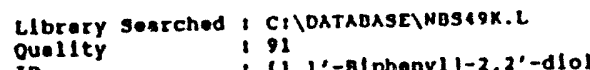

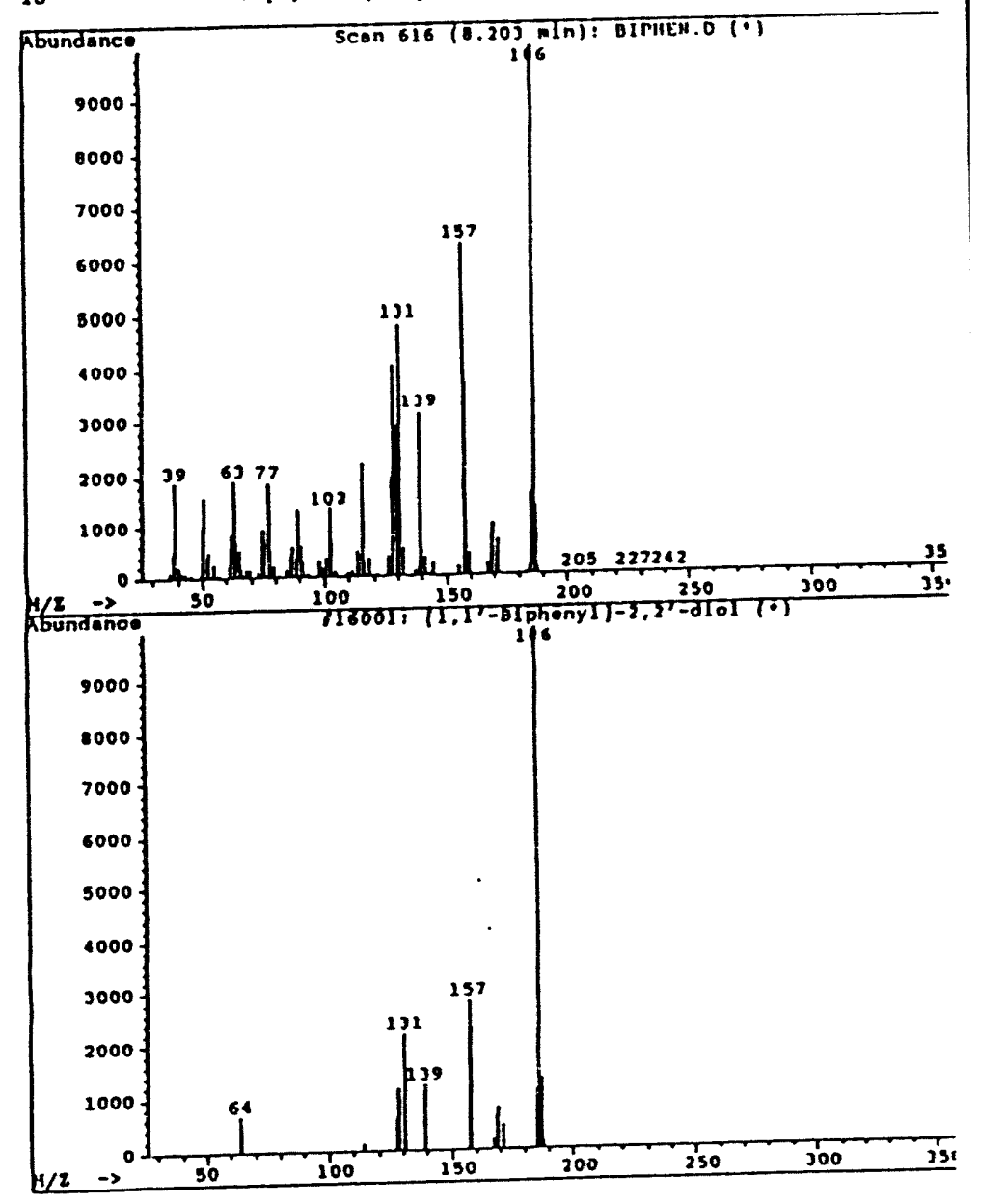



APPENDIX IV

BIOACTIVITY ON DBT.SULFONE

SPRAY-PLATE ASSAY

SHAKE-FLASK ASSAYS

CELL-SLURRY ASSAYS

ASTM SULFATE ASSAYS 
Quarterly Progress Report, Biodesulfurization Project

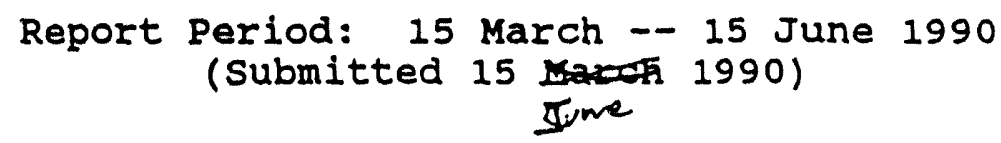

To: Dr. Bill Elmore, Project Manager

Department of Chemical Engineering

P. O. Box 10348 iTS

Louisiana Tech University

Ruston, IA 71272

Telephone: (318) 257-2885 Fax: (318) 257-2562

From: Bailey Ward, Ph.D.: Principal Investigator

Joe Eugene Lepo, Ph.D.: Research Associate

Frank Purdy, Graduate Research Assistant

The University of Mississippi

Laboratory of Environmental Microbiology

Department of Biology

University, MS 38677

Telephone: (601) 232-7203 Fax: (601) 232-5144 
Quarterly Progress Report, Biodesulfurization Project

15 June 1990

TASK 4-MICROBIAL ACTIVITY ON MODEL COAL ORGANOSULFUR COMPOUNDS

\author{
INTRODOCTION
}

Microorganisms offer a potential for the selective removal of organic sulfur from coals. Ideally, the sulfur atoms should be removed from the coal complex with minimal loss of coal organic carbon. Whole cells or cell-free enzymes may be employed to selectively catalyze the cleavage of carbon-sulfur bonds, with the attendant release of sulfate ions.

In this work, dibenzothiophene (DBT) is employed as a model compound with structural similarity to organic sulfides believed to exist in coals. A desulfurization sequence referred to as the "4S" pathway has been proposed (1) in which the sulfide is oxidized to DBT-sulfoxide, DBT-sulfone, and ultimately to the sulfur-free parent compound plus free sulfate ion. Figure 1 illustrates an abbreviated version of the proposed reaction sequence.

our objectives for the work reported here are to isolate from natural environments bacteria that exhibit metabolic activity on either DBT or DBT-sulfone, with evidence of desulfurization activity reflected as production of sulfur-free products (e.g., the 4S products, 2,2'-biphenol or 2-phenylphenol) and possibly free sulfate ion.

\title{
EXPERIMENTAL
}

\section{Cultures}

All of the bacterial cultures tested for the present report were isolated from fresh or weathered crude oils, refined petroleum spills, or activated sludge. Strains A4, B24, C18, and F23 were isolated by Professor Steven Krawiec, Lehigh University, and were obtained with his permission from Dr. Pat Dugan's group at the Idaho National Engineering Laboratory. The Lehigh strains are Pseudomonas spp. that reportedly produce biphenol and DBT-sulfone from DBT (1). The other cultures were isolated by our group at Mississippi. SOC-3 is a Bacillus sp. isolated from a weathered oil spill at the Smith Oil Co., oxford, Miss. strains designated SL1, SL2, SL3 and SL4 were isolated from activated sludge from 
Quarterly Progress Report, Biodesulfurization Project

15 June 1990

the University of Mississippi waste water treatment facility; SLI is a Bacillus sp.; the remaining "SL" strains are most likely pseudomonads. The cultures designated ECUT and TIN were consortia of two or three unidentified bacteria that were obtained from the Mississippi oil fields, Ecuta and Tinsley, respectively.

\section{Screening $\backslash$ Detection Assays}

We used several methods to screen for possible DBT or DBT-sulfone desulfurization activity via $4 \mathrm{~S}$ reactions:

1) Spray-plate assay (developed by Professor Steven Krawiec, Lehigh University). Discrete colonies on the defined agar medium "21C" (2) were sprayed lightly with DBT in ethyl ether (0.1\% $w / v)$, which immediately evaporated leaving a fine coating of crystalline DBT. The proposed 45 products biphenol or phenylphenol fluoresce blue or purple (pure compounds) respectively under shortwave $(254 \mathrm{~nm})$ ultraviolet radiation. The proposed intermediate, DBT-sulfone, also fluoresces bright blue, whereas DBT does not fluoresce; thus the assay is potentially useful only when DBT is the initial substrate. Incubated cultures were monitored for presumptive $4 S$ activity by appearance of fluorescing products in the vicinity of the sprayed colonies. Presumptively positive cultures were extracted directly for chromatographic analysis or retested by one or more of the methods described below.

2) Shake-flask Cultures. DBT or DBT-sulfone $(12.5 \mathrm{mg})$ in acetone was evaporated from culture flasks, after which $25 \mathrm{ml}$ of $21 \mathrm{C}$ medium ( $+0.5 \mathrm{mg} / \mathrm{ml}$ benzoate) was inoculated with pure or mixed cultures or with crude inocula from collection sites. After incubation for up to two weeks, three replicate suspensions were acidified with $\mathrm{HCl}$ and extracted with ethyl acetate. The evaporated extract was redissolved in acetonitrile for analysis bythin-layer chromatography (TLC), gas chromatography (GC), or GC in combination with mass spectrometry (GC/MS) to quantify substrate removal and to detect possible 4S compounds. Controls consisted of medium plus substrate only and cell cultures minus substrate.

3) Cell Slurry Assays. The objective was to use a short-term assay whereby cell/substrate ratios were maximized. Cell suspensions were grown to density in one-tenth strength Bacto tryptic soy broth, harvested by centrifugation, resuspended in a sulfurfree defined mineral medium containing $0.5 \mathrm{mg} / \mathrm{ml}$ sodium benzoate at $\mathrm{pH} 7.0$; the O.D. at $660 \mathrm{~nm}$ was adjusted to $0.45-0.55$. Ethereal solutions of DBT or DBT-sulfone were sprayed onto $100 \mathrm{~mm} \mathrm{di}-$ ameter culture dishes, then evaporated to leave a finely dis- 
Quarterly Progress Report, Biodesulfurization Project

15 June 1990

persed cry'stalline coating of about $2.0 \mathrm{mg}$ DBT. Ten milliliters of cell suspension then was layered over the substrate. After incubation $\left(24 \mathrm{~h}, 30^{\circ} \mathrm{C}\right)$, the preparations were acidified with $\mathrm{HCl}$, then extracted in two volumes ethyl acetate (pooled) and treated as described earlier for shake-flask cultures. Three replicates of each treatment were compared with medium plus substrate controls. Fragmented cell suspensions were prepared with a Parr cell disruption bomb at 2000 psi nitrogen for ca. $10 \mathrm{~min}$.

4) Cell-free extract experiments. We have been preparing cellfree extracts of several cultures grown on tryptic soy broth and on defined media with the intention of allowing such extracts to act on DBT and DBT-sulfone. This approach has the potential of providing direct exposure of the substrates to high concentrations of intracellular enzymes $(30-70 \mathrm{mg}$ protein/ml will be used), and diminishes our concerns about transport and contact-factors that may limit the efficiency of processing. We will examine reaction products for putative "4S" intermediates by our standard procedures (TLC, GC, GC/MS).

5.) Bioassays for sulfur utilization. A low-sulfur, defined broth medium (21C) was consticuted with glycerol as the sole carbon source and supplemented with saturating solutions of DBTS (166 micromolar). Inoculants can consist of washed cell suspensions of pure cultures or of consortia of cells. Serial transfer of bacteria to fresh tubes of this medium establishes a sulfur limitation of growth; control tuses with added $\mathrm{MgSO}_{4}$ will support growth indefinitely. Growth can be monitored by optical density at $660 \mathrm{~nm}$ or visually.

\section{Monitoring of Desulfurization Activity}

1) Production of biphenol or phenylphenol (or both). Desulfurization of DBT or DBT-sulfone via $4 \mathrm{~S}$ reactions is evidenced by release of sulfur free metabolites of the parent compounds. We used TLC, capillary GC or GC/MS to monitor bioconversions of DBT and DBT-sulfone. These methods are detailed and typical analytical results are presented in the preceding two monthly progress reports (April, May 1990 ).

2) Sulfate Assays. The ASTM D516 turbidimetric method was used for sulfate assays of some cultures that exhibited superior biodegradation of DBT in shake-flask cultures. The ASTM method has limitations in sensitivity and is subject to confounding interferences in biological materials and culture media. A highlyspecific and sensitive enzymatic assay for sulfate is being 
developed;'the theoretical basis and status of this assay is discussed in detail in the Monthly Report for May. We are also developing an ion chromatographic method for sulfate analysis that shows considerable promise in being sensitive, specific, and free from interferences.

\section{RESULTS AND DISCUSSION}

Spray-plate Assays. We observed considerable variability in results obtained with the'spray-plate, UV fluorescence assay. No tested culture consistently produced DBT-dependent fluorescence during repeated trials under the same conditions. Cultures that produced fluorescing products also produced yellow or orange products coexisting with the fluorescing zones around colony perimeters. A pathway of DBT degradation leading to sulfur-retaining, mostly water-soluble colored products has been described in detail (4), and some of the products fluoresce blue under 254 $\mathrm{nm}$ irradiation. DBT-sulfoxide also is a product of the alternate pathway (1), but DBT-sulfoxide does not fluoresce.

In our hands, colonies of Lehigh strain C18 demonstrated DBT-dependent fluorescence and simultaneous production of colored products; however, GC analysis of extracts these colonies did not reveal $4 \mathrm{~S}$ products. More recently we have compared a line of $\mathrm{Cl}$ obtained from Dr. Kevin Young (University of North Dakota) with our laboratory $\mathrm{C} 18$ (obtained as described in "Cultures" above). Inocula for the spray plate assays were obtained in two manners: Each line of C18 was first grown for two days on tryptic soy agar plates; the same organisms were used directly from cryostorage vials $\left(-80^{\circ} \mathrm{C}\right)$. All treatments and lines of $\mathrm{C} 18$ produced $z$ ones of colored, diffusing material around the colonies that had been sprayed with DBT. Dichloromethane extractions of these zones were subjected to GC and GC/MS analysis. Peaks with retention times near that of biphenol were evident; GC/MS analyses were equivocal; further GC/MS work is in progress. TLC of these extracts also produced spots with Rf values corresponding to biphenyl and DBTS.

Shake-flask Cultures. After several days of incubation, orange to amber-colored products were obvious in cultures with DBT, but no colored products appeared in DBT-sulfone cultures. For some cultures, GC analysis of ethyl acetate extracts revealed prominent peaks at the retention time for DBT-sulfone and DBT-sulfoxide, with other peaks near the retention times for phenylphenol and biphenol. Figure 2 presents a representative analysis for 
the Ecuta consortium of two bacteria. Further analysis via GC/MS revealed that all unknown products contained sulfur. Peak 6 appeared to be DBT-sulfoxide. TLC separations showed only DBT-sulfoxide; no $4 \mathrm{~S}$ products were detected, and the only UV blue-fluorescing spots were the products that were orange to red-colored under white light. A compound of molecular ion 178 , with an ion spectrum that could result from 3-hydroxy-2-formylbenzothiophene, a major colored product of $\mathrm{DBT}$ biodegradation $(3,4,5,6)$ comprised peak 3 .

Ethyl acetate extracts of strain C18 grown with DBT showed only a prominent GC peak at the retention time for DBT-sulfone/sulfoxide. Analysis by TLC and GC/MS indicated only the presence of DBT-sulfoxide. Water-soluble, colored products fiuoresced blue under UV irradiation.

only one culture tested, soc-3 (a Bacillus sp.) removed DBT from suspension without producing colored compounds (and did not produce fluorescing products); no $4 \mathrm{~S}$ products were detected.

It is apparent that the DBT-dependent production of sulfur-retaining, UV-fluorescing products by cultures being tested for $4 \mathrm{~S}-$ mediated desulfurization of DBT can interfere with detection of possible $4 \mathrm{~S}$ products. Routine gas chromatographic or UV-fluorescence indications of $4 \mathrm{~S}$ products from DBT should be confirmed by more exacting methods such as mass spectrometry.

We were not able to detect (using the ASTM method) increase in sulfate in extracted shake-flask cultures grown in the presence of either DBT or DBT-sulfone. For these tests, the complete growth medium contained sulfate. In a sulfur-limited environment, metabolically active cells probably will scavenge any sulfur removed from organosulfur compounds, or from coal; thus, liberated sulfate would not be detectable, unless the rate of sulfur release exceeded that of sulfur uptake. In a sulfur-sufficient environment, sulfur liberated from model compounds or coals by co-metabolic reactions might accumulate to a detectable level relative to cultures growing in the absence of the organosulfur source. For potential applications to coal biodesulfurization, it would be desirable to use biological systems that do not require coal organic sulfur for growth or metabolic activity, or coal organic carbon for energy. A desired situation would be one whereby coal organic sulfur is liberated via co-metabolic reactions. 
Quarterly Progress Report, Biodesulfurization Project

15 June 1990

Cell Slurry Assays: The monthly report for April details refinements of our cell-slurry assay for the utilization of DBT and DBT sulfone. In addition, we established that disruption of the cell slurries by nitrogen decompression did not significantly enhance the extraction efficiency of DBT sulfone.

Preliminary tests revealed that bioconversions of DBT-sulfone did not generate colored products; thus this substrate was used for further investigations. Our rationale was that a culture capable of desulfurizing DBT via 45 reactions also would be capable of desulfurizing DBT-sulfone. In developing the assay, we compared extractions of whole vs. fragmented cells, and effects of benzoate and sulfate on removal of DBT-sulfone. No significant differences in DBT-sulfone removal occurred between sets of extracted whole and fragmented cells of strain C18. Moreover, repeated extractions with ethyl acetate did not recover additional substrate. We conclude that the microbial activity on DBT-sulfone represents biodegradation of the substrate. Table I illustrates that the presence of benzoate enhanced DBT-sulfone removal, whereas activity appeared to be insensitive to sulfate, under the assay conditions.

TABLE I

EFFECTS OF BENZOATE AND SULFATE ON CELL-SLURRY ASSAY ${ }^{2}$

\begin{tabular}{lcccc}
\hline Conditions: & $-\mathrm{Benz}$ & $-\mathrm{Benz}$ & $+\mathrm{Benz}$ & $+\mathrm{Benz}$ \\
& $+\mathrm{SO}_{4}$ & $-\mathrm{SO}_{4}$ & $+\mathrm{SO}_{4}$ & $-\mathrm{SO}_{4}$ \\
& 33 & 34 & 47 & $50-$
\end{tabular}

a Benzoate at $0.5 \mathrm{mg} / \mathrm{ml}^{\prime} \mathrm{SO}_{4}$ at $0.1 \%(\mathrm{w} / \mathrm{v}) ;$ values are means of three replicates, relative to controls.

A time-course assay of DBT-sulfone degradation vs benzoate utilization in presented in Figure 3. These data may mean that DBTsulfone degradation proceeded via cometabolism, with benzoate serving as the primary organic carbon source.

Figure 4 exhibits the results of cell-slurry assays on a variety of cultures using the sulfate-free defined medium plus benzoate. Strains are described in "Cultures" under the Experimental por- 
Quarterly Progress Report, Biodesulfurization Project

tion of this paper: Although all cultures degraded DBT-sulfone

to some extent, in no case did we detect products of any kind.

\section{REFERENCES}

1. Krawiec, S. Bacterial desulfurization of thiophenes. Developments in Industrial Microbiology. In Press, 1990.

2. Guirard, B. V., and E. E. Snell. Biochemical factors in growth. In Manual of Methods for General Bacteriology Gerhardt, ed.), American Society for Microbiology, 1981, Washington, D.C.

3. Kilbane, J. J. 1989. Desulfurization of coal: the microbial solution. TIBTECH, Vol. 7 (Apr. 1989), 97-101.

4. Kodama, K., K. Umehara, K Shimizu, S. Nakatani, Y. Minoda, and $\mathrm{K}$. Yamada. 1973. Identification of microbial products from dibenzothiophene and its proposed oxidation pathway. Agr. Biol. Chem. 37:45-50.

5. Monticello, D. J., D. Bakker, and W. R. Finnerty. 1985. Plasmid-mediated degradation of dibenzothiophene by Pseudomonas species. Appl. Environ. Microbiol. 49:756-760.

6. Laborde, A. L., and D. T. Gibson. 1977. Metabolism of dibenzothiophene by a Beijerinkia species. Appl. Environ. Microbiol. 34:783-790. 


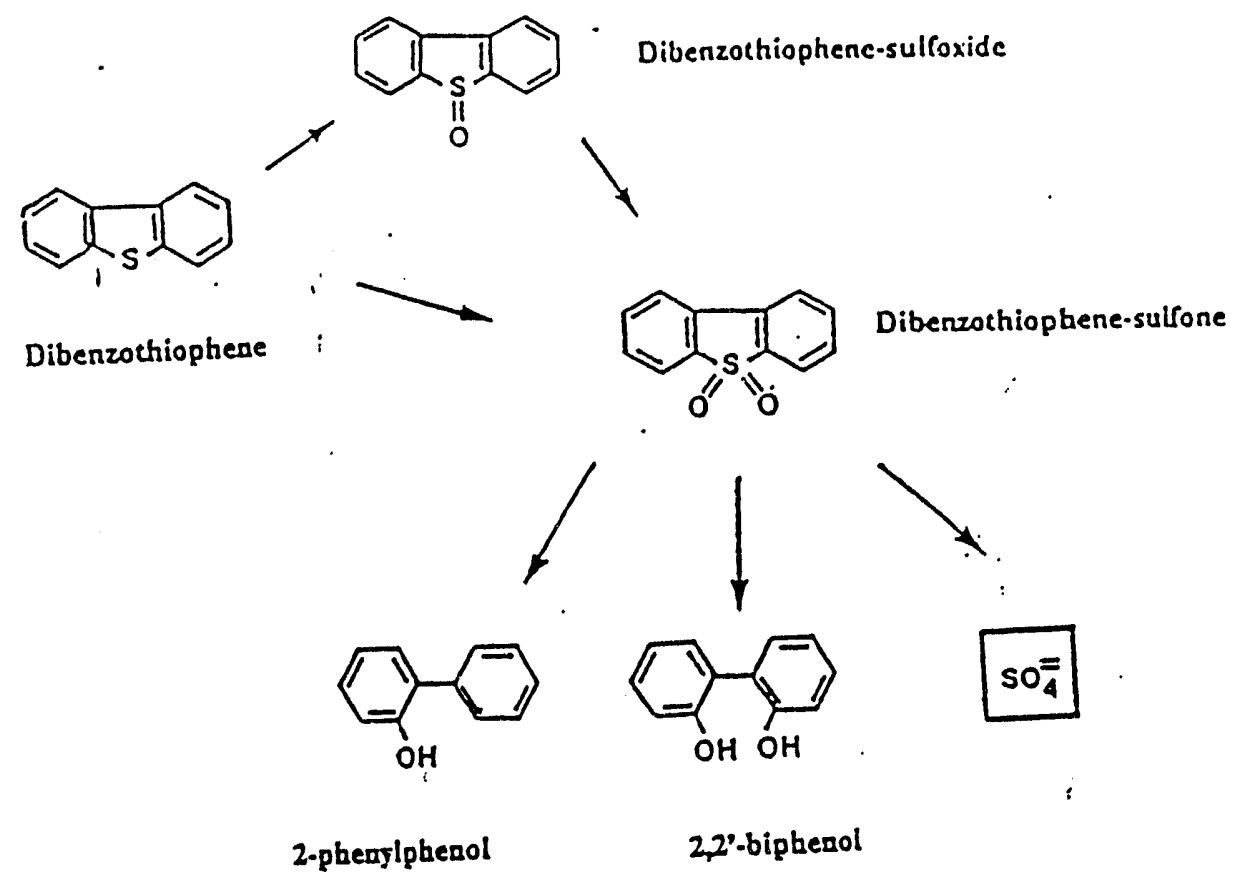

Figure 1 - Representation of proposed " 4 " reactions leading to desulfurization of dibenzothiophene.
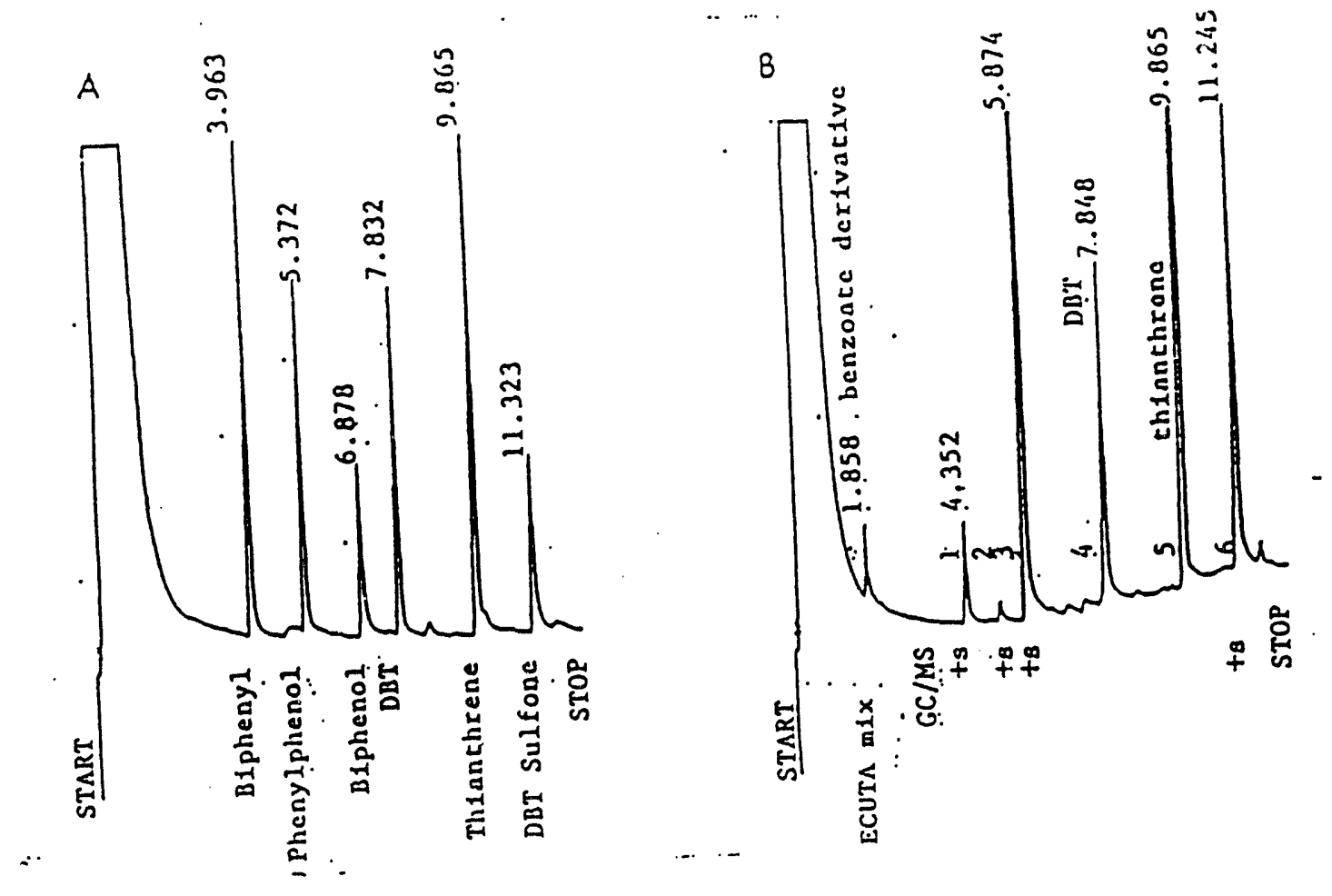

Figure 2 - Gas chromatographic analysis of ethyl acetate extract of the ECUTA culture grown in shake flasks with DBT $(12.5 \mathrm{mg} / 25$ $\mathrm{ml})$ for two weeks. A. Cocktail of pure compounds. B. ECUTA extract (thianthrene = internal standard). All DBT-derived products contained sulfur (GC/MS analysis). 


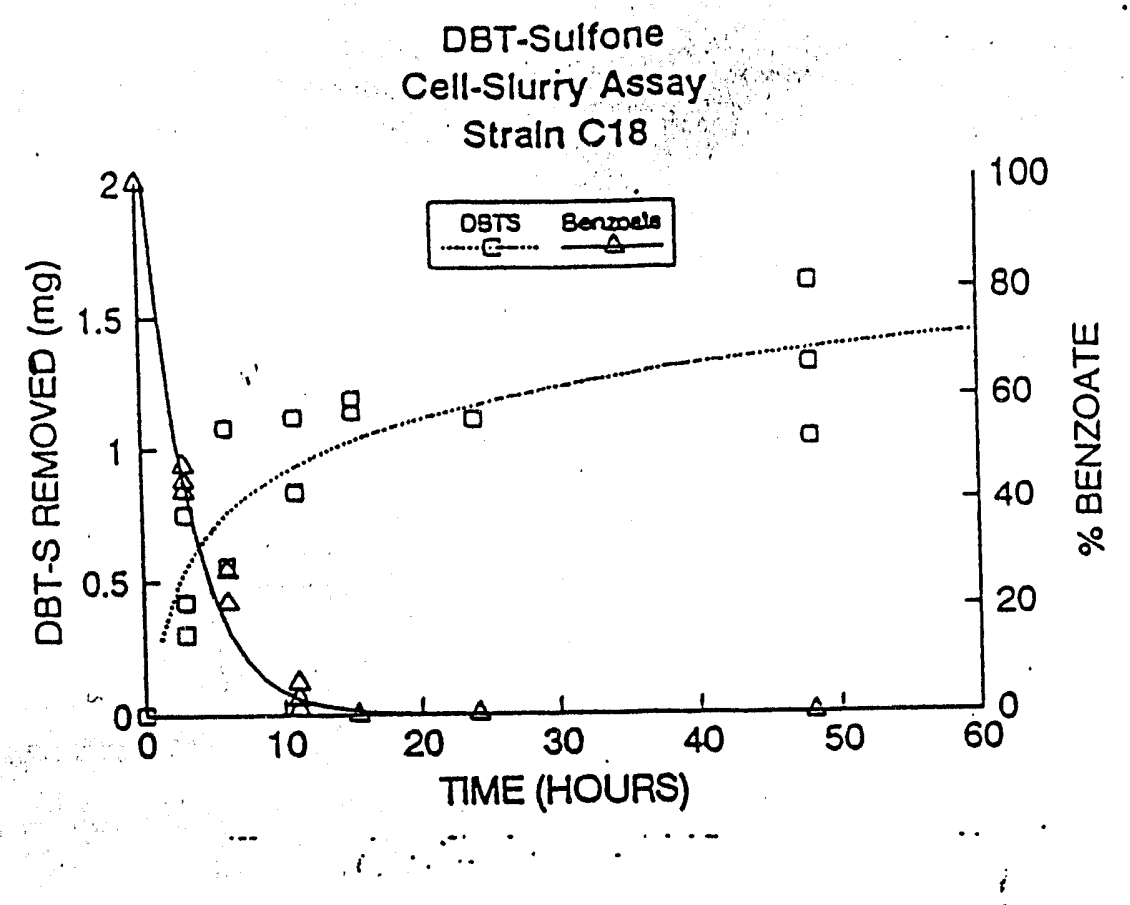

Figure 3 - Time-course, cell-slurry assay of DBT-sulfone degradation by Lehigh strain C18. Replicate cell suspensions plus or minus DBT-S were incubated at $30^{\circ} \mathrm{C}$ for 24 hours, then extracted and analyzed by gas chromatography.

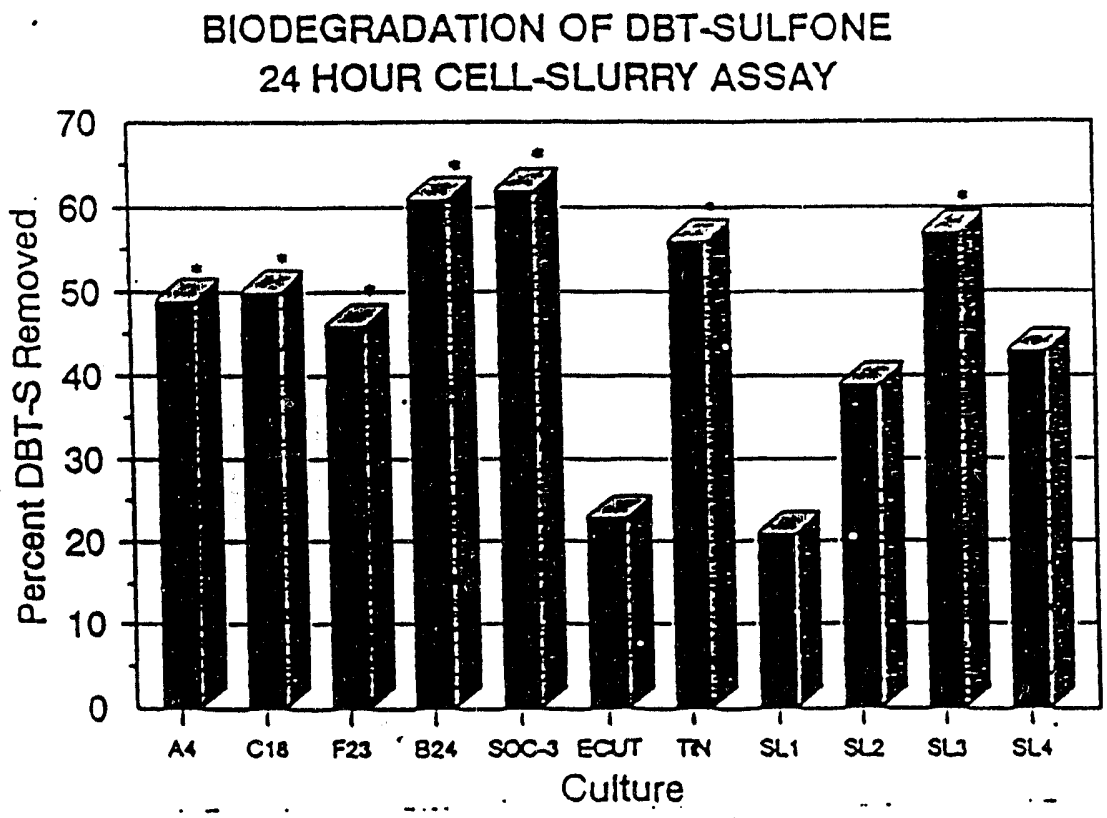

Figure 4 - Biodegradation of DBT-sulfone by various cultüres; strain descriptions and sources are found above in the Experimental section, "Cultures". Conditions are as described in text for cell-slurry assay. Analysis by gas chromatography. starred bars represent significance at $0.05 \%$ level (ANOVA, $\mathrm{n}=3$ ) relative to controls. No degradation products were detected. 


\author{
APPENDIX V \\ THE UMX CONSORTIUM \\ THE SULFUR-STRESS ASSAY \\ ION CHROMATOGRAPHIC SULFATE ASSAY \\ TESTS ON DEPYRITIZED COAL \\ FOCUS ON UMX3 AND UMX9 \\ CELL-FREE EXTRACTS
}


Quarterly Progress Report, Biodesulfurization Project 15 September 1990

TASR 4--MICROBIAL ACTIVITY ON MODEL COAL ORGANOSOLFOR COMPOONDS

Components of the uxp consortia. The consortia derived from a filtrate sent us by John Kilbane have yielded a number of organisms with key characteristics listed below and in Table $1 ;$ only isolates capable of a positive bioassay are described (see monthly reports for July and August 1990 for a more complete description of origin of these isolates).

A positive bioassay depends on growth in a defined broth medium containing dibenzothiophene sulfone (DBTS) in saturated solution (0.166 mM) as the sole sulfur source; glycerol and glucose serve as carbon sources. Comparisons of growth of the organisms and consortia are made with the same medium containing $0.2 \mathrm{mM} \mathrm{MgSO}_{4}$ and medium without added sulfur. Utilization of the organosulfur source was considered positive if the isolated organism or consortium demonstrated vigorous growth on DBTS but not in the no-sulfur nedium for at least five consecutive transfers.

The UMXa consortium was obtained directly from Kilbane's filtrate as received. The UMXb consortium and its isolates were obtained after the filtrate was subcultured to tryptic soy broth.

A description of the isolated organisms follows:

UMX1: Typical Pseudomonas fluorescens; short gram negative rod, bright yellow fluorescent pigment; profuse growth on Sl; grows poorly if at all with DBT or DBTS as sole. source of sulfur.

UNX2: A fluorescent pseudomonad, but elaborating a brown (melanin-colored) pigment in addition to the siderophore pigment. It is also unable to grow with all the characteristics of UMX2

UMX3: A large gram variable coccoid bacterium that shows quite a bit of gram and morphological variability. produces slightly pink mucoid colonies on TSA. This

- organism appears in both of the consortia.

UMX4: Off white to brown colonies on TSA, non-pseudomonad, short, gram-negative rod (almost a coccus). This organisin is clean and does not grow at all on DBT or DBTS as sole sulfur source. 
Quarterly Progress Report, Biodesulfurization Project 15 September 1990

UMX5: Large gram positive rod: looks like Bacillus sp. but spores have never been observed. Seems to be carrying UMX3 with it and thus far we've not separated it cleanly. from that organism.

UMX6: Large gram variable fusiform rod; shows variegated staining with gram stain. This organism as well has not been cleanly separated from UMX3.

UMX9: Large, but short gram positive rod; pink or light orange, waxy colonies that appear grainy on agar surfaces and flocculate from homogeneous suspension in static broth culture.'

TABLE 1. Characteristics for OMX Consortia

UMXa CONSORTIUM a

$\begin{array}{llll}\text { Strain } & \text { Morphology } & \frac{\text { Growth }^{1}}{\text { DBT/DBTS }} & \text { Possible ID } \\ \text { UMX3 } & \text { gm var, coccus } & \text { good } & \text { Rhodococcus sp. } \\ \text { UMXX } & \text { gm +, short rod } & \text { good } & ? ? \\ \text { UMXb CONSORTIUM b } & & \\ \text { Strain } & \text { Morphology } & \text { DBT/DBTS } & \text { Possible ID } \\ \text { UMIX1 } & \text { gm-, short rod } & \text { poor } & \text { Ps. fluorescens } \\ \text { UMX2 } & \text { gm-, short rod } & \text { poor } & \text { Pseudomonas sp. } \\ \text { UMX3 } & \text { gm var, coccus good } & \text { Rhodococcus sp. } \\ \text { UMX9 } & \text { gm }+, \text { short rod } & \text { good } & \text { ?? }\end{array}$

${ }^{1}$ DBT=dibenzothiophene; DBTS=dibenzothiophene sulfone. 
Quarterly Progress Report, Biodesulfurization Project 15 September 1990

Sulfatel Concentration During cell slurry Interaction with Dibenzothiophene sulfone (DBTS). We monitored the concentration of sulfate in minimal medium in the presence and absence of DBTS for certain isolates and the UMX consortium, Cell slurries were made in minimal medium containing $0.2 \mathrm{mM} \mathrm{Mg} 2 \mathrm{SO}_{4}$, and with glycerol and glucose as carbon sources; the slurry was layered over plates sprayed with DBTS and the sulfate remaining was determined by ion chromatography (see APPENDIX) after 24 hours incubation. The results are shown in Table 2 .

TABLE 2. Sulfate Concentration After Cell siurry Assay ppm sulfate/sulfite ${ }^{1}$

Sample

$\mathrm{MM}+0.2 \mathrm{mM} \mathrm{Mg}_{2} \mathrm{SO}_{4}$

E. $\operatorname{coli} \mathrm{WT}^{2}$

C18

$\mathrm{B} 2 \leq$

SL3

UNXI

UMX2

UMX consortium ${ }^{3}$

\section{\pm DBTS}

20.2

11.7

8.8

14.6

7.6

11.1

10.4

not done
Control, w/o DBTS

20.2

9.8

7.3

13.2

not done

9.8

not done

1.6

1. Sulfate was assayed by ion chromatography; the details of the method, standard curves and typical chromatograms are appended to this report.

2. Escherichia coli strain K12, wild type, which does not utilize any of the model organosulfur compounds as a source of sulfate.

3. The UMX consortium (described above) was carried for 3 transfers in the minimal broth medium with DBTS as the sole source of sulfur. This minimal medium has no detectable sulfate unless it is added. 
In all cultures--including those that showed no activity on the organosulfur compounds (e.g., Escherichia coli)--about 50\% of the sulfate was taken up from the medium; in all cases, the slurries exposed to DBI had about 10\% more sulfate remaining than the control slurries.

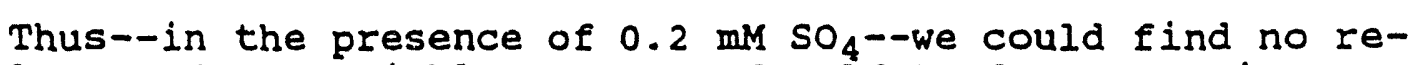
lease of appreciable amounts of sulfate from organic sources. Furthermore, sulfate released into media from organic sources seems negligible and should be interpreted with caution--unless the magnitude of the release is much greater than we observed.

On the other hand, when the same medium was used during a cell slurry assay, but without added sulfate ion, low levels (< $1 \mathrm{ppm}$ ) of organosulfate-derived sulfate could be reliably detected. The organisms/consortia (e.g. UMX) that release sulfate do so only when supplied with DBTS; control organisms (e.g., E. coli) do not release sulfate into the medium with or without DBTS. 
Quarterly Progress Report, Biodesulfurization Project

15 September 1990

Otilization of Dibenzothiophene sulfone. We followed the disappearance of DBTS in broth minimal medium cultures of various isolates and consortia after they had sustained growth on DBTS as the sole source of sulfur for three or more transfers. Table 3, below, tabulates some of these results.

TABLE 3. Otilization of Dibenzothiophene sulfone

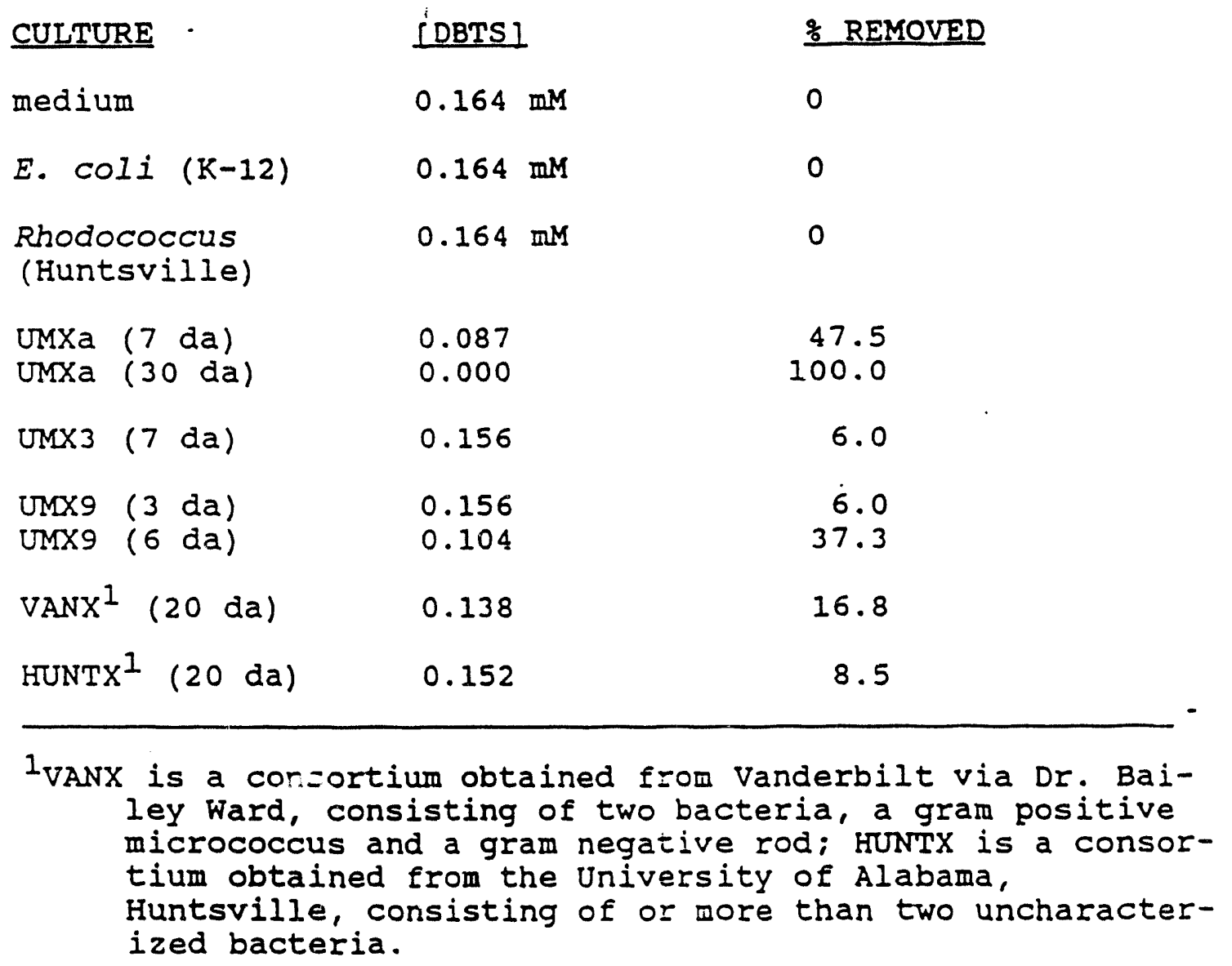

None of tine isolates, including Unx 3 , when grown on DBT or DBTS, released sulfate into the zedium under these conditions; the UMXa consortium and UM: release phenylphenol derived from the model organosulfur compounds. 


\section{Coal culture of desulfurizing bacteria}

In order to determine whether any of the consortia and isolates that grew on or released products from organosulfur compounds would reduce organosulfur content of coal we prepared the sulfate-free minimal medium ( $\mathrm{pH} 7.0$ ) with depyritized coal $(10 \mathrm{~g} / \mathrm{L}) ; 20 \mathrm{ppm}$ sulfate was detectable.

One-liter quantities of this medium were inoculated with Escherichia coli wild type to deplete available sulfate, while leaving the organosulfur intact. Although there was initial bacterial growth in these cultures, the sulfate decreased to $11.5 \mathrm{ppm}$ and then rebounded to $17.7 \mathrm{ppm}$. Thus, the $E$. coli preculture of the coal medium did not give the desired result.

An alternative method proved successful. Samples of depyritized coal ( $10 \mathrm{~g}$ each) were suspended in $100 \mathrm{ml} 6 \mathrm{~N} \mathrm{HCl}$ and stirred for 1 hour; the coal could be removed from the acid by filtration onto Whatman no. 1 paper on a Buchner funnel; after three washes, $200 \mathrm{~mL}$ each with deionized water, the coal was resuspended in $80 \mathrm{ml}$ of water and the $\mathrm{pH}$ adjusted to $\mathrm{pH} 7.0$ and the volume brought to $100 \mathrm{ml}$.

Medium made from coal treated in this manner typically contained 1 to 2 ppm sulfate.

We have inoculated such media with several isolates and consortia that degrade the model compounds and will monitor these cultures for bacterial growth and release of sulfate.

\section{Time course studies of OMXa consortium: ONX3 and ONX9}

Tubes of minimal medium with glycerol as the carbon source and $0.166 \mathrm{mM}$ DBTS as the sole sulfur source were inoculated with the UMXXa consortium, or the isolates UNRX3 or UMX9. The inocula had been precultured on the same medium. Growth was monitored by optical density; the disappearance of DBTS was monitored by UV absorption as previously described, and the appearance of phenylphenol was monitored by HPLC.

Figure 1 depicts the kinetics of the parameters when the inoculum is the UMXa consortium.

Figure 2 and Figure 3 show the growth of the isolate and the disappearance kinetics of DBTS for isolates UMX3 and UMX9, respectively. UMX3 did not produce detectable organic products from DBTS. UNIX9 did produce phenylphenol, but we have not completed the analysis for the levels of this product. 

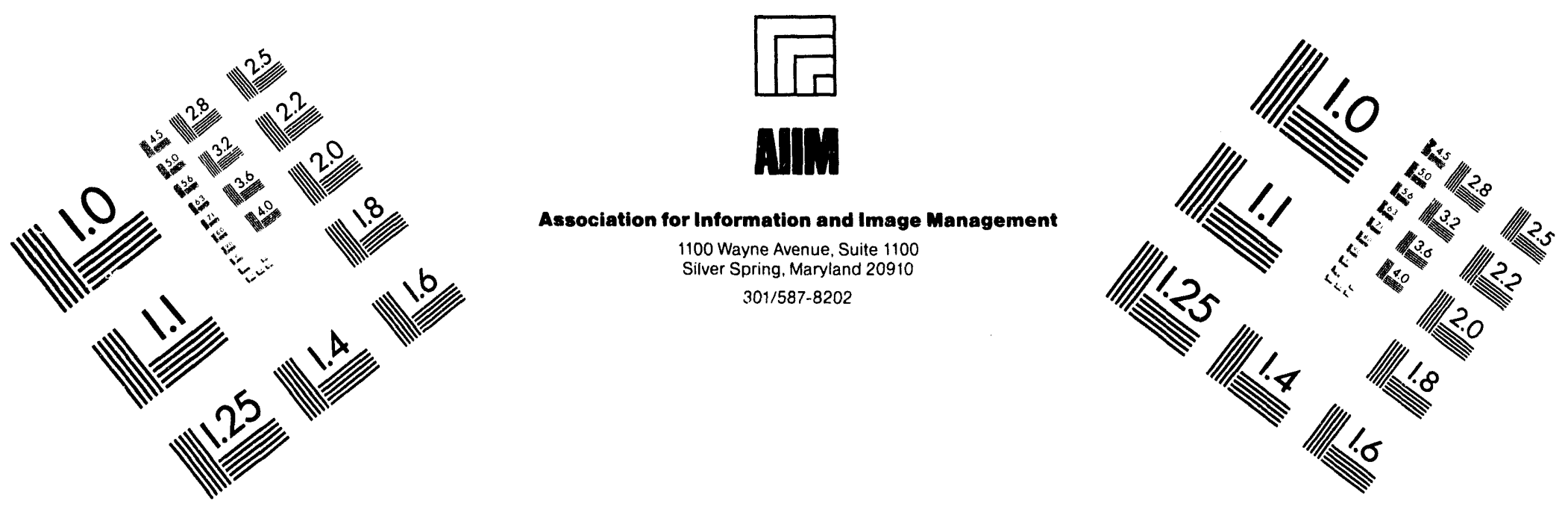

\section{Centimeter}

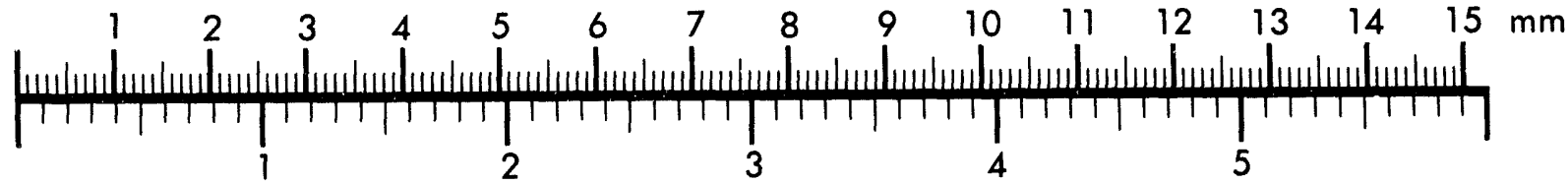
Inches
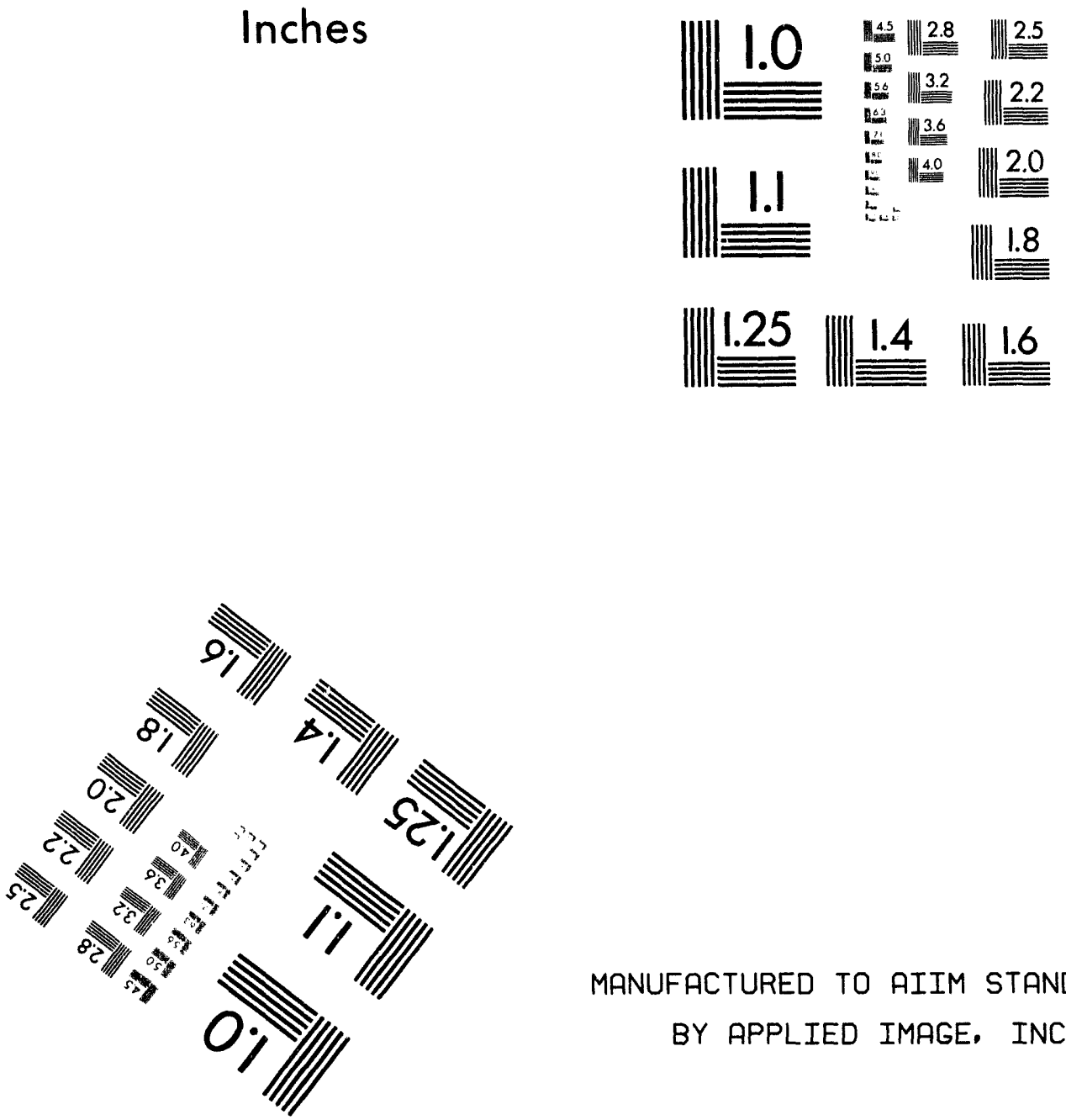

MANUFACTURED TO AIIM STANDARDS BY APPLIED IMAGE, INC.

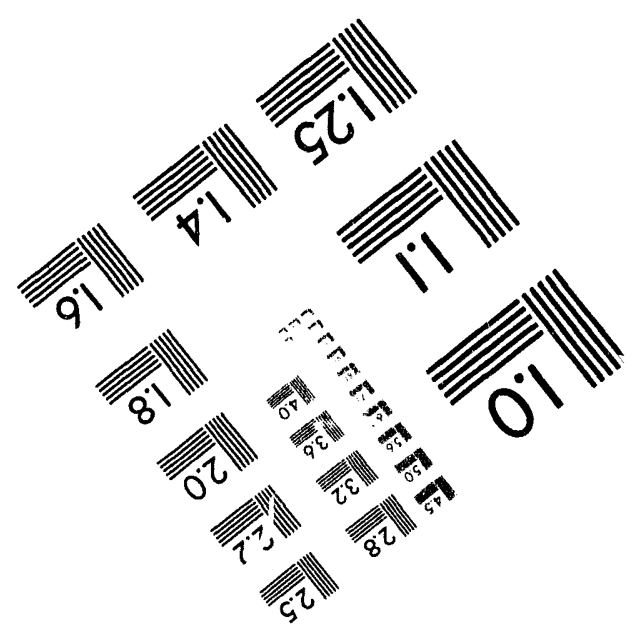



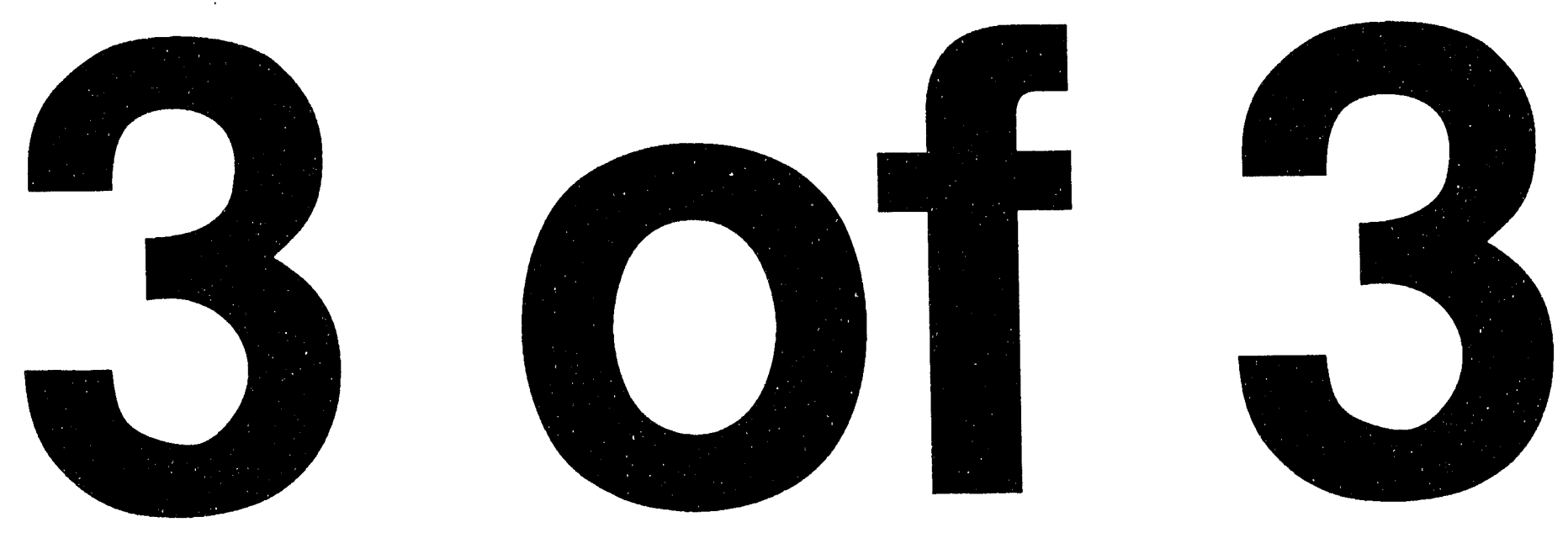
Quarterly Progress Report, Biodesulfurization Project

15 September 1990

\section{APPENDIX}

\section{Ion chromatographic assay for sulfate}

We are now routinely utilizing an ion chromatographic method for sulfate analysis that is specific, sensitive to one-half part per million sulfate (ca. 5 micromolar), and free from interferences in our minimal media. It employs a Dionex Model $2000 i$ instrument equipped with an HPIC-AS4A column and a conductivity detector.

Crucial parameters for setup (taken from literature supplied with the instrument) are as follows.

Eluant: $1.80 \mathrm{mM} \mathrm{Na} \mathrm{CO}_{3}, 1.70 \mathrm{mM} \mathrm{Na} 2 \mathrm{HCO}_{3} ; 2.0 \mathrm{~mL} / \mathrm{min}$

Regenerant: $25 \mathrm{mis} \mathrm{H}_{2} \mathrm{SO}_{4} ; 3 \mathrm{~mL} / \mathrm{min}$

Background conductivity is typically 17 microsiemens

Sulfate standards $\left(\mathrm{MgSO}_{4}\right)$ were prepared in Nanopure deionized water (> 17 megohm). is standard curve was generated by plotting peak height versus parts per million sulfate. Figure 4 shows this relationship is linear from below 1.0 ppr to about $50 \mathrm{ppm}$. Figure 5 is a chromatograph of a mixture of standard anions.

Figure 6 is a chromatogram of our minimal nedium supplemented with $0.2 \mathrm{mM} \mathrm{MgSO}_{4}(19.2 \mathrm{ppm})$. Sulfate consistently eluted at 7.0 - 7.1 minutes after injection regardless of the mixture in which it was supplied. 
Quarterly Progress Report, Biodesulfurization Project

15 September 1990

\section{FIGURE LEGENDS}

Figure 1. Utilization of DBTS by and growth of UMXa consortium described in the text; kinetics of phenylphenol production.

Figure 2. Utilization of DBTS by and growth of UMX 3 isolate described in the text.

Figure 3. Utilization of DBTS by and growth of UMXg isolate described in the text.

Figure 4. Relationship of sulfate concentration to recorder peak height during anion chromatography of sulfate standards.

Figure 5. Anion chromatograph of anion standard mix; peaks are: 1. fluoride, 2. chloride, 3. nitrate, 4. phosphate, 5. sulfate.

Figure 6. Arion chromatograph of the minimal medium supple= mented with $0.2 \mathrm{mM} \mathrm{MgSO}_{4}$ (19.2 ppm sulfate). 


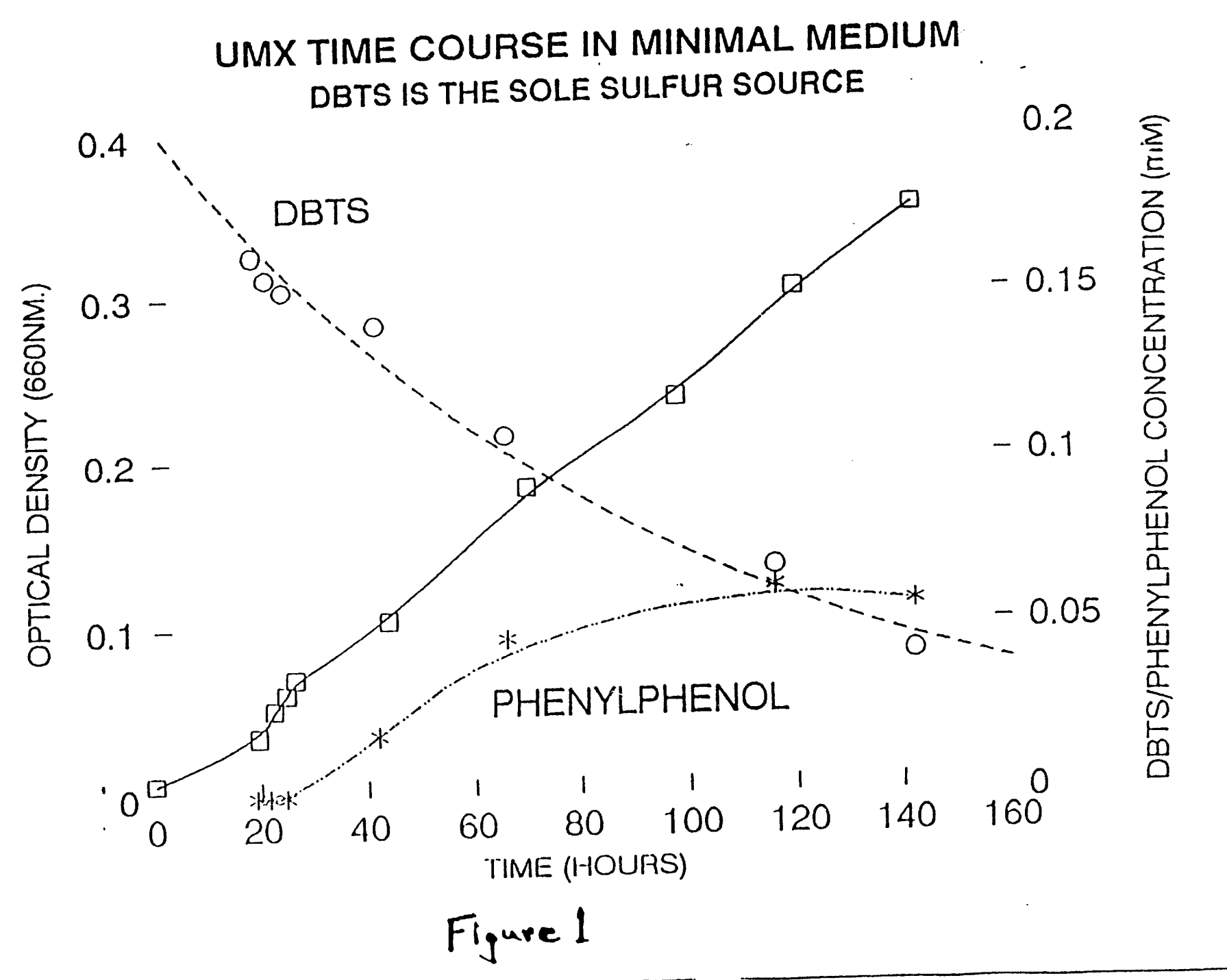




\section{UMX3 TIME COURSE}
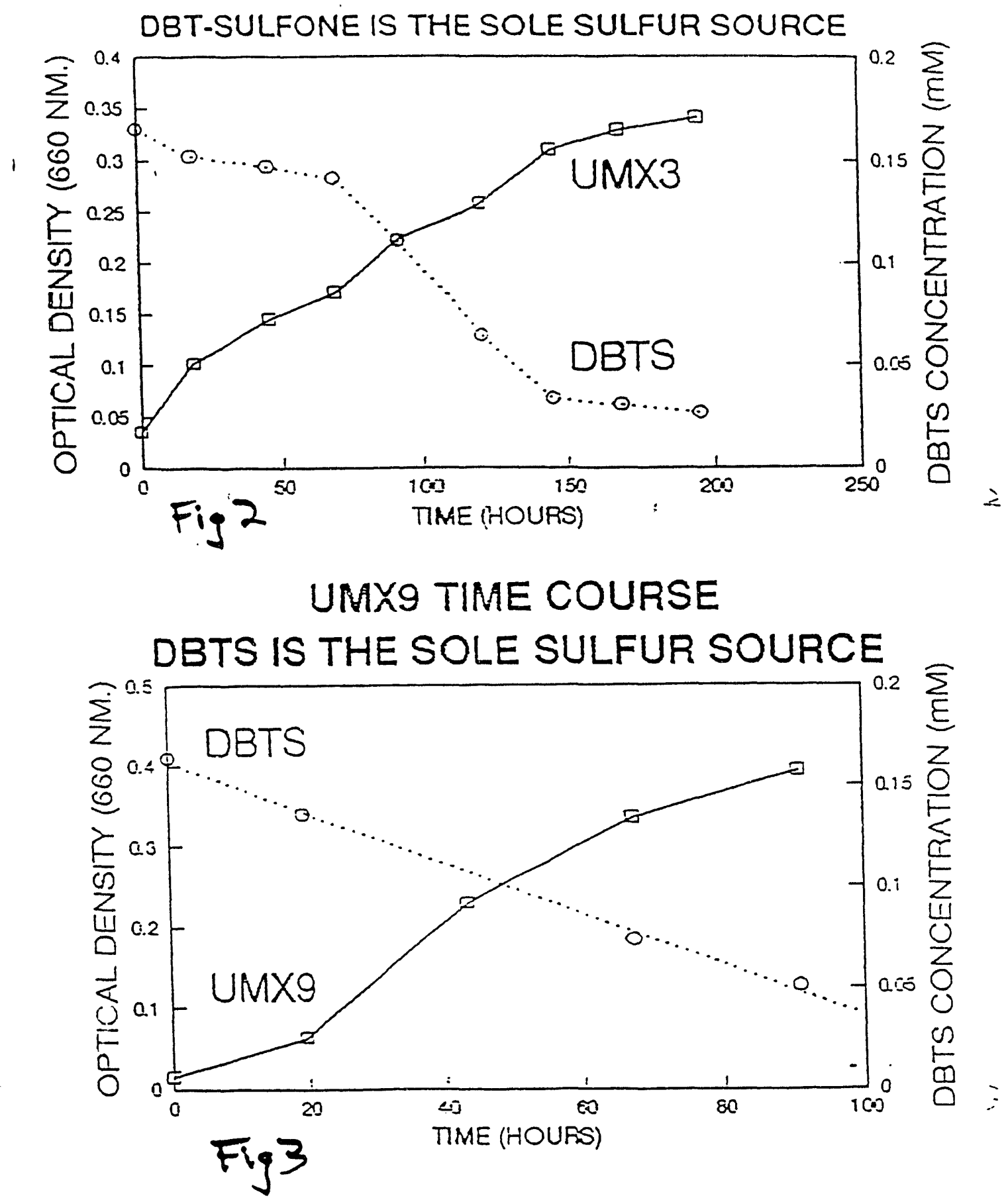

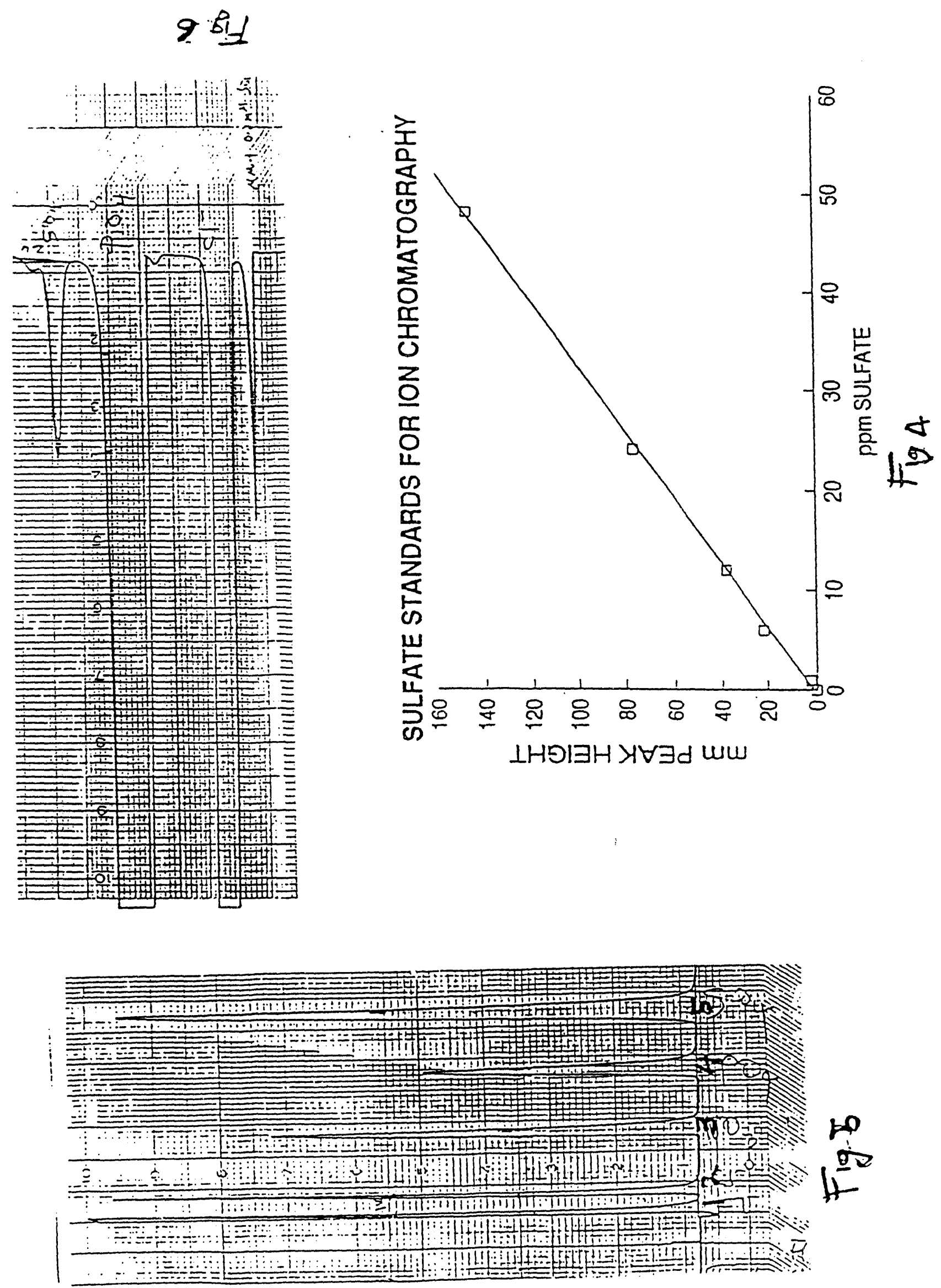
Monthly Progress Report, Biodesulfurization Project

15 October 1990 TASR 4-+MICROBIAL ACTIVITY ON MODEL COAL ORGANOSOLFUR COM-
POONDS

\section{Otilization of Dibenzothiophene sulfone}

Neither UMX3 nor UMX9 (isolates from the UMX consortia that are described in the preceding quarterly progress report; 15 September 1990) were able to use dibenzothiophene sulfone (DBTS; at $0.166 \mathrm{mM}$ ) as the sole carbon source. However, as has been previously reported, either isolate is capable of using DBTS as the sole source of sulfur; under such growth conditions, UMX9 produces phenylphenol as a degradation product; we have been unable to identify any degradation product of DBTS as a result of similar growth by UMX3.

Experiments are in progress to determine the capability of these two strains to degrade DBTS in the presence of $0.2 \mathrm{mM}$ $\mathrm{Mg}_{2} \mathrm{SO}_{4}$ with glucose or glycerol as the carbon sources.

\section{Coal culture of desulfurizing bacteria}

Preliminary growth experiments with UMX3 and UMX9 inoculated into sulfate-free minimal medium with glycerol and glucose as the carbon sources and depyritized coal $(10 \mathrm{~g} / \mathrm{L})$ as the sole source of available sulfur have been completed. (The coal was washed to remove excess sulfate as described in the preceding quarterly progress report; 15 september 1990.)

Because medium made with acid-washed coal typically contained 1 to 2 ppm sulfate, we also ran a control culture without coal but containing 2 ppm sulfate. The cultures were static at room temperature $\left(25^{\circ} \mathrm{C}\right)$ in 2.8 liter low-form flasks; each flask was swirled twice daily to mix the coal slurry with the medium.

We followed growth (by viable cell count), and the concentration of free sulfate (by ion chromatography) in the medium over a course of 16 days. The minimal medium without added sulfate did not support growth of either UMX3 or UMXX9. The control with 2 ppm sulfate added supported an increase from $5 \times 10^{5} \mathrm{CFU} / \mathrm{mL}$ at inoculation to approximately $2 \times 10^{6}$ $\mathrm{CFU} / \mathrm{mL}$ attained at 5 days; no significant increase occurred over the next 11 days. The UMX3 culture supplied with coal increased from the initial $5 \times 10^{5} \mathrm{CFU} / \mathrm{mL}$ to a maximum density of $8.7 \times 10^{8} \mathrm{CFU} / \mathrm{mL}$ over the 16 days. Over the same time period, the UMX9 culture supplied with coal increased 
from $4.2 \times 10^{5} \mathrm{CFU} / \mathrm{mL}$ to a maximum of $3.8 \times 10^{8} \mathrm{CFU} / \mathrm{mL}$; there was noticeable clumping and the formation of small waxy colonies on the surface of the broth in these cultures.

Viable cell count may not be a reliable way of checking accumulated biomass in these experiments; preliminary attempts at colorimetric protein determination were confounded by interferences from culture components with the assay method.

sulfate concentrations of the uninoculated coal + minimal medium control stayed at 2 ppm throughout the experiment. The 2 ppm of sulfate in the control culture without sulfate was no longer detectable within 2 days of inoculation. sulfate concentration of the medium containing coal that was inoculated with UMX3 increased at least twofold within 5 days of inoculation; the analogous UMDX9 culture did not show a similar increase in sulfate.

The coal that had been acted on by either UMX3 or UMX9 showed a noticeable physical deterioration at the conclusion of the experiment. In contrast, coal that simply soaked in uninoculated medium still settled out rapidly as a fine granular mass. A high proportion of the coal exposed to the microbes remained in suspension indefinitely. However, by centrifugation for 20 minutes at $17,700 \times \mathrm{g}$, removed particles from suspension.

Similar experiments have been initiated using other microbial strains and a more valid index of biomass accumulation is being sought.

\section{Summary}

Two isolates of the UMX consortia described in the preceding quarterly progress report have been further characterized regarding their physiologic capabilities in the presence of dibenzothiophene sulfone. Preliminary experiments in which these isolates have been cultured on a minimal medium containing depyritized coal as the sole source of sulfur showed enhanced growth; the increase in colony forming units per $\mathrm{mL}$ in cultures of these organisms that were supplemented with depyritized coal seems to be related to the utilization of organically-combined sulfur. Refinements of these experiments are being considered; among them are more valid determinations of any increase in biomass that is dependent on sulfur derived from coal. 
TASK 4--MICROBIAL ACTIVITY ON MODEL COAL ORGANOSULFUR COMPOUNDS

\section{Otilization of Dibenzothiophene sulfone}

Although both UMX3 and UMX9 are able to use dibenzothiophene sulfone (DBTS) as a sole source of sulfur, neither of the bacteria (isolates from the UMX consortia that are described in the preceding quarterly progress report; 15 September 1990) were able to use DBTS as the sole carbon source.

When sulfate was present in the medium $(0.166 \mathrm{mM})$, and glycerol and glucose were available as carbon sources, the utilization of DBTS by UMX3 was noticeably less than when sulfate was not present; a similar effect on the utilization of DBTS by UMX9 grown under the same conditions was apparent, although not as dramatic.

Strain UMX3 was grown with DBTS as the sole sulfur source and the following as carbon substrates: benzoate, glycerol, glucose. Benzoate supported the highest rate of growth and the highest final cell yield, followed by glycerol and glucose. DBTS utilization with glucose as the sole carbon substrate ceased after 48 hours, whereas DBTS degradation with glycerol as the sole carbon source continued at a steady rate for up to 120 hours. (DBTS degradation in the presence of benzoate was not measured because of its interference with the DBTS assay.)

Strain UMXX was grown under the conditions described in the preceding paragraph: DBTS was the sole sulfur source and either benzoate, glycerol or glucose were carbon sources. As with UMX3, benzoate, followed by glucose and glycerol supported the highest growth rate. In contrast to UMX3, the rate of degradation of DBTS with both glucose and glycerol. was the same.

Thus, UMX3 would not be able to survive with glucose as the sole carbon source and DBTS as the sole sulfur source, whereas UMXI should be able to do so. 


\section{Cell-free extracts of UMX9}

We attempted to use methylene blue as a spectrophotometric assay $f Q r$ potential cleavage of carbon-sulfur bonds by cell-free extracts of UMX9. The bacteria were grown in minimal medium with DBTS as the sulfur source, and glycerol and glucose as carbon sources; after the cells were harvested by centrifugation, they were washed in $0.1 \mathrm{M}$ phosphate (pH 7.0) and passed through a French Press three times at 20,000 psi. The French cell exudate was centrifuged $20,000 \times \mathrm{g}$ for $20 \mathrm{~min}$, and the supernatant fluid (approx. $5 \mathrm{mg}$ protein/ml) served as the cell-free extract.

Two hundred microliters of the CFE was incubated with 0.10 $\mathrm{mM}$ methylene blue and the degradation and/or reduction of the dye was followed by monitoring the decrease in absorbance in the area between 500 to $700 \mathrm{~nm}$. There was a $30 \%$ change in initial absorbance; however, when nitric acid was added to reoxidize methylene blue, and the $\mathrm{pH}$ and dilution factors were compensated for, there was no apparent decrease in optical absorbance that could be related solely to carbon-sulfur cleavage. Thus, the change in absorbance could be entirely accounted for by the reduction of the dye by normal intracellular metabolites and metabolic events.

These experiments suffered from having a low protein concentration in extracts; furthermore, there is doubt as to whether methylene blue can serve as the sole sulfur source for the bacteria. However, we have grown UMX3 and UMX9 on methylene blue-containing, "sulfur-free" agar plates and achieved decolorization of the dye in the locality of the bacterial colonies.

\section{Coal culture of desulfurizing bacteria}

A second series of growth experiments wherein both UNX3 and UMX9 were inoculated into sulfate-free minimal medium with glycerol and glucose as the carbon sources and depyritized coal $(10 \mathrm{~g} / \mathrm{L})$ as the sole source of available sulfur have been completed. (The coal was washed to remove excess sulfate as described in the preceding quarterly progress report; 15 september 1990.)

As described last month, the medium formulated with acid-washed coal typically contained 1 to $2 \mathrm{ppm}$ sulfate; we also.ran a control cultures without coal but containing 2 ppm sulfate. The cultures were static at room temperature $\left(25^{\circ} \mathrm{C}\right), 1 \mathrm{~L}$ in 2.8 liter low-form flasks; each flask was swirled twice daily to mix the coal slurry with the medium.

We followed growth (by viable cell count), and the concentration of free sulfate (by ion chromatography) in the medium over a course of 20 days. The minimal medium without 
added sulfate would not support growth of either UMX3 or UMX9. The control with $2 \mathrm{ppm}$ sulfate added supported an increase from $5 \times 10^{5} \mathrm{CFU} / \mathrm{mL}$ at inoculation to a final population density of approximately $1.0 \times 10^{7} \mathrm{CFU} / \mathrm{mL}$ after 20 days for either UMX3 or UMX9. The UMX3 culture supplied with coal increased from the initial $5 \times 10^{5} \mathrm{CFU} / \mathrm{mL}$ to final density of $2.8 \times 10^{9} \mathrm{CFU} / \mathrm{mL}$. Over the same time period, the UMX9 culture supplied with coal increased from $5 \times 10^{5}$ $\mathrm{CFU} / \mathrm{mL}$ to a maximum of $2.5 \times 10^{8} \mathrm{CFU} / \mathrm{mL}$; as before, there was noticeable clumping and the formation of small waxy colonies on the surface of the broth in the UMXg cultures.

Sulfate concentrations are currently being determined for this experiment.

\section{Aditional cell-free extract work.}

We have grown in static culture for 7 days, a 24 liter volume of UMXg on minimal medium with glycerol as the carbon source and saturating concentrations of DBTS and dibenzothiophene as potential sulfur sources. The cells have been harvested by Sharples centrifugation and are being used to prepare high-protein cell-free extract for further enzymological work using the model compounds and possible catabolic intermediates as substrates.

\section{Summary}

Additional work on the catabolic potential of UMX3 and UMX9 in the presence of DBTS is described. Further work on these isolates grown on depyritized coal as the sole source of sulfur has been done; the coal can apparently supply organically-derived sulfur for these bacteria; additional data on the release of sulfate derived from coal into the medium are being collected from these experiments. 


\section{APPENDIX VI}

ASSAYS ON UMX3 AND UMX9

- Utilization of DBT-sulfone

- Sulfate Effects on Blodesulfurization

- Organic Carbon Effects

ASSAYS ON IGT S-8

- Confirmation of 2-hydroxybiphenyl

TAXONOMIC STUDIES

- MIDI Analysis

TESTS OF UMX3 AND UMX9 ON COAL 
Quarterly Progress Report, Biodesulfurization Project

15 December 1990

\begin{abstract}
TAST 4--MICROBIAL ACTIVITY ON MODEL COAL ORGANOSULFUR COMPOUNDS
\end{abstract}

\title{
Otilization of Dibenzothiophene sulfone.
}

Wa attempted to grow strains UMX3 or UNDX9 (isolates from the UMX consortia that are described in the preceding quarterly progress report: 15 september 1990) on dibenzothiophene sulfone (DBTS; at $0.166 \mathrm{mM}$ ) as the sole carbon source. Neither UMX3 nor UMX9 were able to use DBTS as the sole carbon source.

Either isolate, as we have previously reported, is capable of using DBTS as the sole source of sulfur; under such growth conditions, UMxg produces phenylphenol (2-hydroxybiphenyl) as a degradation product; we have been unable to identify any degradation product of DBTS as a result of similar growth by UNX3.

When we supplied sulfate $(0.166 \mathrm{mM})$ in a medium containing glycerol and glucose as carbon sources, the utilization of DBTS by UMX3 was noticeably less than when sulfate was not present; a similar effect on the utilization of DBTS by UMX9 grown under the same conditions was apparent, although not as dramatic.

In order to investigate the effect of alternate carbon sources on the utilization of organically-combined sulfur. we grew strains UMX3 and UMX9 with DBTS as the sole sulfur source with one of the following as carbon substrates: benzoate, glycerol, glucose. Growth was monitored by optical 
Quarterly Progress Report, Biodesulfurization Project

density and the disappearance of DBTS was monitored by UVabsorption as we have previously described. Figure 1 depicts these data for UMX9, Figure 2 for strain UMX3.

For both strains, benzoate supported the highest rate of growth and the highest final cell yield, followed by glycerol and then by glucose.

For strain UMX3, DBTS utilization with glucose as the sole carbon substrate ceased after 48 hours, whereas DBTS degradation with glycerol as the sole carbon source continued at a steady rate for up to 120 hours. (DBTS degradation in the presence of benzoate was not measured because of its interference with the UV-absorbance assay for DBTS.)

In contrast to $\mathrm{UN}[\mathrm{X} 3$, the rate of degradation of DBTS by UMX9 with either glucose and glycerol as carbon sources was the same. As with UMX3, benzoate, followed by glucose and glycerol supported the highest growth rate.

Thus, UMX3 would not be able to survive with glucose as the sole carbon source and DBTS as the sole sulfur source, whereas UMX9 should be able to do so. These data are consistent with our observations that UMX3 cannot utilize glucose as a sole source of carbon and energy (see Table 1)

\section{Comparison of OMY3, OMX9 and IGTS8}

Dr. John Kilbane of the Institute of Gas Technology has provided us with a culture of IGTS8 to which we have compared the strains designated UMX3 and UMX9. 
Quarterly Progress Report, Biodesulfurization Project

15 December 1990

TABLE 1. Comparison of Rhodococcus-like strains.

\begin{tabular}{|c|c|c|c|}
\hline strain & IGTS8 & UMN3 & $\underline{0 N \times 9}$ \\
\hline Cell Morply & all strains & were gram-variable & coccoid rods \\
\hline Colony Morph & slimy & slimy & rough/waxy \\
\hline Colony color & light pink & light pink & orange/pink \\
\hline Glucose $^{1}$ & - & - & ++ \\
\hline 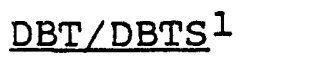 & +++ & $++t$ & +++ \\
\hline $\begin{array}{l}\text { Product } \\
\text { from DBTS }\end{array}$ & $20 \mathrm{HBP} 2$ & none ${ }^{3}$ & $20 \mathrm{HBP}^{2}$ \\
\hline
\end{tabular}

1. Ability to use as the sole source of caybon.

2. 2-hydroxybiphenyl

3. We were unable to detect any aromatic breakdown products traceable to DBTS for this strain.

\section{Confirmation of phenylphenol as a product of DBTS degrada- tion by IGTS8.}

We grew strain IGTS8 in minimal medium with DBTS and thianthrene as the sulfur sources (total culture volume, $9 \mathrm{~mL}$ ). The culture was extracted twice with $5 \mathrm{~mL}$ dichloromethane 
Quarterly Progress Report, Biodesulfurization Project

15 December 1990

and passed through a phase-separating paper; Figure 3 is a gas chromatogram of that extract; the peak labeled 2-OHBP was identified by GS/MS analysis as 2-hydroxybiphenyl

(Figure 4 is the mass spectrum from that peak; Figure 5 is a comparison of the spectrum with the library spectrum for 2hydroxybiphenyl). Thus, we have confirmed that the IGTS 8 strain of Riodococcus rhodochrous obtained from Dr. John Kilbane is capable of releasing detectable quantities of phenylphenol into the medium as a product of DBT's degradation. No other metabolites of DBTS could be identified. other major peaks on the chromatogram appear to be thianthrene derivatives and have not been identified.

"Microbial ID"--fatty acid analysis of UMX3, JMX9 and IGTS8

We supplied cultures of the three strains to Dr. Al Mikel at University of Alabama, Huntsville to be evaluated by the "Microbial ID" method, which is based on the gas-chromatographic analysis of the methyl-esters of the bacterial fatty acids. The data from these analyses are presented in Table 2, Table 3, Table 4, and Table 5 that are appended to this. report.

Table 2 show's the fatty acid content of a Huntsville isolate of Rhodococcus rhodochrous with a match of 0.395 to the database profile for $R$. rhodochrous. Table 3 shows similar data for strain IGTS8; this strain had a match of 0.173 to the database profile. Table 4 shows similar data for strain UMXX3, which had a match of 0.221 to the database profile. Strain UMX9 data are shown in Table 5; there was no match identified for this strain. 
Quarterly Progress Report, Biodesulfurization Project

15 December 1990

FIGURE LEGENDS

Figure 1. Growth of UMX3 on DBTS as the sole sulfur source with either benzoate, or glycerol, or glucose as carbon sources.

Figure 2. Growth of UNX9 on DBTS as the sole sulfur source with, either benzoate, or glycerol, or glucose as carbon sources.

Figure 3. Gas chromatogram of a dichloromethane extract of the broth culture of the IGTS8 strain of Rhodococcus rhodochrous (obtained from Dr. John Kilbane). Details of growth conditions and medium composition are given in the text. The peak at $6.382 \mathrm{~min}$ is 2-hydroxybiphenyl (2-OHBP); the peak at 9.084 is dibenzothiophene (DBT). Most other peaks are unidentified breakdown products of thianthrene.

Figure 4. Frame a: Gas chromatogram of a dichloromethane extract of the broth culture of the IGTS8 strain of Rhodococcus rhodochrous (obtained from Dr. John Kil- bane), employing a mass-170.00 filter to focus on the 2-hydroxybiphenyl peak. Frame b: The mass spectrum of. the peak in frame $a$.

Figure 5. The mass spectrum of the mass 170.00 peak from Figure 4 compared with the library spectrum of 2-hydroxybiphenyl.

Figure 6. Growth on coal of UNXX3 and UMX9 compared to their growth on minimal medium with 2 ppm sulfate. Frames a and $b$ are data from the two independent experiments. 


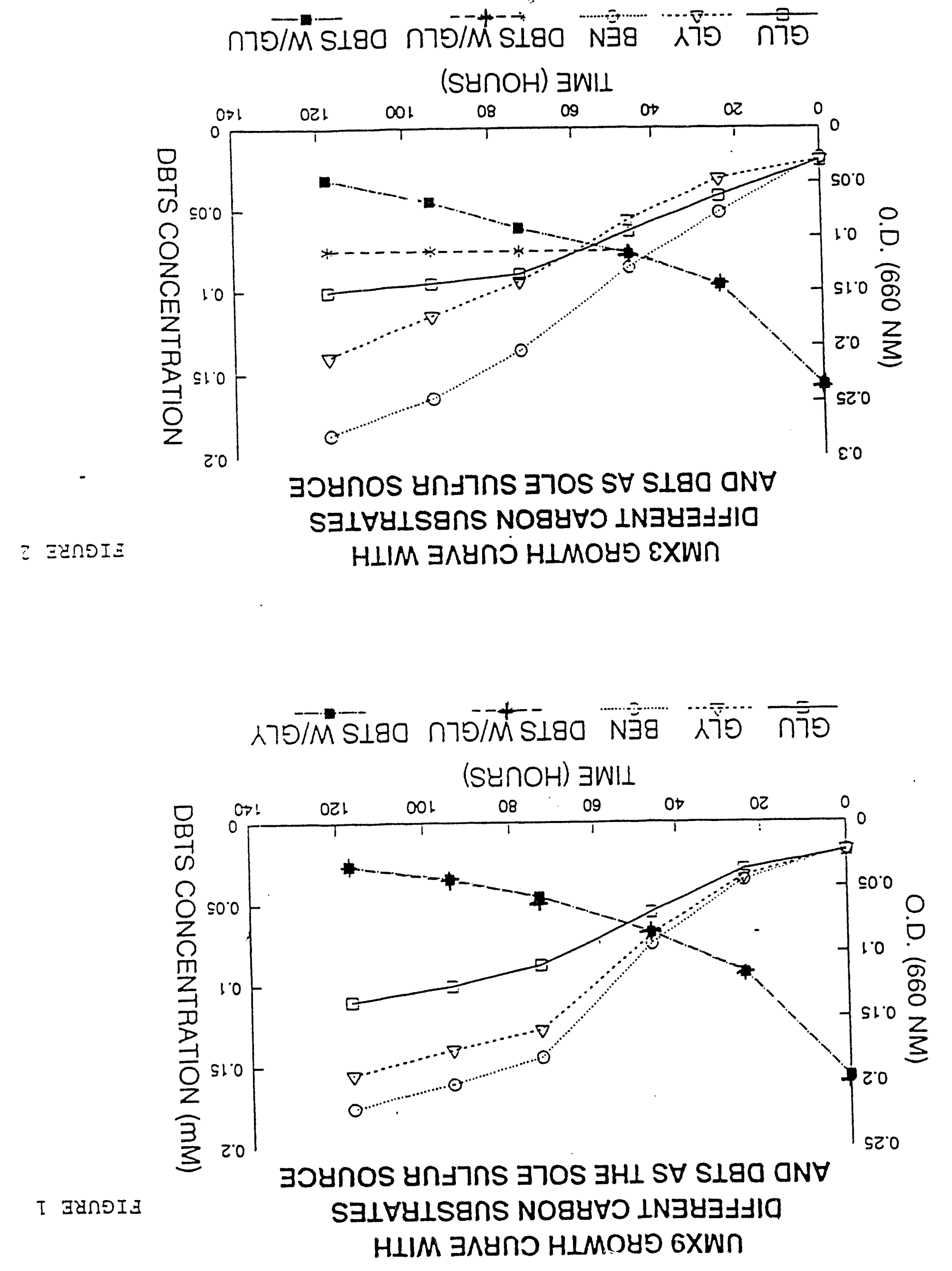




\section{EIGURE 3}

1

+ RUN \# 2 IEN 1. ISEI EZ:IS:ET
STERT

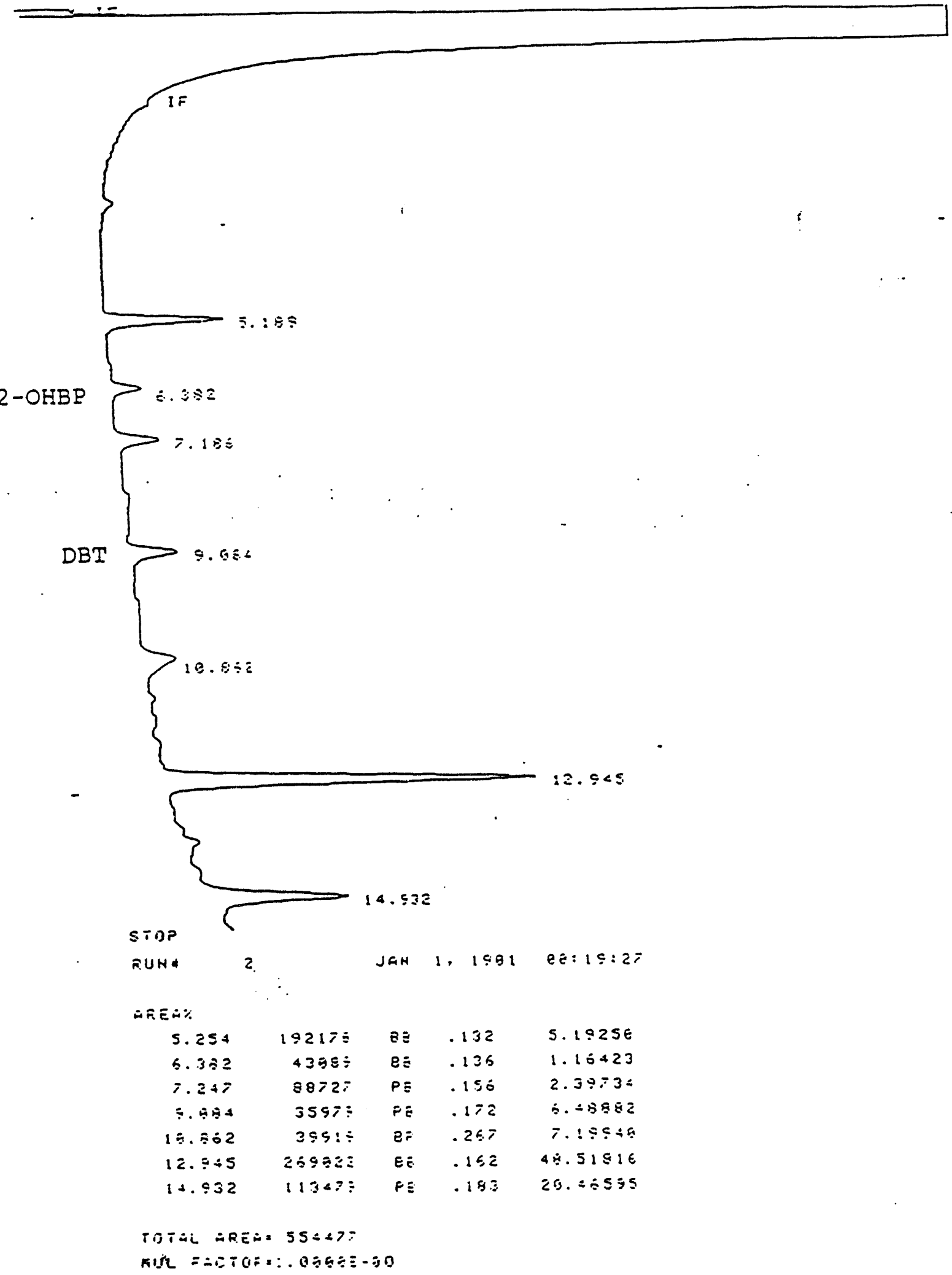


Library searched : C: \DATABASE\HBS49K.L Quality

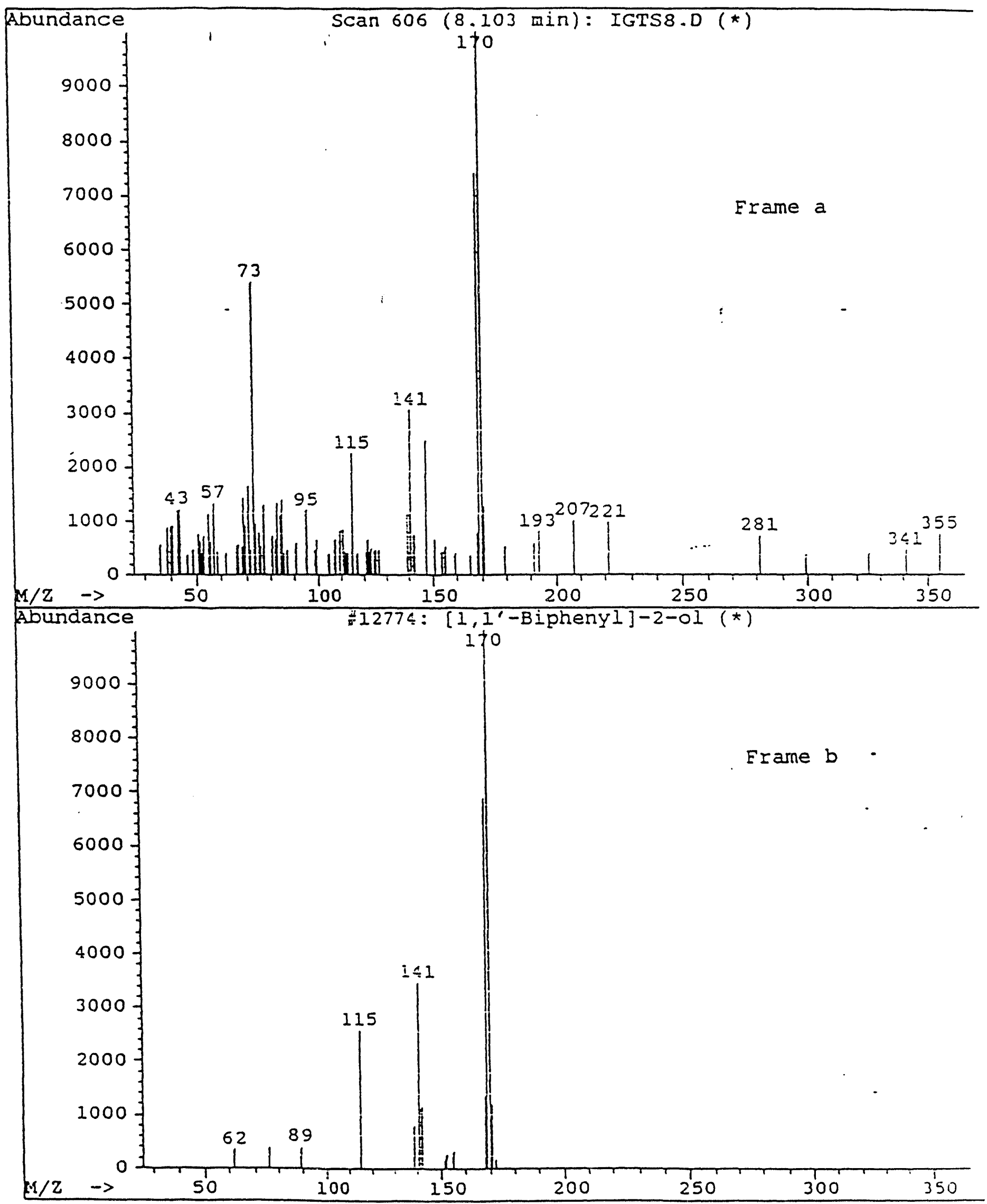


Quarterly Progress Report, Biodesulfurization Project

15 December 1990

There was substantial agreement between the strains with regard both to qualitative and quantitative fatty acid content; however, the strains differed in some fatty acids.

Based on the data shown in Table 1 , as well as the fatty acid analyses, we believe that strain UMX3 is likely the same as IGTS8: like IGTS8, it is unable to grow on glucose as the sole carbon source; moreover, it is morphologically indistinguishable from IGTS 8 and exhibits similar growth kinetics on minimal medium with DBTS as the sulfur source. However, we find it disconcerting that we have been unable to detect any release of phenylphenol in the medium following growth on DBTS by strain UNX3. Strain UMX9 produces phenylphenol when grown on DBTS as the sole source of sulfur; but UMX9 grows on glucose as the sole carbon source and has a markedly different colonial morphology.

We are comparing the abilities of UMX3, UMX9 and IGTS 3 to grow at the sole expense of 40 additional carbon sources; this study should shed additional light on the question of the taxonomic relationship between these strains.

\section{Coal culture of desulfurizing bacteria}

In the past quarter, we did two experiments to determine whether the UMX3 and UMX9 isolates could obtain their sulfur from the organically-combined sulfur in coal. We added biodepyritized coal (prepared by Louisiana Tech University, sample \#1003, A\& B; $10 \mathrm{~g} / \mathrm{L}$ ) as the sole source of available sulfur to a sulfate-free minimal medium ( $\mathrm{pH} 7.0$ ); such media contained $20 \mathrm{ppm}$ sulfate (detectable by ion chromatography), an unacceptably-high anount. 
Quarterly Progress Report, Biodesulfurization Project

15 December 1990

our attempts to deplete this free sulfate from the medium by allowing growth of wild type Escherichia coli, were not successful. An alternative washing method was employed: Samples of depyritized coal ( $10 \mathrm{~g}$ each) were suspended in 100 $m L 6 \mathrm{~N} \mathrm{HCl}$ and stirred for 1 hour; the coal could be removed from the acid by filtration onto whatman no. 1 paper on a Buchner funnel; after three washes of $200 \mathrm{~mL}$ each with deionized water, the coal was resuspended in $80 \mathrm{~mL}$ of water, the $\mathrm{pH}$ adjusted to $\mathrm{pH} 7.0$ and the volume brought to $100 \mathrm{~mL}$. Medium made from coal treated in this manner typically contained 1 to 2 ppm sulfate.

Two series of growth experiments were completed with UMX3 and UMX9 inoculated jnto sulfate-free minimal medium containing glycerol and glucose as the carbon sources and washed, depyritized coal $(10 \mathrm{~g} / \mathrm{L}$ ) as the sole source of available sulfur.

To assess the level of growth of the bacteria that would be supported by residual sulfate in the coal cultures, we also ran control cultures without coal but containing 2 ppm sul- fate. All cultures were static at room temperature $\left(25^{\circ} \mathrm{C}\right)$. one-liter volumes of media were contained in 2.8 liter lowform flasks; each flask was swirled twice daily to mix the coal slurry with the medium.

We followed growth (by viable cell count), and the concentration of free sulfate (by ion chromatography) in the medium over a course of 16 days for the first experiment and 19 days for the second. The minimal mediun without added sulfate did not support growth of either UMX3 or UMX9. 
Quarterly Progress Report, Biodesulfurization Project

15 December 1990

The final $\mathrm{pH}$ values for each culture condition were:

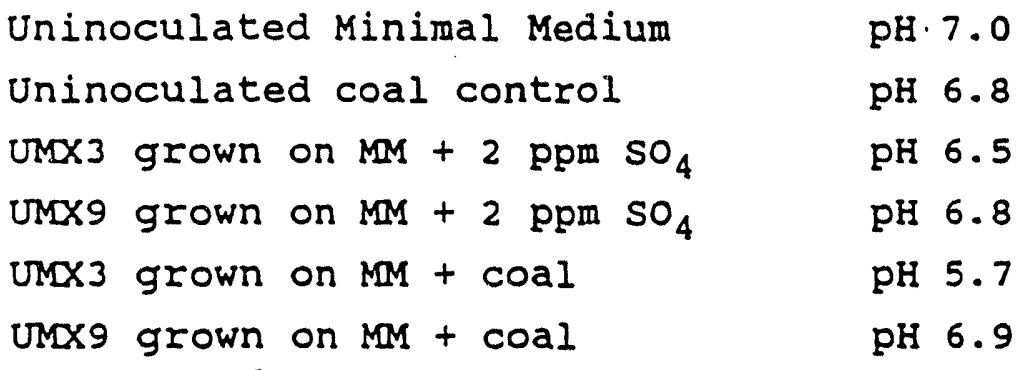

We have no explanation for the substantial drop in $\mathrm{pH}$ that occurred during the growth of UMX3 in the coal culture.

Figure 6 ( $a$ and $b$ ) depicts the growth of UNX3 and UMXX on coal as the sulfur source; "control" lines were generated from the cultures in minimal medium with 2 ppm sulfate added. Uninoculated coal-containing medium maintained a free sulfate concentration of around 2 ppm throughout the course of the experiments.

In all cases, the control cultures with 2 ppm sulfate added supported populations that were 1.5 to 3 logs below those growing on coal. The UMXg bacteria formed small waxy colonies on the surface of the broth: UNX3 seemed to be more evenly distributed throughout the medium.

Although our use of viable cell count as an index of biomass accumulation in these experiments suffers some limitations, it is probably an index of the minimal growth of the bacteria on the coal: The bacteria in the coal cultures were visibly clumped, and one would expect that colonies of bacteria might form on the coal particles; both of these factors tend to lower counts of colony forming units. Our preliminary attempts at colorimetric protein determination 
Quarterly Progress Report, Biodesulfurization Project

15 December 1990

in these experiments were confounded by interferences from culture components with the assay method.

The coal that had been acted on by either UMX3 or UMX9 showed a noticeable physical deterioration when we examined it at the conclusion of the experiment: there was a dramatic increase in fines, so that a high proportion of the coal exposed to the microbes remained in suspension indefinitely. In contrast, coal that simply soaked in uninoculated medium still settled out rapidly as a fine granular mass. However, centrifugation for 20 minutes at $17,700 \times \mathrm{g}$, removed particles from suspension.

Sulfate concentrations durinc the course of the two experiments. In both experiments, sulfate in the uninoculated coal-minimal-medium-control stayed at 1.5 to 2 ppm throughout the experiment; and, the 2 ppm of sulfate in the control culture (without coal) was no longer detectable 2 days after inoculation.

In the first experinent, sulfate concentration of the medium containing coal that was inoculated with UMX3 has increased at least twofold (to $5 \mathrm{ppm}$ ) in the 5-day post-inoculation sample but then declined to 1 to 2 ppm; the analogous UMX9 culture did not show a similar increase in sulfate. In the second experiment, we did not observe this small increase in free sulfate in either the UNX3 or the UMX9 coal culture. Most likely, the sanple vial for the 5-day data point in the first experiment was contaminated with sulfate: points on either side of the 5-day sample showed only 1 to $2 \mathrm{ppm}$ sulfate. 
Quarterly Progress Report, Biodesulfurization Project

Thus, in these experiments we show growth of either strain UMX3 or strain UMX9 on the organically derived sulfur in coal that apparently serves as the sole source of sulfur. However, in neither of these experiments did we see release of substantial amounts of sulfate into the medium. It could be that the low levels of free sulfate we see in the coal cultures is all that can be expected because it is taken up almost as rapidly as it is released. Furthermore, the sulfur from the coal may be either directly incorporated into cell biomass, or else released as some combined form other than sulfate.

We are currently removing the bacterial biomass from the coal harvested from these experiments. We will send the coal to Louisiana Technical University for sulfur analyses (sulfur : silicon ratio) to assess changes in organic sulfur content of the coal effected by growth of the microbes. 

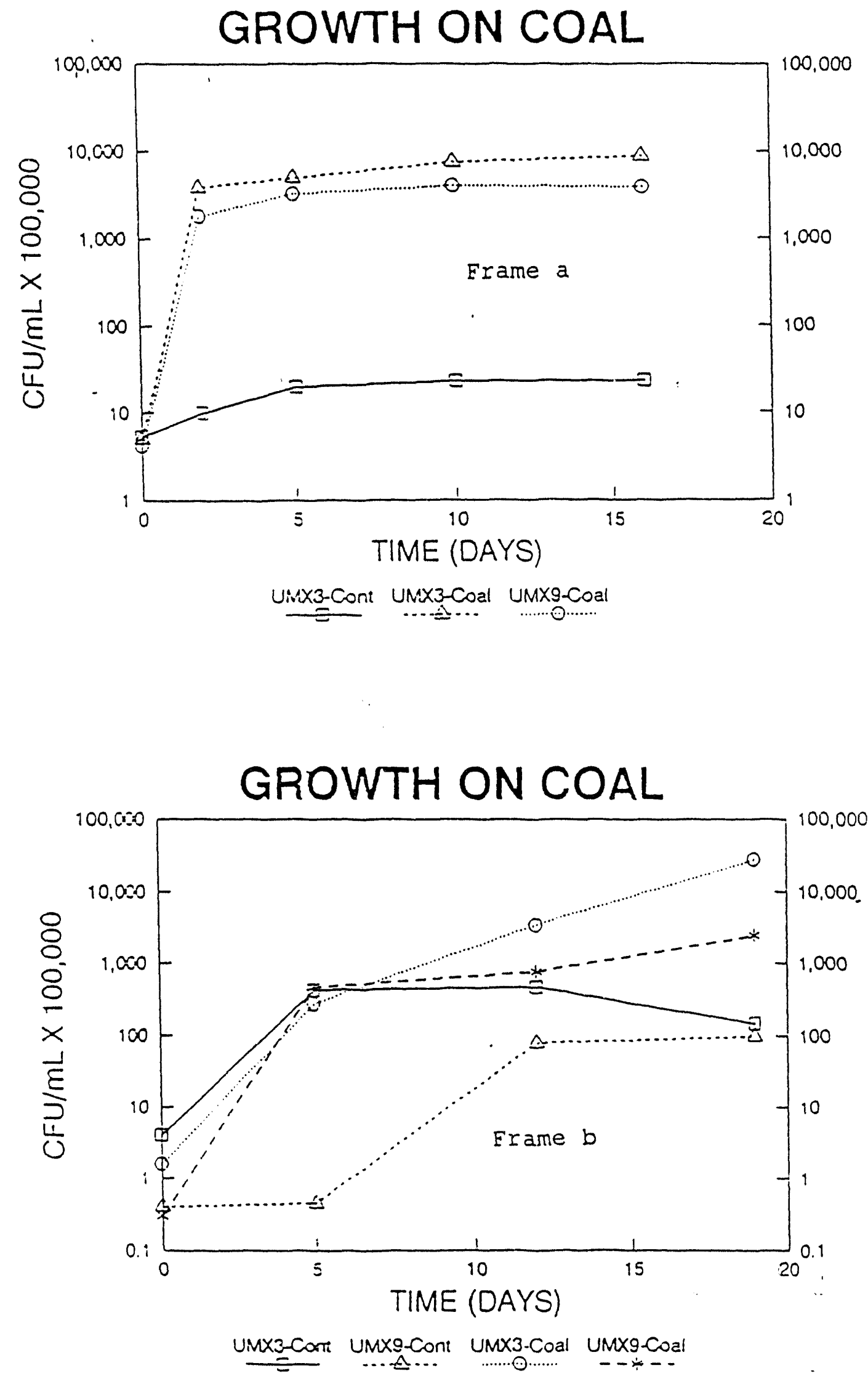
Table 5. Results of the $\mathrm{CH}$ Assay

\begin{tabular}{lccc}
\hline \multicolumn{1}{c}{ Carbohydrate $^{1}$} & UMX3 & IGTS8 & UMX9 \\
\hline Glycerol & Yes & Yes & Yes \\
Ribose & Yes & Yes & Yes \\
D-Glucose & No & No & Yes \\
D-Fructose & Yes & Yes & Yes \\
Inositol & Yes & Yes & Yes \\
Mannitol & Yes & Yes & Yes \\
Sorbitol & Yes & Yes & Yes \\
N-Acetyl-glucosamine & Yes & Yes & Yes \\
Esculin & Yes & Yes & Yes \\
Saccharose & Yes & Yes & Yes \\
Trehalose & Yes & Yes & Yes \\
D-Arabitol & Yes & Yes & Yes \\
Gluconate & Yes & Yes & Yes \\
L-Arabinose & Yes & No \\
\hline
\end{tabular}

1. Carbohydrate utilization was tested by the API CH test kit. The strains were cultivated for 48 hours in organic silfur medium with magnesium sulfate as the sole sulfur source. Cellis were aseptically harvested, centrifuged $(15,000 \mathrm{~g}$ for $20 \mathrm{~min})$, and washed with $0.01 \mathrm{~N}$ phosphate buffer. Cells were then centrifuged again and resuspended in organic sulfur medium with no carbon source. The $O . D$. of the strains was adjusted to 0.016 before inoculation into the API test wells. The length of the assay was 8 days and yes denotes growthh in the test well. 
File: D: $\quad$ BIODATA IIGTS8.D

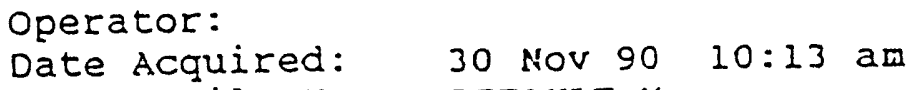

FIGURE 5

Method File Name: DEFAULT.M

Sample Name:,

Misc Info:

Bottle Number: 1
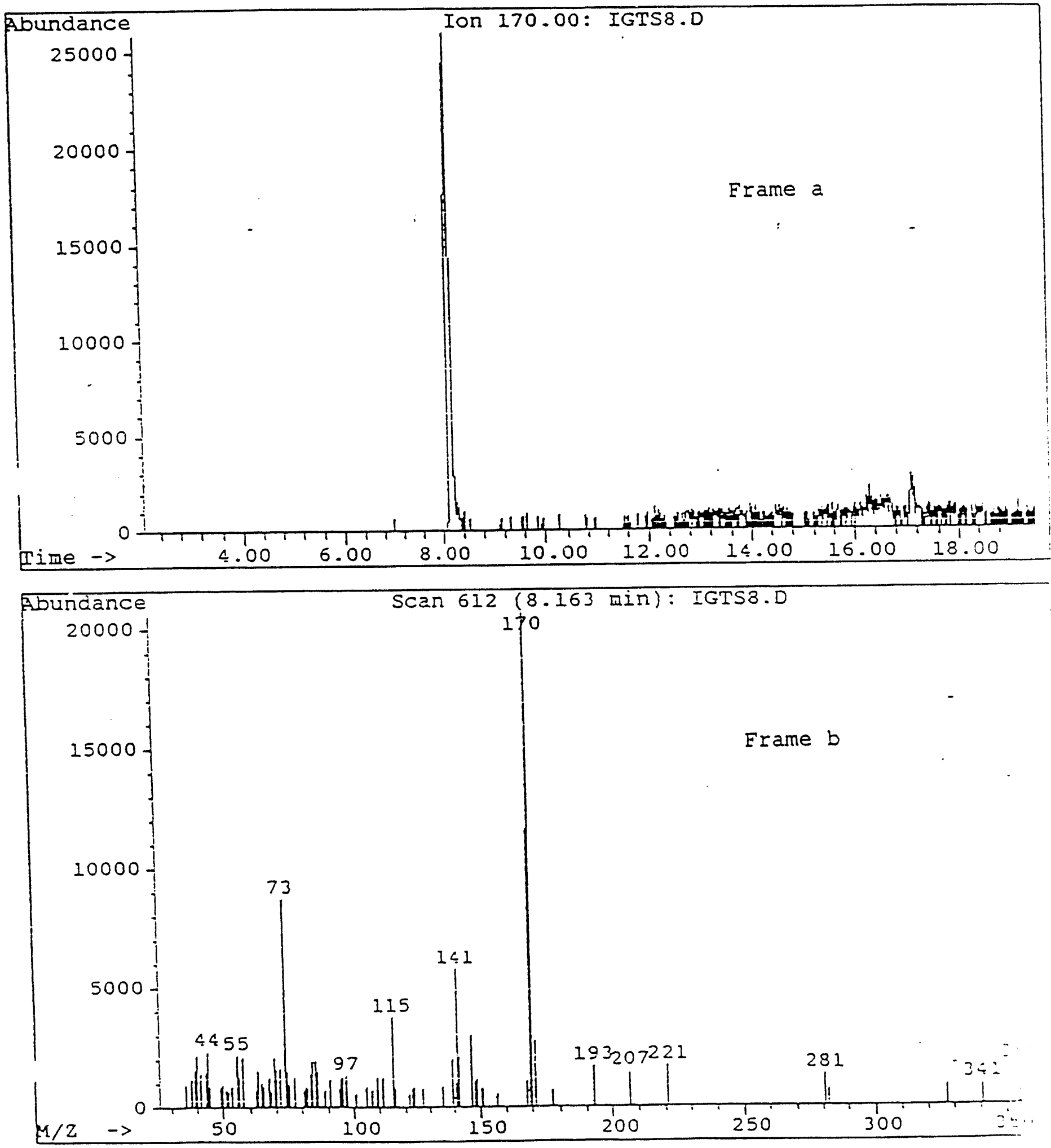


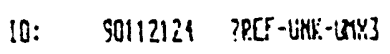

Cate of run: $22-H 01-40$ 0 $05: 02: 54$

Eôtlle: 26 SATPLC [RCROBESO]

\begin{tabular}{|c|c|c|c|c|c|c|c|c|c|c|}
\hline RI & Rred & Arste & Respan & $\ll a$ & يينغ & i & Coment 1 & Come & int 2 & \\
\hline 1.613 & 1067520 & 0.028 & ! & ?.EAZ & SQuent fres & & ( nin rt & & & \\
\hline 6.709 & 4592 & 0.014 & 0.983 & 15.959 & $19: 0$ & 3.87 & [Ci deviates - O.GT & Reference & 0.001 & \\
\hline 8.165 & 1948 & 0.053 & 0.953 & $15.06 ?$ & $15: 0$ & 1.53 & ECL devizites O.Giil & Referance & t. Pell & \\
\hline 9.395 & 1576 & 0.052 & 0.951 & 15. 779 & $16: 18$ & 1.29 & 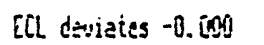 & & & \\
\hline 9.467 & 2200 & 0.541 & 0.550 & 15.917 & $16: 1$ CIS $\Sigma_{\ldots}$ & 1.29 & [C! deviates O. 0 on & & & \\
\hline 9.525 & 12312 & 0.050 & 0.550 & 15.855 & 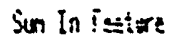 & 10.03 & in devizles -î. Bin! & 16:1 iefis & 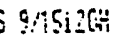 & \\
\hline 9.957 & 37524 & 0.047 & 6.948 & 16.04 & $16: 0$ & 39.59 & SC revistes o.mol & Referstite & 6.96 & \\
\hline 11.981 & 2024 & 0.064 & 0.940 & เร. .31 & $17: 18$ & $1.5 ?$ & 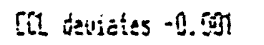 & & & \\
\hline i1. $\$ 31$ & !576 & 0.651 & 0.939 & 17.99? & $17: 0$. & $\therefore 7$ & 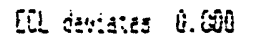 & Reterants & 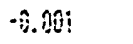 & \\
\hline 2.750 & $3107 ?$ & 0.052 & j. 3 淤 & 17.38 & 18:1 [:: $\vdots \ldots$ & 3.79 & [U deyia:es - 6.60? & & & \\
\hline 13.158 & 3760 & $0.95: 8$ & 0.53 & 17.69 & $18: 0$ & 3.04 & 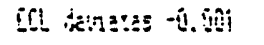 & 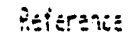 & 4.901 & \\
\hline 15.828 & $152 ? ?$ & $0.05 ?$ & $\{.932$ & $10.33 \%$ & IESh lir:t:ot: & $: 2 . ?$ & Tft isuratso idg & & & \\
\hline 14.875 & 4528 & 0.052 & i. & 18. 998 & $: 3: 0$ & :.6! & 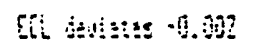 & Petertenzs & s.m! & \\
\hline 15.593 & ?55? & 9. 292 & 0.329 & $3.6 \%$ & $20: 0$ & 1.80 & 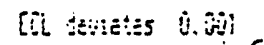 & Bisters: & i.me & \\
\hline$: 8.315$ & 2055 & 0. โิ4\} & & 29.72 & & . . & $; n=x+140$ & & & \\
\hline $15.62 ?$ & 1749 & 0.863 & . & 39.955 & & . . & $\therefore=14.16$ & & & 1.42 \\
\hline $16.23 ?$ & 2168 & 0.35 & . & 29.979 & . & . & ins is lis. & 24 & & 6.5 \\
\hline ……e & 12312 & & & & Sharti & 13 & ¿5:0! ! & 1649 in: & 919 & \\
\hline
\end{tabular}

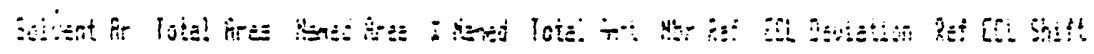

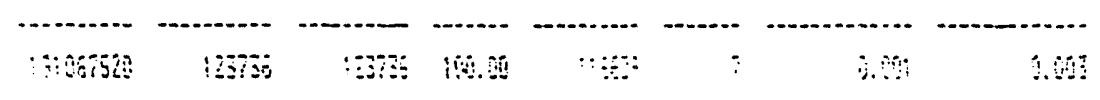

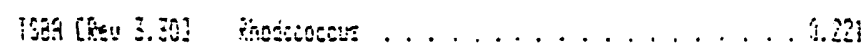

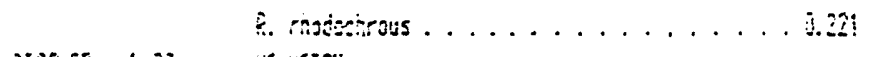

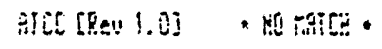

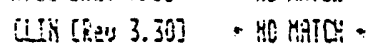

\section{Table 4. $\quad 4 M \times 3$}




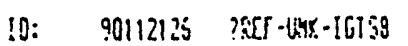

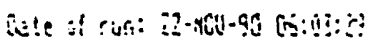

Qutlle: 28 SATPLS CAEPSES50]

\begin{tabular}{|c|c|c|c|c|c|c|c|c|}
\hline $8 !$ & Frea & RrMt B & Respoon & $\mathrm{EQ}$ & Han: & $:$ & Ement : & Comerit : \\
\hline 1.012 & 92508:10 & 0.028 & & 7.036 & SE:STI PER. & & ies: & \\
\hline 6.707 & 2640 & 0.045 & 0.985 & 19.000 & 19:E . . & 4 & 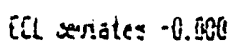 & Reference -0.01 \\
\hline 9.163 & 920 & 0.849 & 0.963 & 15. $(50)$ & $15: \xi$ & 1.5 & 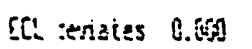 & $\hat{x} \leq \hat{f}$ ertace $-\hat{0}$. gist \\
\hline 9.393 & 816 & 0.045 & 0.951 & 15.73 & $16: 1 \div$ & $1.2 i$ & [il striates -0.01 & \\
\hline $9.46 t$ & 970 & 0.041 & 0.350 & 15.918 & 16:1 015 9. & 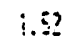 & OAjiztes IM! & \\
\hline 9.525 & 6304 & 0.048 & 0.950 & 15.055 & Sor in fester & 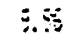 & [0: & 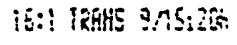 \\
\hline 9.755 & 20335 & 0.043 & 0.948 & 16.0900 & 160 & 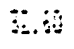 & Eil :enists: 0.6:0 & Peference -iy. Gist \\
\hline 11.061 & 10:93 & 0.055 & 6.949 & 16.799 & צ' & $\therefore$ & 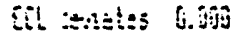 & \\
\hline 12.199 & $2: 972$ & $0.0 S i$ & ก. 933 & 17.767 & 19: & 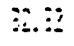 & 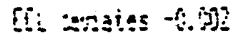 & \\
\hline$\$ 3.148$ & 183 & 0.055 & 8.93 & 17.4:99 & 1E: : & ï: & 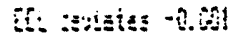 & Reterenes -4.âj: \\
\hline 13.327 & 579 & 3.055 & 5.931 & 19.993 & 15: T:telt: & $\because \%$ & 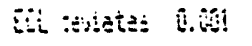 & \\
\hline 14.879 & 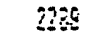 & 0.865 & $8.93 !$ & 19.200 & $15: \div$ & $\vdots 3$ & 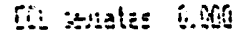 & Ptirthes Af \\
\hline 13.290 & $55 i 4$ & 8.869 & $\therefore$ & 2.202 & $\ldots$ & . & 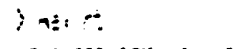 & \\
\hline 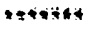 & 94 & & & & 5 & $\ddot{\theta}$ & 15: & 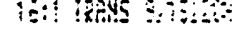 \\
\hline
\end{tabular}

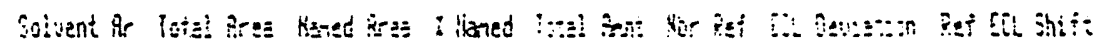

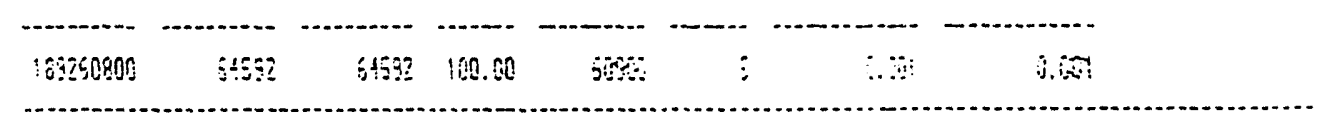

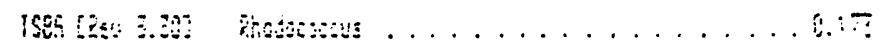

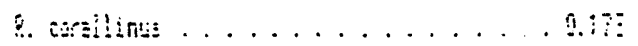

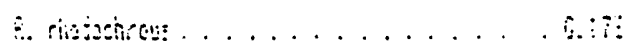

$\vdots$ :

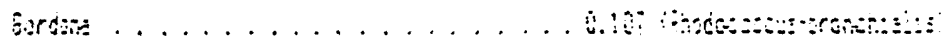

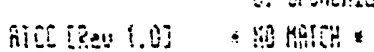

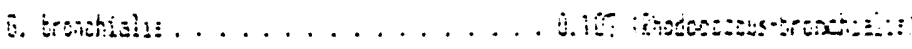

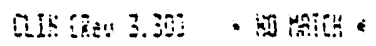

\section{Table 3 I58}




\begin{tabular}{|c|c|c|c|c|c|c|c|c|c|c|}
\hline \multicolumn{2}{|c|}{$\begin{array}{l}\text { I0: } \quad 1980 \\
\text { 8ottle: } 64\end{array}$} & \multicolumn{3}{|c|}{$\begin{array}{l}\text { UKK-SOIL-PHA-390-118-09 } \\
\text { SARPLL [REROBESO] }\end{array}$} & \multirow{2}{*}{\multicolumn{2}{|c|}{ Kart }} & \multirow[b]{2}{*}{ ! } & \multicolumn{3}{|c|}{ Date of run: 03-90R-90 21:03:24 } \\
\hline RI & Prea & $\mathrm{Br} / \mathrm{Hz}$ & Respan & [al & & & & Cont 1 & & Coment 2 \\
\hline 1.475 & 292580000 & 0.058 & & 7.051 & SQuetr & PEFI & & $\ln \sin r$ & & \\
\hline 6.862 & 1986 & 0.051 & 0.991 & 14.000 & $11: 0$. & & $2.6 \$$ & 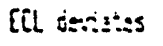 & $0.00 \mathrm{j}$ & Reiessen 0.001 \\
\hline 8.334 & 2262 & 0.042 & 0.966 & 15.000 & $15: 0$. & & 2.59 & CCL ex:2:es & 0.005 & Refersese 0.000 \\
\hline 9.726 & 3135 & 0.055 & 0.949 & 15.812 & $15: 1$ aIs & s 9. & 1.4 & COL he::z:ss & -9.025 & \\
\hline 9.795 & 9621 & 0.047 & 0.948 & 15.854 & $\operatorname{sen}$ in $f$ & featr: & 12.48 & 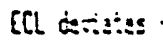 & -0.002 & 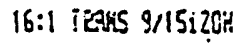 \\
\hline lū.ci33 & 21338 & 0.045 & 0.946 & 15.999 & $15: 0$. & & 27.52 & 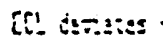 & -0.028 & Ref::=0s -0.002 \\
\hline 11.235 & 1770 & 0.052 & 0.933 & 16.789 & $17: 18$ & & 5.60 & ECl do:_:stes & -8.653 & \\
\hline 11.349 & 1339 & 0.050 & 0.930 & 17.001 & $17: 0$. & & 1.77 & ECL de:oz:es & $0.00:$ & Reiferexe 0.000 \\
\hline 12.455 & 1107 & 0.018 & 0.925 & 17.112 & $18: 1$ is & & 1.49 & 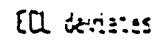 & 0.003 & \\
\hline 12.084 & $2380 ?$ & 0.050 & 0.920 & 17.766 & I:E1 CI & 159 & $x .37$ & צ'] & -0.25: & \\
\hline 14.179 & $84 i 0$ & 0.049 & 0.913 & 18.393 & $i \sin 16$ & Mels:: & $0.5 \mathrm{i}$ & 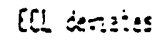 & 0.001 & \\
\hline (nime & 0 & & & & & Tiltris & 12.45 & 15:3: & $115: 1: 5$ & 15:1 \\
\hline
\end{tabular}

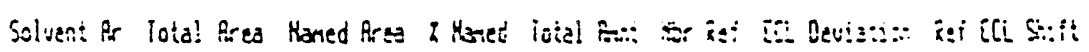

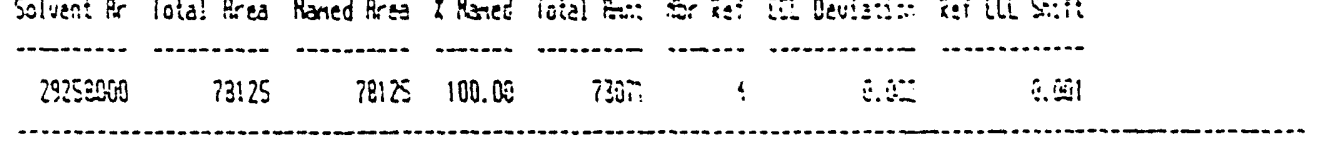

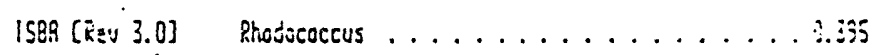

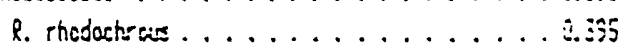

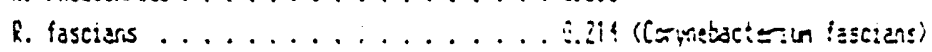

Conce::Son u1 ti isas [Rev 3.0]: Rhodococcus-riodochrese

Cis:s:-2: 4.046

\begin{tabular}{|c|c|c|c|c|c|c|c|c|c|c|c|c|c|c|c|c|c|c|c|c|}
\hline & 0 & 10 & 15 & 20 & $\Sigma$ & 30 & $\Xi$ & 4 & 45 & 50 & $\Xi$ & in & EE & 3 & 75 & 20 & 85 & $5:$ & 55 & 100 \\
\hline & . & - & • & - & . & - & • & $\cdot$ & • & - & - & - & . & . & - & . & . & . & . & . \\
\hline $14: 0 . \ldots . .$. & $\rightarrow-\infty$ & $\cdot$ & $\cdot$ & $\cdot$ & $\cdot$ & - & . & - & • & - & $\cdot$ & $\cdot$ & - & · & ${ }^{\circ}$ & $\cdot$ & , & 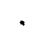 & . & 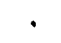 \\
\hline $15: 0 \ldots \ldots \ldots$ & $\cdots$ & · & . & . & . & . & . & - & . & - & • & . & 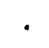 & . & - & - & - & 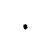 & 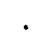 & $\cdot$ \\
\hline $16: 1$ cis 9. . . . & $---+x-$ & - & · & . & . & . & . & . & . & . & . & - & - & . & • & - & • & . & $\cdot$ & • \\
\hline$i 6: 0 \ldots$. & . & 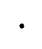 & - & . & 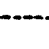 & - & 一 & - & . & . & $\cdot$ & . & . & . & $\because$ & - & - & - & . & . \\
\hline $17: 13 . \ldots \ldots$ & $-\cdots+-x$ & · & . & . & - & - & . & - & . & . & - & · & · & $\cdot$ & - & . & - & • & . & - \\
\hline $17: 0 \ldots \ldots$ & $-x-$ & . & . & . & . & . & . & . & . & . & . & . & . & . & - & . & - & . & - & - \\
\hline 18:1 150 r. . . . & $\rightarrow-$ & . & $\cdot$ & . & . & . & . & - & . & . & . & · & . & . & - & - & - & . & - & . \\
\hline $18: 1$ CIS $9 . \ldots$ & & $\cdot$ & $\cdot$ & & & $-x-$ & ... & $\because$ & . & . & . & . & · & . & - & - & - & - & - & $\cdot$ \\
\hline $1 e: 0 \ldots \ldots$ & $x--+\cdots$ & · & $\cdot$ & $\cdot$ & $\cdot$ & . & $\cdot$ & - & . & $\cdot$ & . & . & · & $\cdot$ & - & • & · & · & • & $\cdot$ \\
\hline I359 IOMel8:0 . . & . -- & $\rightarrow$ & & & . & • & . & - & . & . & . & . & • & · & • & · & • & . & . & $\cdot$ \\
\hline $20: 0 . \ldots \ldots$ & $x+\cdots$ & . & . & & . & · & - & $\cdot$ & · & $\cdot$ & · & - & . & $\cdot$ & . & . & • & - & . & . \\
\hline SUYHE FEAIURE \&. , & . & & & & • & · & - & & · & · & . & - & & - & • & • & • & & & \\
\hline imed regiuRe 8. & $x+\cdots$ & . & . & . & . & . & & & & - & . & . & & - & - & - & • & & & \\
\hline
\end{tabular}




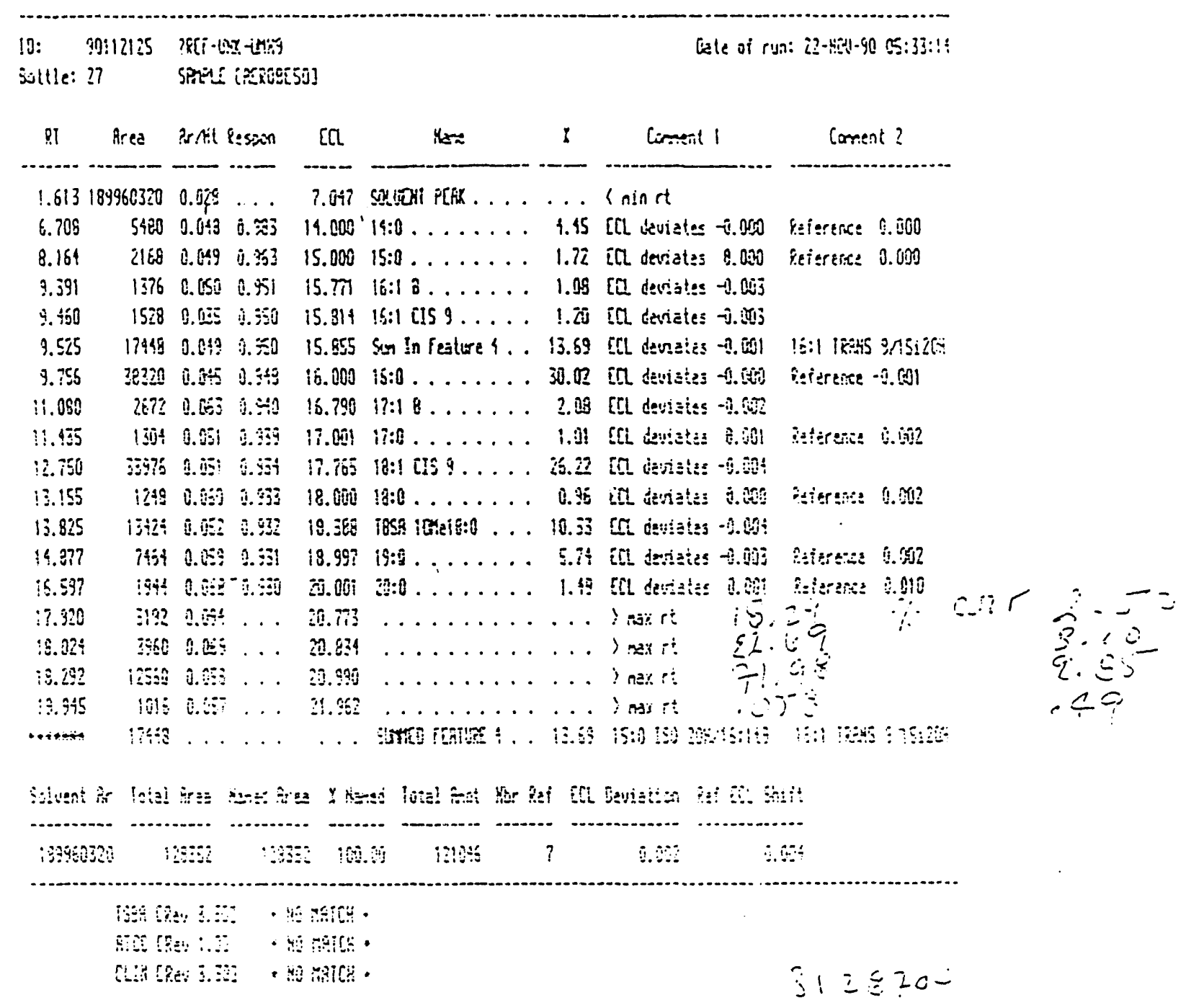




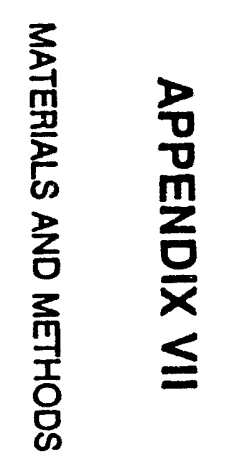

- 


\author{
MATERIALS AND METHODS \\ (adapted from text by R.F. Purdy)
}

Sulfur-Stress Assay. Glassware was acid-washed $(6 \mathrm{~N} \mathrm{HCL}$ for $60 \mathrm{~min}$ ) to remove residual sulfate, then rinsed at least three times in delonized water (Nanopure Type 1, 17 megohm) and capped to prevent sulfur contamination from dust particles. Growth was quantified at $660 \mathrm{~nm}$ using a Milton Roy spectronic 501; optical path was $1.6 \mathrm{~cm}$ with the $20 \mathrm{ml}$ culture tubes. An uninoculated tube containing growth medium served as the reference.

A modified $21 \mathrm{C}$ medium (Table I) in which chloride salts replaced sulfate salts was used for the maintenance of working cultures and testing of cultures on the sulfur-stress assay. Carbon substrates were $0.5 \% \mathrm{w} / \mathrm{v}$ glucose and $0.5 \% \mathrm{v} / \mathrm{v}$ glycerol. Inorganic sulfur (Ion chromatography) in the sulfur-stress medium did not exceed $1 \mathrm{ppm}$ sulfate. Tryptic soy broth $(12 \mathrm{~g} / \mathrm{l})$ was used to grow cells prior to testing in the sulfur-stress assay.

The sulfur-stress assay served both as a screening device to detect organisms capable of desulfurizing model coal organosulfur compounds and to characterize the physiology of the desulfurizing cultures. The assay was a modification of the Kllbane and Blegla sulfur bioavallability assay in which organisms were screened for ability to grow under a sulfur-stress environment where the only plentiful source of sulfur was an organosulfur compound. We used DBT-sulfone because of its greater water-solubility than DBT. A watersaturated solution contained $0.166 \mathrm{mM}$ DBT-sulfone and gave an optically clear medium, needed for accurate measurements of O.D. of cell suspensions. Moreover, DBT-sulfone did not yield Kodama-type products.

Cultures were first grown in tryptic soy broth $(12 \mathrm{~g} / \mathrm{l})$ for a period of $48-72$ hours, then washed twice with $0.01 \mathrm{~N}$ phosphate buffer and resuspended in sulfur-stress medium for 24 hours, at which point the $0 . \mathrm{O}$. of the cultures was about 0.3 . Inoculum size was $0.5 \mathrm{ml} / 10 \mathrm{ml}$ medium in culture tubes. The usual assay consisted of three sets of tubes, each containing sulfur-stress medlum: one set contained organic sulfur compound; a second set contained no sulfur source (negative control); a third set contained $0.16 \mathrm{mM}$ magnesium sulfate (positive control). Initial screening tests also included a fourth set of tubes, containing sulfate plus DBT-sulfone to ascertain possible inhibitory effects of DBT-sulfone; such effects were lacking for UMX3, UMX9, and IGT S-8, thus we eliminated the fourth test set for subsequent trials. Positive biodesulfurization was indicated by growth on DBT-sulfone relative to the negative control.

To isolate bacteria from a consortium that tested positive on the sulfur-stress assay, $12 \mathrm{gm} / \mathrm{l}$ of noble agar was mixed with sulfur-stress medium containing DBT-sulfone. More organic sulfur was added by $1 \mathrm{ml}$ of ether sprayed on the plate from a stock solution of $90 \% \mathrm{wt} / \mathrm{vol}$ DBTS. Separation of organisms that could not utilize DBTS as a sulfur source was by the spread-plate technique on $1.4 \mathrm{~g} / \mathrm{l} \mathrm{TSB}$ with $14 \mathrm{~g} / \mathrm{l}$ of agar.

Cultures capable of growth in the sulfur-stress assay were maintained on the same medium for working stocks. Transfers of stocks were made at least weekly. Cultures were also maintained on TSA slants stored at $-5 \mathrm{OC}$, and in glycerol at $-80^{\circ} \mathrm{C}$.

Instrumental Analysis. Quantification of 2-phenyiphenol (2-hydroxybiphenyl) in the sulfur-stress assays was conducted by gas chromatography. Disappearance of DBT-sulfone in the resting cell assays was also monitored by gas chromatography. The gas chromatograph was a Hewlett Packard 5890 series equipped with a 530 series capillary column with a splittess injector. The carrier gas was helium $(15 \mathrm{ml} / \mathrm{min})$. Hydrogen and compressed air flow were $30 \mathrm{ml} / \mathrm{min}$ and $135 \mathrm{ml} / \mathrm{min}$ respectively. Detection of substrate was by flame ionization detector (FID). Injector temperature was $260 \mathrm{oC}$, and detector temperature was $280 \mathrm{oC}$. Temperature programming for the oven was $100 \mathrm{oC}$ initially with ramped at $1 \mathrm{oC} / \mathrm{min}$ until the maximum oven temperature of $255 \mathrm{oC}$ was reached. Figure 9 depicts the standard curves for DBT-sulfone and 2-phenylphenol as measured by gas chromatography.

Mass spectrometry, courtesy of the Ole Miss chemistry Department, was used to confirm identity of desulfurization products. We used a Hewlet-Packard MSD-5971 GCC/MS coupled with an HP software library of ion spectra plus a customized li' rary of our own standard compounds. Faculty of the Chemistry Department assisted with operation and interpretation of spectra. 
Sulfate analysis was accomplished by the use of anion chromatographic procedures. This method is sensittve and specific for sulfate at concentrations of 0.5 parts per million up to $1000 \mathrm{ppm}$. We used a Dionex Model 2000 lequipped with a HPIC-AS4A column and a conductlvity detector.

The disappearance of DBT-sulfone or 2-phenylphenol was monitored by UV-spectrometry using a Milton Roy Spectronic 1201. This system was coupled to a Zenith XT computer that ran the Spec Scan Application software ver 1.01 (Milton Roy Analytical Products Division, 820 Linden Avenue Rochester, New York 14625). One cm matched-quartz cuvettes were used.

Samples for gas chromatography and GC/MS were extracted according to the following protocol: acidification by the addition of two drops of $6 \mathrm{~N} \mathrm{HCL}$, extraction with dichloromethane equal to one half the total volume of the samples, removal of aqueous portion by phase-separating paper (Whatman IPS). The extraction procedure was performed twice: extracts were pooled, transferred to $50 \mathrm{ml}$ jars, and allowed to evaporate completely. Samples then were resuspended in $1 \mathrm{ml}$ of dichloromethane. To each sample, 0.5 $\mathrm{ml}$ of a $100 \%$ thiantherene solution was added as an internal standard.

The extraction procedures for UV-spectroscopy: a $1.5 \mathrm{ml}$ sample was centrifuged for 10 minutes at $10,000 \times g$, after which the clear supernatant was analyzed.

Comparattve Tests on UMX3. UNX9, and IGT S-8: Cultures were grown for at least three transfers in sulfurstress medium with DBT-sulfone and thiantherene as the sulfur sources. On the third transfer, cells were grown with DBT-sulfone as a sole sulfur source for a period of at least 48 hours and not more then 72 hours. Experimental variables were $\mathrm{pH}$, temperature, different carbon substrates, addition of inorganic sulfur, and different organic sulfur substrates. The O.D. of the starter inoculum was adjusted to about 0.3. Inoculation volume was $1 \mathrm{ml}$ into $9 \mathrm{ml}$ of medium unless otherwise noted. Growth was monitored at 24 hour intervals. The concentration of DBT-sulfone and 2-phenylphend was monitored by UV spectrometry unless otherwise noted.

Carbohydrate utilization was tested by the use of rapid $\mathrm{CH}$ test kit (API analytab products. Division of Sherwood Medical. 200 express Street, Plainview, New York 11803.). Organisms to be tested were incubated in sulfur-stress medium $(50 \mathrm{ml})$ with $0.2 \mathrm{mM}$ magnesium sulfate and no DBT-sulfone for 48 hours. Protocol for $\mathrm{CH}$ test: cells were aseptically harvested by centrifugation $(15,000 \times g$ for $15 \mathrm{~min})$, washed once with $100 \mathrm{ml} 0.01 \mathrm{~N}$ phosphate buffer, centrifuged (as above) and then resuspended in $100 \mathrm{ml}$ of medium (magnesium sulfate instead of DBT-sulfone) with no added carbohydrate source. The final O.D. in the 100 $\mathrm{ml}$ of medium was adjusted to 0.05 . About $1 \mathrm{ml}$ of inoculum was placed in each of the 49 test sites on the API strip. Carbon utilization as evidenced by visual confirmation of growth was monitored at 24 hour intervals for 8 days.

Tests for degradation/utilization of 2-phenolphenyl or DBT-sulfone were made by supplying each compound (at $0.166 \mathrm{mM}$ ) as a sole source of organic carbon. Assays for 2-phenylphenol also contained $0.16 \mathrm{mM}$ magnesiumm sulfate, whereas DBT-sulfone assays contained no other source of sulfur. Inocula were taken from the third transfer cultures grown on standard sulfur-stress media (glucose and glycerol as organic carbon sources). Growth was monitored by optical density and substrate disappearance was monitored by UV spectroscopy.

To determine if the desulfurization process was inhibited by inorganic sulfur, we added $0.166 \mathrm{mM}$ magnesium sulfate to the sulfur-stress medium. Growth and DBT-sulfone disappearance were monitored by standard techniques.

The effect of glucose and glycerol (as carbon substrates) on desulfurization activity was investigated by growing cultures for 140 hours in ssulfur-stress medium medium with a single carbon substrate $(10 \mathrm{mM})$ of either glucose or glycerol. Growth and DBTS disappearance were measured by standard techniques after 140 hours.

Resting-cell cultures were defined as cells that had entered the stationary phase of batch culture. Stationary phase for the cultures occured after growth for 165 hours in flasks (non-agitated) that contained $25 \mathrm{ml}$ of sulfur-stress medium medium with DBT-sulfone and thiantherene. For the resting-cell assays: cells were harvested in staionary phase and centrifuged at $15,000 \times \mathrm{g}$ for $20 \mathrm{~min}$; the cell pellet was washed with $0.01 \mathrm{~N}$ phosphate buffer, then centrifuged again at $15,000 \times \mathrm{g}$ for $20 \mathrm{~min}$, and resuspended in sulfur-stress medium without any type of sulfur source. Cells were allowed to incubate for 24 hours to expend endogenous energy reserves. Ten $\mathrm{ml}$ of cells $(0.45-0.55 \mathrm{O}$.D.) then was layered onto a plate that contained DBT-sulfone and incubated for ior 24 hours at $30 \mathrm{OC}$ and $70 \%$ humidity. The DBT-sulfone plates were 
prepared by this method: $1 \mathrm{ml}$ of ethereal solution of DBT-sulfone $(2.5 \mathrm{mg} / \mathrm{ml})$ was sprayed on a $100 \mathrm{~mm}$ Petri plate, and the ether was allowed to evaporate leaving fine dispersed crystals of DBT-sulfone on the plate. Plates were extracted after 24 hours and analyzed GC.

To test biodesulfurization activity on other organosulfur compounds, a variation of the standard assay was used, whereby ethanol was used to enhance solubility of the compounds. Ethanol also served as organic carbon source (all three cultures-UMX3,UMX9, and IGT S-8-grew on ethanol). Stock solutions of DBT, DBT-sulfone, DBT-5-Oxide, Dlphenyl sulfide, 3-Aminophenyl sulfone, Methylene blue, 3-Carboxyl thiophene, Benzothiophene, Thionapthalene, and trithlane) were prepared by the following method: the sulfur substrate $(1.66 \mathrm{mM})$ was added to $5 \% \mathrm{v} / \mathrm{v}$ ethanol and water. The sulfur-stress medium was prepared without DBT-sulfone or a carbon substrate. The medlum was completed by the addition of one $\mathrm{ml}$ of organosulfur stock solution to $9 \mathrm{ml}$ of assay medium. Final ethanol concentration in each tube was $0.5 \%$ $\mathrm{v} / \mathrm{v}$. Final concentration of the organic sulfur substrate was $0.16 \mathrm{mM}$ in each tube. Sulfur substrates were considered growth supportive in the event of growth (0.1 O.D.) on the third transfer.

Sulfur-stress medlum was used with 3-aminophenyl sulfone at $0.5 \mathrm{mM}$. Utilization of 3-aminophenyl sulfone was monitored by HPLC, and growth was monitored after 165 hours by standard technique.

Fatty acid proflles (MIDI analysis) were conducted by Craig Richardson at the University of Alabama. Huntsville, on the cultures IJMX3, UMX9 and IGTS8 to aid in taxonomic identfication. 
Table 1. Modified 21C medium

stock Solutions: $(500 \mathrm{ml})$

$\mathrm{KH}_{2} \mathrm{PO}_{4}$

$\mathrm{Na}_{2} \mathrm{HPO}_{4}$

$69.25 \mathrm{~g}$

$\mathrm{NH}_{4} \mathrm{CL}$

$50.25 \mathrm{~g}$

$50.00 \mathrm{~g}$

Salts Mix: (L)

$\mathrm{MgCL}_{2}$

$\mathrm{CaCl}_{2}-2 \mathrm{H}_{2} \mathrm{O}$

$\left(\mathrm{NH}_{4}\right)_{6} \mathrm{MO}_{7}-4 \mathrm{H}_{2} \mathrm{O}$

$\mathrm{FeCl}_{3}-6 \mathrm{H}_{2} \mathrm{O}$

$\mathrm{MnCl}_{2}-4 \mathrm{H}_{2} \mathrm{O}$

EDTA

$$
\begin{array}{r}
11.2 \mathrm{~g} \\
5.0 \mathrm{~g} \\
10.0 \mathrm{mg} \\
200.0 \mathrm{mg} \\
50.0 \mathrm{mg} \\
500.0 \mathrm{mg}
\end{array}
$$

Trace Metals: $(100 \mathrm{ml})$

EDTA

$\mathrm{ZnCl} 2$

$\mathrm{CuCL}_{2}$

$\mathrm{NaB}_{4} \mathrm{O}_{7}-1 \mathrm{OH}_{2} \mathrm{O}$

$150.0 \mathrm{mg}$

$71.25 \mathrm{mg}$

$20.6 \mathrm{mg}$

$17.7 \mathrm{mg}$

Organic sulfur Source: (L)

Dibenzothiophene sulfone $50.0 \mathrm{mg}$

Carbon Source: $(100 \mathrm{ml})$

D-glucose

Glycerol

$10.0 \mathrm{~g}$

$10.0 \mathrm{ml}$

Vitamin stock: $(50 \mathrm{ml})$

Biotin

Nicotinic acid

Thiamine HCi

$0.5 \mathrm{mg}$

$50.0 \mathrm{mg}$

$25.0 \mathrm{mg}$

Preparation

1. Measure $500 \mathrm{ml}$ of saturated organic sulfur stock (liquid only).

2. To the liquid portion of the organic sulfur stock, add 20 $\mathrm{ml}$ of each phosphate stock solution and $10 \mathrm{ml}$ of ammonium chloride stock solution.

3. Add $20 \mathrm{ml}$ of salts $\mathrm{mix}, 1 \mathrm{ml}$ trace metals, and $10 \mathrm{ml}$ of each carbon substrate.

4. Add liquid portion of organic stock solution to make $1 \mathrm{~L}$ of medium.

5. Adjust the $\mathrm{pH}$ of the medium to 7 .

6. Filter sterilize.

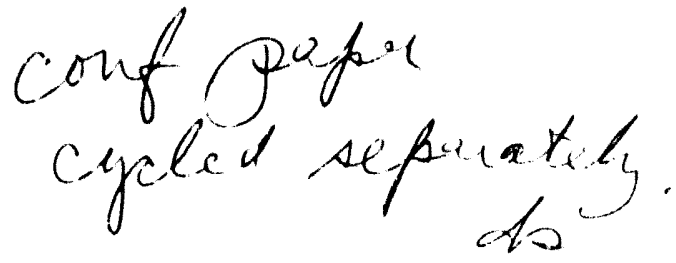



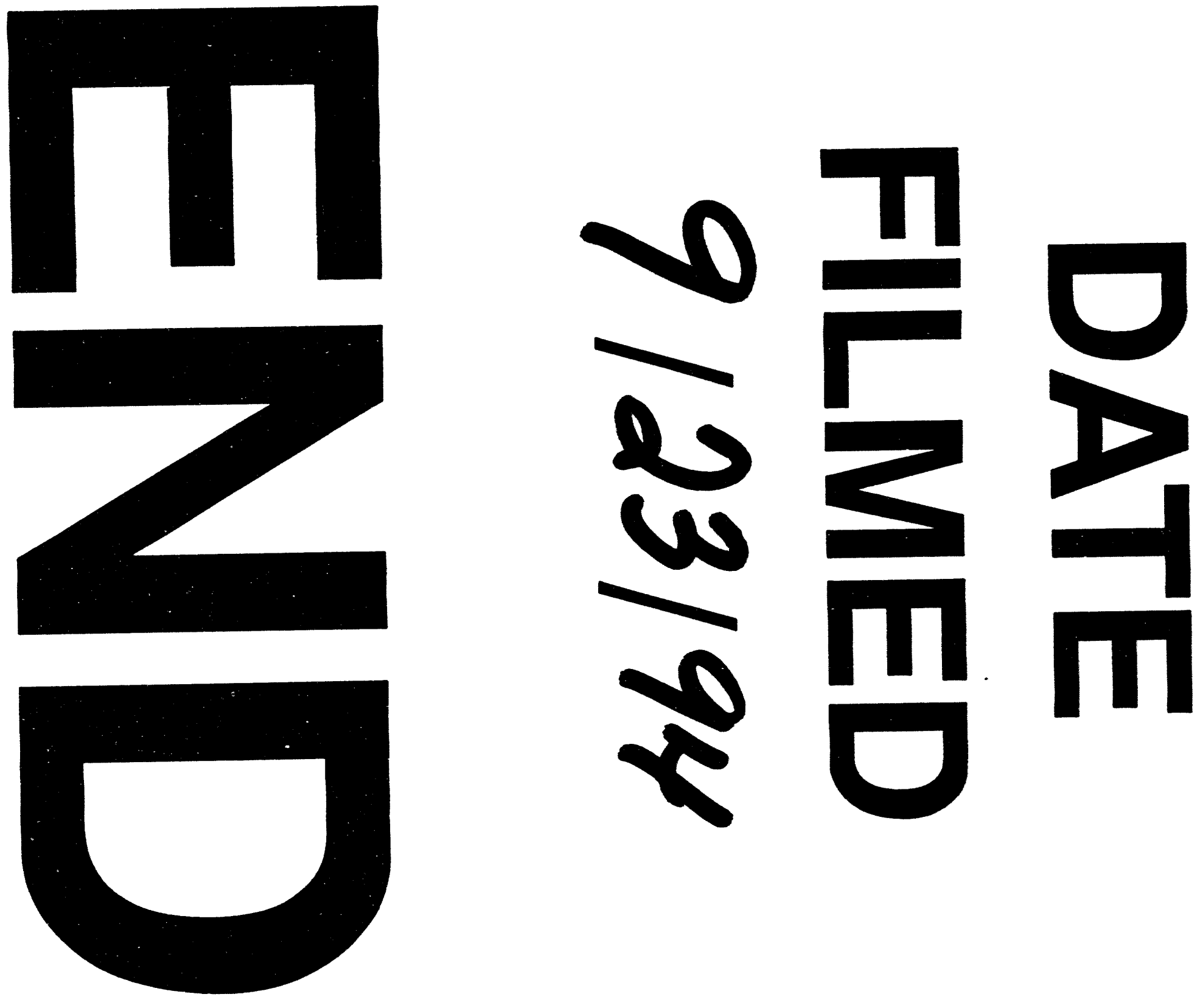
nam 